

\title{
FLUIDIZED-BED COPPER OXIDE PROCESS
}

\author{
PHASE IV \\ CONCEPTUAL DESIGN AND ECONOMIC EVALUATION
}

Volume I

\author{
Prepared for the \\ United States Department of Energy \\ Pittsburgh Energy Technology Center \\ under \\ Contract Number DE-AC22-85PC81004
}

\begin{abstract}
Prepared by
A.E. Roberts \& Associates, Inc.

(under a subcontract from UOP)

Atlanta, Georgia
\end{abstract}

November 30, 1994

DISCLAIMER

This report was prepared as an account of work sponsored by an agency of the United States Government. Neither the United States Government nor any agency thereof, nor any of their employees, makes any warranty, express or implied, or assumes any legal liability or responsibility for the accuracy, completeness, or usefulness of any information, apparatus, product, or process disclosed, or represents that its use would not infringe privately owned rights. Reference herein to any specific commercial product, process, or service by trade name, trademark, manufacturer, or otherwise does not necessarily constitute or imply its endorsement, recommendation, or favoring by the United States Government or any agency thereof. The views and opinions of authors expressed herein do not necessarily state or reflect those of the United States Government or any agency thereof. 
A. E. ROBERT

\section{TABLE OF CONTENTS}

Volume I .

1.0 Introduction

2.0 History of FBCO Process

2.1 Previous Research

2.2 PETC-Funded Studies

2.2.1 1984 FBCO Scale-Up Studies

2.2.2 1986 Studies

2.2.3 Rockwell's Alternative Copper Oxide Sorbent Contactor

2.2.4 FBCO Progress To Date

2.2.5 Technical and Economical Feasibility Studies of the FBCO Process

2.2.6 The FBCO Process and IECM

2.2.7 Determining a FBCO Design Basis

3.0 Process Chemistry

3.1 General Process Chemistry

3.2 Absorber Residence Times

3.3 Copper-to-Sulfur Molar Ratio

3.4 Regeneration Chemistry

3.5 Attrition Losses

4.0 Process Design Description for a 500 MW Coal-Fired Power Plant

4.1 Material Balance Information

4.1.1 Absorber Balance

4.1. Ammonia Requirements

4.1.3 Two Stage Solids Heater and Combustor

4.1.4 Regenerator Balance

4.2 Establishment of the Design Basis for Application to a $500 \mathrm{MW}$ Power Plant

4.3 FBCO Process Description

4.4 The Selection of a Sorbent Transportation System

5.0 Equipment Design and Specifications

5.1 General FBCO Process Description

5.2 Design Basis

5.3 Absorber Design

5.4 Regeneration Design and Specification

5.5 Two Stage Solids Heater and Combustor 
A. E. ROBERTE I ASSOCIATES, INC.

5.6 Sulfur Recovery Facility

5.6.1 General Process Information

5.6.2 RESOX Process Description

5.6.3. System Equipment

5.6.4 RESOX Cost for Sulfur Recovery

6.0 Cost for the FBCO Process

6.1 General Cost Factors

6.2 Estimated Cost for the FBCO Process without Sulfur Recovery

6.3 FBCO System Cost with Sulfur Recovery

7.0 Comparative Sulfur Dioxide Removal Technologies

7.1 Alternative Sulfur Dioxide Technologies

7.2 Comparative Sulfur Dioxide Costs

7.2.1 Wet Scrubbing Costs

7.2.2 Dry Scrubbing Costs

8.0 Comparative Nitrogen Oxide Removal Technologies

8.1 Alternative Nitrogen Oxide Removal Technologies ।

8.1.1 Selective Catalytic Reduction (SCR)

8.2 Comparative Nitrogen Oxide Removal Cost

9.0 Comparative Cost Summary

10.0 Recommendations and Conclusions

11.0 Modeling and Assessment of the Fluidized Bed Copper Oxide Process for $\mathrm{SO}_{2} / \mathrm{NO}_{x}$ Control

12.0 Drawings 


\subsection{INTRODUCTION}

Universal Oil Products, Inc. (UOP) of Des Plaines, Illinois has contracted A.E. Roberts \& Associates, Inc. (AERA) of Atlanta, Georgia to prepare a sensitivity analysis for the development of the Fluidized-bed Copper Oxide (FBCO) process. This work is part of a Department of Energy (DOE) Contract DE-AC22-85PC81004.

To help carry out this work, AERA has utilized Cornell University, Roberts \& Schaefer Company, and Carnegie Mellon University. As proposed by AERA in September 1991 (Proposal No. UOP-RFP-1010), development of the FBCO process design for a $\mathbf{5 0 0}$ mega-watt (MW) unit was divided into three tasks:

- Task 1 - Establishment of a Conceptual Design

- Task 2 - Conceptual Design

- Task 3 - Cost Analysis

Task 1 determined the basis for a conceptual design for the 500 megawatt (MW) FBCO process. It was completed by AERA in September of 1992, and a report was submitted at that time ("Establishment of the Design Basis for Application to a 500 MW Coal-fired Facility." See Appendix I).

Task 2 gathered all pertinent data available to date and reviewed its applicability to the 500 MW FBCO process. Work on this task was carried out on a joint basis by the AERA team members: Roberts \& Schaefers worked on the dense phase transport aspect of the design; Cornell and Carnegie Mellon Universities worked on the design kinetics and modeling; and AERA contributed commercial power and combustion experience.

Task 3 provides budgetary cost estimates for the FBCO process and competing alternative technologies for sulfur dioxide and nitrogen oxide removal. 
The contract deliverable in this Final Design Report combines and details the efforts of Tasks 1,2, and 3. The cost estimates presented are for budget purposes only, and are within a plus or minus 30 percent cost accuracy. This report summarizes the AERA findings as to the current status and commercial viability of the FBCO process. The report is segregated into eleven major sections:

Section 1.0 Introduction

Section 2.0 History of the FBCO Process

Section 3.0 Process Chemistry

Section 4.0 Process Description for a 500 MW Coal-fired Power Plant

Section 5.0 Equipment Design and Specification

Section 6.0 Cost for the FBCO.Process

Section 7.0 Comparative Sulfur Dioxide Removal Technologies

Section 8.0 Comparative Nitrogen Oxide Removal Technologies

Section 9.0 Comparative Cost Summary

Section 10.0 Recommendations and Conclusions

Section 11.0 Modeling and Assessment of the Fluidized Bed Copper

Oxide Process for $\mathrm{SO}_{2} / \mathrm{NO}_{x}$ Control

The overall objective of this sensitivity analysis was to review and update the technical and economic aspects of the FBCO process. The sensitivity analysis includes:

- New conceptual engineering design information and cost estimates developed by AERA. Also the Updated Integrated Environmental Control Model (IECM) that was used in determining the technical and economical bases for the FBCO process;

- Updated professional judgments regarding uncertainties in specific model parameters and factors. These updated judgments were used to redefine the design basis;

- The use of the IECM in a series of case studies! Each requiring the development of input data, the coding of data into the model, running the model, and obtaining outputs; and 
- An in depth analysis of the modeling results for inclusion into the final design report.

As a result of the AERA work discussed in this report, it was concluded that the FBCO process would have a much higher cost per ton of sulfur dioxide and nitrogen oxide removal than would conventional pollution cleanup technologies. It should be emphasized, however, that the lower costs for conventional pollution treatment methods are due, at least in part, to the fact that these technologies have known construction and operating costs. Knowing real capital costs and actual construction experience with the process lessens uncertainties and tends to provide a more accurate cost estimate. 


\subsection{Previous Research}

Copper oxide sulfation and the catalytic reduction of nitrogen oxides by ammonia, constitute the basis for the development of the Fluidized-bed Copper Oxide (FBCO) Process. In 1970, $\mathrm{McCrea}^{1}$ described a sorbent prepared by impregnating a copper salt onto a 1/16-inch alumina catalyst support. Bench-scale evaluations by McCrea, using a fixed-bed reactor, showed that the sorbent absorbed sulfur dioxide from exhaust gases from a coal fired boiler at temperatures between $570^{\circ} \mathrm{F}$ and $800^{\circ} \mathrm{F}$. It was found that the spent sorbent could be regenerated using hydrogen or methane. Regeneration produced a concentrated stream of sulfur dioxide, which can be used to manufacture elemental sulfur.

In 1976 and 1977, UOP $^{2}$ demonstrated that a copper oxide sorbent is capable of absorbing sulfur dioxide from the flue gas of a coal-fired utility boiler. This pilotscale testing was performed in a 0.5 Mega-watt (MW) unit with a fixed-bed reactor. The flue gas used in the UOP testing was from a commercial coal-fired utility boiler that burned high sulfur content coal. In addition to demonstrating that sulfur dioxide was absorbed, in $1983 \mathrm{UOP}^{3}$ also demonstrated the ability to simultaneously reduce nitrogen oxide $\left(\mathrm{NO}_{x}\right)$ with ammonia $\left(\mathrm{NH}_{3}\right)$ in the $0.5 \mathrm{MW}$ pilot plant.

The use of copper-impregnated alumina spheres in a fluidized-bed to simultaneously remove sulfur dioxide and nitrogen oxides from flue gas was first reported by Strakey ${ }^{4}$ at Pittsburgh Energy Technology Center (PETC) in 1979. Supplemental investigations using Strakey's work as a basis was reported by Demski ${ }^{5}$. Demski used a 6-inch diameter fluidized-bed absorber to contact sorbent spheres (impregnated with approximately five weight percent copper) with the cbmbustion products of natural gas stream laden with sulfur dioxide. Demski obtained a concentration of 3,000 parts per million by volume ( $\mathrm{ppm}_{\mathrm{v}}$ ) of sulfur dioxide at the exhaust. Ammonia was also added to the natural gas being burned to generate higher $\mathrm{NO}_{x}$ concentration at the exhaust. This resulted in $800 \mathrm{ppm}_{\mathrm{v}}$ nitrogen oxides concentration in the exhaust gas. Ammonia was also injected into the flue gas after the burner to demonstrate the catalytic reduction of nitrogen oxides to nitrogen and water. Demski's efforts resulted in the removal of 90 to 95 percent of sulfur dioxide and more than 97 percent of the nitrogen oxides. This work used an expanded bed height of 36 inches and a reaction bed temperature of $752^{\circ} \mathrm{F}$. 


\section{$2.2 \quad$ PETC-Funded Studies}

During 1982-1983 PETC commissioned a series of studies to review the FBCO process development. A number of these studies involved the potential application of this process to a $500 \mathrm{MW}$ coal-fired unit. The overall objectives of these studies were to:

- Review the general background and characteristics of metal oxide flue gas treatment processes.

- Review the PETC micro-balance test program results.

- Apply preliminary test results to the conceptual design of a $500 \mathrm{MW}$ plant to establish operating parameters.

- Formulate recommendations for the advancement of the FBCO process based on the conclusions of the process review.

- Establish the equipment design requirements for the FBCO process for a 500 MW power plant application. As part of this objective, the mass and energy balances were reviewed, equipment design requirements were established, sizing calculations were performed, and equipment drawings and specifications for manufacturers budget cost opinions were prepared.

- Prepare a study grade equipment capital cost estimate ( \pm 30 percent), that included: budgetary cost estimates for equipment, installation costs including labor and materials, and cost comparisons with alternative chemical processes.

- Evaluate the potential for sorbent attrition in the process and particularly in the fluidizing moving bed regenerator.

- Establish the design requirements of an integrated sulfuric acid plant.

- Establish the equipment design for a sulfuric acid plant and perform a capital cost estimate to establish the plant's fixed-capital investment. 
- Determine the capital investment needs for the base-case flue gas treatment process and integrated sulfuric acid plant.

- Determine the annual revenue requirements for the base-case flue gas treatment process and integrated sulfuric acid plant.

- Perform economic sensitivity analyses for key parameters.

- Establish the design requirements for an integrated flue gas treatment (FGT)/RESOX process and $\mathrm{FGT} / \mathrm{SO}_{2}$ reduction process.

- Establish conceptual designs for the sulfur-producing plants based on design data.

- Establish plant equipment design information and perform a study grade capital cost estimate to establish the plant's fixed-capital investment.

- Evaluate the technical and economic benefits of using methane-alternative regeneration reducing agents in the $\mathrm{FBCO}$ process.

- Evaluate the relative technical and economic benefits of using a sorbent with increased copper content rather than the approximately five percent copper content sorbent used in previous evaluations of the process.

- Evaluate the technical and economic benefits of using a dense-phase solids conveying system for the process.

- Quantify the potential coal-fired power plant retrofit market for FGT technologies.

- Quantify the adaptability of the fluidized-bed copper oxide process for a power plant retrofit.

The detailed results of these studies were reported by Ratafia-Brown in $1982^{6}$ and $1983^{7}$. 


\subsubsection{FBCO Scale-Up Studies}

Data obtained from the 1979 Strakey study, and from the chemical reaction kinetics model development using a micro-balance reactor, prompted PETC to investigate the FBCO process concept on a larger scale in $1984^{8}$. A $500 \mathrm{lb} / \mathrm{hr}$ coal combustion facility was chosen for scale-up. This investigation found that 90 percent removal of sulfur dioxide and 90 percent reduction of nitrogen oxides can be achieved in a fluidized-bed reactor. During this investigation, copper impregnated alumina spheres $(5 \mathrm{wt} \% \mathrm{Cu}$ ) were contacted with flue gas in a fluidized-bed absorber. A flue gas flow rate of $1300 \mathrm{scfm}(1 \mathrm{~atm}$, $32^{\circ} \mathrm{F}$ ) was produced for these tests from the combustion of bituminous coal containing three weight percent of sulfur. The temperature of the fluidized-bed during testing was varied from $660^{\circ} \mathrm{F}$ to $900^{\circ} \mathrm{F}$ in an attempt to simulate the load conditions of a power plant. Regeneration of the spent absorbent was accomplished using methane, or mixtures of methane and hydrogen, at a temperature of approximately $788^{\circ} \dot{\mathrm{F}}$, using a batch operation. The regeneration of the sorbent material left only one weight percent of residual sulfur.

Yeh's 1984 work for PETC demonstrated that 90 percent removal of sulfur dioxide and 90 percent reduction of nitrogen oxides could be achieved in a large fluidized-bed ( 40 -inches by 48 -inches, rectangular) of copper-impregnated alumina spheres in the presence of fly ash and other combustion products. Yeh demonstrated that absorbent attrition losses increase with increasing absorbent circulation rate. Testing showed that there was no measurable reduction in the chemical activity of the sorbent material after 24 successive cycles of absorption and regeneration. Based upon Yeh's work, Science Management Corporation utilized a 0.08 weight percent of the bed inventory for attrition loss for the preliminary economical evaluation of the fluidized bed absorber in 1981 and 1983. 


\section{2 .21986 Studies}

In $1986,{ }^{9} \mathrm{PETC}$ also funded an alternative flue gas control technology that used a moving bed and copper oxide (supported on alumina pellets) as a sorbent/catalyst for the combined removal of both sulfur dioxide and nitrogen oxides. The primary difference between this technology and the FBCO process was the design of the flue gas/sorbent contactor.

PETC's original 1970 design of the FBCO process, used a fluidized-bed of sorbent material, through which the flue gas from a conventional boiler was bubbled. A successful combination of flue gas superficial velocity, bed height, and sorbent recirculation rates resulted in a gas/sorbent contact time that yielded the desired sulfur dioxide removal rate. In the initial concept, nitrogen oxide reduction was achieved by injecting ammonia into the flue gas prior to its entering the sorbent contactor. Copper sulfate acts as a catalyst for reducing the nitrogen oxides to elemental nitrogen. Using the fluidized-bed design allowed the entrained fly ash in the exhaust gas to pass through the fluidized-bed. However, a relatively large flue gas pressure drop (15-25 in $\mathrm{H}_{2} \mathrm{O}$ ) occurs in the 2 to 3 foot deep bed. In addition, sorbent attrition losses with the copper oxide sorbent in the fluidized-bed tested higher than economically desirable.

\subsubsection{Rockwell's Alternative Copper Oxide Sorbent Contactor}

From 1983 to 1987, PETC funded the development and testing of an alternative copper oxide sorbent contactor by the Rocketdyne Division of Rockwell International. ${ }^{10}$ Rockwell's contactor used a moving bed of granular material contained within a contactor/filtering device consisting of a double-sided louver and a doubled-sided porous filter sheet. This contactor/filter was originally developed for hot gas cleanup in combined cycle power plants. Its primary purpose was the removal of fine particles to protect the gas turbine. Originally, a moving bed of granular material (sand) was used to "clean" dust cake deposits from the porous filter sheet. Rockwell then substituted the copper oxide sorbent/catalyst for the granular material in order to 
simultaneously remove gaseous emissions from the flue gas. An opportune combination of the appropriate flue gas superficial velocity, bed thickness, and sorbent circulation rate produced a gas/sorbent contact time that yielded a desired sulfur dioxide removal rate. Nitrogen oxide reduction was achieved by using an ammonia reducing agent. While the fluidized bed contacter normally is a relatively simple device to design and operate, the Rockwell contactor/filter design is considerably more complicated. This contactor/ filter, however, has the potential to: (1) operate with a much lower gas-side pressure drop, (2) achieve a higher sorbent utilization; and (3) reduce sorbent attrition losses below that of the more traditional fluidized-bed contactor.

The overall goal of the Rockwell project was to compare the Rockwell and FBCO copper oxide processes in terms of design, performance, and cost for both 90 percent and 98 percent sulfur dioxide removal and 90 percent nitrogen oxide reduction. While many conceptual designs and cost estimates have been prepared for the fluidized-bed process during the 1980s, relatively little work was done to establish a baseline design and cost estimate for Rockwell's moving-bed system. Therefore, most of Rockwell's effort was devoted to calculating a baseline material and energy balance, working out the baseline equipment design, and estimating equipment and operating costs for the movingbed system.

To compare the moving bed and FBCO processes the following objectives were specified by PETC:

- A qualitative comparison of the fluidized-bed and moving bed contactor alternatives;

- Review and evaluate design/test results (Rockwell moving bed and the UOP Life Cycle Test Unit);

- Establish realistic moving bed contactor design options; 
- Compare technical performance of the moving bed and the FBCO process conceptual designs for a $300 \mathrm{MW}$ utility power plant burning four percent sulfur coal; and

- Perform an economic assessment and compare the two process options (i.e. capital, operating, and life cycle costs).

\subsection{FBCO Progress To Date}

On the basis of the work performed by Yeh (PETC) and Rockwell, it was determined by Ratafia-Brown in $1991^{11}$ that the following information was important to the further the development of the FBCO process:

- Use of the moving bed could potentially reduce process operating costs significantly, which is critical to the ultimate success of the process.

- The moving bed concept gave the copper oxide process a more "flexible" contactor, from the perspective of achieving high sorbent utilization and emission control objectives. At the same time, it operated with a relatively low flue gas pressure differential. This allows for a significant reduction in power consumption and was probably the most important feature of the moving bed contactor.

- Separating the simultaneous particulate removal feature from the contactor permitted the use of thicker beds than was originally envisioned by Rockwell. This resulted in a significant reduction of the surface area compared with the original Rockwell moving bed concept.

- The moving bed contactor is able to achieve higher sorbent utilization for a specified control objective. This reduced the sorbent circulation rate and attrition, as well as the process methane consumption. 
- Although the moving bed contactor could reduce the sorbent attrition losses which occur in the contactor, better appraisal of the potential improvements is needed via testing in a scaled up "thick bed."

- Use of the moving bed contactor significantly reduced the sorbent inventory required by the process. It reduces the initial amount of sorbent and its associated capital expenditure.

- Although several realistic moving bed design concepts were devised, significant mechanical design aspects must be investigated in greater detail. The method of sorbent containment was the most crucial design problem.

- The moving bed contactor in the copper oxide process does not appear to reduce equipment capital costs significantly.

- Use of the moving bed contactor appeared to increase the complexity and cost of the sorbent transport system.

- The moving bed contactor did not reduce the size or simplify the design of the absorber/ contactor. In that study, the use of realistic bed dimensions resulted in six times as many moving beds as required by the fluidized-bed concept. Flue gas distribution to numerous beds was also a problem.

- Efficient sorbent containment in the moving bed contactor is a critical design problem: both louvers and screens have operating problems.

- Plugging by fly ash and fines occur in stagnant areas of the moving bed contactor. 
- Simultaneous fly ash capture in the moving bed contactor did not appear to be viable or recommended. This did, however, allow for beds of greater thickness, which reduced the bed cross sectional area.

- Some fly ash may be captured by the moving bed and would have to be separated from the sorbent.

- Uniform flue gas distribution to the moving beds would be more difficult than for the fluidized-bed.

2.2.5 Technical and Economic Feasibility Studies of the FBCO Process In 1985, UOP, in conjunction with PETC, began work on a research program to demonstrate the technical and economic feasibility of the fluidized-bed copper oxide process. This program consisted of the following four phases:

- Sorbent testing in a 100 SCFM life-cycle test unit (LCTU).

- Design and construction of a 2,500 SCFM proof-of-concept unit.

- Operation of the 2,500 SCFM proof-of-concept unit.

- Conceptual design and preliminary economic evaluation of a $500 \mathrm{MW}$ commercial unit.

The LCTU was designed and built under PETC supervision and operated by UOP personnel in Pittsburgh during a six-month testing period. Sorbent testing in the 100 SCFM LCTU was completed in March 1987. In the process flow, sorbent was continuously transferred between the absorber and regenerator vessels to allow for continuous and integrated operation. The transfer of spent sorbent between the absorber and regenerator was accomplished with a transfer hopper system using nitrogen as the lift gas. Methane was used to regenerate the sorbent in the moving-bed regenerator. Sorbent flow was by 
gravity from the stacked regenerator to the absorber through a lock hopper system. Sulfur dioxide and nitrogen oxide removal was accomplished in the fluidized-bed reactor.

Flue gas for the LCTU was generated in a $40 \mathrm{lb} / \mathrm{hr}$ coal combustor adjacent to the unit. Lower Kittaning coal was used during all testing. Anhydrous sulfur dioxide was injected into the furnace as required to control the flue gas sulfur dioxide concentration. Testing by UOP ${ }^{12}$ demonstrated that the fluidized-bed copper oxide process is capable of simultaneously removing up to 90 percent of the sulfur dioxide and reducing nitrogen oxide from coal-derived flue gas during continuous operation over extended periods.

Sorbent attrition losses observed by UOP during testing was higher than expected based on previous test programs. However, several design and operating modifications were identified that could reduce attrition to more acceptable levels. No significant reduction in sorbent performance was observed during the testing program. This result indicated that trace flue gas containments and fly ash do not significantly affect the sorbent during extended operation periods, but it was necessary to use about 6 moles of copper per mole of $\mathrm{SO}_{2}$ fed to the bed.

Operation and equipment modifications were identified that would reduce the attrition levels observed during LCTU testing. These modifications were to be incorporated into the design of a large proofof-concept unit. The original capacity of the unit (10,000 SCFM) was based on the flue gas equivalent of a $5 \mathrm{MW}$ power boiler. As a costcutting measure, the size of the unit was reduced by PETC to 25 percent of the $5 \mathrm{MW}$ size or 2500 SCFM. This reduction would have enabled capital and operating costs to be reduced without significant loss in the unit's ability to demonstrate the process on a pilot scale. 
The pilot scale design had to meet the following objectives:

- Demonstrate $90 \%$ removal of sulfur dioxide and $90 \%$ reduction of nitrogen oxides from the flue gas.

- Demonstrate the activity and stability of the sorbent.

- Demonstrate the sorbent's resistance to attrition.

- Determine the optimum operating parameters to minimize capital and operating costs for a commercial size unit.

- Determine the optimum $\mathrm{NH}_{3} / \mathrm{NO}_{x}$ ratio considering $\mathrm{NH}_{3}$ breakthrough.

UOP completed the design of the 2,500 SCFM proof-of-concept unit based on the operating conditions at Commonwealth Edison's Kincaid Station and the results of the LCTU testing. In addition, UOP's experience with continuous catalyst regeneration systems and its expertise in the production of attrition-resistant catalyst base and in catalyst fluidization were directly applied to the design of the proof-ofconcept unit. However, as a further cost cutting measure both the construction and operation of the proof-of-concept unit were cancelled by PETC.

\subsubsection{The FBCO Process and IECM}

To evaluate the copper oxide process, a detailed performance and economic model was developed by Frey in $1987^{13}$. This model was implemented as part of a broader modeling framework, the Integrated Environmental Control Model (IECM), developed by Rubin,${ }^{14}$ et al. The IECM included performance, emissions, and cost models for conventional and advanced technologies for pre-combustion, combustion, and post-combustion environmental controls all based upon theoretical and actual operating data. These component models 
can be configured to evaluate alternative integrated environmental control strategies for coal-fired power plants. Details of the IECM's copper oxide process, power plant air preheater, sulfur recovery, and sulfuric acid recovery plant models were described in detail by Frey, $1987,{ }^{15}$ and by Rubin, Salmento, Frey in $1991^{16}$.

The models include mass and energy balances for key process equipment. Direct and indirect capital costs, variable and fixed operating costs, and levelized costs are calculated using a standard approach. The IECM has a unique capability to explicitly model uncertainties in the performance and cost of advanced technologies using Monte Carlo simulation. Previous versions of the copper oxide process model have been applied in a number of case studies to evaluate: (1) uncertainty in processed costs, (2) payoffs from process design improvements, (3) the dependence of system cost on process design conditions and by-product markets, and (4) the likelihood that the advanced process will yield cost savings relative to conventional technology.

The performance model for the FBCO process has been updated to include new models for the kinetics of sulfation and regeneration, based on work by Harriott ${ }^{17}$, and Markussen and Harriott ${ }^{18}$. The mass and energy balance for the sorbent are modified accordingly. The design base for by-product sulfur recovery and for calculating process energy requirements was also updated. The new performance model is applied to evaluate several design issues, including overall sulfur removal efficiency, fluidized-bed absorber height, sorbent copper loading, and regeneration efficiency.

\subsubsection{Determining a FBCO Design Basis}

As the last element in the PETC FBCO program, A.E. Roberts \& Associates, Inc. was retained in 1992 to define design parameters for a FBCO unit for a $500 \mathrm{MW}$ coal fired unit (See Appendix I). Members of this project team include: Professor P. Harriott of Cornell University, and Dr. H.C. Frey of Carnegie Mellon University. 


\subsection{PROCESS CHEMISTRY}

\subsection{General Process Chemistry}

The FBCO process is a flue gas treatment process that is capable of simultaneously removing sulfur dioxide and reducing nitrogen oxides from flue gas of a conventional coal-fired boiler. This process has several distinct advantages over other conventional flue gas treatment systems:

- This process simultaneously reduces nitrogen oxides and removes sulfur dioxide in the same unit. Other processes typically require two separate mechanical units to perform the same two functions;

- The FBCO process is uniformly effective for various coals and is independent of the sulfur, nitrogen, and ash contents of the coal;

- Unlike conventional wet scrubbing technologies, no waste sludges are produced by the FBCO process; and

- The FBCO process is a dry system which also generates sulfur dioxide which can be reduced to sulfur, a potentially marketable by-product.

The FBCO process has four major processing elements: absorber, regenerator, solids heater, and combustor. As shown in Figure 3-1, the absorbent is introduced into the absorber along with untreated flue gas. In the absorber sulfur dioxide is removed and nitrogen oxides are reduced. From the absorber, treated flue gas is transported to the remaining portions of the flue gas train.

The spent absorbent is pneumatically transported from the absorber to a solids heater. In the solids heater, the spent absorbent temperature is elevated to the reaction temperature before the sorbent enters the regenerator. The combustion gases from the combustor are used to heat the solids before the gases enter the absorber. Spent absorbent from the solids heater is regenerated by reacting it with methane in the regenerator. 
The chemistry and kinetics of each process mechanical unit are vital to the success of the FBCO process. In general, this process uses the chemical absorption of sulfur dioxide on the copper oxide sorbent. In the absorber, copper sulfate is formed by the reaction of sulfur dioxide, oxygen with copper oxide. Additionally, selective reduction of nitrogen oxide by ammonia in the presence of a catalyst $\left(\mathrm{CuSO}_{4}\right)$ occurs. The FBCO process also has an ammonia injection system similar to conventional injection systems on coalfired boilers for each absorber.

Research has shown that reaction kinetics, proper gas residence time, and operating conditions (i.e., bed temperature, \% CuO, solids loading rate, fluidizing velocity, bed height, etc.) all effect the removal of sulfur and nitrogen oxides. Therefore, in discussions of process chemistry, findings of the various potential chemical and physical effects are identified.

The solids heater is used to raise the absorbent temperature before entering the regenerator. The solids heater utilizes exhaust gas from the combustion of methane in the combustor. The heated solids move from the solids heater by gravity and are transported, via a dense phase transportation system, to the regenerator. In the regenerator, the copper sulfate is reduced with methane to copper, carbon dioxide, sulfur oxide, and water. From the regenerator, the regenerated sorbent is transported to the absorber for reuse. Once the sorbent enters the transportation system, the copper is quickly oxidized to copper oxide. Because of attrition losses, fresh absorbent makeup is introduced into the absorber.

The efficiencies of sulfur oxide removal and nitrogen oxide reduction in the FBCO process have been estimated at 90 percent each. The copper-to-sulfur molar ratio utilized was 2.0:1.0. For ammonia injection, the ammonia to nitrogen oxide (NO) ratio of 1.0:1.0 and the ammonia to nitrogen oxide $\left(\mathrm{NO}_{2}\right)$ ratio of $2.0: 1.0$ were used. 
In the FBCO process, the untreated flue gas enters the bottom of the absorber. The absorbent enters the side just above the top of the fluidized bed of the absorber and falls by gravity. The sulfur oxides in the flue gas react with the copper oxide (Equations 1 and 2): $\because \therefore$

$$
\begin{aligned}
& \mathrm{CuO}_{(\mathrm{s})}+\mathrm{SO}_{2(\mathrm{~g})}+1 / 2 \mathrm{O}_{2(\mathrm{~g})} \rightarrow \mathrm{CuSO}_{4(\mathrm{~s})} \\
& \mathrm{CuO}_{(\mathrm{s})}+\mathrm{SO}_{3(\mathrm{~g})} \rightarrow \mathrm{CuSO}_{4(\mathrm{~s})} .
\end{aligned}
$$

Nitrogen oxide removal is accomplished at the same time sulfur oxide removal occurs. Nitrogen oxide removal occurs as a result of the injection of ammonia upstream from the absorber. Selective catalytic $\left(\mathrm{CuSO}_{4}\right)$ reduction of the nitrogen oxides occurs as shown in the following reactions (Equations 3 and 4):

$$
\begin{aligned}
& 4 \mathrm{NO}_{(\mathrm{g})}+4 \mathrm{NH}_{3(\mathrm{~g})}+\mathrm{O}_{2(\mathrm{~g})} \rightarrow 4 \mathrm{~N}_{2(\mathrm{~g})}+6 \mathrm{H}_{2} \mathrm{O}_{(\mathrm{g})} \\
& 2 \mathrm{NO}_{2(\mathrm{~g})}+4 \mathrm{NH}_{3(\mathrm{~g})}+\mathrm{O}_{2(\mathrm{~g})} \rightarrow 3 \mathrm{~N}_{2(\mathrm{~g})}+6 \mathrm{H}_{2} \mathrm{O}_{(\mathrm{g})}
\end{aligned}
$$

The sulfur dioxide absorption reaction and the nitrogen oxide reduction reactions are both exothermic. These reactions produce an increase in the flue gas temperature across the absorber. This temperature increase increases the removal of sulfur dioxide. The elevated temperature will also result in a more recoverable heat for the processes downstream of the FBCO process.

The presence of fly ash in the flue gas stream has little effect on the FBCO process ability to remove either sulfur dioxide or reduce nitrogen oxide. PETC and UOP $^{19}$ have demonstrated that fly ash in the flue gas has no appreciable effect on the absorbent with ash concentrations less than two grains per dry standard cubic foot in the flue gas. 


\subsection{Absorber Residence Times}

The method for determining the residence time of solids in the absorber was developed by Professor Harriott who utilized the following kinetic model for .absorbent residence time:

$$
\alpha R=k_{s} \mathrm{ZPN}_{\mathrm{t}}(1-\mathrm{X}) / \mu_{\mathrm{o}} \mathrm{P}_{\mathrm{m}} \mathrm{Y}_{\mathrm{in}}
$$

where:

$$
\begin{array}{ll}
\alpha & =\text { kinetic parameter (dimensionless) } \\
\mathrm{R} & =\text { moles } \mathrm{Cu} \text { to absorber/moles } \mathrm{SO}_{2} \text { to absorber } \\
\mathrm{k}_{\mathrm{s}} & =\text { rate constant }\left(\mathrm{atm}^{-1}, \mathrm{~min}^{-1}\right) \\
\mathrm{p} & =\text { expanded bed density } \\
\mathrm{Z} & =\text { bed height } \\
\mathrm{P} & =\text { pressure } \\
\mathrm{N}_{\mathrm{t}} & =\text { total moles } \mathrm{Cu} / \mathrm{Kg} \text { sorbent } \\
\mathrm{X}_{\mathrm{m}} & =\text { average conversion of } \mathrm{CuO} \text { to } \mathrm{CuSO}_{4} \\
\mu_{\mathrm{o}} & =\text { bed velocity } \\
\mathrm{P}_{\mathrm{m}} & =\text { molar gas density } \\
\mathrm{Y}_{\mathrm{in}} & =\mathrm{SO}_{2} \text { inlet concentration }
\end{array}
$$

Based upon testing data, Yeh and Harriott ${ }^{20}$ estimated the reaction rate constant $\left(k_{s}\right)$. This estimation is given by (Equation 6$)$ :

$$
k_{s}=840 e^{(-2460 / \mathrm{T})}+2.04 \mathrm{e}^{(-0.14 \mathrm{x})}
$$

where:

$$
\begin{array}{ll}
\mathrm{T} & =\text { Temperature } \\
\mathrm{X} & =\mathrm{wt} . \% \mathrm{Cu} \\
\mathrm{k}_{\mathrm{s}} & =\mathrm{atm}^{-1}, \mathrm{~min}^{-1}
\end{array}
$$


Based upon a $\mathrm{Cu} / \mathrm{S}$ molar ratio of 2.0:1.0, the kinetic model generates a residence time of approximately 87 minutes. This contact time is based upon equations 5 and 6 . It is also reflective of the contact time required by theory and actual bench scale testing.

\subsection{Copper-to-Sulfur Molar Ratio}

The copper-to-sulfur ( $\mathrm{Cu} / \mathrm{S})$ molar ratio is defined by the moles of copper entering the absorber divided by the moles of sulfur entering the absorber with the flue gas. In the FBCO process, the $\mathrm{Cu} / \mathrm{S}$ molar ratio is controlled by adjusting the sorbent circulation rate and the sorbent makeup ratio.

Research has demonstrated that various $\mathrm{Cu} / \mathrm{S}$ molar ratios can be used to achieve a 90 percent sulfur dioxide capture. Research performed by UOP ${ }^{21}$ with the 100 SCFM LCTU test program used a $\mathrm{Cu} / \mathrm{S}$ molar ratio ranging from 4 to 6 and achieved sulfur dioxide and nitrogen oxide removals greater than 90 percent. UOP's investigations used a Lower Kittaning coal. Anhydrous sulfur dioxide was injected into the LCTU test unit as required during testing to achieve the desired sulfur dioxide concentration in the flue gas. This work was used to develop a 2500 SCFM proof-of-concept design unit.

Carnegie Mellon University 2 used test data to develop a theoretical model defining the FBCO process. This model is a best fit of available data. As more data becomes available, the model is updated. Carnegie Mellon University has employed the model to project a $\mathrm{Cu} / \mathrm{S}$ molar ratio of 1.7:1.0 with a regeneration efficiency of 80 percent to obtain a 96 percent sulfur dioxide capture efficiency.

During A.E. Roberts conceptual design work, discussions were held with Harriott $t^{23}$ concerning both his review of Ratafia-Brown's model, and the NOXSO process work ${ }^{24}$. From these discussions, it is now believed that incomplete regeneration of the absorbent bed in the LCTU test process research led to operations with high solids recirculation (four to six times the minimum), and 90 percent sulfur dioxide capture. If nearly complete regeneration of the sorbent is obtained, then greater than 90 percent sulfur dioxide capture can be achieved in the fluidized-bed absorber. AERA used 
a $\mathrm{Cu} / \mathrm{S}$ molar ratio of 2.0:1.0 for the conceptual design. This decision was based upon the combined results of the LCTU tests with the theoretical models led to 80 percent regeneration as a reasonable rate.

Although the theoretical calculations have indicated that lower copper-tosulfur molar ratios are potentially feasible, these lower ratios can not be used until testing has actually demonstrated these projected removal efficiencies. The 2.0:1.0 Cu/S molar ratio chosen by the A.E. Roberts team is the lower limit of practicality based upon the collective experience to date. If lower $\mathrm{Cu} / \mathrm{S}$ molar ratios are pursued in the future, considerable testing would be required before any resizing of equipment could be performed.

\subsection{Regeneration Chemistry}

In the regenerator, methane is used to regenerate the copper sulfate to copper. Other regeneration reaction products are sulfur dioxide, carbon dioxide, and water. It has been assumed that copper sulfite, copper sulfate, and copper oxides are regenerated at varying efficiencies in the regenerator. Regeneration equations for these compounds are (Equations 7, 8 and 9):

$$
\begin{aligned}
& \mathrm{CuSO}_{4}+1 / 2 \mathrm{CH}_{4(\mathrm{~g})} \rightarrow \mathrm{Cu}_{(\mathrm{s})}+\mathrm{SO}_{2(\mathrm{~g})}+1 / 2 \mathrm{CO}_{2(\mathrm{~g})}+\mathrm{H}_{2} \mathrm{O}_{(\mathrm{g})} \\
& \mathrm{CuSO}_{3}+1 / 4 \mathrm{CH}_{4(\mathrm{~g})} \rightarrow \mathrm{Cu}_{(\mathrm{s})}+\mathrm{SO}_{2(\mathrm{~g})}+1 / 4 \mathrm{CO}_{2(\mathrm{~g})}+1 / 2 \mathrm{H}_{2} \mathrm{O}_{(\mathrm{g})} \\
& \mathrm{CuO}+1 / 4 \mathrm{CH}_{4(\mathrm{~g})} \rightarrow \mathrm{Cu}_{(\mathrm{s})}+1 / 4 \mathrm{CO}_{2(\mathrm{~g})}+1 / 2 \mathrm{H}_{2} \mathrm{O}_{(\mathrm{g})}
\end{aligned}
$$


After regeneration, copper and unreacted copper- sulfite (leaving the regenerator) are rapidly oxidized to form copper oxide and copper sulfate in the presence of oxygen. These reactions occur in the dense phase transportation system as shown below (Equations 10 and 11):

$\mathrm{Cu}_{(s)}+1 / 2 \mathrm{O}_{2(g)} \rightarrow \mathrm{CuO}_{(s)}$

$\mathrm{CuSO}_{3(\mathrm{~s})}+1 / 2 \mathrm{O}_{2(\mathrm{~g})} \rightarrow \mathrm{CuSO}_{4(\mathrm{~s})}$

The regeneration process exhaust gas will be recovered to obtain elemental sulfur, as discussed in Section 9.0. The recovery of elemental sulfur is accomplished by reacting methane with sulfur dioxide to form hydrogen sulfide (Equation 12):

$2 \mathrm{CH}_{4(\mathrm{~g})}+3 \mathrm{SO}_{2(\mathrm{~g})} \rightarrow \mathrm{S}_{(\mathrm{l})}+2 \mathrm{H}_{2} \mathrm{~S}_{(\mathrm{g})}+2 \mathrm{CO}_{2(\mathrm{~g})}+2 \mathrm{H}_{2} \mathrm{O}_{(\mathrm{g})}$

The remaining sulfur dioxide is then quickly reacted with hydrogen sulfide over $\mathrm{Al}_{2} \mathrm{O}_{3}$ catalyst to generate elemental sulfur and water (Equation 13):

$2 \mathrm{H}_{2} \mathrm{~S}+\mathrm{SO}_{2(\mathrm{~g})} \rightarrow 2 \mathrm{~S}_{(\mathrm{l})}+2 \mathrm{H}_{2} \mathrm{O}_{(\mathrm{g})}$

Overall recovery of elemental sulfur is as follows (Equation 14):

$\mathrm{CH}_{4}+2 \mathrm{SO}_{2(\mathrm{~g})} \rightarrow 2 \mathrm{~S}_{(\mathrm{l})}+2 \mathrm{H}_{2} \mathrm{O}_{(\mathrm{g})}+\mathrm{CO}_{2}$

As shown in Equation (13), the methane requirement for sulfur recovery is one-half the molar flow rate of the sulfur dioxide in the exhaust gas. To economize, a portion of this requirement can be obtained from the unreacted methane in the regeneration exhaust gas. 


\subsection{Attrition Losses}

Fresh absorbent will be added to the process to compensate for attrition losses. Based upon the dense phase transportation system losses and the circulation losses developed by Roberts and Schaefer, the sorbent makeup rate was approximated at $0.067 \mathrm{wt}$. \% of the circulation rate. The actual calculation of the attrition loss is based upon $0.02 \mathrm{wt} . \%$ per hour of the bed inventory and $0.047 \mathrm{wt} . \%$ of the actual circulated absorbent rate per hour. These percentages are based upon the pilot demonstration experience of the NOXSO process ${ }^{25}$. This NOXSO process is similar to the fluidized-bed copper oxide process except that the NOXSO process uses sodium impregnated on a gamma alumina oxide as a carrier. Based upon a testing program which involved 17 runs to "êaluiate attrition loss, NOXSO concluded that the attrition rate was relatively constant. Based upon NOXSO experimented data, the attrition loss in the operating system was 0.02 wt. \% per hour of the weight of the absorbent in the absorber. The average attrition loss in the simulated fluidized bed totaled approximately $0.047 \mathrm{wt} . \%$ of the circulating rate. US DOE of PETC measured the attrition characteristics of the NOXSO sorbent and reported that it was similar to the material PETC had subjected to a similar long term attrition test. PETC's attrition rate due to operation varied between $0.02 \mathrm{wt} \%$ and $0.03 \mathrm{wt}$ \% per hour.

Although the AERA utilized NOXSO test results for approximately attrition losses, Roberts and Schaefer had attrition loss tests performed by Macawber. Results from the Macawber test program, which was a non ideal duplication of the fluidized-bed copper oxide process, indicated that after 100 cycles, only 3 wt. \% (0.03\% per cycle) of the catalyst was lost to attrition and the collection of dust in the bag house. This loss per cycle was comparable to the loss presented by NOXSO and utilized by AERA. However, another 11 wt. $\%$ was found to be attributable to the use of less than 30 mesh during the Macawber test. These higher values of absorbent loss are attributed to the design of the Macawber test equipment which is not customized for the FBCO process. The FBCO transport system design incorporates all the features discussed under pipe design in Section 4.5. The Macawber test system does not incorporate any of these features. Also, the test receiving bin has a free fall of about 10 feet as compared to the 2-3 feet of the FBCO process. The Macawber test equipment had a total conveying distance of about 355 feet, 
and the pipework contained six $\times 90^{\circ}$ and two $\times 45^{\circ}$ bends. All of those features would significantly impact upon the overall sorbent attrition rate, and would account for the differences between the actual test results and the FBCO design: 


\subsection{PROCESS DESIGN DESCRIPTION FOR A $500 \mathrm{MW}$} COAL-FIRED POWER PLANT

\subsection{Material Balance Information}

The conceptual design discussed in this report was developed based upon the following assumptions: it is for a new $500 \mathrm{MW}$ coal-fired power-plant boiler, to be constructed in the state of Illinois. As shown in Table 4-1, the fuel for this hypothetical plant has a heating value of $10,500 \mathrm{Btu}$ per pound and contains 3.12 percent sulfur and 16 percent ash (on an as-fired basis). The coal compositions and the input coal requirements (based on a heat rate of 9,000 Btu/Kwh) for the $500 \mathrm{MW}$ boiler are listed in Table 4-1. The firing rate for the facility is 4500 million Btu per hour (MBtu/hr) and the coal loading rate is approximately 430,000 pounds per hour: :

A material balance for the FBCO process, based upon a $\mathrm{Cu} / \mathrm{S}$ molar ratio of 2.0:1.0, is provided in Appendix II. It is divided into four sections. Each section provides the overall balance for each major piece (absorber, combustor, solids heater, and regenerator) of process equipment. Section 1 discusses the balance around the fluidized-bed absorber. Sections 2, 3, and 4 discuss the balances around the combustor, the two-stage solids heater, and the regenerator, respectively. Section 9.0 discusses the sulfur recovery system.

The material balance for the FBCO process is discussed in the following four sections:

- Absorber;

- Ammonia injection requirements;

- Two-stage solids heater and combustor; and

- $\quad$ Regenerator. 
A. E. ROBERTs \& ASSOCIATES, INC.

TABLE 4-1

Coal Composition and Input Flow Rate

Power Plant Capacity, MW

500

Heating Rate, Btu/Kwh

Flow Rate, $\mathrm{lb} / \mathrm{hr}$

9,000

Heating value, Btu/lb

428,571

10,500

Coal Component Wt.\% as-fired

Wt. $-\%$ dry

$\underline{\mathrm{lb} / \mathrm{hr}}$

C

57.56

4.14

$\mathrm{N}$

1.29

7.00

O

3.12

$\mathrm{Cl}$

0.15

Ash

16.00

$\mathrm{H}_{2} \mathrm{O}$

10.74

64.49

246,686

4.64

17,743

1.45

5,529

7.84

30,000

3.50

13,371

0.17

643

17.93

68,571

46,029

Total

100.00

100.00

428,571

\subsubsection{Absorber Balance}

The combustion process, assumes that the FBCO process will be located after the plant's economizer, in order to use the elevated flue gas temperatures to optimize sulfur dioxide removal. The flue gas composition is presented in Table 4-2. This composition was determined for the combustion of the design coal at $4500 \mathrm{MBta} / \mathrm{hr}$, based upon the assumption that 95 percent of the sulfur in the coal is emitted in the flue gas as sulfur oxides with a $\mathrm{SO}_{2}$ to $\mathrm{SO}_{3}$ molar ratio of 99 to 1. The material balance utilized to develop the flue gas composition is provided in Appendix III*. This flue gas composition also assumed that 80 percent of the fly ash is emitted with the flue gas stream. The nitrogen oxide concentration of the flue gas was estimated to be $650 \mathrm{ppm}$ and consists of approximately 95 percent nitric oxide and 5 percent nitrogen dioxide.

*This same computerized balance has been utilized by AERA in the development of flue gas compositions in over 20 coal-fired facilities. 
As shown in Table 4-2, the mass flow rates of sulfur dioxide and sulfur trioxide in the flue gas are estimated at 25,229 and 364 pounds per hour respectively. The nitric oxide and nitrogen dioxide mass flow rates are estimated at 2,818 and 209 pounds per hour respectively. Assuming a 90 percent removal rate for sulfur oxides and nitrogen oxides by the absorbent, the estimated quantities of sulfur and nitrogen to be removed are 11,485 and 1,379 pounds per hour respectively.

Table 4-2

Flue Gas Composition and Flow Rate

$\mathrm{S}$ emitted as $\mathrm{SO}_{x}$ in flue gas, \% of coal S

95

Ratio of $\mathrm{SO}_{2} / \mathrm{SO}_{3}$

Flow Rate SCFM 957,871 @ 60 $\mathrm{F}$, atm pressure

\begin{tabular}{|c|c|c|c|c|}
\hline Component & $\underline{\text { Vol-\% }}$ & Vol-\% (Dry) & $\underline{\mathrm{lb} / \mathrm{hr}}$ & Mol.Wt \\
\hline Nitrogen & 73.390 & 81.076 & $3,114,070$ & 28.01 \\
\hline Oxygen & 3.230 & 3.568 & 156,553 & 31.99 \\
\hline Carbon Dioxide & 13.560 & 14.980 & 903,933 & 44.01 \\
\hline Sulfur Dioxide & 0.260 & 0.287 & 25,229 & 64.06 \\
\hline Sulfur Trioxide & 0.003 & 0.003 & 364 & 80.06 \\
\hline Nitric Oxide & 0.062 & 0.068 & 2,818 & 30.00 \\
\hline Nitrogen Dioxide & 0.003 & 0.003 & 209 & 46.00 \\
\hline Hydrochloric Acid & 0.012 & 0.013 & 645 & 35.46 \\
\hline Water & 2.480 & 0.000 & $\underline{258.686}$ & 18.01 \\
\hline Total & 100.000 & 100.000 & $4,462,507$ & 29.46 \\
\hline
\end{tabular}

To determine the quantity of absorbent required for a $\mathrm{Cu} / \mathrm{S}$ molar ratio of 2.0:1.0, the total quantity of sulfur in the flue gas must be estimated. The total sulfur oxide $\left(\mathrm{SO}_{2}\right.$ and $\left.\mathrm{SO}_{3}\right)$ molar flow rate is estimated at 398.8 mole $\mathrm{SO}_{x}$ per hour. There is one mole of sulfur per mole of sulfur oxide. Based upon a $\mathrm{Cu} / \mathrm{S}$ molar ratio of 2.0:1.0 and the molecular weight of copper (63.55 pounds $\mathrm{Cu} /$ pounds mole $\mathrm{Cu}$ ), the estimated quantity of absorbent is 724,107 pounds per hour. The percent copper in the absorbent is seven weight percent. Based upon the desired absorbent flow rate, the quantity of copper oxide is estimated at 50,688 pounds per hour and the quantity of aluminum oxide with the absorbent is 673,419 pounds per hour. The characteristics of the absorbent are given in Table 4-3. 
Table 4-3

Physical Properties of Copper Impregnated UOP SOX-3 Sorbent

Particle Șize

Bulk Density

Particle Density

Copper Concentration
$1 / 16$ inch diameter $(0.0016 \mathrm{~m})$

$35.5 \mathrm{lb} / \mathrm{ft}^{3}\left(569 \mathrm{~kg} / \mathrm{m}^{3}\right)$

$64.7 \mathrm{lb} / \mathrm{ft}^{3}\left(1.040 \mathrm{~kg} / \mathrm{m}^{3}\right)$

7.0 wt. \%

Within the absorber, the quantity of copper sulfate generated from the reaction of copper oxide and sulfur oxide is estimated at 57,241 pounds per hour. Since only 90 percent capture of sulfur occurs, not all of the copper oxide is converted to copper sulfate. Based upon the quantity of sulfur dioxide captured, the amount of unreacted copper oxide is estimated at approximately 22,157 pounds per hour. The quantity of solids removed from the absorber is estimated at approximately 752,817 pounds per hour. To transport these solids to the solids preheater, transport air is required. Based upon the air-to-mass ratio (0.11:1.0) used in the conceptual design, the quantity of transport air needed is 81,304 pounds per hour.

\subsubsection{Ammonia Requirements}

An ammonia-to-nitric oxide molar ratio of 1.0:1.0 was used to reduce nitrogen oxides in the absorber. The reduction of nitrogen dioxide is done in the absorber, using an ammonia-to-nitrogen dioxide molar ratio of 2.0:1.0. Based upon a nitrogen dioxide molar flow rate of 4.54 moles per hour (209 pounds per hour), the quantity of $\mathrm{NH}_{3}$ required is 9.09 moles per hour. With a nitrogen oxide molar flow rate of 93.9 moles per hour (2,818 pounds per hour), the quantity of $\mathrm{NH}_{3}$ required is 93.9 moles per hour (1596 pounds per hour), using equations (3) and (4) in Section 3.1. The required ammonia flow rate for the reduction of nitrogen oxides is 103 moles per hour (1,751 pounds per hour).

Air will be utilized as the carrier medium to inject the ammonia into the flue gas streams ahead of the absorber. As discussed above, the ammonia demand for nitrogen oxide reduction is estimated at 1,751 pounds per hour. As shown in Equations (3) and (4) in Section 3.1, irrespective of the equation used, the quantity of oxygen required is one mole oxygen per four moles of ammonia. Applying this molar ratio, the quantity of oxygen required is approximately 25.8 moles per hour. Using a molar ratio of 0.21 moles of oxygen per mole of air and a molecular weight of air of 29 pounds per pound mole, the quantity of air required is 3,557 pounds per hour. The total demand of the ammonia injection system is approximately 5,308 pounds per hour. 
4.1.3 Two-Stage Solids Heater and Combustor

A two-stage solids heater has been selected to increase the thermal efficiency, economics, and to minimize size. Exiting solids from the absorber are transported by air to the top of the two stage solids heater. . Using a sorbent mass flow of 752,817 pounds per hour, an exiting absorbent temperature from the absorber of $738^{\circ} \mathrm{F}$, exhaust gas temperature from the combustor $\left(1200^{\circ} \mathrm{F}\right)$, the estimated operating conditions in stage 1 and 2 in the solids heater sections are as follows:

Stage 1

Solids Temperature In:

Combustion Gas Temperature In:

Combustion Gas Temperature In:

Solids Temperature Out:

Exhaust Gas Temperature Out:

Exhaust Gas Flow Rate:

Stage 2

Solids Temperature In:

Solids Temperature Out:

Combustion Gas Temperature In:

Exhaust Gas Temperature Out:

Exhaust Gas Flow Rate: $738^{\circ} \mathrm{F}$

$1200^{\circ} \mathrm{F}$ (Stage 1 Flow)

$900^{\circ} \mathrm{F}$ (Stage 2 to Stage 1 )

$815^{\circ} \mathrm{F}$

$815^{\circ} \mathrm{F}$

124,260 pounds per hour

The specific heat capacity of the absorbent and the flue gas are 0.29 and $0.24 \mathrm{Btu} /$ pound ${ }^{\circ} \mathrm{F}$ respectively. Based upon the quantity of flue gas required, 321,230 pounds per hour, the quantity of methane required at a $10 \%$ excess air ratio is 19,174 pounds per hour. Utilizing 21,500 Btu per pound, the energy requirements for the combustor is approximately 412.2 million Btu's per hour.

\subsubsection{Regenerator Balance}

As shown in Equation 7 Section 3.4, the methane reduction of copper sulfate in the regenerator generates copper, sulfur dioxide, carbon dioxide, and water. Since the exhaust gas from the regenerator will be utilized to recover sulfur, excess amounts of methane can not be utilized. The sulfur recovery system does not have the ability to treat or remove methane. Based upon the 57,241 pounds per hour mass of copper sulfate generated and 100 percent copper sulfate reduction, and no excess methane, an estimated 2,871 pounds of methane is required per hour. Using Equation 9 , Section 3.4, it is found that the reduction of 22,157 pounds of unreacted copper oxide per hour with no excess methane requires an estimated 
pounds of methane per hour. The combined methane requirements for regeneration is therefore 3,985 pounds per hour. If using 15 percent excess methane, this would yield 4,583 pounds per hour. Using an average heating value for methane of 21,500 Btu's per pound, the energy requirements for methane are 98.5 million Btu's per hour.

Assuming a 90 percent sulfur compound removal rate in the absorber and a flow rate of 25,229 pounds per hour sulpher dioxide and 364 pounds per hour of sulpher trioxide an estimated 11,485 pounds per hour of sulpher would be captured. With a 90 percent capture, an estimated 57,248 pounds of copper sulfate would be produced in the absorber. The quantity of copper oxide reacted is estimated at approximately 28,531 pounds per hour. With a 100 percent absorbent flow rate, the amount of unreacted copper oxide from the absorber would be 22,157 pounds per hour. On the basis of unreacted alumina oxide, copper sulfate, and unreacted copper oxide, the solids flow rate to the regenerator would be approximately 752,817 pounds per hour.

4.2 Establishment of the Design Basis for Application to a 500 MW Power Plant AERA previously developed the design basis for a $500 \mathrm{MW}$ coal-fired power plant. This design report was initially submitted in September 1992, and was then revised, based upon UOP and DOE comments, in January 1993. This report is included in Appendix I.

\subsection{FBCO Process Description}

The fluidized-bed copper oxide (FBCO) process is an innovative technology for controlling sulfur dioxide and nitrogen oxide emissions from fossil-fired power plants. The FBCO process is shown in Figure 3-1. The general treatment concept with the FBCO process is relatively simple. Sorbent media (copper oxide and alumina oxide) is transported to the top of a counter-current absorber and allowed to fall by gravity to remove sulfur dioxide and nitrogen oxides from the flue gas. Untreated flue gas from the boiler is introduced through the bottom of the absorber. When the sorbent media contacts the flue gas, it reacts with sulfur dioxide to form copper sulfate. Nitrogen oxides are reduced by reacting with ammonia to form nitrogen and water in the presence of a catalyst, copper sulfate. Reacted sorbent is then collected from the absorber and transported to the regenerators where methane is used to regenerate the spent absorbent to copper oxide. The regenerated copper oxide sorbent is then recirculated back to the absorber.

The FBCO process has a number of advantages over more traditional sulfur dioxide and nitrogen oxide reduction methods: (1) both sulfur dioxide and nitrogen oxide removal occurs in the same reaction vessel; (2) the reagent (absorbent) is regenerated and used again with minimal or nominal losses; and (3) a readily salable sulfur by-product is produced, which is unlike the conventional sulfur dioxide removal processes. 
The conceptual design presented by AERA has two fluidized-bed absorbers and two regenerator trains. The desired copper-to-sulfur ratio for the absorber is estimated to be 2.0:1.0. Typically, with most flue gas cleaning, the conventional cleaning units are back end cleaning mechanisms (end of treatment in the flue gas train), or absorbents are introduced into the boiler for exhaust gas control. However, with the FBCO process, the absorber is placed directly after the boiler and before the air preheater. This allows for a slightly higher inlet air temperature for combustion and will increase the overall efficiency of the boiler.

In the AERA design, the flue gas from the boiler is separated 50/50 upon exiting the boiler, and the two flue gas streams are treated by separate absorbers and regenerators. The treated flue gas is then recombined upstream after the dust collection device.

When sizing the absorber units, both the economics and practical considerations must be considered, as well as the type of application. If the FBCO process is for a retrofit, a three or four-train system may be more practical and economical. However, if space considerations are most critical, then a three of four-train system may not be practical. In the case of the "green field" approach presented in the conceptual design, AERA took advantage of the economies of scale, to develop a two-train design system. With a smaller boiler design, it may be more advantageous to provide a stack design for flue gas cleaning. For the $500 \mathrm{MW}$ conceptual design, however, due to the size of the absorber and regenerator, a side-by-side design is preferred. Additionally, structural requirements for a stacked design would not be economical considering the height of the absorber and regenerator, and the quantity of sorbent recirculated through the system.

A primary practical consideration of the absorber system is the quantity of sorbent and the method of sorbent transportation. Due to the high volume of flue gas to be treated (approximately 4,500,000 pounds per hour), the quantity of sorbent is estimated at 724,107 pounds per hour at a Cu:S molar ratio of 2.0:1.0.

\subsection{The Selection Of a Sorbent Transportation System}

Flue gas treatment is based upon the amount of copper oxide (supported on alumina) needed to react with sulfur dioxide to form copper sulfate. Nitrogen oxides in the flue gas stream are reduced via a reaction with vaporized ammonia over the copper sulfate. In the FBCO process, the sorbent flows through the absorber by gravity and is collected and transported to the regenerator. In the regenerator, the spent sorbent is reacted with methane and regenerated. From the absorber the sorbent is transported to the regenerator by a dense phase transport system. Other modes of transportation were considered, however, a search of the literature showed that sorbent attrition rates for these alternatives were higher than the dense phase transport system. 
A dense-phase semi-continuous transport system has been designed to recirculate the sorbent to the absorber. This dense phase transportation system consists of a pressure pot, swing valves, controls, compressors, and piping. It was designed to be an effective high-capacity conveyor system, free-flowing, fluidizable, and minimizés the losses associated with a highly friable and abrasive media. When in the absorber and regenerator mode of operation, the sorbent transport system is considered an intermittent plug-flow system, not a continuous phase-flow system. Based on the sorbent recirculation rate, a design rate of one million pounds per hour was considered. In this system only about 20 percent of the volume of the pipe is occupied by the material as it flows through the pipe at a high velocity ranging from 400 to 600 feet per minute. The operating pressure of the blow tank typically ranges from 20 to 30 psia. For the conceptual design, ambient air was utilized for transportation. During the development of the FBCO process it may be possible that treated flue gas could be recirculated as the transport medium.

The key costs for the dense phase catalyst transport system are: (1) energy costs associated with the compressor operation; and (2) the makeup cost for the sorbent lost by attrition. With a pneumatic system attrition losses are minimized. Normally attrition losses are associated with material entrapped on the perimeter of the swing valve, and with the material that impacts pipe bends and connections. For these reasons, considerable attention was given to piping design. To minimize absorbent attrition losses, changes in flow direction are kept to a minimum. Where changes are necessary, long radius bends are used to reduce losses. The AERA design has only three such bends. To further minimize attrition losses, pipework joints will utilize (male/female) alignment flanges that provide a smooth internal surface across flange connections. Another design feature that minimizes absorbent attrition loss is chute bins with circular or conical design, with a minimum cone angle of $60^{\circ}$ to reduce impact attrition. The absorbent free fall distance is kept to two-three feet with minimum impacting material, thereby providing a "cushioning effect." Also the overall conveyance distance is kept to a minimum to be consistent with overall system design. This results in a total conveyance distance of about 250 feet. 
A. E. ROBERT ${ }^{\top}$ ASSOCIATES, INC.

\subsection{EQUIPMENT DESIGN AND SPECIFICATIONS}

5.1 General FBCO Process Description

As previously noted, the FPCO. process was developed at the Pittsburgh Energy Technology Center (PETC). This process has been studied on a conceptual basis. Extensive reaction kinetic models have been developed to determine the reaction kinetics of the flue gas cleaning. AERA used the technical information developed by PETC, UOP, and the reaction kinetic models of Cornell and Carnegie Mellon Universities to develop the FBCO conceptual design. The material balance for the $500 \mathrm{MW}$ coal-fired facility is discussed in Section 4.0 and provided in Appendix II. Typically, conventional flue gas cleaning methods are back-end cleaning methods and are introduced into the combustion chambers for exhaust gas control (in-situ). With the FBCO process, sulfur and nitrogen oxides are removed prior to particulate removal and is therefore not considered a back-end process.

The general treatment concept used in the FBCO process is a relatively straightforward technical process. However, due to the relatively large quantities of flue gas that will require cleaning (approximately 960,000 SCFM @ $60^{\circ} \mathrm{F}$ ), the quantity of absorbent, size of absorber, and regenerator equipment could become too large for commercial applications. In the FBCO process, the absorbent media (copper oxide and alumina oxide) are transported to the top of a counter-current absorber via a pneumatic transfer system as discussed in Section 4.4. The absorbent media then fall by gravity through the absorber. Untreated flue gas is introduced through the bottom of the absorber. In the absorber the sulfur dioxide reacts with the copper oxide in the absorbent to form copper sulfate. Concurrently, nitrogen oxides are reduced to nitrogen and water, as discussed in Section 3.0. The treated flue gas then leaves the top of the absorber and is transported through the rest of the flue gas train. The remaining train could consist of either a baghouse and/or scrubber.

Spent sorbent is collected from the absorbers and is transported to regenerators where it is regenerated to copper oxide. It is then recirculated back through the system to the absorber.

The principal factors influencing the FBCO process design include: coal properties, fly ash properties, site conditions, environmental regulations, mechanical and structural limitations, as well as a number of practical considerations. As presented in the conceptual design, coal properties determine the flue gas properties, and therefore, the degree of sulfur and nitrogen oxide control is required to maintain emission levels within regulatory limits. 
- The emission limits for nitrogen oxides and sulfur oxides are becoming more and more stringent. The amount of sulfur dioxide generated during combustion is typically the most important factor in determining the type and size of the flue gas cleaning equipment. On the basis of the conceptual design used, the quantity of sulfur dioxide generated is 25,229 pounds per hour. The quantity of sulfur trioxide is estimated at 364 pounds per hour. The amount of nitrogen oxides generated is estimated at 3,027 pounds per hour: 209 pounds per hour nitrogen dioxides, and 2,818 pounds per hour nitrogen oxide.

The FBCO process uses two fluidized-bed absorbers and two regenerator trains for flue gas treatment. This treatment scheme is discussed in Section 5.3 and 5.4. The desired copper-to-sulfur ratio for the absorber is 2.0:1.0. The AERA conceptual design calls for the untreated flue gas streams to be treated in separate absorber/regenerator trains as shown in Figure 5-1.

\subsection{Design Basis}

As shown in Figure 5-1, the following FBCO process design objectives were established by UOP, PETC, and AERA:

- The unit will be able to simultaneously remove 90 percent of sulfur dioxide and 90 percent of nitrogen oxides from the flue gas burning a coal with 3.12 percent sulfur content.

- A design copper-to-sulfur molar ratio: 2.0:1.0.

- An ammonia injection system based upon the following molar ratios:

$$
\begin{aligned}
& \mathrm{NH}_{3}: \mathrm{NO} \rightarrow 1.0: 1.0 \\
& \mathrm{NH}_{3}: \mathrm{NO}_{2} \rightarrow 2.0: 1.0
\end{aligned}
$$

- An air carrier media for ammonia injection. The superficial gas velocity, through the absorber is approximately $4.5 \mathrm{ft} / \mathrm{sec}$.

- Regenerator superficial gas velocity 6 feet per second.

- An attrition loss 0.067 weight percent using both the circulatory rate and the bed volume:

0.02 wt. \% per hour of bed volume

$(0.02 / 100$ \# of material in unit $/ \mathrm{hr})$

$0.047 \mathrm{wt} \%$ of the circulatory rate

(0.047/100 circulating rate) 
The air requirements for the conversion of $\mathrm{Cu}$ to $\mathrm{CuO}$ outside of the regenerator, is 10 percent in excess of the theoretical.

- Methane requirements for the regenerator should not be at an excess or at a minimum due to the inability of the sulfur recovery system to remove methane.

As previously noted, the AERA FBCO process design is a side-by-side layout of the absorbers and regenerators. This configuration was selected for its economy of scale, the size of the equipment, and a greenfield approach. The following subsections discuss the individual pieces of equipment, their design basis, and sizing.

\subsection{Absorber Design}

With a two absorber parallel train design, the flue gas from the coal-fired boiler is separated into two parallel flue gas streams by dampers and the induced draft fan. As discussed in Section 4.0, the quantity of absorbent leaving the absorbers is 752,817 pounds per hour. With the flow of absorbent to and from each absorber separated, the amount going to each absorber is estimated at approximately 376,409 pounds per hour. For the AERA conceptual design, a 25 mass percent increase was utilized for sizing. Based upon AERA experience, it was felt that a 25 percent margin would best define the operable limits of each absorber. Utilizing this safety factor with the projected mass flow rates, each absorber was designed to accommodate approximately a 470,500 pound per hour sorbent flow rate. A higher loading rate would effect the comparison of AERA's design to the model design With this design loading rate, a dense phase transportation system able to handle up to $1,000,000$ pounds per hour will be adequate for solid transportation.

Based upon the solids loading, flue gas flow rate, a fluidized-bed height of four feet, and a desired superficial gas velocity of $4.5 \mathrm{ft} / \mathrm{sec}$, the diameter for each absorber is approximately 72.5 feet. The straight wall height of the absorber is approximately 29 feet. The straight wall height is defined as the height from the flue gas inlet to the absorbent inlet. The absorbent enters the absorber above the fluidizing height. The absorber is segregated into two sections. The first section is designed for solids distribution and the second stage was designed for absorption and reduction.

The absorber, regenerator, and solids heater, will each require approximately eight inches of refractory liner. The base or inner refractory will be approximately two inches thick and cover the internal surface. On top of this liner layer will be a hot base approximately six inches thick. The densities of 
these two refractory materials are: 35 pounds per cubic foot for the inner layer, and 140 pounds per cubic foot for the outer layer. The specific refractory requirements are estimated by assuming that each piece of equipment is a cylinder. Having thus determined the area, the refractory quantity can then be estimated.

As shown in Appendix IV, the characteristics of the absorber, excluding the controls with split streams flue gas recirculation, are:

Quantity:

Inlet Air Flow Rate (SCFM @ 705 F):

Effluent Air Flow Rate (SCFM @ 705 F):

Design Pressure (PSIG):

Design Temperature ( $\left.{ }^{\circ} \mathrm{F}\right)$ :

Diameter of Absorber:

Absorber Surface Area:

Overall Length:

Straight Wall Height:

Top Wall Height (First Stage):

Center Wall Height (Second Stage):

Support Grid Height:

Gas Velocities:

Inlet Gas Velocity in Inlet Pipe:

Outlet Gas Velocity in Outlet Pipe:

Superficial Gas Velocity:

Grid Support - Johnson Wire Mesh:

Slot Opening:

Maximum Opening:

Minimum Opening:

Absorbent Inlet Pipe Diameter:

Absorbent Outlet Pipe Diameter:

Expanded Bed Height:

Refractory Requirements:

Material of Construction:

Minimum Thickness:

Manufacturer:

Refractory Cost

(@ $\$ 55 / \mathrm{ft}^{2}$ combined for both layers):

Capital Cost (2 absorbers):

Supporting Structural Cost '(2 absorbers):
Two

500,000

500,000

10

1,000

72.5 feet

4,128 square feet

116.7 feet

29 feet

20.3 feet

12 feet

10 feet

$40 \mathrm{feet} / \mathrm{sec}$

$40 \mathrm{feet} / \mathrm{sec}$

$4.5 \mathrm{feet} / \mathrm{sec}$

0.24 inches $(0.002)$

0.02 inches

0.018 inches

32 inches

24 inches

4 feet

8 inches

Killed Carbon Steel

$1 / 2$ inches

HPS Industries, Inc.

\& $865,000.00$

$\$ 2,868,000.00$

$\$ 200,000.00$ 
Bed Diameter

The bed diameter of the absorber is determined by the superficial flue gas velocity required to keep the bed fluidized or "bubbling." Based upon pilot work performed by the PETC and UOP, this velocity has been optimized at 4.5 feet per second. The diameter of the absorbers is 72.5 feet.

Flue Gas Residence Time

The residence times discussed in Section 4.0 are for absorbent residence time. The residence times used above are flue gas contact times per section of the absorber. These residence times are estimated by dividing the absorber volume by the flue gas flow rate. Based upon previous sizing work by PETC $^{27}$, the combined residence time in the first and second chamber was estimated at 7.5 seconds. Based upon the design flue gas flow rate, AERA used 10 seconds in the first stage and 5 seconds in the second, a slightly greater residence time.

\section{Level Control}

Control of the level of absorbent in the absorber is accomplished by two methods: (1) overflow pipes, and (2) nuclear level detectors to sense the fluidized level and control the hopper cycle. As shown in the absorber design (Appendix III), the sorbent is withdrawn from the bottom, and fresh makeup is obtained via the return stream from the regenerator. The absorbent levelizing overflow pipes are 36 inches in diameter.

\section{Ammonia Injection}

In addition to capital and structural requirements for the absorbers, additional mechanical equipment is required. For selective non-catalytic nitrogen oxide reduction, ammonia is injected into the flue gas before it enters the absorber. With the injection of ammonia at the appropriate reaction temperature and with copper sulfate as a catalyst, nitrogen oxides are reduced to nitrogen and water vapor. The reduction efficiency of nitrogen oxides is dependent upon many variables, including flue gas temperature, uniformity of temperature in the absorber, available residence time, flue gas composition, and nitrogen oxide concentration. The AERA conceptual design assume a 100 percent reduction. In actual application, however, 100 percent reduction is unlikely. The basis for the sizing of the ammonia injection system is provided in Appendix IV. The ammonia injection process requires the following equipment:

- Three ammonia storage tanks (one for each absorber and one spare that can feed both absorbers).

- Tank Capacity:

25,000 gallons each -3 tanks

75,000 gallon total 
$\bullet$

-

- Injection Probes:

Air Compressors (3):

Vaporizers (2):

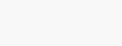

- Local Control Panel:

- Equipment Life:

- Manufacturer:

- Cost:
1,000 CFM each

1,000 pounds each (ammonia requirement 875 pounds per hour per absorber)

4 sets

8 probes

219 pounds per hour per probe

Two, one panel for each absorber

20 years

Exxon, Inc.

Annualized Cost - $\$ 2,300,000$ (Cost estimate for ammonia injection is presented in Section 6.0.)

\subsection{Regeneration Design and Specification}

The regenerator returns copper sulfate and unreacted copper oxide to copper. The specification for the regenerator is in Appendix V. A schematic of the regenerator is shown in Figure 5-2. As discussed in Section 5.1, the FBCO process will require two absorbers and two regenerators to operate in parallel. Specifications for the absorbers and regenerators are provided in Appendix III and V, respectively.

In the regenerator, as in the absorber, solids fall by gravity through a 40 inch diameter discharge pipe. Methane enters through the side of the regenerator and is forced down the regenerator to a distribution plate. At the distribution plate the gas is forced up through the regenerator, thereby fluidizing the spent absorbent. Unreacted gas and conversion products exit through a 42 inch exhaust line at the top of the unit.

\section{Regenerator}

For each of the flue gas trains, a regenerator will be provided. The size of the regenerator is based upon a 30 minute contact time for regeneration. This corresponds to approximately 92,150 cubic feet of volume in the regenerator. For the spent absorbent loading of 470,500 pounds per hour, with a bulk density of 26.6 pounds per cubic foot, and a methane introduction rate of 2,314 pounds per regenerator per hour, all at a reactor temperature of $900^{\circ} \mathrm{F}$. Each regenerator has been sized at 20 feet in diameter, and 28 feet 2 inches in straight wall height. 
As shown in Appendix V, the characteristics of the regenerator, excluding controls, include:

Quantity:

2

Design Pressure:

10 psig

Design Temperature (Maximum):

Refractory:

$1000^{\circ} \mathrm{F}$

Regeneration Diameter:

8 inches

Straight Wall Height:

20 feet

Regenerator Gas Inlet:

28 feet 2 inches

Regenerator Gas Outlet:

Regenerator Inlet Gas Velocity:

Regenerator Outlet Gas Velocity:

Regenerator Solids Inlet Diameter:

16.3 inches

Regenerator Solids Outlet Diameter:

37 inches

$30 \mathrm{ft} / \mathrm{sec}$

$40 \mathrm{ft} / \mathrm{sec}$

38.5 inches

Total Regenerator Height:

38.5 inches

Material of Construction:

92.8 feet

Capital Cost for Regenerators (2):

Killed Carbon Steel

Structural Cost (2 Regenerators):

$\$ 950,000$

Refractory Cost (@ \$55/ $\left.\mathrm{ft}^{2}\right)$ :

$\$ 85,000$

Regenerator Manufacturer:

$\$ 540,000$

HPS Industries, Inc.

5.5 Two Stage Solids Heaters and Combustor

The methane reducing agent for the spent absorbent requires the temperature of the solids in the regenerator to be between 850 and $900^{\circ} \mathrm{F}$. The AERA solids heater design has an effluent solids temperature of $900^{\circ} \mathrm{F}$. The spent sorbent temperature from the absorber is estimated at $738^{\circ} \mathrm{F}$. Based upon the findings of previous work performed by DOE, PETC and AERA, two twostage solids heaters were selected. A two- stage system provides both an economical and effective design. The heat needed to raise the temperature of the spent sorbent will be provided by a combustor/boiler. The design of the two-stage solids heaters has the following criteria:

Inlet Gas Temperature to the First and Second Stage:

$1200^{\circ} \mathrm{F}$

$\left(650^{\circ} \mathrm{C}\right)$

Refractory Size:

8 inches

Outlet Sorbent Temperature:

$900^{\circ} \mathrm{F}$

Exhaust Gas Outlet Temperature:

$815^{\circ} \mathrm{F}$

Fluidizing Velocity:

$6 \mathrm{ft} / \mathrm{sec}$

The sizing for the two-stage solids heaters is in Appendix VI. The size of the solids heater is based upon a copper-to-sulfur ratio of 2.0:1.0 and a fresh absorbent feed of 724,107 pounds per hour. The spent sorbent flow rate leaving the absorbers is 752,817 pounds per hour. The exhaust gas flow rate from the 
combustor is 124,260 pounds per hour for Stage 1 , and a combined 381,230 pounds per hour for Stage 2. These balances are shown in Appendix II.

A 40 feet per second velocity in the inlet pipe to the solids heater, and an exit temperature of $1,200^{\circ} \mathrm{F}$ from the combustor to the solids heater, requires an inlet pipe 74 inches in diameter for Stage 1 and 92 inches in diameter for Stage 2. The solids will fall by gravity through the solids heater. The exhaust gas from the solids heater is recirculated back to the absorber.

The diameter of the two stage solids heater is approximately 20 feet. The velocity in the second stage is $6 \mathrm{ft}$ per second and the velocity in the second stage is $8.9 \mathrm{ft}$ per second. The solids loading pipe diameter is 26 inches at both the inlet and outlet. The solids loading exit pipe from the bottom of the first stage is about 26 inches in diameter.

As shown in Appendix VI, the characteristics of the two stage heaters (not including controls) are as follows:

Quantity:

Exhaust Gas Flow Rates

Inlet Stage $1 @ 1200^{\circ}$ F:

Inlet Stage 2 @ $1200^{\circ} \mathrm{F}$ :

Outlet Gas Flow @ 900 F:

Inlet Gas Velocity:

Outlet Gas Velocity:

Stage 1 Inlet Gas Pipe Diameter:

Stage 2 Inlet Gas Pipe Diameter:

Exit Gas Pipe Diameter:

Solids Loading:

Solids Heater Diameter:

Straight Wall Height:

Overall Heater Length:

Material of Construction:

Design Temperature:

Refractory:

Manufacturer:

Refractory Cost ( $\$ 55 / \mathrm{FT}^{2}$ at $\left.8^{\prime \prime}\right)$ :

Structural Cost:

Capital Cost:
2

739 cubic feet/sec 1527 cubic feet/sec 3934 cubic feet/sec $40 \mathrm{feet} / \mathrm{sec}$ $60 \mathrm{feet} / \mathrm{sec}$

74 inches

92 inches

132 inches

376,408 pounds/hr

. 20 feet

25.6 feet

50.8 feet

Killed Carbon Steel $1200^{\circ} \mathrm{F}$

Eight inches

HPS Industries, Inc.

$\$ 177,500$

$\$ 72,500$

$\$ 360,000$ 


\section{Combustor}

Methane is the energy source in the combustor. The AERA design sizes the combustors based upon a 10 percent excess air. The quantity of methane burned in the combustors should be about 19,174 pounds per hour. Based upon a methane heating value of 21,500 Btu per pound, the combined capacity of the combustors is approximately 412.2 million Btu's per hour. In sizing the combustors for the conceptual design, three 150 million Btu per hour combustors will be used.

A three-combustor design was selected to better accommodate the two-stage solids heater design and to avoid the control problems and expenses associated with trying to adjust gas flows to both heater stages from a single source.

The combustors need a refractory different from that used in the absorber and regenerator. This refractory will be a combination of mineral wool (four inches thick) and ceramic fill (six inches thick). The average density for the refractory is 80 pounds per cubic foot. For purposes of estimating; it is assumed that the vessel is cylindrical.

The characteristics of the three combustors are as follows:

Quantity:

Exhaust Flow (per combustor):

Outlet Air Temperature:

Material of Construction:

Outside Diameter:

Overall Length:

Capacity (per combustor):

Fuel:

Air Blower (per combustor):

Refractory:

Capital Cost:
Three

500,000 SCFM @60 F

$1,200^{\circ} \mathrm{F}$

Killed Carbon Steel

Six feet

60 feet

$150 \mathrm{MM} \mathrm{Btu} / \mathrm{hr}$

Methane

500,000 SCFM @ 12" w.g.

Four inches mineral wool

Six inches ceramic fill $\$ 580,000$ (Each including refractory) 


\subsection{Sulfur Recovery Facility}

\subsubsection{General Process Information}

The exhaust gas from the regenerator is enriched with sulfur dioxide. As discussed in Section 3.4, this gas will be reduced to recover elemental sulfur. The recovery system selected by AERA is the RESOX process, developed by Foster Wheeler, Inc. It reduces sulfur dioxide, in the presence of carbon, to yield carbon dioxide and sulfur as follows:

$\mathrm{SO}_{2}+\mathrm{C} \rightarrow \mathrm{CO}_{2}+1 / 2 \mathrm{~S}_{2}$

The RESOX process uses coal as the source of carbon. The elemental sulfur vapor produced in the RESOX process is condensed and recovered, while the noncondensables are recycled to the system boiler and oxidized. The potential condensables generated as a side reaction include hydrogen sulfide, carbonyl sulfide, and carbon disulfide. The reduction reaction is sustained by injecting a controlled amount of air into the exhaust gas stream from the regenerator. The reduction reaction occurs at a temperature range of $1100^{\circ}$ to $1600^{\circ} \mathrm{F}$. This temperature is higher than the temperature of the exhaust gas from the regenerator $\left(900^{\circ} \mathrm{F}\right)$. The reduction reaction temperature is dependent upon the specific coal used and the characteristics of the exhaust gas stream from the regenerator. In the operation of the sulfur recovery system, the same coal used in the PC boiler can be used in the reduction of sulfur dioxide.

The conversion efficiency for sulfur dioxide reduction is approximately 80 percent. The RESOX process is normally used with sulfur enriched exhaust streams. It has been effective in streams that are five to $\mathbf{3 0}$ percent sulfur dioxide. The overall conversion of this process is effected by side reactions. To minimize the amount of these reactions, steam is injected into the reduction reactor, which enables the sulfur reaction to occur at lower temperatures. Potential side reactions include:

$\mathrm{C}+\mathrm{H}_{2} \mathrm{O} \rightarrow \mathrm{CO}+\mathrm{H}_{2}$

$\mathrm{CO}+\mathrm{H}_{2} \mathrm{O} \rightarrow \mathrm{CO}_{2}+\mathrm{H}_{2}$

$3 \mathrm{H}_{2}+\mathrm{SO}_{2} \rightarrow \mathrm{H}_{2} \mathrm{~S}+2 \mathrm{H}_{2} \mathrm{O}$

$\mathrm{H}_{2}+\mathrm{S} \rightarrow \mathrm{H}_{2} \mathrm{~S}$

$\mathrm{CO}+\mathrm{S} \rightarrow \mathrm{COS}$

$\mathrm{CO}_{2}+\mathrm{H}_{2} \mathrm{~S} \rightarrow \mathrm{COS}+\mathrm{H}_{2} \mathrm{O}$ 
$\mathrm{CO}_{2}+2 \mathrm{H}_{2} \mathrm{~S} \rightarrow \mathrm{CS}_{2}+2 \mathrm{H}_{2} \mathrm{O}$

$\mathrm{CH}_{4}+2 \mathrm{~S} \rightarrow \mathrm{CS}_{2}+2 \mathrm{H}_{2}$

The amount of introduced steam needs to be optimized, since excessive steam promotes reactions that generate hydrogen and carbon monoxide. These constituents eventually result in the formation of hydrogen sulfide and $\operatorname{COS.~Hydrogen~sulfide~significantly~degrades~the~sulfide~yield~in~the~}$ reduction reaction. The generation of hydrogen sulfide can also react with sulfur dioxide in the presence of aluminum oxide.

\subsubsection{RESOX Process Description}

A RESOX process flow diagram for sulfur recovery is shown in Drawing 9-1. In this recovery system, the flue gas from the exhaust of the regenerator is separated into four treatment trains, whereby three trains can process 100 percent of the gas flow. The fourth train is a spare, or backup.

Before the exhaust gas is introduced into the RESOX reactor, it must first be conditioned. This conditioning is accomplished by injecting steam to achieve a desired steam-to-sulfur dioxide molar ratio (2.0:1.0 to 3.0:1.0). After injecting the steam, the combined gas is fired in an in-line burner, at a near stoichiometric air-to-fuel ratio. This burner is used to raise the exhaust gas temperature to approximately $1000^{\circ} \mathrm{F}$. The burner exhaust gases are then transported to the RESOX reactors. Before entering the reactors, additional air is added to achieve a desired 3 mole percent oxygen. This conditioned gas should have a sulfur dioxide concentration of between 20 to 30 percent, and an oxygen concentration of approximately 3 mole percent. Oxygen is used to help control the temperature within the reactor by combusting small portions of coal near the reactor's gas inlet.

Each exhaust gas stream has its own RESOX reactor. Due to the elevated temperature in the reactors, refractory will be needed to control heat transfer. The reactors are filled with coal used in the reduction reaction. Coal movement in the reactor is controlled by bottom discharge feeders. Upon leaving the reactor, the coal drops onto a vibrating screen that removes ash accumulated on the coal. The ash is removed from the system and stored in a bin. The coal with the ash removed is then recirculated back to the front-end coal-feeder bin. The amount of fresh coal introduced into the feeder bin equals the amount of ash removed from the vibrating screen and coal utilized. The ash is disposed of either on or off-site. 
The coal leaving the vibrating screen is fed to the front-end coal-storage bin by a bucket elevator. From the bin, it is fed by gravity to the RESOX reactor. Although the exhaust gas enters at $1100^{\circ} \mathrm{F}$, the temperature in the RESOX reactor quickly rises to approximately $1700^{\circ} \mathrm{F}$. The exhaust gases from the reactor exit at the top, and are further processed to recover sulfur.

After leaving the RESOX reactor, the exhaust gases are circulated through a cyclone to remove particulate matter. After the particulate material is removed, the sulfur-rich gas is transported to two stages of conventional shell-and-tube heat exchangers. These exchangers are in series that allow for the process to recover sulfur when the system is operating at a higher than designed capacity. The shell-and-tube heat exchanger is designed to transport the sulfur enriched exhaust gas through the tube side. The shell side will contain pressurized boiling water which will condense the elemental sulfur in the tube side of the exchanger. The sulfur will then be collected in first and second stage storage tanks. The first stage storage tank will collect sulfur from the first bay of heat exchangers, while the second tank will collect sulfur from the second stages of heat exchangers. The heat exchangers bave two-inch OD tubes in the first stage, and 1-1/2inch $O D$ in the second stage. This tube staging minimizes the pressure drop across the exchangers, and minimizes the potential plugging of the tubes due to high viscosity of the recovered sulfur.

The coal-fired system of the reactor operates continuously. The partially spent coal from the RESOX reactor is discharged, screened, and transported continuously to the recycle bin. When the coal level is low in the coal feed bins, the fresh coal feeders and bucket elevator are automatically activated. Coal is uniformly fed into the reactors at the same time.

Filters are used in the recovery of sulfur to remove small quantities of carbon and ash that are entrained with the sulfur. The filter system used is a two-stage system. The first stage receives more sulfur than the second stage. The sulfur purity after filtration is designed to be 99.7 percent. The filters are "enclosed-pressure" types that have a number of plates suspended inside a steam-jacket shell. The sulfur to be filtered is charged into this filter shell under pressure. Each filter holds approximately 73 cubic feet of sulfur.

Exhaust gases from the heat exchangers are transported to the boiler to be oxidized. The tail gas from the heat exchanger normally contains hydrogen sulfide, sulfur dioxide, carbonyl sulfide, and carbon disulfide. These tail gases can be converted to sulfur dioxide in the boiler. 


\section{A. E. ROBERTS $\because$ ASSOCIATES, INC.}

\subsubsection{System Equipment}

The RESOX equipment includes: (4) tail gas fans; (16) reactor fans; (4) in-line burner air fans; (2) start-up heater fans; (4) coal feed bucket elevators; (4) blended coal conveyors; (4) first stage steam drums; (4) second stage steam drums; (8) first stage condensers; (8) second stage condensers; (4) fresh coal feeders; (4) recycle coal feeders; (16) reactor coal dischargers; (2) start-up heaters; (4) in-line burners; (3) sulfur pumps; (1) first stage filter pump; (1) second stage filter pump; (1) filter pre-coat pump; (4) cyclone separators; (4) vibrating screen conveyors; (2) sulfur filters; (4) fresh coal dry bins; (4) recycle coal bins; (4) ash bins; (9) bin vent - coal feed bins; (4) coal feed bins; (4) recycle coal bins; (2) fresh coal storage bins; (4) RESOX reactors; (4) first stage sulfur storage tanks; (4) second stage sulfur storage tanks; (4) ash bins; (4) cyclone hoppers; (1) sulfur filter precoat and drain tank; (1) sulfur transfer tank; (1) second stage sulfur transfer tank; (4) flash drums; and (2) cake hoppers.

\subsubsection{RESOX Cost for Sulfur Recovery}

The cost of the recovered sulfur is dependent upon the amount of sulfur dioxide processed. The quantity of sulfur captured by the absorbent is about 22,970 pounds per hour. Assuming this sulfur is converted into sulfur dioxide, the quantity obtained through the sulfur recovery process is 45,940 pounds per hour.

Utilizing costing factors developed for the RESOX process, the total capital cost for the RESOX process is estimated at $\$ 26,550,000$ in 1993 dollars. These cost factors are based upon cost for 100, 500, and 1800 MW applications. This RESOX capital cost includes all costs associated with the process through construction. Based upon discussions with RESOX manufacturers, the annual operation and maintenance cost is about 10 percent of the capital cost, or $\$ 2,655,000$. The annual levelized capital cost is estimated at $\$ 2,894,000$. 


\subsection{General Cost Factors}

The cost of the FBCO process includes the costs for the absorber, regenerator, solids, heater, combustor, structural requirements, duct work, instrumentation and controls, and miscellaneous equipment. The costing breakdown is provided in Table 6-1 and discussed in Section 6.2. Costing information for the commercially available sulfur dioxide and nitrogen oxide units were estimated from best available control technology demonstrations performed for coal-fired facilities in the United States and vendor cost estimates. These cost estimates are discussed in Section 7.0. The cost estimates developed from the best available control technology demonstrations are included in Section 7.0.

Part of the costing for the FBCO process is also based upon experience with similar flue gas treatment projects, and vendor equipment estimations. Vendors and manufacturers that provided quotes to AERA are listed in Section 5.0. Cost ranges provided in the analysis are based primarily upon the removal rates of nitrogen oxides and sulfur dioxides. Theoretical models developed by various research and development organizations are not directly applicable for cost comparison to this $500 \mathrm{MW}$ facility due to equipment limitations. The majority of the research and development costing basis is scale-up equations and bench-scale and small-pilot-scale testing results. In order to provide consistent costing comparisons between the FBCO process and conventional flue gas cleaning technologies, the following cost factors were used:

\section{Cost Factors:}

- The amount of nitrogen oxide removal, based upon 90 percent removal efficiency, is estimated at 11,932 tons per year. (Discussed in Section 4.0.)

- The amount of sulfur oxides removed from the flue gas is estimated at 99,452 tons per year, based upon a 90 percent sulfur dioxide removal. (Discussed in Section 4.0.)

- Equipment life: 20 years

- Interest rate: 8 percent

- Refractory cost: $\$ 55$ per square foot, 8 inches thick

- Absorbent cost: $\$ 5.00$ per pound

- $\quad$ Catalyst cost: $\quad \$ 9.69$ per pound

- Energy cost: $\$ 0.1 / \mathrm{KW}-\mathrm{Hr}$

- Ammonia cost: $\quad \$ 240$ per ton delivered 
- Waste disposal: $\quad \$ 50$ per ton

- Levelizing factors: 0.109 for capital cost over 20 years

Leveling factors were developed to compare the annual capital and operating costs, on an equivalent basis. Cost are shown herein to the nearest $\$ 10,000$ when comparing technologies which are discussed in Section 7.0.

6.2 Estimated Cost for the FBCO Process without Sulfur Recovery The estimated cost for the FBCO process includes the total capital cost of the process equipment, annualized capital cost, capital expense, operating maintenance cost, and energy cost. The equipment life for the FBCO process is estimated at 20 years. The levelized energy cost was based upon a \$0.1/KW-Hr costing factor. Table 6-1 provides a breakdown of the costing for the FBCO process. The process areas for the FBCO process includes: absorber (2), regenerator (2), combustor (2), solids heater (1), structural requirements, duct work, and dense phase transportation system. The installation cost was estimated at 40 percent of the equipment and structural cost. Sulfur recovery is discussed in Section 5.6. - The cost for the sulfur removing system is discussed in Section 6.3. As shown in Table 6-1, the estimated process area capital costs for the absorber system, excluding the cost for sulfur recovery, are:

- $\quad$ Absorber System - $\$ 17,250,000$. Costs include: (2) absorbers (\$2,870,000 for both); absorber structural support requirements for two absorbers $(\$ 200,000$ for both); dampers and isolation valves for both absorbers (5 - \$350,000); booster fan for each absorber $(2-\$ 370,000)$; booster fan motors ( 2 - $\$ 190,000$ for both); refractory (both absorbers, $\$ 1,870,000$ ); duct work (both absorbers - $\$ 240,000$ ); instrumentation and control (both absorber units -\$490,000); ammonia injection system (detailed in Section 5.0-\$2,300,000); absorbent for the initial fill $(\$ 5,000,000)$; engineering $(\$ 1,220,000)$; installation of absorbers $(\$ 2,180,000)$; and a 20 percent contingency cost $(\$ 970,000)$.

- Regenerator System - $\$ 5,690,000$. Cost include: (2) regenerators $(\$ 950,000)$; regenerator structural support requirements $(\$ 90,000$ for both regenerators); refractory for both regenerators $(\$ 540,000)$; dampers and isolation valves $(8-\$ 560,000)$; booster fans and motors (2 - \$560,000); duct work (both regenerators - \$140,000); instrumentation and controls (both regenerator - $\$ 270,000$ ); methane feed system (both regenerators $-\$ 140,000$ ); engineering $(\$ 690,000)$; installation $(\$ 1,210,000)$; and 20 percent contingencies $(\$ 540,000)$. It has been assumed that methane storage is not required at the site. 
- Two Stage Solids Heater $-\$ 4,760,000$. The costs for the two-stage solids heater includes: (1) two stage solids heater $(\$ 720,000)$; refractory for the two-stage solids heater $(\$ 360,000)$; structural support requirements ( $\$ 150,000)$; dampers and isolation valves $(\$ 560,000)$; booster fans and motors $(\$ 540,000)$; duct work $(\$ 120,000)$; instrumentation and controls $(\$ 230,000)$; process and structural engineering $(\$ 580,000)$; installation $(\$ 1,040,000)$; and contingencies $(\$ 460,000)$.

- Dense Phase Transport System $-\$ 14,550,000$. The cost for this system has been identified in the Roberts and Schaeffer Report submitted to UOP in September 1992. The cost breakdown of the dense phase transportation system is: mechanical equipment $(\$ 6,500,000)$; four isolation dampers $(\$ 280,000)$; two booster fans and motors $(\$ 270,000)$; two storage silos $(\$ 190,000)$; air/lock storage $(\$ 140,000)$; instrumentation and controls $(\$ 750,000)$; process engineering $(\$ 1,490,000)$; system installation $(\$ 3,360,000)$; and contingencies $(\$ 1,490,000)$.

- Combustion Process - \$5,200,000. The cost of the combustion process is based upon a prepackaged manufacturers system for the combustors. The combustion units will be provided in a manner that assures their direct installation at minimal cost. The cost of the combustion process includes: pre-engineered combustion units $(\$ 1,740,000)$; structural requirements for the combustor $(\$ 650,000)$; duct work associated with the combustors $(\$ 130,000)$; dampers and isolation valves $(\$ 140,000)$; instrumentation and control for the combustors $(\$ 250,000)$; process and structural engineering requirements $(\$ 640,000)$; installation of the combustors $(\$ 1,140,000)$; and contingencies $(\$ 510,000)$.

The estimated cost of the FBCO process is $\$ 56,924,000$ excluding the sulfur recovery plant which is discussed in Section 6.3. The costing range of the equipment is estimated \pm 30 percent. This range was chosen because the majority of the cost is based upon preliminary vendor estimations. There were no detailed vendor estimations provided by manufacturers since site location, detailed project manual for bidding the project were not included.

The annual FBCO investment cost includes the capital equipment cost, general facility cost, and engineering services. It is estimated at $\$ 5,170,000$ on a 20 year basis. This cost is based upon multiplying the total process cost $(\$ 47,450,000)$ by the annual levelized cost factor $(0.109)$. For costing purposes, the duct work for each process is estimated at five percent of the process capital cost. Instrumentation and control cost have been estimated at 10 percent of the capital cost. Typically instrumentation can range from eight to 15 percent of the process cost. Engineering services have been estimated 


\begin{tabular}{|c|c|c|c|c|}
\hline \multicolumn{5}{|c|}{$\begin{array}{l}\text { TABLE 6-1 } \\
\text { Cost for the CuO Process without Sulfur Recovery }(1,2,8)\end{array}$} \\
\hline Equipment & QTY. & Capital Cost & $\begin{array}{l}\text { Levelizing } \\
\text { Factor }{ }^{(3)}\end{array}$ & Annual Cost \\
\hline $\begin{array}{l}\text { Absorber System } \\
\text { Absorber Material } \\
\text { Absorber Structural } \\
\text { Dampers/Isolation Valves } \\
\text { Booster Fans } \\
\text { Booster Motors } \\
\text { Refractory for Absorber } \\
\text { Duct Work (5\%) } \\
\text { Instrumentation \& Control (10\%) } \\
\text { Ammonia Injection System } \\
\text { Installation of Absorber System(45\%) } \\
\text { Absorbent Fill } \\
\text { Process Engineering (20\%) } \\
\text { Structural Engineering (5\%) } \\
\text { Contingency (20\%) } \\
\text { Absorber System Cost }\end{array}$ & $\begin{array}{l}2 \\
2 \\
5 \\
2 \\
2 \\
2\end{array}$ & $\begin{array}{r}\$ 2,870,000 \\
200,000 \\
350,000 \\
370,000 \\
190,000 \\
870,000 \\
240,000 \\
490,000 \\
2,300,000 \\
2,180,000 \\
5,000,000 \\
970,000 \\
240,000 \\
970,000 \\
17,250,000\end{array}$ & 0.109 & \$ $1,880,000$ \\
\hline $\begin{array}{l}\text { Regenerator System } \\
\text { Regenerator } \\
\text { Refractory for Regenerator } \\
\text { Regenerator Structural Requirements } \\
\text { Dampers/Isolation Valves } \\
\text { Booster Fans } \\
\text { Booster Motors } \\
\text { Duct Work (5\%) } \\
\text { Instrumentation \& Control (10\%) } \\
\text { Methane Feed System (5\%) } \\
\text { Structural Engineering (5\%) } \\
\text { Process Engineering (20\%) } \\
\text { Installation of Regenerator System (45\%) } \\
\text { Contingency (20\%) } \\
\text { Regenerator System Cost }\end{array}$ & $\begin{array}{l}2 \\
2 \\
2 \\
8 \\
2 \\
2\end{array}$ & $\begin{array}{r}950,000 \\
540,000 \\
90,000 \\
560,000 \\
370,000 \\
190,000 \\
140,000 \\
270,000 \\
140,000 \\
140,000 \\
550,000 \\
1,210,000 \\
540,000 \\
5,690,000 \\
\end{array}$ & 0.109 & \$ 620,000 \\
\hline $\begin{array}{l}\text { Two-Stage Solids Heater } \\
\text { Two Stage Solids Heater } \\
\text { Refractory for Solids Heater } \\
\text { Heater Structural Requirements } \\
\text { Dampers/Isolation Valves } \\
\text { Booster Fans } \\
\text { Booster Motors } \\
\text { Duct Work (5\%) } \\
\text { Instrumentation \& Control (10\%) } \\
\text { Structural Engineering (5\%) } \\
\text { Process Engineering (20\%) } \\
\text { Installation of Heater System (45\%) } \\
\text { Contingency (20\%) } \\
\text { Solids Heater System Cost }\end{array}$ & $\begin{array}{l}2 \\
2 \\
2 \\
8 \\
2 \\
2\end{array}$ & $\begin{array}{r}720,000 \\
360,000 \\
150,000 \\
560,000 \\
380,000 \\
160,000 \\
120,000 \\
230,000 \\
120,000 \\
460,000 \\
1,040,000 \\
460,000 \\
4,760,000\end{array}$ & 0.109 & \$ 519,000 \\
\hline
\end{tabular}




\begin{tabular}{|c|c|c|c|c|}
\hline Equipment & QTY. & $\begin{array}{c}\text { Capital } \\
\text { Cost }\end{array}$ & $\begin{array}{l}\text { Levelizing } \\
\text { Factor }^{(3)}\end{array}$ & Annual Cost \\
\hline $\begin{array}{l}\text { Dense Phase Transport System } \\
\text { Dense Phase System } \\
\text { Dampers/Isolation Valves } \\
\text { Booster Fans } \\
\text { Booster Motors } \\
\text { Storage Silos } \\
\text { Air/Lock Storage } \\
\text { Instrumentation \& Control (10\%) } \\
\text { Process Engineering (20\%) } \\
\text { Installation of Transport System (45\%) } \\
\text { Contingency (20\%) } \\
\text { Dense Phase System Cost }\end{array}$ & $\begin{array}{l}1 \\
4 \\
2 \\
2 \\
2 \\
2\end{array}$ & $\begin{array}{r}\$ 6,580,000 \\
280,000 \\
190,000 \\
80,000 \\
190,000 \\
140,000 \\
750,000 \\
1,490,000 \\
3,360,000 \\
1,490,000 \\
14,550,000 \\
\end{array}$ & 0.109 & $\$ 1,590,000$ \\
\hline $\begin{array}{l}\text { Combustion Process (Pre-Engineered Only } \\
\text { Boilers } \\
\text { Structural } \\
\text { Dampers/Isolation Valves } \\
\text { Duct Work (5\%) } \\
\text { Instrumentation and Control (10\%) } \\
\text { Structural Engineering (5\%) } \\
\text { Process Engineering (20\%) } \\
\text { Installation of Transport System (45\%) } \\
\text { Contingency (20\%) } \\
\text { Combustion System Cost } \\
\end{array}$ & $\begin{array}{l}3 \\
2 \\
2\end{array}$ & $\begin{array}{r}\$ 1,740,000 \\
650,000 \\
140,000 \\
130,000 \\
250,000 \\
130,000 \\
510,000 \\
1,140,000 \\
510,000 \\
5,200,000 \\
\end{array}$ & 0.109 & S 570,000 \\
\hline CuO Process Cost & & $\$ 47,450,000$ & 0.109 & $\$ 5,170,000$ \\
\hline $\begin{array}{l}\text { Operating Cost } \\
\text { Material Storage (5\%) } \\
\text { Operational Labor } \\
\text { Maintenance Labor } \\
\text { Administrative Cost } \\
\text { Electrical Cost } \\
\text { Sorbent Make-up Cost } \\
\text { Methane Cost }^{7} \\
\text { Ammonia Cost } \\
\text { Operating Cost Subtotal }\end{array}$ & & $\begin{array}{r}\$ 2,850,000 \\
300,000 \\
140,000 \\
60,000 \\
1,140,000 \\
23,210,000 \\
31,200,000 \\
1,840,000 \\
60,740,000 \\
\end{array}$ & . & $\$ 60,740,000$ \\
\hline Levelized Annual Cost & & & & $\$ 65,910,000$ \\
\hline $\begin{array}{l}\text { Tons of } \mathrm{NO}_{x} \text { Captured per year }{ }^{4} \\
\text { Tons of } \mathrm{SO}_{x} \text { Captured per year }\end{array}$ & & & & $\begin{array}{l}11,932 \\
99,452 \\
\end{array}$ \\
\hline $\begin{array}{l}\text { Cost Effectiveness } \\
\text { (Annual \$/ton NO } \mathrm{N}_{\mathrm{\gamma}} \text { removed) }\end{array}$ & & & & $\$ 592$ \\
\hline
\end{tabular}

\section{NOTES:}

(1) Costs are estimated to the nearest $\$ 10,000$.

(2) Annual costs are used to compare technologies.

(3) Levelizing Factor based upon a 20 year equipment life and 8 percent interest rate. Reference for Levelizing Factor: Engineering in Training Review Manual, Sixth Edition, Page 2-28.

(4) Tons removed are based upon AERA conceptual design report.

(5) Ammonia cost based upon \$240/ton delivered.

(6) Sorbent cost $(\mathrm{CuO})$ is estimated at $\$ 5.00$ per pound.

(7) Methane cost are estimated at $\$ 0.15$ per pound.

(8) This cost does not include the cost of the sulfur recovery plant. The cost of the sulfur recovery plant is provided in Sect. 6.3. 


\begin{tabular}{|c|c|c|c|c|}
\hline \multicolumn{5}{|c|}{$\begin{array}{c}\text { TABLE 6-1 } \\
\text { Cost for the CuO Process with Suflur Recovery }(1,2,8)\end{array}$} \\
\hline Equipment & QTY. & $\begin{array}{l}\text { Capital } \\
\text { Cost }\end{array}$ & $\begin{array}{l}\text { Levelizing } \\
\text { Factor }^{(3)}\end{array}$ & Annual Cost \\
\hline $\begin{array}{l}\text { Absorber System } \\
\text { Regeneration System } \\
\text { Two-Stage Solids Heater } \\
\text { Dense Phase Transport System } \\
\text { Combustion Process } \\
\text { Sulfur Recovery System }\end{array}$ & $\begin{array}{l}1 \\
1 \\
1 \\
1 \\
1 \\
1\end{array}$ & $\begin{array}{r}\$ 17,250,000 \\
5,690,000 \\
4,760,000 \\
14,550,000 \\
5,200,000 \\
26,550,000\end{array}$ & $\begin{array}{l}0.109 \\
0.109 \\
0.109 \\
0.109 \\
0.109 \\
0.109\end{array}$ & $\begin{array}{r}\$ 1,880,000 \\
620,000 \\
520,000 \\
1,590,000 \\
570,000 \\
2,890,000\end{array}$ \\
\hline Subtotal Cost & & $\$ 74,000,000$ & & $\$ 8,070,000$ \\
\hline $\begin{array}{l}\text { Operating Cost } \\
\text { CuO Process } \\
\text { Sulfur Recovery }\end{array}$ & $\begin{array}{l}1 \\
1\end{array}$ & $\begin{array}{r}\$ 60,740,000 \\
2,655,000\end{array}$ & $\begin{array}{l}1.0 \\
1.0\end{array}$ & $\begin{array}{r}\$ 60,740,000 \\
2,655,000\end{array}$ \\
\hline Subtotal Cost & & $\$ 63,395,000$ & & $\$ 63,395,000$ \\
\hline$\frac{\text { Credit }}{\text { Sulfur (TPY) }}$ & 49,726 & & 1.0 & (\$ 290,000) \\
\hline Revised Operating Cost & & 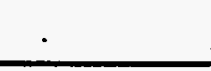 & & $\$ 63,105,000$ \\
\hline $\begin{array}{l}\text { Cost Effectiveness } \\
\text { (Annual S/ton SO } \text { removed) }^{-}\end{array}$ & & & & $\$ 635$ \\
\hline
\end{tabular}

\section{NOTES:}

(1) Costs are estimated to the nearest $\$ 10,000$.

(2) Annual costs are used to compare technologies.

(3) Levelizing Factor based upon a 20 year equipment life and 8 percent interest rate. Reference for Levelizing Factor: Engineering in Training Review Manual, Sixth Edition, Page 2-28.

(4) Tons removed are based upon AERA conceptual design report.

(5) Ammonia cost based upon $\$ 240 /$ ton delivered.

(6) Sorbent cost $(\mathrm{CuO})$ is estimated at $\$ 5.00$ per pound.

(7) Methane cost are estimated at $\$ 0.15$ per pound.

(8) This cost does not include the cost of the sulfur recovery plant. The cost of the sulfur recovery plant is provided in Sect. 9.0. 
at 20 percent of the capital cost. Engineering costs typically range from 15 to 25 percent of the process capital cost. Installation costs are conservatively estimated at 40 percent of the capital cost. Contingencies have been estimated at 20 percent of the capital cost. Typically contingencies vary from 10 to 30 percent.

The annual fixed operating costs are estimated at $\$ 60,740,000$. They include: absorbent utilization, power associated with the transportation system, transportation operation and maintenance cost, operating labor, maintenance labor, maintenance material, methane and ammonia costs, energy costs for the FBCO process, and administrative support. Operating labor includes two supervisors and five operators. Maintenance labor cost includes four facilities personnel per year. Maintenance material cost one percent of the process area cost. Administrative cost includes two administrative personnel with an annual salary of $\$ 30,000$ each. The costs for these annual services are as follows:

\begin{tabular}{llr} 
- & Material storage: & $\$ 2,850,000$ \\
- Operating labor: & 300,000 \\
- & Maintenance labor: & 140,000 \\
- & 60,000 \\
- & Electrical: & $1,140,000$ \\
- & Methent mane cost: & $23,210,000$ \\
- Ammonia cost: & $31,200,000$ \\
& Total Operating cost: & $1,840,000$ \\
\hline
\end{tabular}

The annual levelized cost is derived from the annual capital and operating costs, and the levelizing factor. The annual capital cost is an eight percent interest leveled over a 20 year equipment life. The levelizing capital cost factor is 0.109 . The annual operating cost is based upon the information provided in the conceptual design.

For making cost comparisons, AERA developed a cost-effectiveness factor for comparing the FBCO process to other conventional flue gas treatment processes. The cost effectiveness of the FBCO process is defined as the capital cost of the FBCO process, divided by the quantity of either sulfur dioxide or nitrogen oxide removal. Based upon discussion with the A.E. Roberts team members the capital and operations costs for the FBCO process is proportioned based upon the quantity of material removal. 
Based upon 99,452 tons per year of sulfur oxides removed, the costeffectiveness for its removal (excluding the cost of the sulfur recovery plant) is $\$ 592$ per ton. The quantity of nitrogen oxide removed is estimated at 11,932 tons per year. Its cost-effectiveness for removal is $\$ 592$ per ton (excluding the cost of the sulfur recovery plant). These costs cover 90 percent control of the sulfur oxide and nitrogen oxide removal. These costs will vary dramatically depending upon the sulfur oxide and nitrogen oxide removal efficiencies. Additionally, the cost-effectiveness of this process is also based in this document upon the cost of the sulfur recovery facility, and is discussed in Section 9.0.

\subsection{FBCO System Cost with Sulfur Recovery}

As discussed in Chapter 6, the cost of the FBCO process without sulfur recovery is $\$ 56,924,000$. The cost breakdown of this process with sulfur recovery is as follows:

Absorber System

Regenerator System

Two-Stage Solids Heater

Dense Phase Transport System

Combustion Process

Sulfur Recovery

Subtotal
$\$ 17,242,000$

$5,660,000$

$3,057,000$

$14,550,000$

$5,191,000$

$\underline{26,550,000}$

$\$ 72,250,000$

The annual levelized capital cost for the FBCO process with sulfur recovery is based upon a 20 year equipment life with an 8 percent interest rate. The annual levelized cost for the FBCO system is $\$ 7,875,000$. The annual operational cost for the FBCO process is $\$ 63,395,000$. The operational cost includes operation, maintenance, disposal of waste as non-hazardous material, etc. The combined annual cost which includes the annual levelized capital cost and the operational costs is $\$ 71,270,000$. 
The commercial viability of the FBCO process is dependent upon whether the process is economical and feasible when compared to other conventional flue gas cleaning methods. It is the intent of Sections 7.0 and 8.0 to provide technical and economical information on alternative flue gas cleaning technologies. Section 7.0 discusses alternative sulfur dioxide removal technologies and Section 8.0 discusses other nitrogen oxide removal technologies.

This section discusses the advantages and disadvantages, as well as the operational and maintenance costs associated with alternative technologies. Sulfur dioxide removal technologies during coal combustion can be classified as providing either insitu or post-combustion control. In-situ controls inject limestone into the boiler or adjust conditions in the boiler to optimize emission levels. Post-combustion control technologies for sulfur dioxide control include the reaction of excess reagents with sulfur dioxide and the use of fabric filtration to remove entrained particulates from the flue gas stream. Conventional technologies considered comparable to the FBCO process for sulfur dioxide removal include:

- Limestone injection (either combustion, or post-combustion control); and

- Wet scrubbing.

Both of these technologies are discussed in the following sections.

\subsection{Alternative Sulfur Dioxide Technologies}

There are a large number of post-combustion flue gas desulfurization (FGD) systems available for commercial use in coal combustion. The FGD systems are either wet or dry scrubbing. There are also a large number of treatment technologies in various stages of development, (i.e. bench-scale, pilot, and fullscale). Only the commercially available applications were considered (Tables 7-1 and 7-2). Table 7-1 lists the advantages and disadvantages of these technologies for non-regenerated wet scrubbing processes. Table 7-2 lists the advantages and disadvantages of non-regenerative dry scrubbing processes. Figure 7-1 is a matrix of commercially proven clean-up technologies.

Wet scrubbing, with either lime or limestone slurries, are currently the principal methods used for post-combustion control of sulfur oxide emissions. Non-regenerable wet scrubbing with wet lime or limestone accounts for 79 percent of the FGD technology used. Other types of wet scrubbing systems account for another seven percent, while dry scrubbing makes up about eight percent. The remaining six percent are processes primarily used to develop a resalable by-product. 


\section{FIGURE 7-1}

COMMERCIALLY PROVEN SULFUR OXIDE CONTROL TECHNOLOGIES

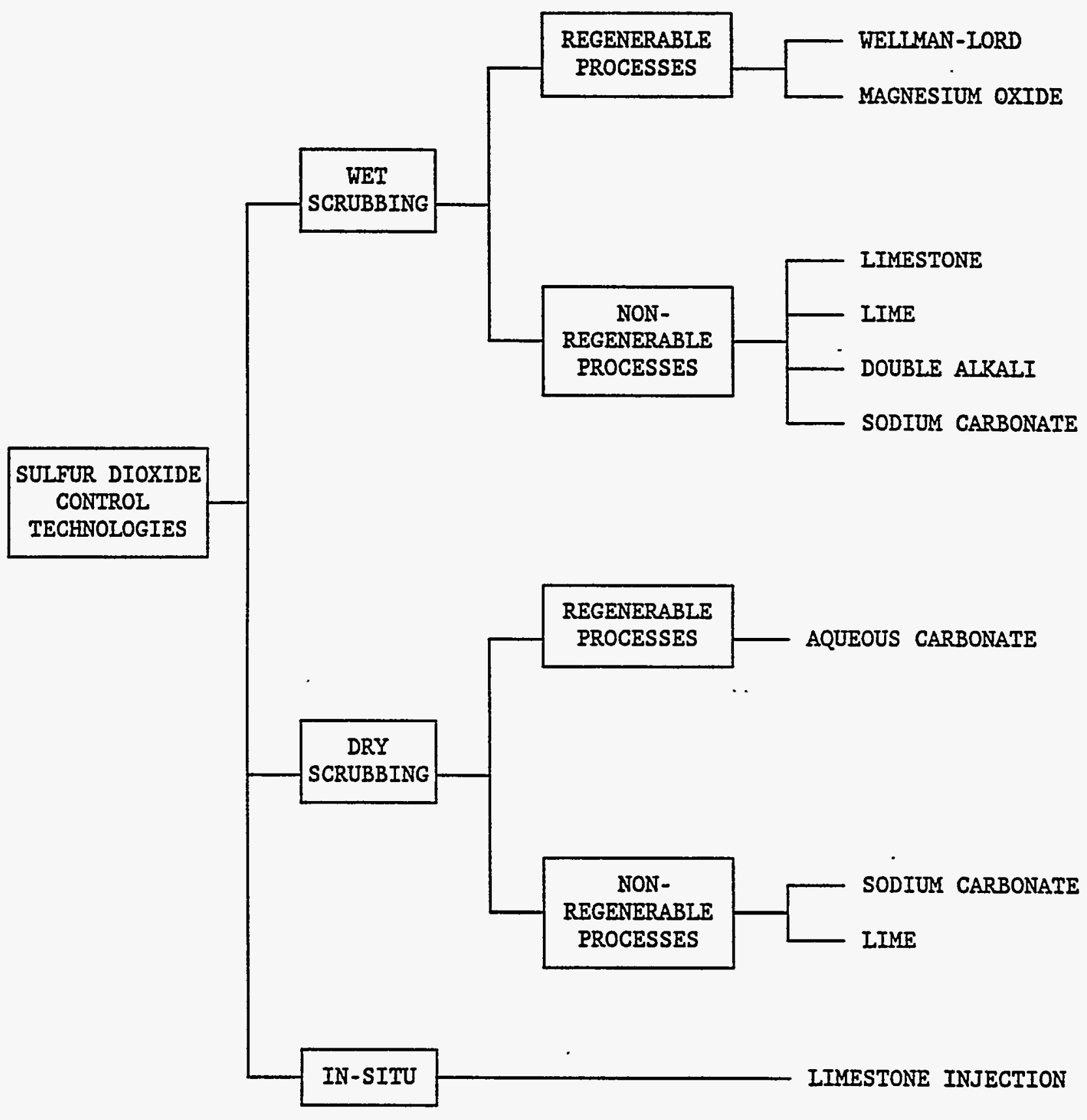


One sulfur dioxide removal technology that is not considered for comparison is the direct addition of limestone into the combustion chamber. Direct injection has been demonstrated on a commercial scale with various types of conventional boilers, and has achieved sulfur dioxide removal efficiencies greater than 90 percent. This technology is considered an in-situ combustion control technology, not a post-combustion control technology. With the introduction of limestone into the boiler for in-situ control, for a given weight percent sulfur in the fuel, a fuel-to-limestone weight ratio will result in 80 percent sulfur dioxide removal.

Wet scrubbing technologies are generally capable of reducing sulfur dioxide emissions by up to 95 percent. Dry scrubbing technologies can remove up to 90 percent of sulfur dioxide. Both wet and dry scrubbing technologies will be considered in making cost comparisons with the FBCO process. Cost comparisons for sulfur dioxide removal are presented in Section 7.2. Scrubbing technologies normally require combining flue gas desulfurization technology with a particulate removal technology. In the wet scrubbing process, flue gas must first be cleaned by removing fly ash particles, using either a bag house or multi-cyclones. With dry scrubbing, flue gas passes through the dry scrubber and is then routed to a particulate control device.

Dry scrubbing involves the removal of sulfur dioxide by contacting the flue gas with an atomized slurry in a spray dry scrubber. Water evaporates in the scrubber, and the sulfur oxides are subsequently absorbed by the remaining fine solids. Reaction temperatures are maintained slightly above gas dew points by controlling the amount of water in the slurry. The scrubbed gases are then processed through a particulate control device and exhausted to the stack. Dry FGD systems typically use lime in the slurry. Sodium carbonate is also used in dry scrubbing systems. Approximately 90 percent of the commercial dry scrubbing systems use lime. Lime dry scrubbing systems will therefore be used for comparison with the FBCO process.

7.2 Comparative Sulfur Dioxide Costs

Two conventional sulfur dioxide technologies were compared with the FBCO process: wet scrubbing and dry scrubbing. For wet scrubbing, a common limestone base system is expected to have the lowest capital and operational costs of the three commercially available wet scrubbing processes compared. The costing for the wet scrubbing system includes cost for a single wet scrubbing system; solid waste handling and disposal; wastewater handling and disposal; and support equipment. The other two wet scrubbing systems not used for cost comparison include: lime and sodium carbonate scrubbing systems. 
For the dry scrubbing system, a dry lime process is used for comparison. Its major process areas are: sulfur dioxide removal equipment; gas handling and reheat; reagent handling; waste handling and disposal; and support equipment.

\subsubsection{Wet Scrubbing Costs}

In comparing the FBCO process with the wet scrubbing process, the percentage of sulfur dioxide removal ( 90 percent) is comparable. With the wet scrubbing process, either a two or three module removal system is considered. With the two module system, two 100 percent capacity units were considered for removal. With the three module system, each unit would be a 50 percent unit.

Table 7-2 provides a cost breakdown of the wet scrubbing process. Based upon the sulfur oxide loading to the wet scrubber, $(25,593$ pounds per hour), the estimated total cost of the wet scrubbing system is $\$ 71,050,000$. The cost breakdown of the wet scrubbing system is as follows: $\$ 33,690,000$ for the equipment and installation; $\$ 24,020,000$ for the flue gas handling and instrumentation and controls; $\$ 4,710,000$ for reagent handling, storage, and processing; $\$ 1,430,000$ for solid and liquid waste handling; $\$ 740,000$ for additional support equipment; and $\$ 6,460,000$ for process and engineering contingencies.

The annual operating cost for the wet scrubbing system is $\$ 23,300,000$ for a $500 \mathrm{MW}$ power station. The annual fixed operating cost breakdown is $\$ 240,000$ for operating labor; $\$ 270,000$ for maintenance labor; $\$ 2,330,000$ for maintenance material; $\$ 150,000$ for administration and support; $\$ 3,040,000$ for reagent (calcium oxide at $\$ 60$ per ton); $\$ 770,000$ for water at $\$ 1.00$ per 1,000 gallons; $\$ 4,440,000$ for steam at $\$ 3.00$ per 1,000 pounds; $\$ 3,480,000$ for electricity at $\$ 0.1$ per kilowatt hour; and $\$ 7,680,000$ for solid waste disposal at $\$ 50$ per ton.

The annual levelized capital cost for the wet scrubbing process is approximately $\$ 7,740,000$. The annual operating cost is estimated at $\$ 23,300,000$. The total annual levelized cost is $\$ 31,040,000$. Based upon the amount of sulfur dioxide removed per year ( 99,452 tons), and the annual levelized cost, the cost effectiveness factor for the wet scrubbing process is $\$ 312$ per ton of sulfur dioxide removal. 
TABLE 7-2

Cost Summary for Wet Scrubbing Process ${ }^{(1,2)}$

\begin{tabular}{|c|c|c|c|}
\hline Equipment & $\begin{array}{c}\text { Capital } \\
\text { Cost }\end{array}$ & $\begin{array}{l}\text { Levelizing } \\
\text { Factor }^{(3)}\end{array}$ & Annual Cost \\
\hline $\begin{array}{l}\mathrm{SO}_{2} \text { Removal Equipment with } \\
\text { Installation } \\
\text { Flue Gas Handling Equipment with I\&C } \\
\text { Reagent Handling } \\
\text { Waste Handling } \\
\text { Support Equipment } \\
\text { Contingency (10\%) } \\
\text { Wet Scrubbing Process Cost } \\
\end{array}$ & $\begin{array}{r}\$ 33,690,000 \\
24,020,000 \\
4,710,000 \\
1,430,000 \\
740,000 \\
6,460,000 \\
71,050,000 \\
\end{array}$ & 0.109 & $\$ 7,740,000$ \\
\hline $\begin{array}{l}\text { Operating Costs } \\
\text { Operating Labor } \\
\text { Maintenance Labor } \\
\text { Maintenance Material } \\
\text { Administrative/Support } \\
\text { Reagent }^{6} \\
\text { Water }^{7} \\
\text { Steam }^{8} \\
\text { Electricity }^{9} \\
\text { Solid Waste Disposal } \\
\text { Annual Operating Cost } \\
\end{array}$ & $\begin{array}{r}\$ 240,000 \\
270,000 \\
3,230,000 \\
150,000 \\
3,040,000 \\
770,000 \\
4,440,000 \\
3,480,000 \\
7,680,000 \\
23,300,000 \\
\end{array}$ & 1 & $\$ 23,300,000$ \\
\hline Annual Levelized Cost & & & $\$ 31,040,000$ \\
\hline Tons of $\mathrm{SO}_{x}$ Captured per year ${ }^{4}$ & & & 99,452 \\
\hline $\begin{array}{l}\text { Cost Effectiveness } \\
\text { (Annual \$/ton SO }{ }_{x} \text { removed) }\end{array}$ & & & $\$ 312$ \\
\hline
\end{tabular}

\section{NOTES:}

(1) Costs are estimated to the nearest $\$ 10,000$.

(2) Annual costs are used to compare technologies.

(3) Factor based upon a 20 year equipment life and 8 percent interest rate. Reference for Factor: Engineering in Training Review Manual, Sixth Edition, Page 2-28.

(4) Tons removed are based upon AERA conceptual design report.

(5) Ammonia cost based upon \$240/ton delivered.

(6) Calcium oxide cost is estimated at $\$ 60 /$ ton.

(7) Water cost is estimated at $\$ 1 / 1,000$ gallons.

(8) Steam cost is estimated at $\$ 3 / 1,000$ pounds.

(9) Electricity cost is estimated at $\$ 0.10 / \mathrm{KWh}$.

(10) Solid waste disposal cost dry is estimated at $\$ 50 /$ ton. 
7.2.2 Dry Scrubbing Costs

Table 7-3 provides a cost breakdown for a dry scrubbing system. The major process areas for this technology are: sulfur dioxide removal, gas handling and reheat, reagent handling, waste handling, and general support equipment. The dry scrubbing system evaluated is a lime scrubbing system.

An atomizer is provided for each $\mathrm{SO}_{2}$ removal unit. For dry scrubbing, either two 100 percent or three 50 percent units can be provided for similar cost. The major reaction product in the process is dry calcium sulfate. Major equipment for this process includes absorbers with atomizers, and associated support equipment and materials. The support equipment and materials include: foundation, structural steel, enclosures, controls, and electrical power.

For gas handling, each absorber unit will have an inlet and outlet isolation damper, fuel bypass and shutoff dampers. With this type of system, a slight increase in the size of the ID fan compensates for the absorber pressure drop.

Reagent handling requires a supply system for a lime slurry. The lime system will include: storage bins; day bins; pneumatic conveying; slakers; classifier; holding tanks; and transfer pumps.

Waste handling includes the removal of a dry product from the absorber. No wastewater is generated with this process.

Support equipment for this process includes: facility and dry instrument air; make-up water for pump seals; and transfers.

The estimated capital cost for the dry scrubbing process is $\$ 55,580,000$. The cost breakdown of this process is:

$\mathrm{SO}_{2}$ Removal Equipment:

Flue Gas Handling:

Reagent Handling:

Waste Handling:

Support Equipment:

Contingency (10\%):

Total:
$\$ 24,840,000$

$17,990,000$

$5,600,000$

$1,040,000$

$1,060,000$

$5,050,000$

$\$ 55,580,000$ 
TABLE 7-3

Cost Summary for Dry Scrubbing Process ${ }^{(1,2)}$

\begin{tabular}{|c|c|c|c|}
\hline Equipment & $\begin{array}{c}\text { Capital } \\
\text { Cost }\end{array}$ & $\begin{array}{l}\text { Levelizing } \\
\text { Factor }^{(3)}\end{array}$ & Annual Cost \\
\hline $\begin{array}{l}\mathrm{SO}_{2} \text { Removal Equipment with } \\
\text { Installation } \\
\text { Flue Gas Handling Equipment with I\&C } \\
\text { Reagent Handling } \\
\text { Waste Handling } \\
\text { Support Equipment } \\
\text { Contingency (20\%) } \\
\text { Dry Scrubbing Process Cost }\end{array}$ & $\begin{array}{r}\$ 24,840,000 \\
17,990,000 \\
5,600,000 \\
1,040,000 \\
1,060,000 \\
5,050,000 \\
55,580,000 \\
\end{array}$ & 0.109 & $\$ 6,060,000$ \\
\hline $\begin{array}{l}\text { Operating Cost } \\
\text { Operating Labor } \\
\text { Maintenance Labor } \\
\text { Maintenance Material } \\
\text { Administrative/Support } \\
\text { Reagent }^{6} \\
\text { Water }^{7} \\
\text { Steam }^{8} \\
\text { Electricity }^{9} \\
\text { Solid Waste Disposal } \\
\text { Annual Operating Cost }\end{array}$ & $\begin{array}{r}\$ 90,000 \\
140,000 \\
2,530,000 \\
70,000 \\
2,990,000 \\
180,000 \\
0 \\
1,980,000 \\
1,670,000 \\
9,650,000\end{array}$ & 1 & $\$ 9,650,000$ \\
\hline Annual Levelized Cost & & & $\$ 15,710,000$ \\
\hline Tons of $\mathrm{SO}_{\mathrm{x}}$ Captured per year ${ }^{4}$ & & & 99,452 \\
\hline $\begin{array}{l}\text { Cost Effectiveness } \\
\text { (Annual \$/ton } \mathrm{SO}_{x} \text { removed) }\end{array}$ & & & $\$ 158$ \\
\hline
\end{tabular}

\section{NOTES:}

(1) Costs are estimated to the nearest $\$ 10,000$.

(2) Annual costs are used to compare technologies.

(3) Factor based upon a 20 year equipment life and 8 percent interest rate. Reference for Factor: Engineering in Training Review Manual, Sixth Edition, Page 2-28.

(4) Tons removed are based upon AERA conceptual design report.

(5) Ammonia cost based upon \$240/ton delivered.

(6) Calcium oxide cost is estimated at $\$ 60 /$ ton.

(7) Water cost is estimated at $\$ 1 / 1,000$ gallons.

(8) Steam cost is estimated at $\$ 3 / 1,000$ pounds.

(9) Electricity cost is estimated at $\$ 0.10 / \mathrm{KWh}$.

(10) Solid waste disposal cost dry is estimated at $\$ 50 /$ ton. 
The annual operating cost for a dry scrubbing system is $\$ 9,650,000$. The annual fixed operating cost breakdown is: $\$ 90,000$ for operating labor; $\$ 140,000$ for maintenance labor; $\$ 2,530,000$ for maintenance

- material; $\$ 70,000$ for administrative support services; $\$ 2,990,000$ for reagent at $\$ 60$ per ton; $\$ 780,000$ for water at $\$ 1.00$ per 1,000 gallons; $\$ 1,980,000$ for electricity at $\$ 0.1$ per kilowatt per hour; and $\$ 1,670,000$ for solid waste disposal at $\$ 50$ per ton.

The annual levelized capital cost for the dry scrubbing process is $\$ 6,050,000$. Annual operating costs are estimated at $\$ 9,650,000$. The total levelized annual cost is $\$ 15,710,000$. Based upon the amount of sulfur dioxide removed ( 99,452 tons per year), and the annual levelized cost, the cost effectiveness of the dry scrubbing process is approximately $\$ 158$ per ton of sulfur oxide removed. 
TABLE 7-1

COMMERCIALIY PROVEN SULFUR CONTROL TECHNOLOGIES Nonregenerable Wet Scrubbing Processes

\begin{tabular}{|c|c|c|c|c|}
\hline $\begin{array}{c}\text { Control } \\
\text { Technology }\end{array}$ & Operating Principle & $\begin{array}{c}\text { Development } \\
\text { Status }\end{array}$ & Advantages & Disadrantages \\
\hline Iimestone & $\begin{array}{l}\text { Absorbs } \mathrm{SO}_{2} \text { with a limeatone } \\
\text { alurry. A bleed stream of the } \\
\text { slurry is partially dewatered } \\
\text { and disposed of in a landfill. } \\
\end{array}$ & $\begin{array}{l}\text { Many commercial } \\
\text { unitg in } \\
\text { operation } \\
\text { worldwide. }\end{array}$ & $\begin{array}{l}\text { Low capital and } \\
\text { operating cost. Simple } \\
\text { and proven process with } \\
\text { conventional process } \\
\text { equipment. Gypsum } \\
\text { product can be produced } \\
\text { if forced oxidation is } \\
\text { utilized. }\end{array}$ & $\begin{array}{l}\text { Has a low operability } \\
\text { factor due to } \\
\text { gcaling, erosion, and } \\
\text { corrosion. Sulfur is } \\
\text { nonrecoverable. }\end{array}$ \\
\hline IIme & $\begin{array}{l}\text { Absorbs } \mathrm{SO}_{2} \text { with a lime olurry. } \\
\text { A bleed stream of the slurry } \\
\text { is partially dewatered and } \\
\text { disposed of in a landfill. }\end{array}$ & $\begin{array}{l}\text { Many commercial } \\
\text { units in } \\
\text { operation } \\
\text { worldwide. }\end{array}$ & $\begin{array}{l}\text { Very oimilar to the } \\
\text { limestone process and } \\
\text { can potentially have a } \\
\text { greater so removal } \\
\text { efflciency than } \\
\text { limestone. }\end{array}$ & $\begin{array}{l}\text { Lime costs are rising } \\
\text { rapidly because of } \\
\text { higher energy costa. } \\
\text { sulfur is } \\
\text { nonrecoverable. }\end{array}$ \\
\hline $\begin{array}{l}\text { Sodium } \\
\text { Carbonate }\end{array}$ & $\begin{array}{l}\text { Absorbs } \mathrm{SO}_{2} \text { with a sodium } \\
\text { carbonate solution. A bleed } \\
\text { gtream of the spent solution } \\
\text { is partialiy dewatered and } \\
\text { disposed of in a landfill. }\end{array}$ & $\begin{array}{l}\text { Several } \\
\text { commerclal } \\
\text { units in } \\
\text { operation in } \\
\text { the U.S. }\end{array}$ & $\begin{array}{l}\text { Low capital cost. A } \\
\text { very simple and } \\
\text { reliable process. }\end{array}$ & $\begin{array}{l}\text { Soda ash is an } \\
\text { expensive raw } \\
\text { material. }\end{array}$ \\
\hline $\begin{array}{l}\text { Chiyoda } \\
\text { Thoroughbred } \\
121\end{array}$ & 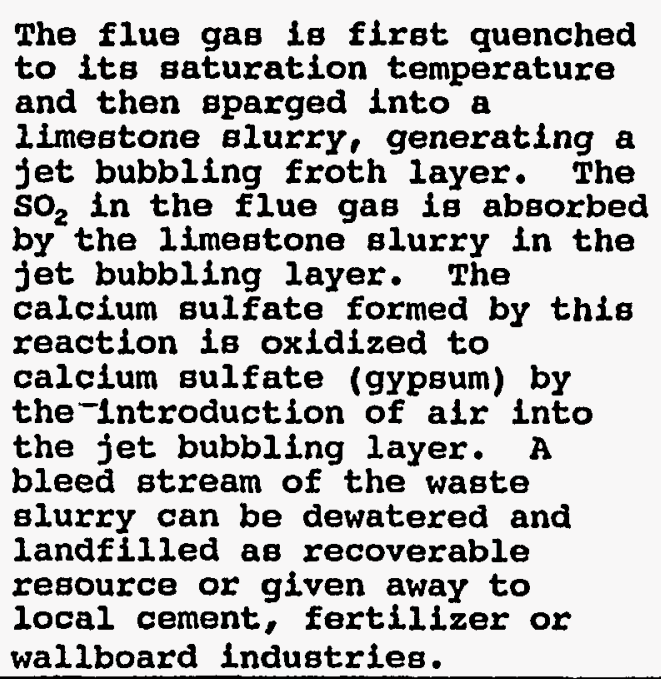 & $\begin{array}{l}\text { Several } \\
\text { commercial } \\
\text { plants in } \\
\text { operation } \\
\text { worldwide. }\end{array}$ & $\begin{array}{l}\text { Absorbs } \mathrm{SO}_{2} \text { and oxidizes } \\
\text { calclum sulfite to } \\
\text { gypsum in one reactor } \\
\text { veseel. }\end{array}$ & $\begin{array}{l}\text { Sulfur ig } \\
\text { nonrecoverable. }\end{array}$ \\
\hline
\end{tabular}


TABLE 7-1

COMMERCIALIY PROVEN SULFUR CONTROL TECHNOLOGIES

Nonregenerable Dry Scrubbing Processes

\begin{tabular}{|c|c|c|c|c|}
\hline $\begin{array}{l}\text { Control } \\
\text { Technology }\end{array}$ & Operating Principle & $\begin{array}{c}\text { Development } \\
\text { Status }\end{array}$ & Advantages & Disadvantages \\
\hline Lime & $\begin{array}{l}\text { Flue gas is contacted with an } \\
\text { atomized lime slurry in a } \\
\text { opray dryer gcrubber. The } \\
\text { lime absorbs the so }{ }_{2} \text { is dried, } \\
\text { and then collected in a } \\
\text { baghouse or electrostatic } \\
\text { precipitator. }\end{array}$ & $\begin{array}{l}\text { Many commercial } \\
\text { units are in } \\
\text { operation in } \\
\text { the U.S. }\end{array}$ & $\begin{array}{l}\text { Since the flue gas is } \\
\text { gaturated, slightly } \\
\text { less makeup water is } \\
\text { needed and lesg stack } \\
\text { gas reheat is needed. }\end{array}$ & $\begin{array}{l}\text { This system is } \\
\text { usually only } \\
\text { economically feasible } \\
\text { where low sulfur fuel } \\
\text { lo burned because of } \\
\text { the low reagent } \\
\text { utilization rate. } \\
\text { Very high removal } \\
\text { efflciencies are also } \\
\text { not usually possible } \\
\text { because of the low } \\
\text { reagent utilization } \\
\text { rate. Sulfur is } \\
\text { nonrecoverable. }\end{array}$ \\
\hline $\begin{array}{l}\text { Sodium } \\
\text { Carbonate }\end{array}$ & $\begin{array}{l}\text { Flue gas is contacted with an } \\
\text { atomized solution of aqueous } \\
\text { sodium carbonate in a gpray } \\
\text { dryer scrubber. The sodium } \\
\text { carbonate absorbs the } \mathrm{SO}_{2} \text {, is } \\
\text { drled, and then collected in a } \\
\text { baghouge or electrostatic } \\
\text { preclpitator. }\end{array}$ & $\begin{array}{l}\text { One commercial } \\
\text { unit in } \\
\text { operation in } \\
\text { the U.s. }\end{array}$ & $\begin{array}{l}\text { same as for the lime } \\
\text { dry scrubbing process. }\end{array}$ & $\begin{array}{l}\text { Same as for the lime } \\
\text { dry scrubbing } \\
\text { process, Also, soda } \\
\text { ash is an expensive } \\
\text { raw material. Sulfur } \\
\text { lo nonrecoverable. }\end{array}$ \\
\hline
\end{tabular}


Nitrogen oxides are products of all combustion processes. The emission of nitrogen oxides is typically controlled at the boiler, by special burners, uniform and lower average combustion temperatures, staged combustion, and low excess air levels. Fuel gas recirculation gives greater operational flexibility. The AERA design uses a pulverized coal (PC) boiler for coal combustion.

The nitrogen oxide removal technologies evaluated in this analysis include selective catalytic reduction (SCR) and selective non catalytic reduction (SNCR), flue gas recirculation, and advanced boiler controls. The SNCR could include both urea and ammonia injection. The injection of ammonia into boilers provides control in both the SCR and SNCR processes. In the SCR process, the ammonia is injected just prior to the catalyst and is reacted in the presence of the catalyst. In the SNCR process, the ammonia is reacted without a catalyst being present.

Nitrogen oxide control technologies can be classified into two different types: combustion modifications and flue-gas denitrification processes. Combustion modifications include spacial uniform and low average combustion temperatures, stage combustion, low excess air, and boiler flue-gas recirculation. Post-combustion flue-gas denitrification processes are used to control nitrogen oxides. Some postcombustion control technology advantages and disadvantages are presented in Table 8-1. Figure 8-1 shows some of the control technologies used for nitrogen oxide removal and combined nitrogen oxide and sulfur oxide removal.

\subsection{Alternative Nitrogen Oxide Removal Technologies}

The most promising flue gas denitrification processes include: SCR, SNCR, activated carbon absorption, electron beam scrubbing, absorption-reduction, absorption-oxidation, and oxidation-absorption-reduction. Of these technologies, SCR, urea injection, and ammonia injection have been demonstrated commercially on various types of fossil-fired boilers. Urea and ammonia injection are usually not used for PC boilers and were therefore not retained. For cost comparison, only the SCR process was retained for comparison to the FBCO process. The FBCO process uses a 90 percent nitrogen oxide removal efficiency. The efficiencies of alternative nitrogen oxide removal technologies typically vary from 60 to 80 percent. 
TABLE 8-1

NITROGEN OXIDE CONTROI TECHNOLOGIES

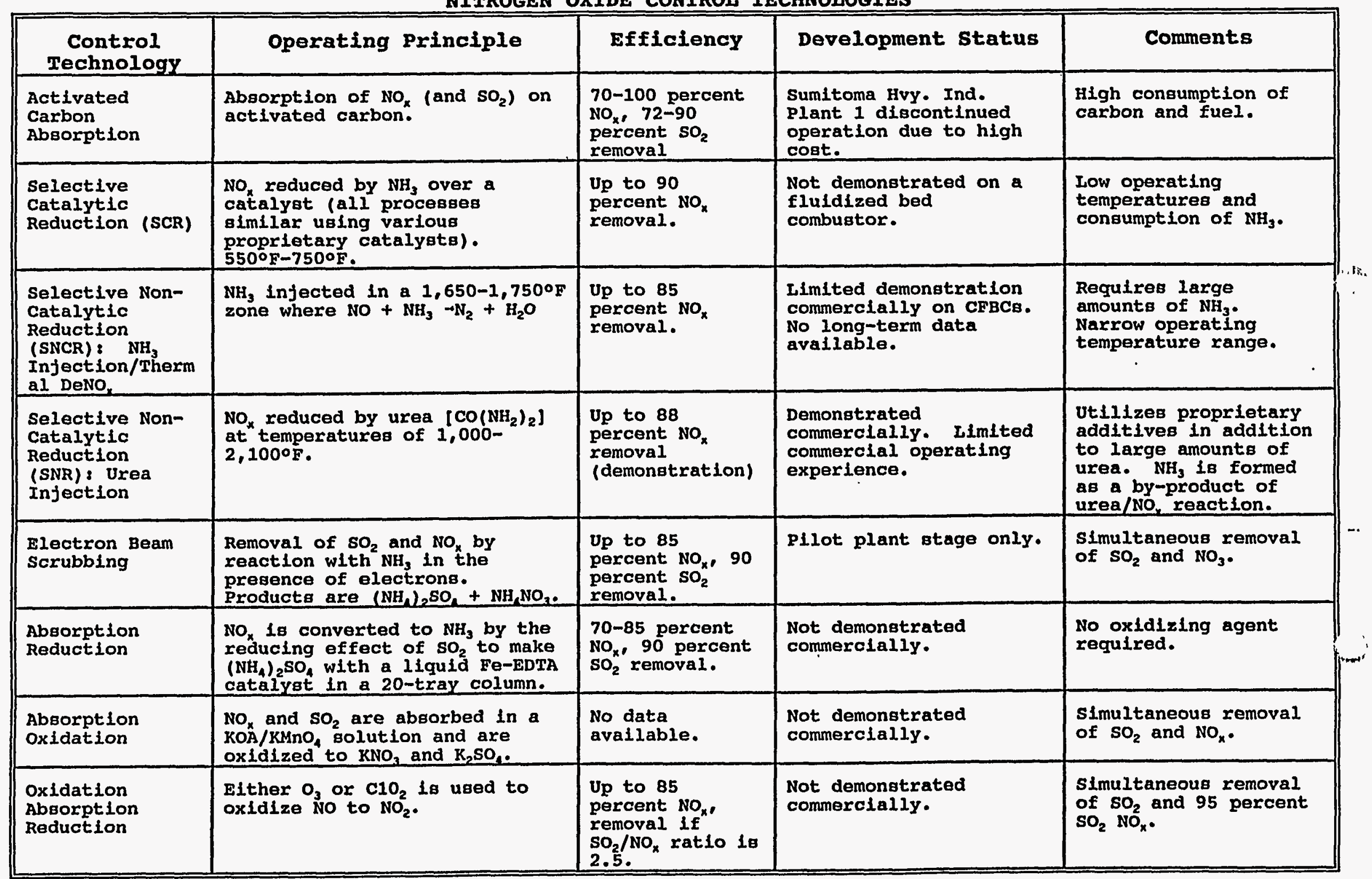




\section{$\div \quad$ FIGURE 8-1 \\ POST-COMBUSTION NOX CONTROL TECHNOLOGIES}

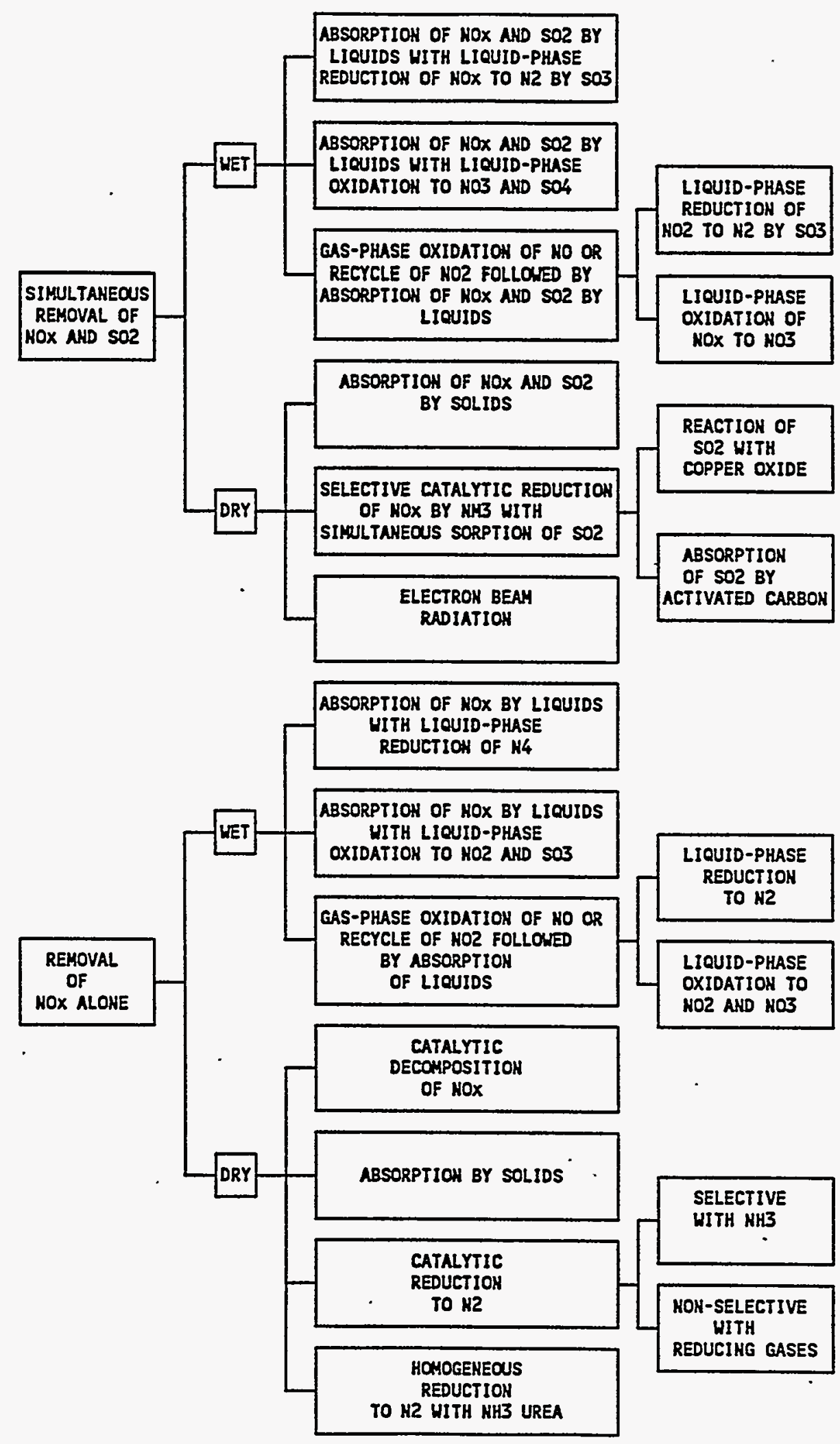




\subsubsection{Selective Catalytic Reduction (SCR)}

Selective Catalytic Reduction (SCR) reacts ammonia $\left(\mathrm{NH}_{3}\right)$, in the presence of a catalyst, with nitrogen oxide to produce nitrogen and $\therefore$ water. The Honeycomb and plate-type catalysts are usually manufactured from a mixture of titanium oxide and vanadium pentoside. Tungsten is also added to suppress the conversion of sulfur dioxide to sulfur trioxide. In the SCR process, ammonia is injected before the catalyst to promote the reduction of nitrogen oxide to nitrogen:

$$
\begin{gathered}
4 \mathrm{NO}+4 \mathrm{NH}_{3}+\underset{[\mathrm{CAT}]}{\mathrm{O}_{2} \rightarrow} 4 \mathrm{~N}_{2}+6 \mathrm{H}_{2} \mathrm{O} \\
2 \mathrm{NO}_{2}+4 \mathrm{NH}_{3}+\underset{\substack{[\mathrm{CAT}] \\
550-750^{\circ} \mathrm{F}}}{\mathrm{O}_{2} \rightarrow \mathrm{N}_{2}}+6 \mathrm{H}_{2} \mathrm{O}
\end{gathered}
$$

The reaction temperature range during reduction is less than that of the FBCO process. The SCR technology can remove up to 90 percent of the nitrogen oxide. However, removal efficiencies usually range from 65 to 80 percent, depending upon temperature and initial nitrogen oxide concentrations.

Although the SCR process has been used to control nitrogen oxide, several issues are of concern:

- Fouling of the catalyst by trace materials and solids in the flue gas.

- Catalyst life is dependent upon solids loading and quantity of constituents in the flue gas.

- Potential formation of ammonium bisulfate.

- Release of unreacted ammonia (ammonia slip).

- Disposal of spent catalyst.

- Not as effective as the FBCO process in removing nitrogen oxide.

\subsection{Comparative Nitrogen Oxide Removal Cost}

Table 8-2 provides a cost breakdown for the SCR process for a $500 \mathrm{MW}$ coalfired facility. The cost of the SCR process is divided into the following areas:

- Equipment Cost

- Structural Support

- Installation

- Catalyst Inventory

- Engineering 
- Instrumentation and Controls

- Contingency

The capital cost for the $S C R$ process is estimated at $\$ 69,640,000$. This cost includes: equipment $(\$ 39,290,000)$; structural supporting equipment $(\$ 3,140,000)$; catalyst inventory $(\$ 1,290,000)$; installation of the SCR system $(\$ 4,700,000)$; structural and process engineering $(\$ 8,490,000)$; instrumentation and controls $(\$ 4,240,000)$; and contingencies $(\$ 8,490,000)$.

The annual operational cost for the SCR process includes: operation and maintenance; catalyst exchange; energy cost; and ammonia cost. The annual operational cost is estimated at $\$ 5,890,000$, including: $\$ 3,480,000$ for operation and maintenance; $\$ 650,000$ for catalyst exchange; $\$ 930,000$ for electrical cost, including fan power and electric load; and ammonia $(\$ 830,000)$.

The annual levelized capital cost is $\$ 7,590,000$ and the annual operational cost is $\$ 5,890,000$. This totals an annual levelized cost of $\$ 13,480,000$. Based upon 11,932 tons per year of nitrogen oxides removed, the cost effectiveness factor for removal is $\$ 1,130$ per ton removed. If all nitrogen oxides are nitrogen dioxide, the cost effectiveness factor for removal is $\$ 753$ per ton removed. 


\begin{tabular}{|c|c|c|c|}
\hline \multicolumn{4}{|c|}{$\begin{array}{l}\text { TABLE 8-2 } \\
\text { Cost Summary for the SCR Process }{ }^{(1,2)} \\
\end{array}$} \\
\hline Equipment & $\begin{array}{c}\text { Capital } \\
\text { Cost }\end{array}$ & $\begin{array}{l}\text { Levelizing } \\
\text { Factor }^{(3)}\end{array}$ & Annual Cost \\
\hline $\begin{array}{l}\text { Equipment Cost } \\
\text { Equipment Cost (reactor vessels, } \\
\text { catalyst ammonia injection system, } \\
\text { storage, etc.) } \\
\text { Structural Supporting Equipment (8\%) } \\
\text { Inventory (Catalyst) } \\
\text { Installation of SCR } \\
\text { Process Engineering (20\%) } \\
\text { Instrumentation \& Controls (10\%) } \\
\text { Contingency (20\%) } \\
\text { Process Cost Subtotal } \\
\end{array}$ & $\begin{array}{r}\$ 39,290,000 \\
3,140,000 \\
1,290,000 \\
4,700,000 \\
8,490,000 \\
4,240,000 \\
8,490,000 \\
69,640,000 \\
\end{array}$ & 0.109 & $\$ 7,590,000$ \\
\hline $\begin{array}{l}\text { Operating Cost } \\
\text { Operation and Maintenance Cost (5\%) } \\
\text { Catalyst Exchange Cost } \\
\text { Energy Cost } \\
\text { Fan Power } \\
\text { Electric Load } \\
\text { Ammonia Cost } \\
\text { Operating Cost Subtotal } \\
\end{array}$ & $\begin{array}{r}\$ 3,480,000 \\
650,000 \\
\\
680,000 \\
250,000 \\
830,000 \\
5,890,000 \\
\end{array}$ & 1.0 & $\$ 5,890,000$ \\
\hline Levelized Annual Cost & & & $\$ 13,480,000$ \\
\hline $\begin{array}{l}\text { Tons of } \mathrm{NO}_{x} \text { Generated Per Year } \\
\text { Uncontrolled Emissions } \\
\text { (pounds/MMBTU) } \\
\text { Tons of NO }{ }_{x} \text { Captured Per Year } \\
\text { Emissions (pounds/MMBTU) }\end{array}$ & & & $\begin{array}{r}13,258 \\
0.67 \\
11,932 \\
0.07\end{array}$ \\
\hline $\begin{array}{l}\text { Cost Effectiveness } \\
\text { (Annual \$/ton No } \text { removed) }\end{array}$ & & & $\$ 1,130$ \\
\hline
\end{tabular}

\section{NOTES:}

(1) Costs are estimated to the nearest $\$ 10,000$.

(2) Annual costs are used to compare technologies.

(3) Factor based upon a 20 year equipment life and 8 percent interest rate. Reference for Factor: Engineering in Training Review Manual, Sixth Edition, Page 2-28.

(4) Tons removed are based upon AERA conceptual design report.

(5) Ammonia cost based upon \$240/ton delivered.

(6) Catalyst cost based upon a catalyst rate of $\$ 9.69$ per pound of catalyst. 
In order to compare current conventional technologies with the FBCO process a unit cost rate needs to be developed. Difficulty in developing the unit rate is that the FBCO process combines both sulfur oxide and nitrogen oxide removal, where conventional technologies perform these removals separately. AERA has developed two methods that could be utilized for the unit rate. The first method assumes that conventional technologies and the FBCO process are directly comparable in cost of quantity of pollutant removed, i.e. cost of FBCO process divided by the quantity of pollutant removed compared to cost of conventional technology divided by quantity of pollutant removed. The second method proportions the cost of the FBCO process in the proportion of the quantity of pollutant removed. Both methodologies are presented to represent completeness and to demonstrate that various methods of cost justification can be performed, but the results may be considered subjective.

AERA has identified the unit cost rate as a cost effectiveness factor. Effectiveness is utilized since the removal of sulfur oxides and nitrogen oxides varies between the FBCO process and the conventional technologies considered. The quantity of nitrogen dioxide (total) removed per year is 11,932 tons per year. For the costing summary and consistent with the clean air act, AERA has converted all nitrogen oxides to nitrogen dioxide. The quantity of sulfur dioxide removed by the FBCO process is 99,452 tons per year.

If the first methodology is utilized, the annualized cost effectiveness factor for nitrogen dioxide and sulfur dioxide removal are $\$ 5973$ per ton removed for nitrogen dioxide and is $\$ 717$ per ton for sulfur dioxide removal. By converting all nitrogen oxides to nitrogen dioxides the cost effectiveness factor for nitrogen oxide removal reduces to $\$ 3592$ per ton of nitrogen.

Utilizing the second methodology and proportioning the cost based on quantity of pollutant removed, the cost effectiveness factor for nitrogen oxides and sulfur dioxide removal is $\$ 640$ per ton removed. If all nitrogen oxide is converted to nitrogen dioxide, the cost effectiveness factor per ton of constituent removed is $\$ 600$.

The comparison of costs between the alternative flue-gas cleanup technologies for nitrogen oxide and sulfur dioxide is based upon cost-effectiveness. Cost-effectiveness is defined as the total annual cost divided by the quantity of pollutant removed. The cost- effectiveness factors for nitrogen oxide and sulfur dioxide are:

\section{Nitrogen Oxides:}

FBCO Process: $\quad \$ 5973$ per ton of nitrogen oxide removed $(*)$ $\$ 3592$ per ton of nitrogen dioxide removed $\left(^{*}\right)$ $\$ 640$ per ton of nitrogen oxides removed $\left({ }^{* *}\right)$ $\$ 600$ per ton of nitrogen dioxide removed $(* *)$ 
A. E. ROBERTS \& ASSOCIATES, ING.

SCR Process: $\quad \$ 1,130$ per ton of nitrogen oxide removed $\$ 753$ per ton of nitrogen dioxide removed

$\left.{ }^{*}\right)$ Based only on the quantity of nitrogen oxide or dioxide removed.

$\left.{ }^{* *}\right)$ Indicated proportioning cost based upon the total quantity of material removed.

Sulfur Dioxide:

FBCO Process: $\quad \$ 717$ per ton of sulfur dioxide removed only

$\$ 640$ per ton of sulfur dioxide removed when nitrogen oxides are removed

$\$ 600$ per ton of sulfur dioxide removed when nitrogen dioxides are removed

Wet Scrubbing: $\$ 312$ per ton of sulfur dioxide removed

Dry Scrubbing: $\quad \$ 158$ per ton of sulfur dioxide removed 


\subsection{RECOMMENDATIONS AND CONCLUSIONS}

The FBCO process has been demonstrated to be effective for the removal of nitrogen oxides and sulfur dioxide in a combined unit on both bench and pilot scale systems. This co-removal is strongly desired to minimize the amount of flue gas cleaning equipment required at a power station. The costing for the FBCO process is speculative at this time. Competing technologies of the FBCO process have been constructed for many full scale system and detailed costings are well understood. The costings for the FBCO process need to be further developed and confirmed before a conclusive statement can be made solely based on cost.

As demonstrated in Section 9.1 Comparative Cost Summary, the FBCO process could be competitive with conventional nitrogen removal technologies if we consider the total mass of constituent removed by the FBCO process. This consideration, however, is not likely to be valid since the conventional technologies do not perform a combined removal. A direct comparison based upon nitrogen oxides or total dioxides removed indicate a technology that is of an order of magnitude higher in cost than the conventional technologies considered. As with nitrogen oxide removal, sulfur dioxide removal was found to be two or three times the cost of conventional technologies.

The high cost of the FBCO process is primarily based upon the annual operational and maintenance cost. Of the annual cost $(\$ 71,270,000)$ for the FBCO process, 89 percent of the cost is associated with operations and maintenance and the remaining is associated with annual capital costs. The primary cost in the annual operational and maintenance cost is the cost of the absorbent. In order to reduce the cost of the FBCO process, this cost must first be addressed. To address the absorbent costs the following issues should be investigated:

- Is there a more cost effective absorbent?

- Is there a more stable absorbent which will reduce attrition losses and initial absorbent cost?

- Can a lower copper to sulfur molar ratio be utilized with a full scale system?

Once the absorbent is addressed, experience and full scale development and construction can be the only possibility to reduce the operational and maintenance costs.

At this time, the FBCO process is not cost competitive with conventional technologies. Although the cost data can be manipulated to reflect a potentially competitive technology, the unknowns in construction operation and maintenance leave the practicality of this technology uncertain. 


\section{MODELING AND ASSESSMENT OF THE FLUIDIZED BED COPPER OXIDE PROCESS FOR $\mathrm{SO}_{2} / \mathrm{NO}_{x}$ CONTROL}

Prepared for:

A.E. Roberts and Associates, Inc. UOP, Inc.

U.S. Department of Energy

Prepared by:

H. Christopher Frey, Ph.D.

Department of Civil Engineering

North Carolina State University

Raleigh, NC 27695-7908

March 30, 1994 


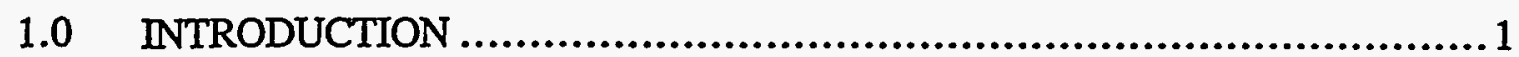

2.0 PROCESS CHEMISTRY .................................................... 3

3.0 NEW ANALYTICAL PERFORMANCE MODELS.................................... 7

3.1 SORBENT MASS BALANCE............................................7

3.2 SULFATION REACTION MODEL ........................................11

3.3 TWO-STAGE ABSORBER MODEL........................................16

3.4 REGENERATION PERFORMANCE MODEL...............................21

3.4.1 REGENERATOR MASS BALANCE............................21

3.4.2 REGENERATOR ENERGY BALANCE........................22

3.4.3 REGENERATOR RESIDENCE TIME ........................25

3.5 BYPRODUCT RECOVERY..........................................29

3.6 ENERGY PENALTIES AND CREDITS ..............................30

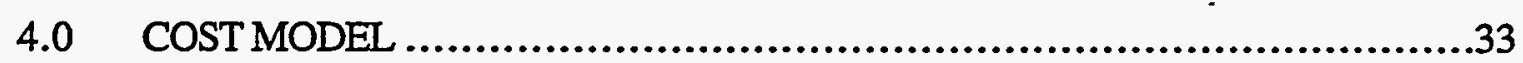

4.1 CAPITAL COST MODELS..................................................33

4.1.1 FLUIDIZED BED ABSORBERS..............................33

4.1.2 AMMONIA INJECTION SYSTEM ............................35

4.1.3 REGENERATOR ............................................36

4.1.4 SOLIDS HEATER .............................................38

4.1.5 SORBENT TRANSPORT SYSTEM............................39

4.1.6 SOLIDS HEATER COMBUSTOR ..............................40

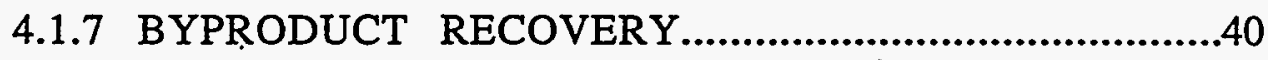

4.1.8 AIR PREHEATER MODIFICATIONS ..........................40

4.1.9 INTTAL SORBENT INVENTORY ...........................41

4.2 TOTAL CAPITAL REQUIREMENT........................................41

4.3 ANNUAL COSTS ................................................43

4.3.1 FIXED OPERATING COSTS ...............................43

4.3.2 VARIABLE OPERATING COSTS.....................................44

5.0 SENSTIVITY ANALYSES OF THE FLUIDIZED BED COPPER OXIDE

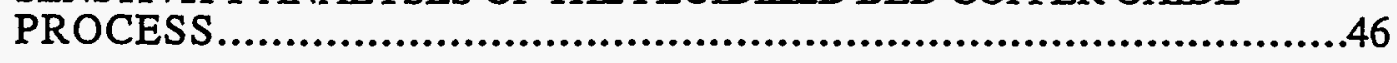

5.1 INTEGRATION OF COPPER OXIDE PROCESS AND BYPRODUCT RECOVERY SYSTEM ...................................................46

5.2 SORBENT BED HEIGHT: SINGLE STAGE FLUIDIZED BED ABSORBER 
5.3 SORBENT COPPER LOADING ...................................54

5.4 REGENERATION EFFICIENCY .................................55

5.5 REGENERATOR INLET TEMPERATURE...........................57

6.0 PROBABILISTIC ANALYSIS ........................................60

6.1 INPUT UNCERTAINTY ASSUMPTIONS. .........................60

6.2 CHARACTERIZING UNCERTAINTY IN PERFORMANCE AND COST ...............................................................65

6.3 IDENTIFYING KEY SOURCES OF UNCERTAINTY ................70

6.4 EVALUATING DESIGN TRADE-OFFS PROBABILISTICALLY .......73

7.0 DISCUSSION AND FUTURE WORK.........................................75

NOMENCLATURE ......................................................77

8.0 REFERENCES...........................................................80

APPENDIX A: GUIDE TO UNCERTAINTY ANALYSIS 


\section{LIST OF FIGURES}

Figure 1. Schematic Diagram of the PETC Fluidized Bed Copper Oxide Process. .........3

Figure 2. Comparison of copper-to-sulfur molar ratios from experimental results and from the PETC sulfation model. ...........................................13

Figure 3. Comparison of copper-to-sulfur molar ratios from experimental results and from the Harriott sulfation model. .............................................14

Figure 4. Sensitivity of $\mathrm{Cu} / \mathrm{S}$ Ratio to regeneration efficiency and fluidized bed height...16

Figure 5. Simplified Schematic of a Two-Stage Fluidized Bed Absorber Model...........17

Figure 6. Sensitivity of the $\mathrm{Cu} / \mathrm{S}$ Ratio to Distribution of Sorbent in Two Fluidized Beds ..........................................................................20

Figure 7. Distribution of Sorbent Between Two Absorber Stages with Constant Total Sorbent Inventory......................................................................20

Figure 8. Sensitivity Analysis of the Two-Stage Absorber Model .........................21

Figure 9. Schematic of Regenerator Residence Time Model............................26

Figure 10. Sensitivity of Energy Penalty and Sorbent Circulation Rate to the Expanded Fluidized Bed Height for a Single-Stage Absorber-Based Copper Oxide System. ...................................................................50

Figure 11. Sensitivity of Levelized Cost to the Expanded Fluidized Bed Height for a Single-Stage Absorber-Based Copper Oxide System. ..........................51

Figure 12. Sensitivity of Levelized Cost to the The Design of a Two-Stage AbsorberBased Copper Oxide System...................................................52

Figure 13. Sensitivity of Sorbent Circulation Rate and Second-Stage Kinetic Rate Constant to the Sorbent Copper Loading. ....................................54

Figure 14. Sensitivity of Capital, O\&M, and Levelized Costs to the Sorbent Copper Loading. ......................................................................55

Figure 15. Sensitivity of the Total Cu/S Molar Ratio to Regeneration Efficiencies..........56

Figure 16. Sensitivity of Levelized Cost to Regeneration Efficiencies.....................56

Figure 17. Sensitivity of Total Methane Requirement and Regenerator Residence Time to the Regenerator Inlet Temperature. ...........................................57

Figure 18. Sensitivity of Total Methane Requirement and Regenerator Residence Time to the Regenerator Inlet Temperature. ........................................58

Figure 19. Uncertainty Assumption for the Sorbent Bed Attrition Rate. ...................62

Figure 20. Uncertainty Assumption for the Sorbent Circulation Attrition Rate............63

Figure 21. Uncertainty Assumption for the Fractional Conversion of $\mathrm{CuO}$ to $\mathrm{CuSO} 3$ at the Regenerator Inlet...............................................................63

Figure 22. Uncertainty Assumption for the Regeneration Efficiency of CuSO3.............64

Figure 23. Uncertainty Assumption for the Sorbent Expanded Density.....................64

Figure 24. Uncertainty Assumption for the Sorbent Unit Cost..............................64

Figure 25. Uncertainty Result for Regenerator Residence Time..........................66

Figure 26. Uncertainty Result for Available Copper-to-Sulfur Molar Ratio....................66

Figure 27. Uncertainty Result for Sorbent Circulation Rate (on a Fresh Basis)...........66

Figure 28. Uncertainty Result for the Direct Cost of the Absorber Process Area............67

Figure 29. Uncertainty Result for the Equipment Cost of the Regenerator Vessel.........67

Figure 30. Uncertainty Result for the Direct Capital Cost of the Regenerator Process

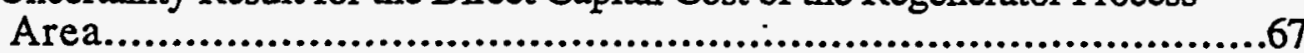

Figure 31. Uncertainty Result for the Make-Up Sorbent Flow Rate.......................68 69

Figure 32. Uncertainty Result for the Copper Oxide Process Total Capital Cost..........69

Figure 33. Uncertainty Result for the Copper Oxide Process Total Operating and Maintenance Cost...........................................................69

Figure 34. Uncertainty Result for the Copper Oxide Process Total Levelized Cost........70

Figure 35. Uncertainty Result for the Copper Oxide Process Total Levelized Cost........73

Figure 36. Uncertainty in the Cost Savings for a Two-Stage Absorber System Versus

a One-Stage Absorber System. 


\subsection{INTRODUCTION}

The fluidized bed copper oxide process is an advanced technology for controlling $\mathrm{SO}_{2}$ and $\mathrm{NO}_{\mathrm{x}}$ emissions from coal-fired power plants. The development of this process has been sponsored by the U.S. Department of Energy's Pittsburgh Energy Technology Center (DOE/PETC). Testing of the copper oxide process began at PETC in 1975 and has progressed through several stages in three different test units (Demski et al, 1982; Yeh et al, 1984; Plantz et al, 1986; Williamson et al, 1987). Key features of the copper oxide process are that it: (1) combines $\mathrm{SO}_{2}$ and $\mathrm{NO}_{\mathrm{x}}$ removal in a single reactor vessel; (2) is regenerative (i.e. the reagent is reused rather than disposed of); and (3) produces a saleable sulfur or sulfuric acid byproduct, in contrast to the sludge produced by conventional flue gas desulfurization systems (Drummond et al, 1985). Conceptual designs of commercial scale copper oxide systems were developed in the early 1980's (SMC, 1983a, b and c; 1984).

Based on mass and energy balances, PETC test results, and the conceptual design studies, a detailed performance and cost model of the copper oxide process was developed (Frey, 1987). The copper oxide process is in an early phase of development, with limited test data and no commercial operating experience. Uncertainties in system performance at the commercial scale lead to uncertainties in capital and operating costs. Furthermore, even if process performance were known with certainty, uncertainties regarding the costs of equipment and reagents would remain. To explicitly characterize these uncertainties, and to evaluate the overall uncertainty in process costs, a probabilistic engineering modeling framework has been developed.

Analytic models for a conventional pulverized coal (PC) power plant, coal cleaning processes, and selected conventional and advanced post-combustion pollution control systems are available in the Integrated Environmental Control Model (IECM), developed by Rubin et al. (1986, 1991, 1992). Details of the IECM's copper oxide process, power plant air preheater, sulfur recovery, and sulfuric acid recovery plant models are described elsewhere (Frey, 1987; Rubin et al., 1991; Frey and Rubin, 1991).

The models characterize mass and energy balances for key process equipment. The capital cost models are based on equipment cost estimates from the literature, adjusted for plant size using key process stream flow rates and exponential scaling factors. Indirect capital costs, and variable and fixed operating costs, are also calculated using a standard approach (EPRI, 1986).

To characterize uncertainties in advanced emission control systems, the IECM is implemented in a probabilistic modeling enyironment (Henrion and Wishbow, 1987). 
Uncertainties in process parameters can therefore be characterized using a variety of user-specified probability distribution functions. The resulting uncertainty distributions for model outputs are calculated using median Latin hypercube sampling, a variant of Monte Carlo simulation.

Probabilistic modeling has several advantages over traditional sensitivity analysis. In probabilistic analysis, the values of any number of parameters may vary simultaneously, and the likelihood of obtaining particular results is explicitly estimated. Furthermore, statistical analysis on the model input and output data can be used to identify trends (e.g., key input uncertainties affecting output uncertainties) without need to re-run the analysis. This permits the identification of key input parameters when many other parameters are simultaneously uncertain.

The probabilistic performance and cost model of the copper oxide process has been applied in a number of case studies to evaluate uncertainty in process costs, payoffs from process design improvements, the dependence of system cost on process design conditions and the availability of byproduct markets, and the likelihood that the advanced process will yield cost savings relative to conventional technology (Frey et al., 1989; Frey and Rubin, 1991; Frey and Rubin, 1992; Rubin et al., 1988; Rubin et al., 1989).

In this study, the performance model for the copper oxide process is updated to account for a recent study of the kinetics of sorbent regeneration (Harriott and Markussen, 1992). New models developed by Harriott (1992a,b,c) are employed to characterize the kinetics of both the sulfation and regeneration reactions. Furthermore, the mass and energy balances for the sorbent are modified to account for the formation of copper sulfite in the regenerator. Estimates of uncertainty in key process parameters form the basis for a probabilistic analysis of the fluidized bed copper oxide process. 


\subsection{PROCESS CHEMISTRY}

The copper oxide sorbent circulates between an absorber and regenerator. A schematic of the process is shown in Figure 1. During the cycles, the sorbent composition undergoes changes due to chemical reactions occuring in both of these reactor vessels. In the absorber, copper oxide $(\mathrm{CuO})$ reacts with sulfur oxides in the flue gas to form copper sulfate $\left(\mathrm{CuSO}_{4}\right)$. In a commercialscale process, a bed of copper-impregnated sorbent, consisting of small diameter (e.g., 1/8 inch) alumina spheres, is fluidized by the power plant flue gas. In addition to sulfur dioxide removal, nitrogen oxides are also removed by reaction with ammonia injected into the inlet flue gas. The sulfated sorbent is transported to a solids heater, where the sorbent temperature is raised to achieve a reasonable regeneration residence time. The heated sorbent then flows by gravity to a regenerator reactor vessel. A portion of the copper sulfate is regenerated to copper oxide in the regenerator.

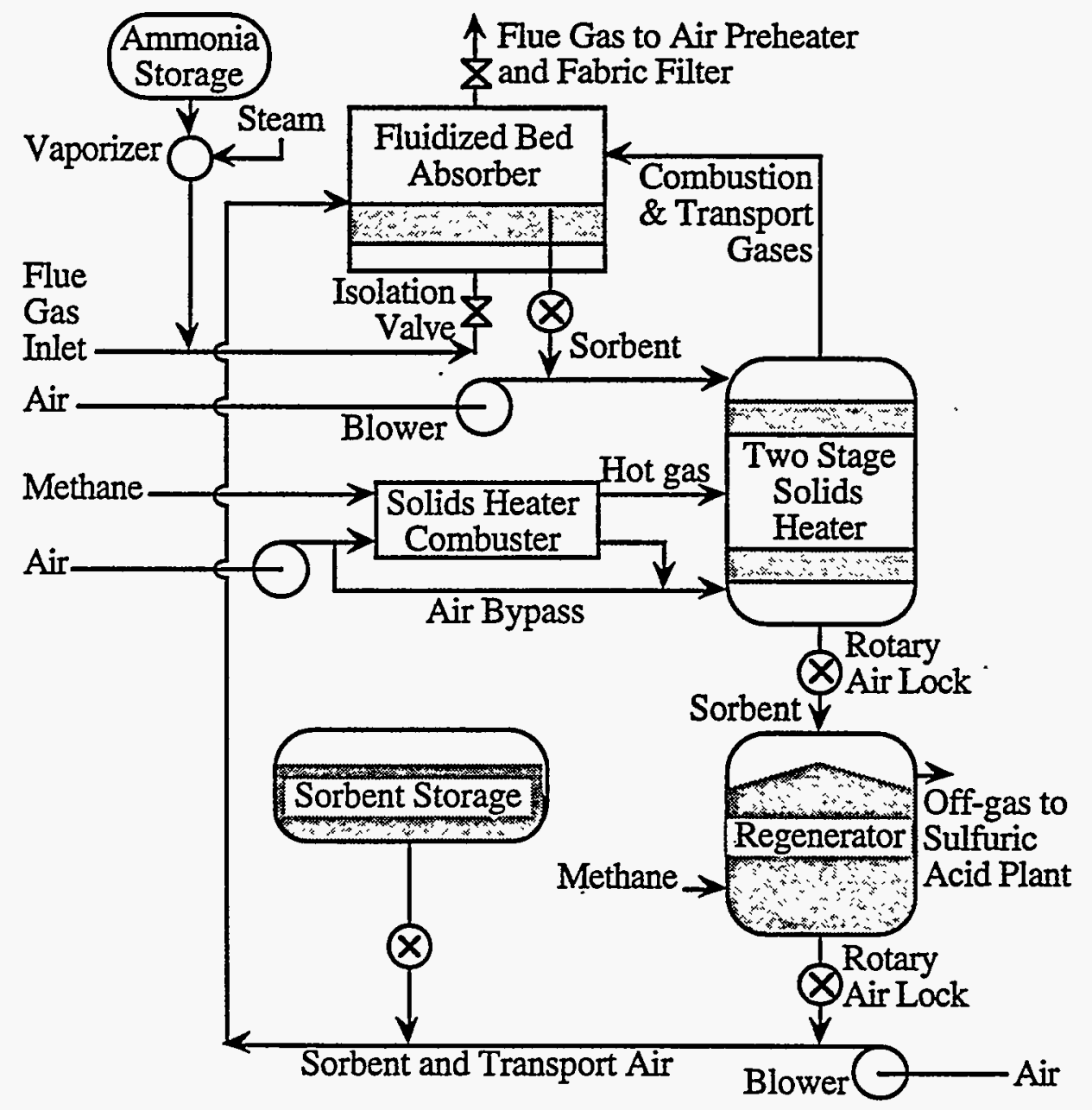

Figure 1. Schematic Diagram of the PETC Fluidized Bed Copper Oxide Process. 
The regenerated sorbent is then returned to the absorber.

The net chemical reactions occuring in the absorber are:

$$
\begin{gathered}
\mathrm{CuO}_{(\mathrm{s})}+\mathrm{SO}_{2(\mathrm{~g})}+\frac{1}{2} \mathrm{O}_{2}(\mathrm{~g}) \rightarrow \mathrm{CuSO}_{4}(\mathrm{~s}) \\
\mathrm{CuO}_{(\mathrm{s})}+\mathrm{SO}_{3}(\mathrm{~g}) \rightarrow \mathrm{CuSO}_{4}(\mathrm{~s}) \\
4 \mathrm{NO}_{(\mathrm{g})}+4 \mathrm{NH}_{3(\mathrm{~g})}+\mathrm{O}_{2(\mathrm{~g})} \rightarrow 4 \mathrm{~N}_{2}(\mathrm{~g})+6 \mathrm{H}_{2} \mathrm{O}_{(\mathrm{g})} \\
2 \mathrm{NO}_{2(\mathrm{~g})}+4 \mathrm{NH}_{3}(\mathrm{~g})+\mathrm{O}_{2}(\mathrm{~g}) \rightarrow 3 \mathrm{~N}_{2}(\mathrm{~g})+6 \mathrm{H}_{2} \mathrm{O}_{(\mathrm{g})}
\end{gathered}
$$

During sorbent regeneration, an offgas containing sulfur dioxide $\left(\mathrm{SO}_{2}\right)$ is evolved. In the regenerator, the sorbent flows downward in a moving bed, countercurrent to the regeneration offgases. Copper oxide contained in the sorbent entering the regenerator may react rapidly with $\mathrm{SO}_{2}$ in the exiting off-gas to form copper sulfite $\left(\mathrm{CuSO}_{3}\right)$ (Harriott and Markussen, 1992):

$$
\mathrm{CuO}_{(\mathrm{s})}+\mathrm{SO}_{2}(\mathrm{~g}) \rightarrow \mathrm{CuSO}_{3}(\mathrm{~s})
$$

Thus, just inside the regenerator, the sorbent may consist of copper oxide, copper sulfite and copper sulfate. Some tests have also indicated the presence of compounds such as $\mathrm{Cu}_{2} \mathrm{O}$ and $\mathrm{Cu}_{2} \mathrm{SO}_{3}$ within the regenerator (Harriott and Markussen, 1992). However, pending further studies to provide a design basis, these species are excluded from consideration in this model.

It is assumed that copper sulfite, copper sulfate, and copper oxide are regenerated to copper with efficiencies $\eta_{\mathrm{r} 1}, \eta_{\mathrm{r} 2}$, and $\eta_{\mathrm{r} 3}$, respectively. The regeneration reactions are:

$$
\begin{gathered}
\mathrm{CuSO}_{4(\mathrm{~s})}+\frac{1}{2} \mathrm{CH}_{4}(\mathrm{~g}) \rightarrow \mathrm{Cu}(\mathrm{s})+\mathrm{SO}_{2}(\mathrm{~g})+\frac{1}{2} \mathrm{CO}_{2}(\mathrm{~g})+\mathrm{H}_{2} \mathrm{O}_{(\mathrm{g})} \\
\mathrm{CuSO}_{3(\mathrm{~s})}+\frac{1}{4} \mathrm{CH}_{4}(\mathrm{~g}) \rightarrow \mathrm{Cu}_{(\mathrm{s})}+\mathrm{SO}_{2}(\mathrm{~g})+\frac{1}{4} \mathrm{CO}_{2}(\mathrm{~g})+\frac{1}{2} \mathrm{H}_{2} \mathrm{O}_{(\mathrm{g})} \\
\mathrm{CuO}_{(\mathrm{s})}+\frac{1}{4} \mathrm{CH}_{4(\mathrm{~g})} \rightarrow \mathrm{Cu}_{(\mathrm{s})}+\frac{1}{4} \mathrm{CO}_{2(\mathrm{~g})}+\frac{1}{2} \mathrm{H}_{2} \mathrm{O}_{(\mathrm{g})}
\end{gathered}
$$

The regenerated copper is rapidly oxidized to copper oxide upon contact with oxygen in solids transport air or the flue gas:

$$
\mathrm{Cu}_{(\mathrm{s})}+\frac{1}{2} \mathrm{O}_{2(\mathrm{~g})} \rightarrow \mathrm{CuO}_{(\mathrm{s})}
$$

Similarly, any unregenerated copper sulfite is also assumed to completely oxidize to copper sulfate upon contact with oxygen:

$$
\mathrm{CuSO}_{3(\mathrm{~s})}+\frac{1}{2} \mathrm{O}_{2(\mathrm{~g})} \rightarrow \mathrm{CuSO}_{4}(\mathrm{~s})
$$


Thus, the sorbent entering the absorber is assumed to contain only copper oxide and copper sulfate.

The regeneration offgas is sent to a byproduct recovery plant. Here, it is assumed that elemental sulfur is recovered in a Claus plant. The Claus reaction is:

$$
2 \mathrm{H}_{2} \mathrm{~S}_{(\mathrm{g})}+\mathrm{SO}_{2(\mathrm{~g})} \rightarrow 3 \mathrm{~S}_{(\mathrm{l})}+2 \mathrm{H}_{2} \mathrm{O}_{(\mathrm{g})}
$$

However, because the regeneration offgas contains no hydrogen sulfide, a portion of the $\mathrm{SO}_{2}$ must be reduced with natural gas to produce the required quantity of hydrogen sulfide.

$$
2 \mathrm{CH}_{4}(\mathrm{~g})+3 \mathrm{SO}_{2}(\mathrm{~g}) \rightarrow \mathrm{S}_{(\mathrm{l})}+2 \mathrm{H}_{2} \mathrm{~S}_{(\mathrm{g})}+2 \mathrm{CO}_{2}(\mathrm{~g})+2 \mathrm{H}_{2} \mathrm{O}(\mathrm{g})
$$

Thus, some elemental sulfur is obtained via the reducing reaction, while the remainder is obtained via the Claus reaction. The overall reaction is:

$$
\mathrm{CH}_{4(\mathrm{~g})}+2 \mathrm{SO}_{2}(\mathrm{~g}) \rightarrow 2 \mathrm{~S}_{(\mathrm{l})}+2 \mathrm{H}_{2} \mathrm{O}(\mathrm{g})+\mathrm{CO}_{2(\mathrm{~g})}
$$

Thus, the overall required inlet molar flow rate of methane is one-half the molar flow rate of sulfur dioxide in the offgas. A portion of this requirement is met by unreacted methane contained in the regenerator offgas. 


\subsection{NEW ANALYTICAL PERFORMANCE MODELS}

New analytical models for the sorbent mass balance, the absorber sulfation reaction, regeneration, byproduct recovery, and energy penalties are derived and documented. These models supersede previous versions developed by Frey (1987).

\subsection{Sorbent Mass Balance}

To calculate the sorbent flow rate at the absorber inlet, a single equation that accounts for the key assumptions regarding process chemistry has been developed. This equation is based on a mass balance of copper, copper oxide, copper sulfite and copper sulfate. The basis for the sorbent mass balance per mole of $\mathrm{SO}_{2}$ in the flue gas is given in Table 1. This approach can be extended to include other species (e.g., $\mathrm{Cu}_{2} \mathrm{O}, \mathrm{Cu}_{2} \mathrm{SO}_{4}$ ) if a design basis for the process chemistry can be characterized.

At the absorber inlet, the sorbent contains available copper (in the form of copper oxide) and an unknown molar amount of copper sulfate, which is residual unregenerated copper from the previous absorption/regeneration cycle. A portion of the copper oxide reacts with $\mathrm{SO}_{2}$ in the flue gas to form additional copper sulfate. The available copper to sulfur molar ratio, $R$, is estimated using a kinetics model described in a later section.

As the sorbent enters the regenerator, a fraction of the copper oxide may react with $\mathrm{SO}_{2}$, evolved in the lower regions of the regenerator, to form copper sulfite (based on Harriott and Markussen, 1992). The copper oxide, copper sulfite, and copper sulfate are regenerated to copper. Harriott and Markussen (1992) suggest that the regeneration efficiency for copper sulfite may be substantially lower than that for copper sulfate for a given regeneration residence time. Therefore, the regeneration efficiencies are parameterized for each species to permit investigation of the sensitivity of sorbent requirements to alternative assumptions regarding regenerator performance.

All of the species are assumed to be rapidly and completely oxidized after exiting the absorber and entering the solids transport system. Thus, all of the copper is assumed to be oxidized to copper oxide, and all of the copper sulfite is assumed to be oxidized to copper sulfate. The sorbent composition in the solids transport system is the same as that entering the absorber.

The mass balance is closed by solving for the unknown molar amount of copper sulfate entering the absorber per mole of $\mathrm{SO}_{2}$. It can be shown that (see Table 1 and Nomenclature):

$$
\mathrm{R}_{\mathrm{CuSO}_{4}}=\frac{\eta_{\mathrm{s}}\left(1-\eta_{\mathrm{r} 2}\right)+\mathrm{x}_{1}\left(1-\eta_{\mathrm{r} 1}\right)\left(\mathrm{R}-\eta_{\mathrm{s}}\right)}{\eta_{\mathrm{r} 2}}
$$


This expression for $\mathrm{RCuSO}_{4}$ also yields closure on the mass balance for $\mathrm{CuO}$ entering the absorber.

The molar flow rate of any copper species at any point in the process can be calculated by multiplying the absorber inlet molar flow of $\mathrm{SO}_{2}$ by the appropriate coefficient in Table 1. For example, the molar flow rate of copper oxide at the absorber inlet is given by:

$$
\mathrm{M}_{\mathrm{CuO}, \mathrm{A}, \mathrm{i}}=\mathrm{R} \cdot \mathrm{M}_{\mathrm{SO}_{\mathrm{x}}, \mathrm{A}, \mathrm{i}}
$$

where:

$$
\mathrm{MSO}_{x, \mathrm{~A}, \mathrm{i}}=\mathrm{MSO}_{2, \mathrm{~A}, \mathrm{i}}+\mathrm{MSO}_{3, \mathrm{~A}, \mathrm{i}}
$$

The sorbent copper sulfate loading at the absorber entrance is given by:

$$
\mathrm{M}_{\mathrm{CuSO}_{4}, \mathrm{~A}, \mathrm{i}}=\mathrm{R}_{\mathrm{CuSO}} \cdot \mathrm{M}_{\mathrm{SO}_{2}, \mathrm{~A}, \mathrm{i}}
$$

Note that the total molar amount of copper entering the absorber is greater than the available molar amount. The available copper to sulfur molar ratio is defined as $R$, and the total copper to sulfur molar ratio is given by:

$$
\mathrm{R}_{\mathrm{tot}}=\mathrm{R}+\mathrm{R}_{\mathrm{CuSO}_{4}}
$$

A general formula is developed for calculating the sorbent mass flow as a function of the sorbent composition. Consider fresh sorbent, which contains copper only as copper oxide. The convention used in previous studies has been to define the sorbent composition based on the weight percent of copper, assuming that all of the copper is in the form of copper oxide. Therefore, the sorbent mass flow rate on an equivalent fresh sorbent basis is given by:

$$
\mathrm{m}_{\mathrm{s}, \mathrm{fresh}}=\left(\frac{\mathrm{MWOu}_{\mathrm{Cu}}}{\mathrm{W}_{\mathrm{Cu}}}\right)\left(\mathrm{M}_{\mathrm{Cu}}+\mathrm{M}_{\mathrm{CuO}}+\mathrm{M}_{\mathrm{CuSO}_{3}}+\mathrm{M}_{\mathrm{CuSO}_{4}}\right)
$$

However, in general, the sorbent may consist of other copper species as well. While the total molar amount of copper is not affected by the speciation, the mass flow is. Thus, factors must be included to account for the effect of different copper species on the sorbent mass flow rate. For example, for each mole of copper sulfate present in the sorbent, there is an incremental increase in sorbent mass flow rate due to the mass differential between a mole of copper oxide and a mole of copper sulfate. This difference must be calculated on a copper basis: 
Table 1. Mass balance for sorbent in fluidized bed copper oxide process.

\begin{tabular}{|c|c|c|c|c|}
\hline \multirow[b]{2}{*}{ Location } & \multicolumn{4}{|c|}{ Moles of Species per mole of $\mathrm{SO}_{2}$} \\
\hline & $\mathrm{Cu}$ & $\mathrm{CuO}$ & $\mathrm{CuSO}_{3}$ & $\mathrm{CuSO}_{4}$ \\
\hline $\begin{array}{l}\text { Absorber } \\
\text { Inlet }\end{array}$ & 0 & $\mathbf{R}$ & 0 & $\mathrm{R}_{\mathrm{CuSO}} 4$ \\
\hline $\begin{array}{l}\text { Absorber } \\
\text { Outlet and } \\
\text { Regenerator } \\
\text { Inlet }\end{array}$ & 0 & $\left(\mathrm{R}-\eta_{\mathrm{s}}\right)$ & 0 & $\left(\mathrm{RCuSO}_{4}+\eta_{\mathrm{s}}\right)$ \\
\hline $\begin{array}{l}\text { Just Inside } \\
\text { Regenerator }\end{array}$ & 0 & $\left(1-x_{1}\right)\left(R-\eta_{s}\right)$ & $\mathrm{x}_{1}\left(\mathrm{R}-\eta_{\mathrm{S}}\right)$ & $\left(\mathrm{R}_{\mathrm{CuSO}}+\eta_{\mathrm{s}}\right)$ \\
\hline $\begin{array}{l}\text { Regenerator } \\
\text { Outlet }\end{array}$ & $\begin{array}{c}\eta_{\mathrm{r} 3}\left(1-\mathrm{x}_{1}\right)\left(\mathrm{R}-\eta_{\mathrm{s}}\right) \\
+\eta_{\mathrm{r} 1} \mathrm{x}_{1}\left(\mathrm{R}-\eta_{\mathrm{s}}\right) \\
+\eta_{\mathrm{r} 2}\left(\mathrm{R}_{\mathrm{CuSO}}+\eta_{\mathrm{s}}\right)\end{array}$ & $\begin{array}{c}\left(1-\eta_{\mathrm{r} 3}\right)\left(1-\mathrm{x}_{1}\right) \\
\cdot\left(\mathrm{R}-\eta_{\mathrm{s}}\right)\end{array}$ & $\left(1-\eta_{\mathrm{r} 1}\right) \mathrm{x}_{1}\left(\mathrm{R}-\eta_{\mathrm{s}}\right)$ & $\begin{array}{c}\left(1-\eta_{\mathrm{r} 2}\right) \\
\left(\mathrm{R}_{\mathrm{CuSO}}+\eta_{\mathrm{s}}\right)\end{array}$ \\
\hline $\begin{array}{l}\text { Transport } \\
\text { line and } \\
\text { absorber inlet }\end{array}$ & 0 & $\begin{array}{c}\mathrm{R}=\left(1-\mathrm{x}_{1}\right)\left(\mathrm{R}-\eta_{\mathrm{s}}\right) \\
+\eta_{\mathrm{r} 1} \mathrm{x}_{1}\left(\mathrm{R}-\eta_{\mathrm{s}}\right) \\
+\eta_{\mathrm{r} 2}\left(\mathrm{R}_{\mathrm{CuSO}}+\eta_{\mathrm{s}}\right)\end{array}$ & 0 & $\begin{array}{c}\mathrm{R}_{\mathrm{CuSO}_{4}}= \\
\left(1-\eta_{\mathrm{r} 1}\right) \mathrm{x}_{1}\left(\mathrm{R}-\eta_{\mathrm{s}}\right) \\
+\left(1-\eta_{\mathrm{r} 2}\right) \cdot \\
\left(\mathrm{R}_{\mathrm{CuSO}}+\eta_{\mathrm{s}}\right)\end{array}$ \\
\hline
\end{tabular}

$$
\Delta \mathrm{MW}_{\mathrm{CuSO}_{4}}=\frac{\mathrm{MW}_{\mathrm{CuSO}_{4}}-\mathrm{MW}_{\mathrm{CuO}}}{\mathrm{MW}}=\frac{159.54-79.54}{63.54}=1.26
$$

The total effect of the weight difference is proportional to the weight fraction of copper as copper oxide in the sorbent. Thus, for a sorbent containing copper oxide and copper sulfate, the mass flow rate is given by:

$$
\mathrm{m}_{\mathrm{s}}=\left(\frac{\mathrm{MW}_{\mathrm{Cu}}}{\mathrm{W}_{\mathrm{Cu}}}\right)\left\{\mathrm{M}_{\mathrm{CuO}}+\left(1+1.2 \mathrm{~W}_{\mathrm{Cu}}\right) \mathrm{M}_{\mathrm{CuSO}_{4}}\right\}
$$

This formulation is easily extended to account for other species, such as copper and copper sulfite. The general equation is therefore:

$$
\mathrm{m}_{\mathrm{s}}=\left(\frac{\mathrm{MW}}{\mathrm{W}_{\mathrm{Cu}}}\right)\left\{\left(1-0.252 \mathrm{~W}_{\mathrm{Cu}}\right) \mathrm{M}_{\mathrm{Cu}}+\mathrm{M}_{\mathrm{CuO}}+\left(1+1.007 \mathrm{~W}_{\mathrm{Cu}}\right) \mathrm{M}_{\mathrm{CuSO}_{3}}+\left(1+1.26 \mathrm{~W}_{\mathrm{Cu}}\right) \mathrm{M}_{\mathrm{CuSO}}\right\}
$$

For example, the absorber inlet sorbent mass flow rate on a $\mathrm{lb} / \mathrm{hr}$ basis can be calculated as:

$$
\mathrm{m}_{\mathrm{s}, \mathrm{A}, \mathrm{i}}=\left(\frac{\mathrm{MW}_{\mathrm{Cu}}}{\mathrm{W}_{\mathrm{Cu}}}\right)\left\{\mathrm{R}+\left(1+1.260 \mathrm{~W}_{\mathrm{Cu}}\right) \mathrm{R}_{\mathrm{CuSO}_{4}}\right\} \cdot \mathrm{M}_{\mathrm{SO}_{\mathrm{x}} \mathrm{A}, \mathrm{i}}
$$


The sorbent composition and mass flow at the absorber exit is given by:

$$
\begin{gathered}
\mathrm{M}_{\mathrm{CuO}, \mathrm{A}, \mathrm{O}}=\left(\mathrm{R}-\eta_{\mathrm{s}}\right) \cdot \mathrm{M}_{\mathrm{SO}_{x}, \mathrm{~A}, \mathrm{i}} \\
\mathrm{M}_{\mathrm{CuSO}_{4}, \mathrm{~A}, \mathrm{O}}=\left(\mathrm{R}_{\mathrm{CuSO}_{4}}+\eta_{\mathrm{s}}\right) \cdot \mathrm{M}_{\mathrm{SO}_{x}, \mathrm{~A}, \mathrm{i}} \\
\left.\mathrm{m}_{\mathrm{s}, \mathrm{A}, \mathrm{O}}=\left(\frac{\mathrm{MW}_{\mathrm{Cu}}}{\mathrm{W}_{\mathrm{Cu}}}\right)\left(\mathrm{R}-\eta_{\mathrm{s}}\right)+\left(1+1.260 \mathrm{~W}_{\mathrm{Cu}}\right)\left(\mathrm{R}_{\mathrm{CuSO}_{4}}+\eta_{\mathrm{s}}\right)\right) \cdot \mathrm{M}_{\mathrm{SO}_{2}, \mathrm{~A}, \mathrm{i}}
\end{gathered}
$$

The absorber exit sorbent composition is the same as that of the solids heater inlet and outlet and of the regenerator inlet. It is assumed that no chemical reactions occur in the solids heater.

Just inside the regenerator, a portion of the copper oxide may react with sulfur dioxide in the regenerator off-gas to form copper sulfite. Thus, at the regenerator outlet the sorbent may contain copper, copper oxide, copper sulfite, and copper sulfate. The molar flow rates of each of these four species are:

$$
\begin{aligned}
& \mathrm{M}_{\mathrm{Cu}, \mathrm{R}, \mathrm{o}}=\left\{\left[\eta_{\mathrm{r} 3}\left(1-\mathrm{x}_{1}\right)+\eta_{\mathrm{r} 1} \mathrm{x}_{1}\right]\left(\mathrm{R}-\eta_{\mathrm{s}}\right)+\eta_{\mathrm{r} 2}\left(\mathrm{R}_{\mathrm{CuSO}_{4}}+\eta_{\mathrm{s}}\right)\right\} \cdot \mathrm{M}_{\mathrm{SO}_{\mathrm{x}} \mathrm{A}, \mathrm{i}} \\
& \mathrm{M}_{\mathrm{CuO}, \mathrm{R}, 0}=\left[\left(1-\mathrm{x}_{1}\right)\left(1-\eta_{\mathrm{r} 3}\right)\left(\mathrm{R}-\eta_{\mathrm{s}}\right)\right] \cdot \mathrm{M}_{\mathrm{SO}_{\mathrm{x}}, \mathrm{A}, \mathrm{i}} \\
& \mathrm{M}_{\mathrm{CuSO}_{3, \mathrm{R}, 0}}=\left[\mathrm{x}_{1}\left(1-\eta_{\mathrm{r} 1}\right)\left(\mathrm{R}-\eta_{\mathrm{S}}\right)\right] \cdot \mathrm{M}_{\mathrm{SO}_{\mathrm{O}}, \mathrm{A}, \mathrm{i}} \\
& \mathrm{M}_{\mathrm{CuSO}_{4}, \mathrm{R}, 0}=\left\{\left(1-\eta_{\mathrm{r} 2}\right)\left(\mathrm{R}_{\mathrm{CuSO}_{4}}+\eta_{\mathrm{s}}\right)\right\} \cdot \mathrm{M}_{\mathrm{SO}_{x}, \mathrm{~A}, \mathrm{i}}
\end{aligned}
$$

The sorbent mass flow can be calculated by substituting Equation (27) for $\mathrm{M}_{\mathrm{Cu}}$, Equation (28) for $\mathrm{M}_{\mathrm{CuO}}$, Equation (29) for $\mathrm{MCuSO}_{3}$, and Equation (30) for $\mathrm{MCuSO}_{4}$ into Equation (22). It is assumed that any copper and copper sulfite in the sorbent will react completely upon contact with oxygen in the sorbent transport system to form copper oxide and copper sulfate, respectively. Therefore, the sorbent composition entering the absorber is given by Equations (15) and (17).

The molar flow rate of the alumina oxide substrate is the same at all points in the absorption/regeneration cycle. As a convenience, this flow is calculated based on the absorber inlet sorbent mass flow:

$$
\mathrm{M}_{\mathrm{Al}_{2} \mathrm{O}_{3}}=\left(\frac{\mathrm{MW}_{\mathrm{Cu}}}{\mathrm{W}_{\mathrm{Cu}}}-\mathrm{MW} \mathrm{CuO}\right)\left(\frac{1}{\mathrm{MW}_{\mathrm{Al}_{2} \mathrm{O}_{3}}}\right) \mathrm{R}_{\mathrm{tot} \cdot \mathrm{M}_{\mathrm{SO}_{x}, \mathrm{~A}, \text { in }}}
$$




\subsection{Sulfation Reaction Model}

Yeh et al. (1987) developed a kinetic model of the sulfation reaction (Equation (1)). Their model assumed plug flow of both the flue gas and the solids. This model had been employed in a previous version of the copper oxide process performance model (Frey and Rubin, 1991; Rubin $e t$ al., 1991). Harriott (1992a) has developed a kinetic model for the sulfation reaction assuming that the solids in the fluidized bed are perfectly mixed. Harriott's model is:

$$
\ln \left(\frac{y_{0}}{y_{i}}\right)=-\alpha R y_{i}+\alpha\left(y_{i}-y_{0}\right)
$$

where:

$$
\alpha=\frac{k_{s} P \rho_{s} Z A}{F_{s}}
$$

The $\mathrm{SO}_{2}$ removal efficiency is defined as:

$$
\eta_{s}=\frac{y_{i}-y_{0}}{y_{i}}
$$

Therefore, we may rewrite the sulfation model as:

$$
R=\eta_{s}-\frac{\ln \left(1-\eta_{s}\right)}{\alpha y_{i}}
$$

The quantity $\left(\rho_{\mathrm{s}} \mathrm{ZA}\right)$ in the kinetic parameter $\alpha$ is the sorbent bed inventory in the absorber. We note that the sorbent residence time is calculated based on the bed inventory and the feed rate:

$$
\mathrm{t}_{\mathrm{r}, \mathrm{a}}=\frac{\rho_{\mathrm{s}} \mathrm{ZA}}{\mathrm{F}_{\mathrm{s}}} \text {. }
$$

Thus, the term $\alpha$ is:

$$
\alpha=k_{s} P t_{r, a}
$$

The reaction rate constant, corrected for the sorbent copper loading, is given by (Yeh, 1992):

$$
\mathrm{k}_{\mathrm{s}}=1,573 \exp \left(-14.23 \mathrm{w}_{\mathrm{Cu}}\right) \exp \left(-\frac{2,417.6}{\mathrm{~T}}\right)
$$

Test data reported by Yeh, Drummond, and Joubert (1987) were used with Harriott'sl sulfation model to estimate the available $\mathrm{Cu} / \mathrm{S}$ ratio and to compare with experimental results. Table 2 shows the key process parameters measured during testing, including the available copper to sulfur molar ratio, $\mathrm{R}$. The inlet $\mathrm{SO}_{2}$ concentration is reported on a total gas flow basis, including moisture. These values were estimated from the dry $\mathrm{SO}_{2}$ concentrations reported by $\mathrm{Yeh}$ 
et al and from the reported flue gas moisture content of approximately 7.5 percent. Estimates by Frey and Rubin (1991) of the molar ratio $R$ based on test data using a reaction model developed by Yeh et al. (1987) are reported. Similarly, estimates of the $\mathrm{Cu} / \mathrm{S}$ molar ratio based on the Harriott sulfation model are also reported.

As an example of the calculations, consider Test No. 1. The sorbent residence time is:

$$
t_{r, a}=\frac{\rho_{s} Z A}{F_{s}}=\frac{I_{b}}{F_{s}}=\frac{614 \mathrm{~kg}}{\left(372 \frac{\mathrm{kg}}{\mathrm{hr}}\right)\left(\frac{\mathrm{hr}}{60 \min }\right)}=99.0 \mathrm{~min}
$$

The reaction rate constant is:

$$
\mathrm{k}_{\mathrm{s}}=1,573 \exp (-14.23\{0.051\}) \exp \left(-\frac{2,417.6}{723 \mathrm{~K}}\right)=26.87 \frac{1}{\mathrm{~atm} \cdot \min }
$$

The kinetic parameter $\alpha$ is:

$$
\alpha=\mathrm{k}_{\mathrm{s}} \mathrm{Pt}_{\mathrm{r}, \mathrm{a}}=\left(26.87 \frac{1}{\mathrm{~atm} \cdot \min }\right)(1 \mathrm{~atm})(99.0 \mathrm{~min})=\underline{2,661}
$$

The resulting copper-to-sulfur molar ratio is:

$$
\mathrm{R}=\eta_{\mathrm{s}}-\frac{\ln \left(1-\eta_{\mathrm{s}}\right)}{\alpha \mathrm{y}_{\mathrm{i}}}=0.79-\frac{\ln (1-0.79)}{2,661\left(2.109 \times 10^{-3}\right)}=1.07
$$

Figure 2 shows a comparison of the $\mathrm{Cu} / \mathrm{S}$ ratio estimated using the PETC model versus experimental results. Figure 3 shows a similar comparison using the Harriott model.

The comparison of the Harriott and PETC sulfation models with experimental data indicates that Harriott's model provides generally better estimates of the $\mathrm{Cu} / \mathrm{S}$ ratio than the PETC model. Although both models yield estimates typically within \pm 10 percent of the experimentally measured values, the estimates from Harriott's model tend to be less scattered from the parity line. Harriott's model appears to be somewhat conservative in predicting $\mathrm{Cu} / \mathrm{S}$ ratios slightly higher than the experimentally measured results. The model results diverge most noticable for the high $\mathrm{Cu} / \mathrm{S}$ ratios, which represents testing with low (18-inch) fluidized bed heights. Such bed heights are unlikely for commercial scale designs, and the experimental results themselves are considered less certain than the ones reported for higher bed heights. Therefore, Harriott's model is employed here. 
Table 2. Comparison of Alternative Sulfation Models.

\begin{tabular}{|c|c|c|c|c|c|c|c|c|c|}
\hline $\begin{array}{c}\text { Test } \\
\text { No. }\end{array}$ & $\begin{array}{c}\mathrm{SO}_{2} \\
\text { Removal } \\
\text { (frac.) }\end{array}$ & $\begin{array}{c}\text { Inlet } \\
\mathrm{SO}_{2} \\
\text { (ppm, } \\
\text { wet) }\end{array}$ & $\begin{array}{c}\text { Bemp. } \\
\text { Temp. } \\
\left({ }^{\circ} \mathrm{C} \text { ) }\right.\end{array}$ & $\begin{array}{c}\text { Copper } \\
\text { Loading } \\
\text { (wt-\%) }\end{array}$ & $\begin{array}{c}\text { Sorbent } \\
\text { Feed } \\
(\mathrm{kg} / \mathrm{h})\end{array}$ & $\begin{array}{c}\text { Bed } \\
\text { Invent'y } \\
(\mathrm{kg})\end{array}$ & $\begin{array}{c}\text { Avail. } \\
\mathrm{Cu} / \mathrm{S} \\
\text { Ratio }\end{array}$ & $\begin{array}{c}\text { PETC } \\
\text { Model } \\
\mathrm{Cu} / \mathrm{S}\end{array}$ & $\begin{array}{c}\text { Harriott } \\
\text { Model } \\
\mathrm{Cu} / \mathrm{S}\end{array}$ \\
\hline 1 & 0.79 & 2,109 & 450 & 5.1 & 372 & 614 & 0.99 & 0.95 & 1.07 \\
2 & 0.71 & 2,109 & 460 & 5.1 & 290 & 614 & 0.78 & 0.78 & 0.87 \\
3 & 0.90 & 2,177 & 400 & 5.1 & 669 & 636 & 1.57 & 1.74 & 1.78 \\
4 & 0.91 & 2,479 & 400 & 5.1 & 854 & 641 & 1.80 & 1.75 & 1.94 \\
5 & 0.70 & 2,479 & 465 & 5.1 & 351 & 638 & 0.80 & 0.78 & 0.85 \\
6 & 0.81 & 2,479 & 400 & 5.1 & 423 & 638 & 0.96 & 1.10 & 1.16 \\
7 & 0.91 & 2,868 & 405 & 5.1 & 1,053 & 696 & 1.71 & 1.89 & 1.89 \\
8 & 0.90 & 1,943 & 420 & 5.1 & 762 & 585 & 1.86 & 1.75 & 2.01 \\
9 & 0.67 & 2,174 & 480 & 5.1 & 154 & 523 & 0.65 & 0.67 & 0.75 \\
10 & 0.91 & 2,118 & 425 & 5.1 & 453 & 469 & 2.00 & 1.15 & 1.68 \\
11 & 0.70 & 2,729 & 425 & 5.1 & 479 & 491 & 0.89 & 0.95 & 1.00 \\
12 & 0.82 & 2,729 & 415 & 5.1 & 668 & 491 & 1.27 & 1.44 & 1.45 \\
13 & 0.91 & 2,313 & 400 & 5.1 & 1,352 & 505 & 2.76 & 2.47 & 3.13 \\
14 & 0.88 & 2,220 & 350 & 5.1 & 1,111 & 472 & 2.70 & 2.65 & 3.26 \\
15 & 0.89 & 2,081 & 390 & 5.1 & 1,127 & 448 & 2.93 & 2.37 & 3.13 \\
16 & 0.90 & 2,174 & 390 & 5.1 & 1,177 & 446 & 3.27 & 2.08 & 3.25 \\
17 & 0.95 & 1,989 & 415 & 7.0 & 311 & 376 & 1.99 & 1.92 & 2.15 \\
18 & 0.93 & 1,758 & 425 & 7.0 & 375 & 399 & 2.03 & 2.24 & 2.23 \\
19 & 0.90 & 1,943 & 440 & 7.0 & 412 & 422 & 1.60 & 1.91 & 1.89 \\
20 & 0.70 & 2,165 & 465 & 5.1 & 488 & 195 & 1.11 & 2.40 & 1.51 \\
21 & 0.78 & 2,035 & 455 & 5.1 & 839 & 241 & 1.96 & 2.06 & 2.35 \\
22 & 0.84 & 1,989 & 455 & 5.1 & 859 & 208 & 2.30 & 3.13 & 3.15 \\
\hline
\end{tabular}

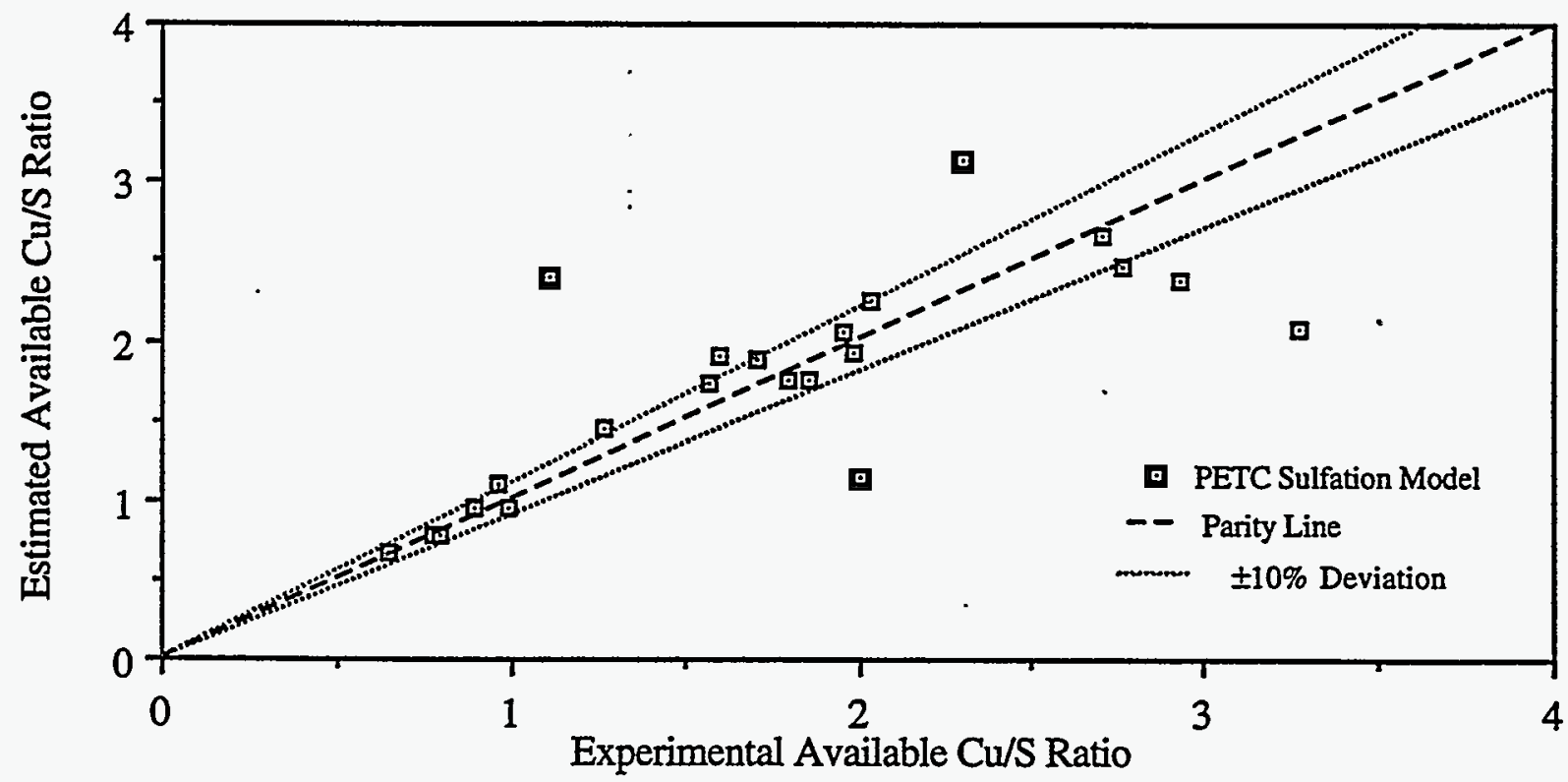

Figure 2. Comparison of copper-to-sulfur molar ratios from experimental results and from the PETC sulfation model. 


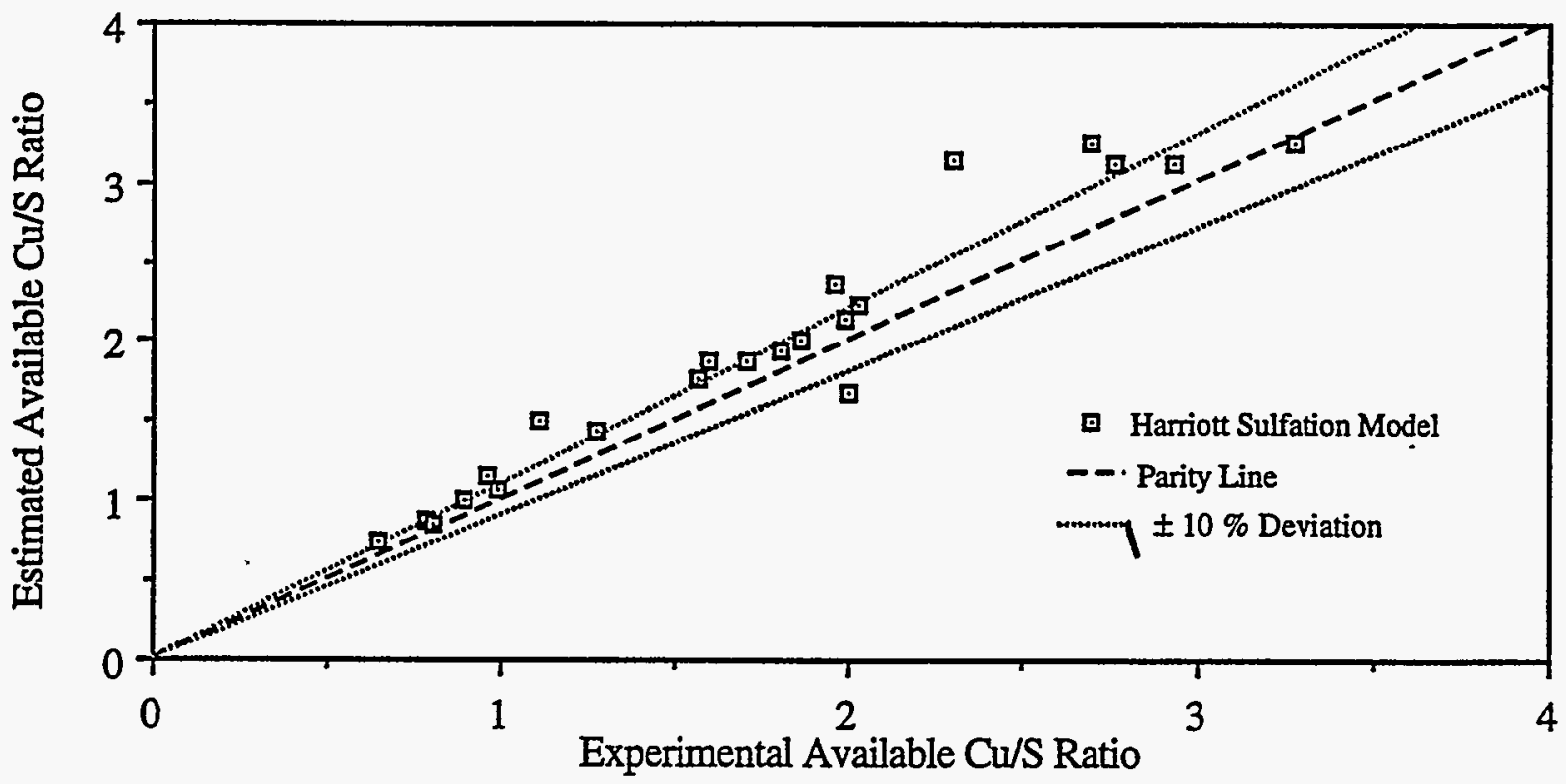

Figure 3. Comparison of copper-to-sulfur molar ratios from experimental results and from the Harriott sulfation model.

As a prerequisite to estimating the sorbent bed inventory, the absorber bed area is calculated based on the flue gas volumetric flow rate and the reactor bed gas superficial velocity:

$$
A=\left(\frac{G_{F G}}{60 V_{s}}\right)
$$

The sorbent bed inventory and the sorbent feed rate should both be calculated on a consistent basis (e.g., fresh sorbent, or actual sorbent) to estimate the sorbent residence time. The simpler case is to base the calculations on equivalent fresh sorbent, in terms of mass flow and inventory. A calculation based on actual composition would yield the same ratio of bed inventory to feed rate, as both estimates would increase by the same proportion (assuming that the fluidized bed density increases proportionally for a given superficial velocity and bed height). Thus, the sorbent feed rate to be used in the sulfation model is:

$$
F_{s}=\left(\frac{M_{\mathrm{Cu}}}{W_{\mathrm{Cu}}}\right)\left\{R+\left[\frac{\eta_{\mathrm{s}}\left(1-\eta_{\mathrm{r} 2}\right)+\mathrm{x}_{1}\left(1-\eta_{\mathrm{r} 1}\right)\left(\mathrm{R}-\eta_{\mathrm{s}}\right)}{\eta_{\mathrm{r} 2}}\right]\right) \cdot\left(\frac{\mathrm{M}_{\mathrm{SO}_{\mathrm{x}}, \mathrm{A}, \mathrm{i}}}{60 \mathrm{~min} / \mathrm{hr}}\right)
$$

If this equation is used to estimate the sorbent feed rate, than the sorbent density used to estimate the sorbent bed inventory should be based on the expanded bed density for fresh sorbent. An expanded sorbent density $\left(\rho_{\mathrm{s}}\right)$ of $26.6 \mathrm{lb} / \mathrm{ft}^{3}$ is used for this purpose. This density is valid for a four foot bed height with a superficial gas velocity of approximately $4.2 \mathrm{ft} / \mathrm{sec}$. 
Equation (43) is a function of the copper-to-sulfur molar ratio. In order to develop an explicit equation for $\mathrm{R}$, it is necessary to rewrite Equation (43) as:

$$
F_{s}=a+b \cdot R
$$

where:

$$
\begin{gathered}
\mathrm{a}=\left(\frac{\mathrm{MW}_{\mathrm{Cu}}}{\mathrm{W}_{\mathrm{Cu}}}\right)\left(\frac{\mathrm{M}_{\mathrm{SO}_{\mathrm{x}}, \mathrm{A}, \mathrm{i}}}{60 \frac{\min }{\mathrm{hr}}}\right]\left[\frac{\eta_{\mathrm{s}}\left(1-\eta_{\mathrm{r} 2}\right)-\mathrm{x}_{1} \eta_{\mathrm{s}}\left(1-\eta_{\mathrm{r} 1}\right)}{\eta_{\mathrm{r} 2}}\right] \\
\left.\left.\mathrm{b}=\left(\frac{\mathrm{MW}_{\mathrm{Cu}}}{\mathrm{W}_{\mathrm{Cu}}}\right) \frac{\mathrm{M}_{\mathrm{SO}_{\mathrm{x}}, \mathrm{A}, \mathrm{i}}}{60 \frac{\min }{\mathrm{hr}}}\right] \frac{\eta_{\mathrm{r} 2}+\mathrm{x}_{1}\left(1-\eta_{\mathrm{r} 1}\right)}{\eta_{\mathrm{r} 2}}\right]
\end{gathered}
$$

We also define the following quantities:

$$
\begin{gathered}
\hat{\alpha}=k_{s} P \rho_{s} z A \\
\beta=\frac{\ln \left(1-\eta_{s}\right)}{\hat{\alpha} y_{i}}
\end{gathered}
$$

The sulfation model in Equation (35) is then rewritten in terms of the quantities in Equations (45), (46), (47), and (48):

$$
\mathrm{R}=\frac{\eta_{\mathrm{s}}-\mathrm{a} \beta}{1+\mathrm{b} \beta}
$$

The sensitivity of the model to regeneration efficiency and fluidized bed height is illustrated in Figure 4, for the same conditions as given in the last example above. The figure indicates that for poor regeneration efficiencies, the required available $\mathrm{Cu} / \mathrm{S}$ ratio can become excessive. For example, for a 48 inch bed height and a 50 percent regeneration efficiency, an available $\mathrm{Cu} / \mathrm{S}$ ratio of 4.15 is required for 90 percent $\mathrm{SO}_{2}$ capture. This available $\mathrm{Cu} / \mathrm{S}$ ratio corresponds to a total $\mathrm{Cu} / \mathrm{S}$ ratio of 8.3. However, for regeneration efficiencies greater than 80 percent, there is relatively little change in the required $\mathrm{Cu} / \mathrm{S}$ ratio. ${ }^{\circ}$ For a $48 \mathrm{inch}$ bed height, the $\mathrm{Cu} / \mathrm{S}$ ratio decreases from 1.76 to 1.59 as the regeneration efficiency increases from 80 to 90 percent. 


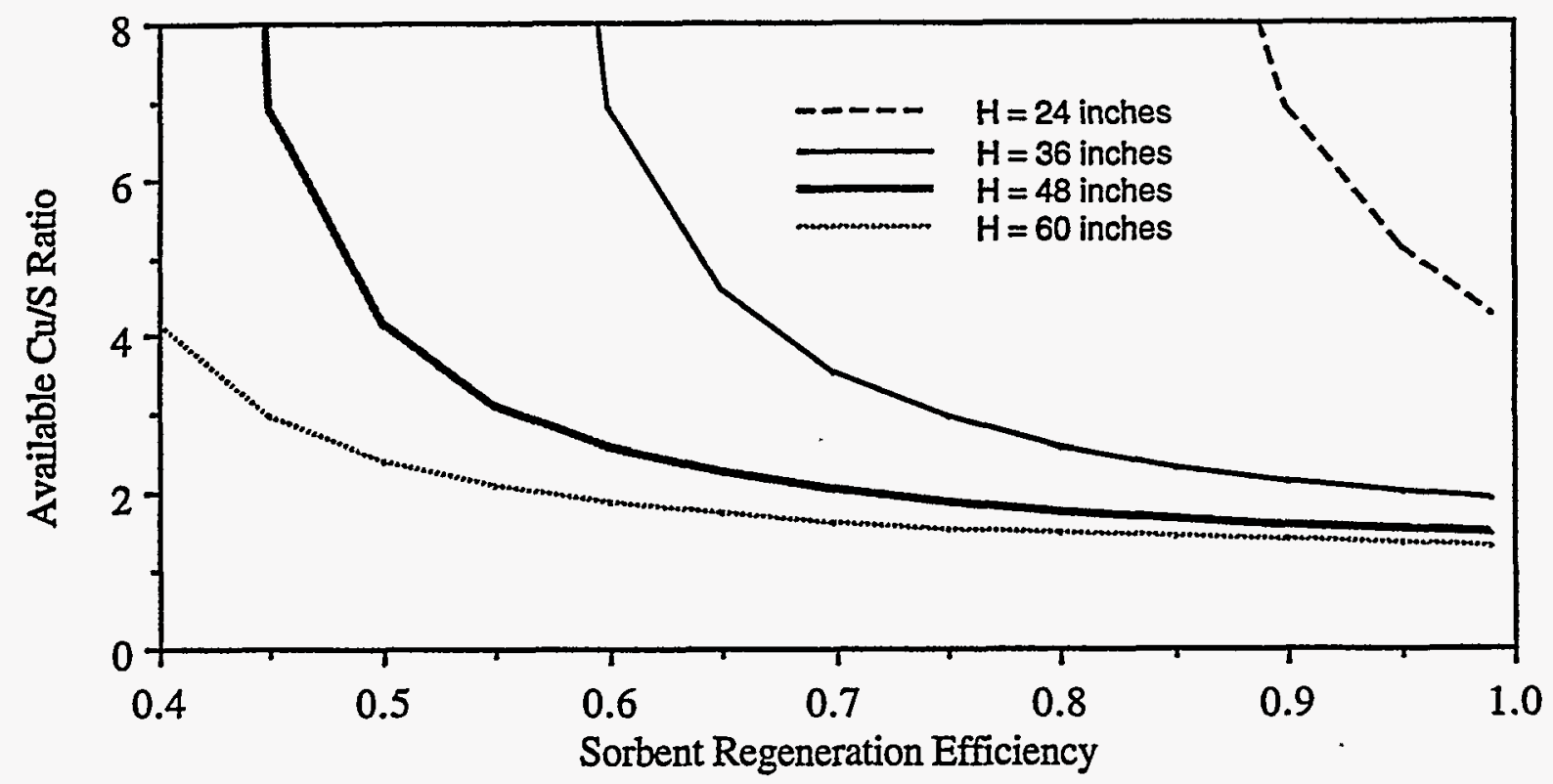

Figure 4. Sensitivity of $\mathrm{Cu} / \mathrm{S}$ Ratio to regeneration efficiency and fluidized bed height.

\subsection{Two-Stage Absorber Model}

A promising alternative to the single-stage fluidized bed design described above is a design featuring two fluidized beds in series. A schematic of the two-stage fluidized bed absorber is shown in Figure 5. In the two-stage design, regenerated sorbent enters a first stage fluidized bed, where the sorbent reacts with flue gas which has already passed through a second stage sorbent bed. The partially sulfated sorbent from the first bed then goes to a second bed, where it contacts inlet flue gas. Each of the two beds can have different bed heights and sulfur capture efficiencies. The overall sulfur removal efficiency is given by:

$$
\eta_{s}=\eta_{s 2}+\eta_{s 1}\left(1-\eta_{s 2}\right)
$$

For each of the two beds, the general models given in Equation (35) and (49) apply. For the first stage, the sulfation model is:

$$
\mathrm{R}=\frac{\eta_{\mathrm{s1}}\left(1-\eta_{\mathrm{s} 2}\right)-\mathrm{a} \beta_{1}}{1+\mathrm{b} \beta_{1}}
$$

where

$$
\beta_{1}=\frac{\ln \left(1-\eta_{\mathrm{s} 1}\right)}{\mathrm{k}_{\mathrm{s}}\left(\mathrm{T}_{1}\right) \mathrm{P} \rho_{\mathrm{s}} \mathrm{Z}_{1} \mathrm{Ay_{i }}}
$$




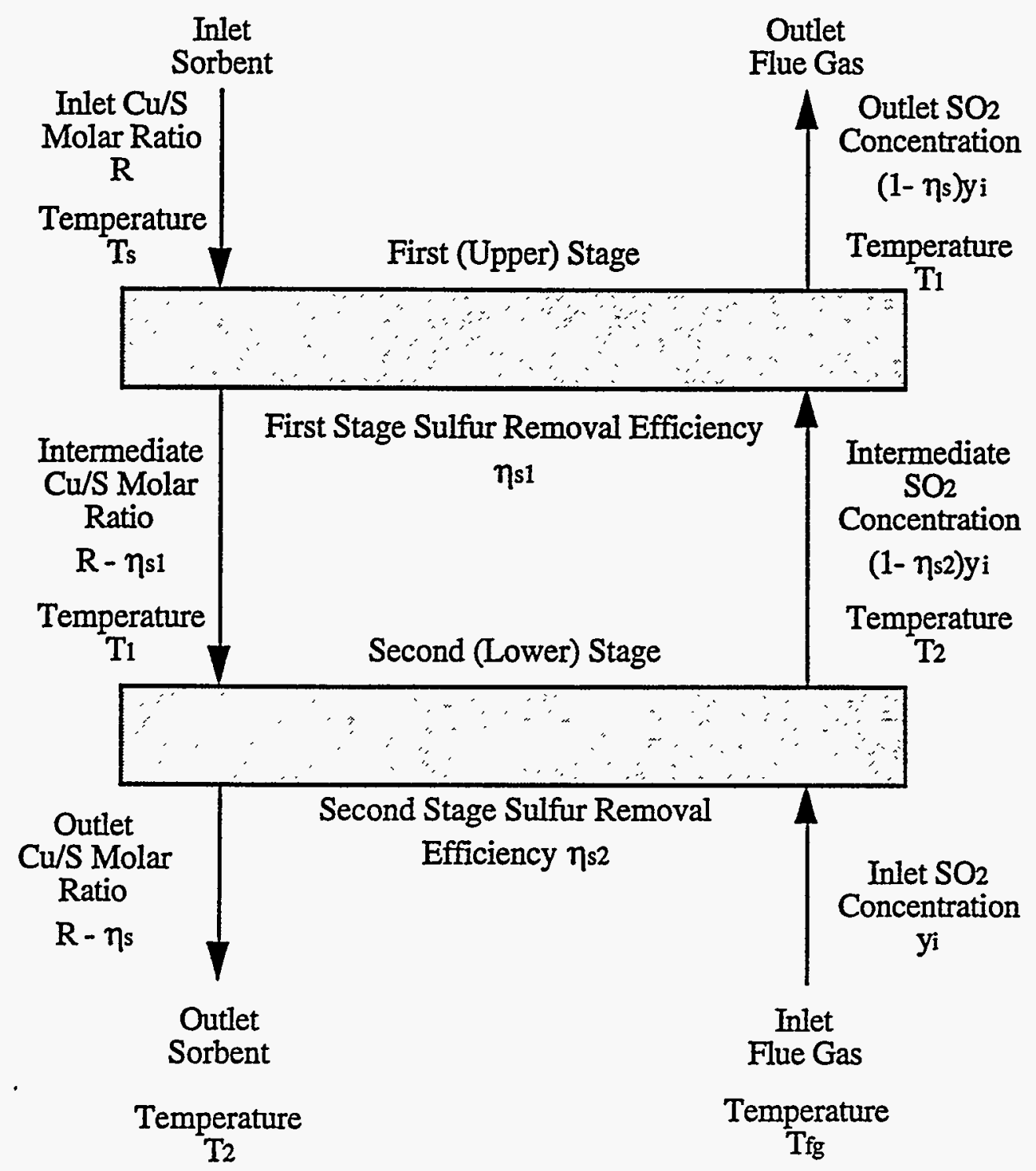

Figure 5. Simplified Schematic of a Two-Stage Fluidized Bed Absorber Model.

and the subscripts for temperature, sulfur removal efficiency, and bed height refer to the first stage absorber bed. For the second stage, the sulfation model is:

$$
\mathrm{R}=\frac{\eta_{\mathrm{s}}-\mathrm{a} \beta_{2}}{1+\mathrm{b} \beta_{2}}
$$

where:

$$
\beta_{1}=\frac{\ln \left(1-\eta_{\mathrm{s} 2}\right)}{\mathrm{k}_{\mathrm{s}}\left(\mathrm{T}_{2}\right) \mathrm{P} \rho_{\mathrm{s}} \mathrm{Z}_{2} \mathrm{~A} \mathrm{y}_{\mathrm{i}}}
$$

Typically, the desired overall sulfur removal efficiency is known. If the removal efficiency and bed height for one of the beds are specified, then the values for the other bed can be calculated. 
Thus, the calculation procedure in the two-stage model is to specify an overall sulfur capture efficiency, a second stage fluidized bed height, and a second stage sulfur capture efficiency. The first stage capture efficiency is given by:

$$
\eta_{\mathrm{s} 1}=\frac{\eta_{\mathrm{s}}-\eta_{\mathrm{s} 2}}{1-\eta_{\mathrm{s} 2}}
$$

The first stage bed height is given by:

$$
z_{1}=\left(\frac{a+b R}{\eta_{s 1}\left(1-\eta_{s 2}\right)-R}\right)\left\{\frac{\ln \left(1-\eta_{s 1}\right)}{k_{s}\left(T_{1}\right) P \rho_{s} A y_{i}}\right\}
$$

In the limiting case in which the second stage capture efficiency is the same as the overall capture efficiency, the first stage capture efficiency and bed height go to zero. Thus, the two-stage model can reduce to the special case of a single stage model.

An additional consideration in the two-stage model is the need to estimate the bed temperatures for both stages. To estimate the bed temperature requires developing a mass balance for the sorbent and flue gas in each stage. The energy balance is a function of the sorbent mass flow rate, which depends on $R$. Therefore, it is necessary to iterate on solutions for $R$ obtained from the kinetic-based models in Equations (51) and (53) and on solutions for the bed temperatures, which in turn affect the sulfation reaction rates. Such energy balance equations have been included in the computerized version of the two-stage absorber model.

The simplified energy balance for Staige 1 and Stage 2 of the absorber are given by:

$$
\begin{aligned}
& m_{s} c_{p, s}\left(T_{1}-T_{s}\right)+m_{f g} c_{p, f g}\left(T_{1}-T_{2}\right)+\Delta H_{r, 1}=0 \\
& m_{s} c_{p, s}\left(T_{2}-T_{1}\right)+m_{f g} c_{p, f g}\left(T_{2}-T_{f g}\right)+\Delta H_{r, 2}=0
\end{aligned}
$$

Assuming that the mass flow rates of flue gas and sorbent are approximately constant through the two stages of the absorber, and that the specific heats of both flue gas and sorbent are also approximately constant over the temperatures in the absorber inlet and outlet, Equations (57) and (58) can be solved for the first and second stage bed temperatures $T_{1}$ and $T_{2}$, respectively:

$$
\begin{gathered}
T_{1}=T_{2}+\frac{m_{f g} c_{p, f g}\left(T_{2}-T_{f g}\right)+\Delta H_{r, 2}}{m_{s} c_{p, s}} \\
T_{2}=\frac{\left(m_{s} c_{p, s}+m_{f g} c_{p, f g}\right)\left(m_{f g} c_{p, f g} T_{f g}-\Delta H_{r, 2}\right)+m_{s} c_{p, s}\left(m_{s} c_{p, s} T_{s}-\Delta H_{r, 1}\right)}{\left(m_{s} c_{p, s}+m_{f g} c_{p, f g}\right)^{2}-\left(m_{s} c_{p, s}\right)\left(m_{f g} c_{p, f g}\right)}
\end{gathered}
$$

The heats of reaction for each stage are based on the desulfurization and deNO $\mathrm{N}_{\mathrm{x}}$ reactions. For simplicity, it is assumed that all $\mathrm{NO}_{\mathbf{x}}$ reduction reactions occur in the second (lower) stage. In the 
special case where there is only a single stage absorber, the energy balance of Equations (59) and (60) are not valid. The temperature of the single fluidized bed may be estimated with the following model, assuming that the outlet sorbent and flue gas temperature is represented by $T_{2}$ :

$$
\mathrm{T}_{2}=\frac{\mathrm{m}_{\mathrm{s}} \mathrm{c}_{\mathrm{p}, \mathrm{s}} \mathrm{T}_{\mathrm{s}}+\mathrm{m}_{\mathrm{fg}} \mathrm{c}_{\mathrm{p}, \mathrm{fg}} \mathrm{T}_{\mathrm{fg}}-\Delta \mathrm{H}_{\mathrm{r}, \mathrm{total}}}{\mathrm{m}_{\mathrm{s}} \mathrm{c}_{\mathrm{p}, \mathrm{s}}+\mathrm{m}_{\mathrm{fg}} \mathrm{c}_{\mathrm{p}, \mathrm{fg}}}
$$

The two-stage absorber design offers an advantage over a single stage design in terms of reduced copper-to-sulfur ratio requirements for a given total sorbent inventory in the absorber vessel. An illustration of this is given in Figure 6. The available copper-to-sulfur molar ratio is shown with respect to the first stage sulfur removal efficiency. The total sulfur removal efficiency, and the total sorbent inventory in both stages of the absorber, are held constant at 90 percent and $829,500 \mathrm{lb}$, respectively. At a first stage removal efficiency of zero, only a single-stage absorber exists. The available $\mathrm{Cu} / \mathrm{S}$ ratio for this base case is 1.59. As shown in Figure 7, all of the sorbent is allocated into a single absorber stage. When a second stage is added to the absorber design, the sulfur removal burden may be allocated between the two stages. As the sulfur removal efficiency in the first (upper) stage of the absorber increases, the sulfur removal efficiency in the second (lower) stage decreases. The portion of the total sorbent inventory allocated to the first stage increases non-linearly with first stage sulfur removal efficiency, as shown in Figure 7. The available $\mathrm{Cu} / \mathrm{S}$ ratio reaches a minimum value of 1.23 at a first stage removal efficiency of approximately 83 percent, which corresponds to a second stage removal efficiency of approximately 40 percent. This represents a reduction in sorbent circulation rate of approximately 23 percent, while holding total sorbent bed inventory constant. These results clearly illustrate that a two stage design can yield substantial economic benefits compared to a single stage design.

If the total sorbent inventory in the absorber is allowed to increase, the sorbent circulation rate can be reduced further. For example, if we fix the second (lower) stage bed hieght at 48 inches, and the total sulfur removal efficiency at 90 percent, then the first stage bed height will vary as the removal efficiency of the second stage varies. An example of this analysis is shown in Figure 8. Again, the model reduces to the base case single stage absorber design when the sulfur removal efficiency of the second stage is set at 90 percent: the first stage bed height is zero and the available $\mathrm{Cu} / \mathrm{S}$ ratio is 1.59 . As the second stage removal efficiency is reduced, then sorbent must be added to the first stage bed to achieve the required overall sulfur removal efficiency. As more sorbent is added to the first stage, the total sorbent inventory increases, but the sorbent circulation decreases. For example, at a second stage removal efficiency of 29.4 percent, the required first stage bed height is 48 inches and the available $\mathrm{Cu} / \mathrm{S}$ ratio is 0.98 , a 38 percent reduction from the base case. However, the sorbent bed inventory is increased by 100 percent. (By contrast, if the same bed inventory were contained in a single $96 \mathrm{inch}$ bed, the required available $\mathrm{Cu} / \mathrm{S}$ ratio would 
be 1.16). The trade-offs between reduced sorbent circulation rate and increased bed inventory must be evaluated based on process economics.

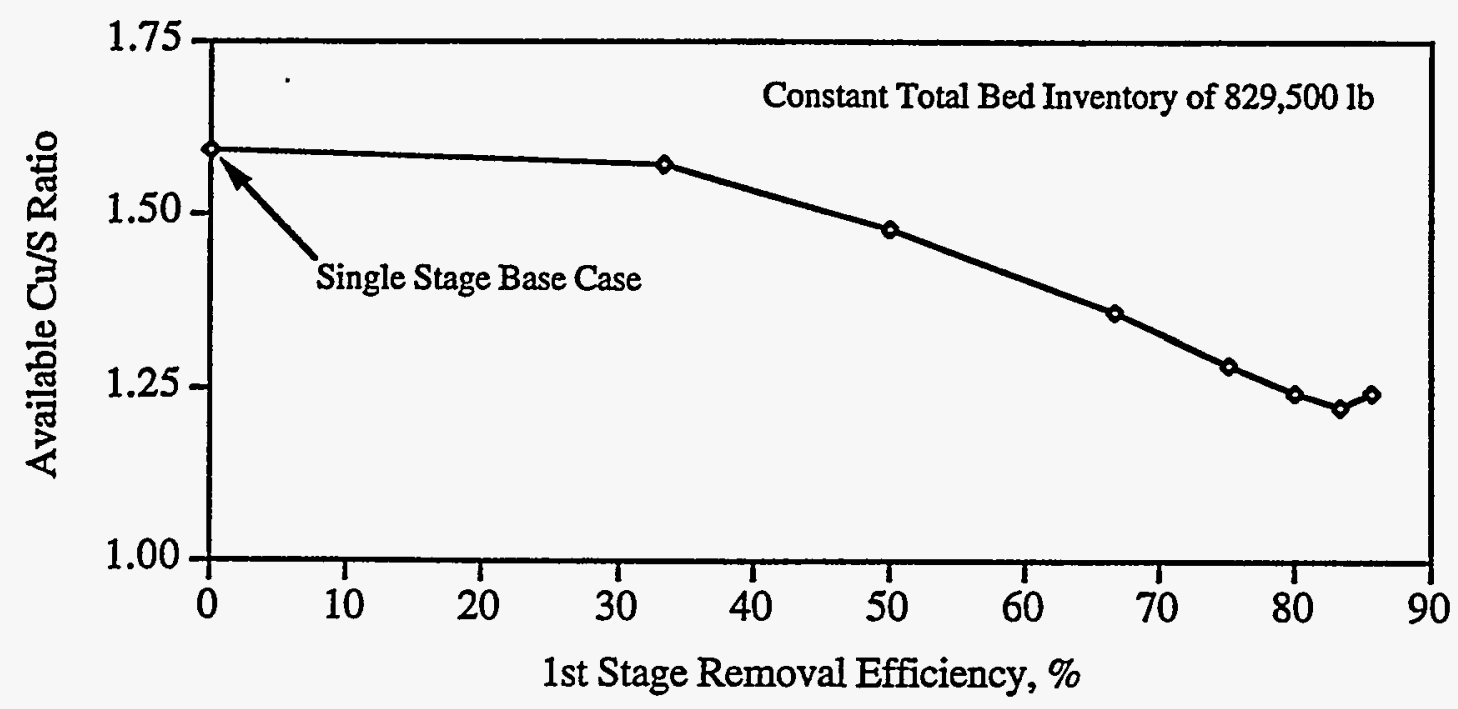

Figure 6. Sensitivity of the $\mathrm{Cu} / \mathrm{S}$ Ratio to Distribution of Sorbent in Two Fluidized Beds

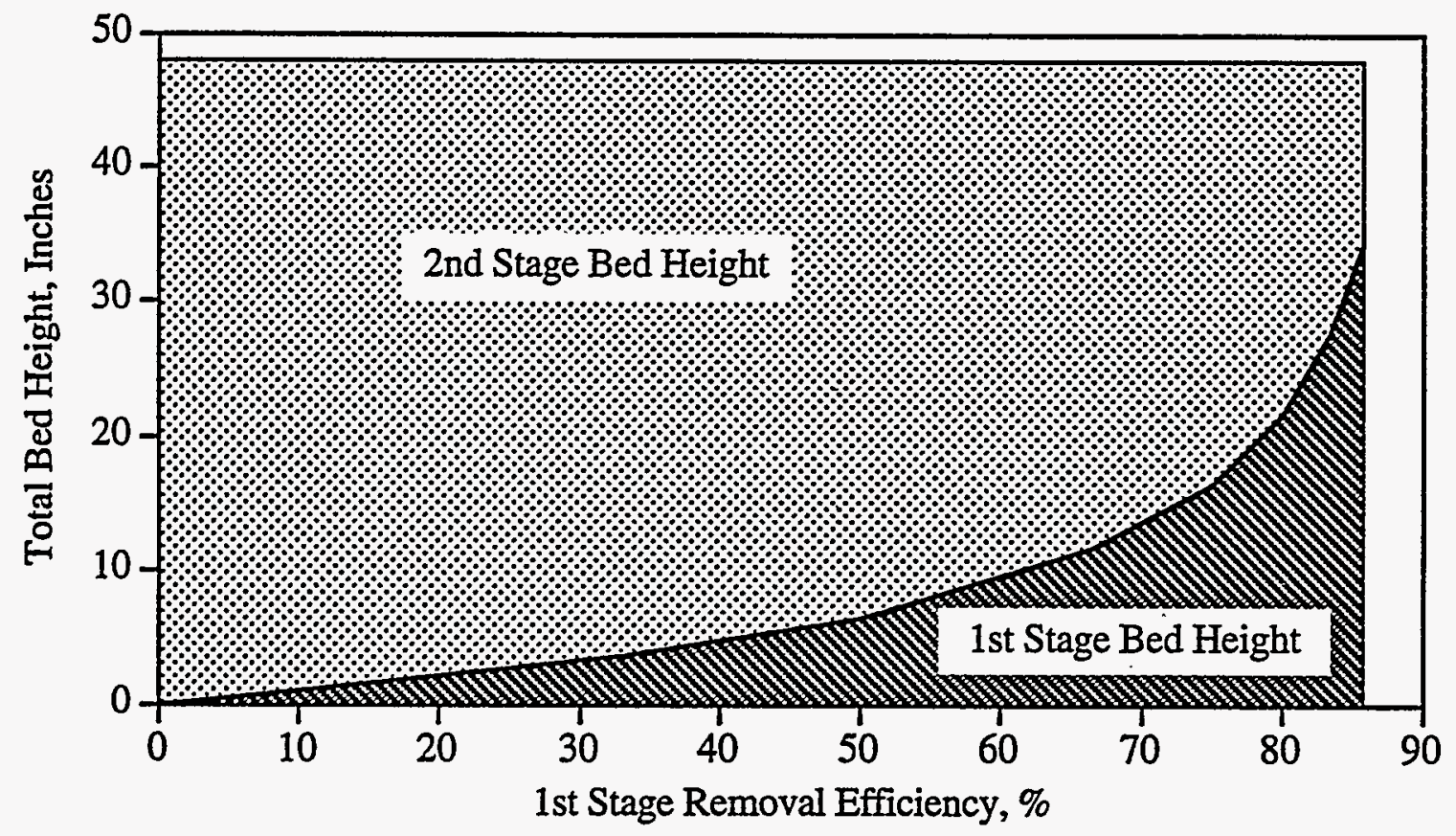

Figure 7. Distribution of Sorbent Between Two Absorber Stages with Constant Total Sorbent Inventory 


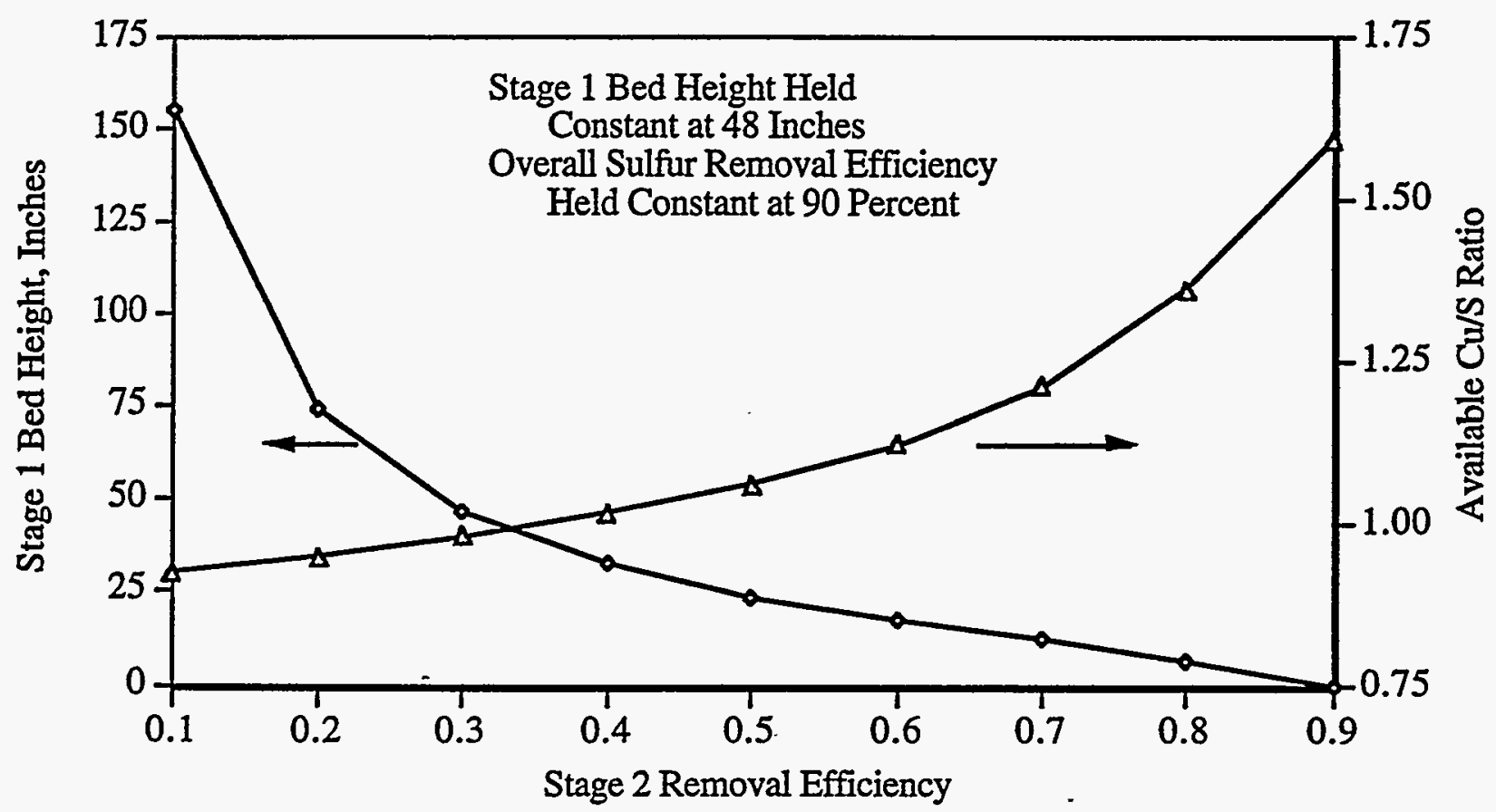

Figure 8. Sensitivity Analysis of the Two-Stage Absorber Model

\subsection{Regeneration Performance Model}

The key chemical equations governing the performance of the regenerator are given by Equations (5) to (8). The regenerator mass and energy balance for the copper oxide model developed by Frey (1987) is revised here based on the need to account for the potential formation of copper sulfite in the regenerator (Harriot, 1992c; Harriot and Markussen, 1992). Furthermore, a kinetic model developed by Harriott is used to estimate regenerator residence time associated with regeneration of copper sulfate.

\subsubsection{Regenerator Mass Balance}

The mass balance for sorbent in the regenerator is given by Equations (24) to (30). At the regenerator inlet, the molar fraction of total copper in the sorbent which is in the form of copper sulfate is given by:

$$
\mathrm{x}_{\mathrm{CuSO}_{4}}=\frac{\left(\mathrm{R}_{\mathrm{CuSO}_{4}}+\eta_{\mathrm{s}}\right)}{\mathrm{R}_{\mathrm{tot}}}
$$

The mass balance for gaseous species in the regenerator includes methane at the regenerator inlet, and regeneration off-gas containing methane, sulfur dioxide, carbon dioxide, and water vapor. 
The total amount of methane required for regeneration is estimated per Harriott (1992c) based on the minimum requirement for 100 percent regeneration and a multiplier for excess methane. For each mole of copper sulfate, one-half mole of methane is required, and for each mole of copper oxide or copper sulfite, one-quarter mole of methane is required, as indicated by equations (7) and (8). Thus, the total methane requirement is:

$$
\mathrm{M}_{\mathrm{CH}_{4}, \mathrm{R}, \mathrm{i}}=\mathrm{R}_{\mathrm{CH}_{4}}\left[0.5 \mathrm{x}_{\mathrm{CuSO}_{4}}+0.25\left(1-\mathrm{x}_{\mathrm{CuSO}_{4}}\right)\right] \mathrm{R}_{\mathrm{tot}} \mathrm{M}_{\mathrm{SO}_{\mathrm{x}}}
$$

The amount of sulfur dioxide produced depends on the fraction of copper oxide converted to copper sulfite and the actual regeneration efficiencies for copper sulfite and copper sulfate. Sulfur dioxide is consumed by the conversion of copper oxide to copper sulfite, while it is produced by the regeneration of both copper sulfite and copper sulfate. The net production of sulfur dioxide is given by:

$$
\mathrm{M}_{\mathrm{SO}_{2}, \mathrm{R}, 0}=\left[\eta_{\mathrm{r} 2} \mathrm{x}_{\mathrm{CuSO}_{4}}+\left(\eta_{\mathrm{r} 1}-1\right) \mathrm{x}_{1}\left(1-\mathrm{x}_{\mathrm{CuSO}_{4}}\right)\right] \mathrm{R}_{\mathrm{tot}} \mathrm{M}_{\mathrm{SO}_{\mathrm{x}}}
$$

Water vapor is produced in all three of the assumed regeneration reactions. Thus, the total amount of water vapor produced is:

$$
\mathrm{M}_{\mathrm{H}_{2} \mathrm{O}, \mathrm{R}, 0}=\left\{\eta_{\mathrm{r} 2} \mathrm{x}_{\mathrm{CuSO}_{4}}+0.5\left(1-\mathrm{x}_{\mathrm{CuSO}_{4}}\right)\left[\eta_{\mathrm{r} 1} \mathrm{x}_{1}+\eta_{\mathrm{r} 3}\left(1-\mathrm{x}_{1}\right)\right]\right\} \mathrm{R}_{\mathrm{tot}} \mathrm{M}_{\mathrm{SO}_{\mathrm{x}}}
$$

For each mole of water vapor produced, one-half mole of carbon dioxide is produced as shown in Equations (6), (7) and (8). Therefore, the total molar amount of carbon dioxide produced is:

$$
\mathrm{M}_{\mathrm{CO}_{2}, \mathrm{R}, \mathrm{o}}=0.5 \mathrm{M}_{\mathrm{H}_{2} \mathrm{O}, \mathrm{R}, \mathrm{o}}
$$

The molar amount of methane consumed in the regenerator is the same as the molar amount of carbon dioxide produced. Therefore, the net amount of methane exiting the regenerator is given by:

$$
\mathrm{M}_{\mathrm{CH}_{4}, \mathrm{R}, \mathrm{O}}=\mathrm{M}_{\mathrm{CH}_{4}, \mathrm{R}, \mathrm{i}}-\mathrm{M}_{\mathrm{CO}_{2}, \mathrm{R}, \mathrm{O}}
$$

\subsubsection{Regenerator Energy Balance}

The regenerator energy balance is calculated based on the sorbent and gas mass balance given above, and the energy released or absorbed by the chemical reactions occuring in the regenerator. A total of four chemical reactions are assumed to occur within the regenerator and each has an associated heat of reaction.

For the reaction of copper oxide to form copper sulfite (Equation (5)), a heat of reaction cannot be calculated based on heats of formation because thermodynamic data for copper sulfite are not available in the standard reference literature (e.g., Barin and Knacke, 1973; Barin, I., O. 
Knacke, and O. Kubaschewski, 1977; Chase et al., 1985). Harriott (1992c) estimated a heat of reaction based on data for $\mathrm{SO}_{2}$ oxidation and $\mathrm{CuSO}_{4}$ formation. The estimated heat of reaction is $\Delta \mathrm{H}_{1}=-93,240 \mathrm{Btu} / \mathrm{lbmole}$ CuO.

Heats of reaction for the regeneration of copper sulfate and copper oxide (Equations (6) and

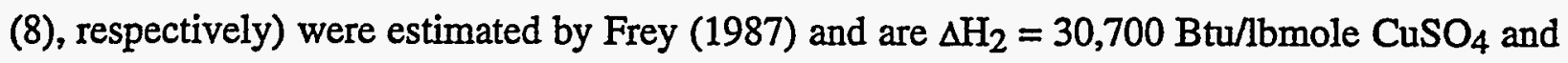
$\Delta \mathrm{H}_{3}=-19,380 \mathrm{Btu} / \mathrm{lbmole} \mathrm{CuO}$, respectively. The heat of reaction for the regeneration of copper sulfite was estimated based on the heats of reaction for the regeneration of copper oxide and the conversion of copper oxide to copper sulfite:

$$
\begin{aligned}
\mathrm{CuO}_{(\mathrm{s})}+\mathrm{SO}_{2(\mathrm{~g})} \rightarrow \mathrm{CuSO}_{3(\mathrm{~s})} & \Delta \mathrm{H}_{1}=-93,240 \mathrm{Btu} / \mathrm{lbmole} \mathrm{CuO} \\
\mathrm{CuSO}_{3(\mathrm{~s})}+\frac{1}{4} \mathrm{CH}_{4}(\mathrm{~g}) \rightarrow \mathrm{Cu}(\mathrm{s})+\mathrm{SO}_{2(\mathrm{~g})}+\frac{1}{4} \mathrm{CO}_{2(\mathrm{~g})}+\frac{1}{2} \mathrm{H}_{2} \mathrm{O}_{(\mathrm{g})} & \Delta \mathrm{H}_{4}=?
\end{aligned}
$$

Thus:

$$
\Delta \mathrm{H}_{4}=\Delta \mathrm{H}_{3}-\Delta \mathrm{H}_{1}=73,860 \mathrm{Btu} / \mathrm{lbmole} \mathrm{CuSO}_{3}
$$

The total heat of reaction for all chemical reactions in the regenerator is given by:

$$
\begin{aligned}
\Delta \mathrm{H}_{\mathrm{r}, \mathrm{tot}} & =\mathrm{x}_{1}\left(1-\mathrm{x}_{\mathrm{CuSO}_{4}}\right) \Delta \mathrm{H}_{1}+\eta_{\mathrm{r} 2} \mathrm{x}_{\mathrm{CuSO}_{4}} \Delta \mathrm{H}_{2} \\
+ & \eta_{\mathrm{r} 3}\left(1-\mathrm{x}_{1}\right)\left(1-\mathrm{x}_{\mathrm{CuSO}_{4}}\right) \Delta \mathrm{H}_{3}+\eta_{\mathrm{r} 1} \mathrm{x}_{1}\left(1-\mathrm{x}_{\mathrm{CuSO}_{4}}\right) \Delta \mathrm{H}_{4}
\end{aligned}
$$

The total molar flow of solids entering the regenerator is:

$$
\mathrm{M}_{\mathrm{s}, \mathrm{R}, \mathrm{i}}=\mathrm{M}_{\mathrm{Cu}, \mathrm{R}, \mathrm{i}}+\mathrm{M}_{\mathrm{CuO}, \mathrm{R}, \mathrm{i}}+\mathrm{M}_{\mathrm{CuSO}_{3}, \mathrm{R}, \mathrm{i}}+\mathrm{M}_{\mathrm{CuSO}_{4}, \mathrm{R}, \mathrm{i}}+\mathrm{M}_{\mathrm{Al}_{2} \mathrm{O}_{3}, \mathrm{R}, \mathrm{i}}
$$

The solids enter at a specified temperature $T_{R, i}$, which is the same as the solids heater outlet temperature. The enthalpy of the solids entering the regenerator is given by:

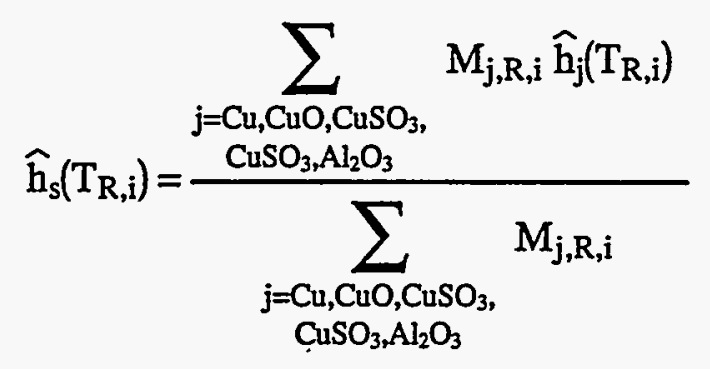

The total molar flow and enthalpy of the solids at the regenerator outlet are similarly calculated.

Because thermodynamic data for copper sulfite are not available, the enthalpy of copper sulfite is estimated based on a multiplier and the enthalpy of copper sulfate: 


$$
\widehat{\mathrm{h}}_{\mathrm{CuSO}_{3}}(\mathrm{~T})=\mathrm{r}_{\mathrm{h}} \widehat{\mathrm{h}}_{\mathrm{CuSO}_{4}}(\mathrm{~T})
$$

The value of the multiplier is estimated to be between 0.7 and 0.9 , based on comparison of the specific heats of copper oxide, copper sulfate, sulfur dioxide, and oxygen at a temperature of 500 ${ }^{\circ} \mathrm{C}$. The lower bound is based on comparing the specific heats of copper oxide and sulfur dioxide to the specific heat of copper sulfate, while the upper number is based on comparing the specific heat of copper sulfate minus oxygen to copper sulfate. A most likely value is assumed to be 0.8 . This parameter can be treated as a probability distribution in the IECM pending development of thermodynamic data for copper sulfite.

The only inlet gas is methane, which enters at a temperature of $\mathrm{T}_{\mathrm{CH}_{4}, \mathrm{R}, \mathrm{i}}$. The total molar flow of the off-gases is:

$$
\mathrm{M}_{\mathrm{OG}, \mathrm{R}, \mathrm{o}}=\mathrm{MSO}_{2, \mathrm{R}, \mathrm{o}}+\mathrm{M}_{\mathrm{H}_{2} \mathrm{O}, \mathrm{R}, \mathrm{o}}+\mathrm{M}_{\mathrm{CO}_{2}, \mathrm{R}, \mathrm{o}}+\mathrm{M}_{\mathrm{CH}_{4}, \mathrm{R}, \mathrm{o}}
$$

The off-gas is assumed to exit at the same temperature as the solids inlet. Therefore, the average enthalpy of the off-gas is given by:

$$
\hat{\mathrm{h}}_{\mathrm{OG}}\left(\mathrm{T}_{\mathrm{R}, \mathrm{i}}\right)=\frac{\sum_{\substack{\mathrm{j}=\mathrm{SO}_{2}, \mathrm{H}_{2} \mathrm{O}, \mathrm{CO}_{2}, \mathrm{CH}_{4}}} \mathrm{M}_{\mathrm{j}, \mathrm{R}, \mathrm{o}} \widehat{\mathrm{h}}_{\mathrm{j}}\left(\mathrm{T}_{\mathrm{R}, \mathrm{i}}\right)}{\sum_{\substack{\mathrm{j}=\mathrm{SO}_{2}, \mathrm{H}_{2} \mathrm{O}, \mathrm{CO}_{2}, \mathrm{CH}_{4}}} \mathrm{M}_{\mathrm{j}, \mathrm{R}, \mathrm{O}}}
$$

The only unknown to be calculated in the energy balance is the temperature of the sorbent leaving the regenerator. The energy balance is given by:

$$
M_{s, R, o} \widehat{h}_{s}\left(T_{s, R, o}\right)+M_{O G, R, o} \widehat{h}_{O G}\left(T_{R, i}\right)+\Delta H_{r, t o t}=M_{s, R, i} \widehat{h}_{s}\left(T_{R, i}\right)+M_{C_{4}, R, i} \widehat{h}_{C_{4}}\left(T_{C_{H}, R, i}\right)
$$

To facilitate an explicit equation for the sorbent outlet temperature, the term for the outlet sorbent molar flow and enthalpy can be rewritten as:

$$
M_{s, R, 0} \widehat{h}_{s}\left(T_{s, R, o}\right)=M_{s, R, o}\left[\widehat{h}_{s}\left(T_{R, i}\right)+c_{p, s}\left(T_{s, R, o}-T_{R, i}\right)\right]
$$

Thus, the temperature of the sorbent exiting the regenerator is given by:

$T_{s, R, o}=T_{R, i}+\frac{M_{s, R, i} \widehat{h}_{s}\left(T_{R, i}\right)+M_{C_{4}, R, i} \widehat{h}_{C H_{4}}\left(T_{C H_{4}, R, i}\right)-M_{s, R, 0} \widehat{h}_{s}\left(T_{R, i}\right)-M_{O G, R, 0} \widehat{h}_{O G}\left(T_{R, i}\right)-\Delta H_{r, t o t}}{M_{s, R, o} c_{p, s}}$ 


\subsubsection{Regenerator Residence Time}

A kinetic model developed by Harriott and Markussen (1992) and Harriott (1992c) is used to estimate the residence time for the regeneration of copper sulfate. This model requires the development of a temperature profile within the regenerator. A schematic of this model is shown in Figure 9.

At a point "just inside" the regenerator, it is assumed that.copper oxide has reacted to form copper sulfite. Thus, a mass and energy balance is developed for the uppermost portion of the regenerator in which this reaction occurs. The molar sorbent composition after the formation of copper sulfite is given by:

$$
\begin{gathered}
\mathrm{M}_{\mathrm{CuO}_{3}, \mathrm{R}, \mathrm{I}}=\left(1-\mathrm{x}_{1}\right)\left(\mathrm{R}-\eta_{\mathrm{s}}\right) \cdot \mathrm{M}_{\mathrm{SO}_{\bar{x}}, \mathrm{~A}, \mathrm{i}} \\
\mathrm{M}_{\mathrm{CuSO}_{3}, \mathrm{R}, \mathrm{I}}=\mathrm{x}_{1}\left(\mathrm{R}-\eta_{\mathrm{s}}\right) \cdot \mathrm{M}_{\mathrm{SO}_{x}, \mathrm{~A}, \mathrm{i}} \\
\mathrm{M}_{\mathrm{CuSO}_{4}, \mathrm{R}, \mathrm{I}}=\left(\mathrm{R}+\eta_{\mathrm{s}}\right) \cdot \mathrm{M}_{\mathrm{SO}_{x}, \mathrm{~A}, \mathrm{i}}
\end{gathered}
$$

The molar gas composition just inside the regenerator is the same as that at the regenerator outlet, with the exception of the $\mathrm{SO}_{2}$ component due to the absorption of $\mathrm{SO}_{2}$ in the formation of copper sulfite. Therefore, the $\mathrm{SO}_{2}$ molar flow rate just inside the regenerator is given by:

$$
\mathrm{M}_{\mathrm{SO}_{2}, \mathrm{R}, \mathrm{I}}=\left[\eta_{\mathrm{r} 2} \mathrm{x}_{\mathrm{CuSO}_{4}}+\eta_{\mathrm{r} 1} \mathrm{x}_{1}\left(1-\mathrm{x}_{\mathrm{CuSO}_{4}}\right)\right] \mathrm{R}_{\mathrm{tot}} \mathrm{M}_{\mathrm{SO}_{\mathrm{x}} \mathrm{A}, \mathrm{i}}
$$

with the molar flow rates of the other species the same as given by Equations (64), (65), and (66).

The temperatures of the sorbent and the regeneration gases are assumed to be the same just inside the regenerator. Therefore, the temperature just inside the regenerator is:

$T_{R, J I}=T_{R, i}+\frac{M_{O G, R, 0} \hat{h}_{O G}\left(T_{R, i}\right)-M_{s, R, i} \widehat{h}_{s}\left(T_{R, i}\right)+M_{s, R, J I} \widehat{h}_{s}\left(T_{R, i}\right)-M_{O G, R, I I} \widehat{h}_{O G}\left(T_{R, i}\right)+\Delta H_{r, J I}}{M_{O G, R, I I} c_{p, O G}-M_{s, R, I I} c_{p, s}}$

where:

$$
\Delta \mathrm{H}_{\mathrm{r}, \mathrm{I}}=\mathrm{x}_{1}\left(1-\mathrm{x}_{\mathrm{CuSO}_{4}}\right) \Delta \mathrm{H}_{\mathrm{r}, 1} \mathrm{R}_{\mathrm{tot}} \mathrm{MSO}_{\mathrm{x}}, \mathrm{A}, \mathrm{i}
$$

For small increments of conversion of copper sulfate to copper, a mass and energy balance is calculated to estimate the temperature profile in the reactor. This temperature profile is then used to estimate the average reaction rates for each increment, and the overall reaction residence time. If the number of increments in the kinetic model is $\mathrm{n}$, then the incremental copper sulfate conversion is: 


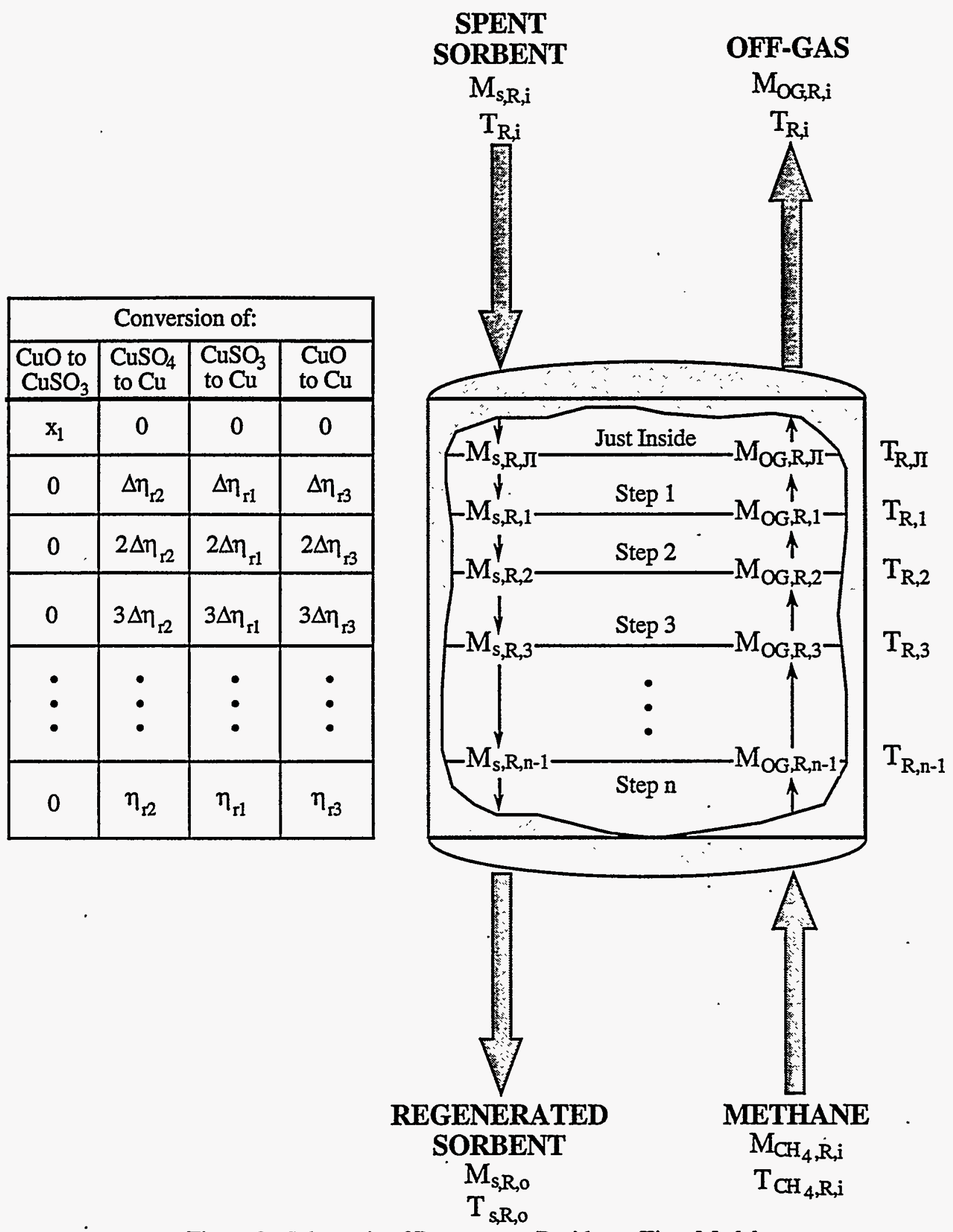

Figure 9. Schematic of Regenerator Residence Time Model. 


$$
\Delta \eta_{\mathrm{r} 2}=\frac{\eta_{\mathrm{r} 2}}{\mathrm{n}}
$$

Similarly, the conversion increments for regeneration of copper sulfite and copper oxide are assumed to be:

$$
\begin{aligned}
\Delta \eta_{\mathrm{r} 1} & =\frac{\eta_{\mathrm{r} 1}}{\mathrm{n}} \\
\Delta \eta_{\mathrm{r} 3} & =\frac{\eta_{\mathrm{r} 3}}{\mathrm{n}}
\end{aligned}
$$

There are $\mathrm{n}$ regeneration increments. At the end of each regeneration increment, $k(k=1, n)$, the sorbent composition is:

$$
\begin{gathered}
\mathrm{M}_{\mathrm{Cu}, \mathrm{R}, \mathrm{k}}=\mathrm{k}\left\{\left[\Delta \eta_{\mathrm{r} 3}\left(1-\mathrm{x}_{1}\right)+\Delta \eta_{\mathrm{r} 1} \mathrm{x}_{1}\right]\left(\mathrm{R}-\eta_{\mathrm{s}}\right)+\Delta \eta_{\mathrm{r} 2}\left(\mathrm{R}_{\mathrm{CuSO}_{4}}+\eta_{\mathrm{s}}\right)\right) \cdot \mathrm{M}_{\mathrm{SO}_{\mathrm{x}} \mathrm{A}, \mathrm{i}} \\
\mathrm{M}_{\mathrm{CuO}, \mathrm{R}, \mathrm{k}}=\left[\left(1-\mathrm{x}_{1}\right)\left(1-\mathrm{k} \Delta \eta_{\mathrm{r} 3}\right)\left(\mathrm{R}-\eta_{\mathrm{s}}\right)\right] \cdot \mathrm{M}_{\mathrm{SO}_{x}, \mathrm{~A}, \mathrm{i}} \\
\mathrm{M}_{\mathrm{CuSO}_{3, \mathrm{R}, \mathrm{k}}}=\left[\mathrm{x}_{1}\left(1-\mathrm{k} \Delta \eta_{\mathrm{r} 1}\right)\left(\mathrm{R}-\eta_{\mathrm{s}}\right)\right] \cdot \mathrm{M}_{\mathrm{SO}_{x}, \mathrm{~A}, \mathrm{i}} \\
\mathrm{M}_{\mathrm{CuSO}_{4, \mathrm{R}, \mathrm{k}}}=\left\{\left(1-\mathrm{k} \Delta \eta_{\mathrm{r} 2}\right)\left(\mathrm{R}_{\mathrm{CuSO}_{4}}+\eta_{\mathrm{s}}\right)\right\} \cdot \mathrm{M}_{\mathrm{SO}_{x}, \mathrm{~A}, \mathrm{i}}
\end{gathered}
$$

The molar flow rate of the components of the regeneration gases at the bottom of each increment is given by:

$$
\begin{gathered}
\mathrm{M}_{\mathrm{SO}_{2}, \mathrm{R}, \mathrm{k}}=\left\{(1-\mathrm{k}) \Delta \eta_{\mathrm{r} 2} \mathrm{x}_{\mathrm{CuSO}_{4}}+\left[(1-\mathrm{k}) \Delta \eta_{\mathrm{r} 1}-1\right] \mathrm{x}_{1}\left(1-\mathrm{x}_{\mathrm{CuSO}}\right)\right\} \mathrm{R}_{\mathrm{tot}} \mathrm{M}_{\mathrm{SO}_{\mathrm{x}}} \\
\mathrm{M}_{\mathrm{H}_{2} \mathrm{O}, \mathrm{R}, \mathrm{k}}=(1-\mathrm{k})\left\{\Delta \eta_{\mathrm{r} 2} \mathrm{x}_{\mathrm{CuSO}_{4}}+0.5\left(1-\mathrm{x}_{\mathrm{CuSO}}\right)\left[\Delta \eta_{\mathrm{r} 1} \mathrm{x}_{1}+\Delta \eta_{\mathrm{r} 3}\left(1-\mathrm{x}_{1}\right)\right]\right\} \mathrm{R}_{\mathrm{tot}} \mathrm{M}_{\mathrm{SO}_{\mathrm{x}}} \\
\mathrm{M}_{\mathrm{CO}_{2}, \mathrm{R}, \mathrm{k}}=0.5 \mathrm{M}_{\mathrm{H}_{2} \mathrm{O}, \mathrm{R}, \mathrm{k}} \\
\mathrm{M}_{\mathrm{CH}_{4}, \mathrm{R}, \mathrm{k}}=\mathrm{M}_{\mathrm{CH}_{4}, \mathrm{R}, \mathrm{i}}-\mathrm{M}_{\mathrm{CO}_{2}, \mathrm{R}, \mathrm{k}}
\end{gathered}
$$

The heat of reaction for each conversion step in the regenerator is:

$$
\Delta \mathrm{H}_{\mathrm{r}, \mathrm{k}}=\Delta \eta_{\mathrm{r} 2} \mathrm{x}_{\mathrm{CuSO}_{4}} \Delta \mathrm{H}_{2}+\Delta \eta_{\mathrm{r} 3}\left(1-\mathrm{x}_{1}\right)\left(1-\mathrm{x}_{\mathrm{CuSO}_{4}}\right) \Delta \mathrm{H}_{3}+\Delta \eta_{\mathrm{r} 1} \mathrm{x}_{1}\left(1-\mathrm{x}_{\mathrm{CuSO}_{4}}\right) \Delta \mathrm{H}_{4}
$$

and the temperature is:

$$
T_{R, k}=T_{R, k-1}+\left\{\begin{array}{c}
M_{O G, R, k-1} \hat{h}_{O G}\left(T_{R, k-1}\right)-M_{s, R, k-1} \widehat{h}_{s}\left(T_{R, k-1}\right) \\
+M_{s, R, k} \widehat{h}_{s}\left(T_{R, k-1}\right)-M_{O G, R, k} \widehat{h}_{O G}\left(T_{R, k-1}\right)+\Delta H_{r, k} \\
M_{O G, R, k} c_{p, O G}-M_{s, R, k} c_{p, s}
\end{array}\right\}
$$

The rate constant for the regeneration of copper sulfate is: 
Table 3. Regenerator Residence Time Model Input Assumptions

\begin{tabular}{lccc}
\hline Model Parameter & $\begin{array}{c}\text { Deterministic } \\
\text { (Nominal) Value }\end{array}$ & $\begin{array}{c}\text { Probability } \\
\text { Distribution }\end{array}$ & Values $^{\mathrm{a}}$ \\
\hline Methane Inlet Temperature & $\mathbf{7 7} \% \mathrm{~F}$ & $\cdot$ & \\
Sorbent Copper Loading & $7 \mathrm{wt}-\%$ & Triangular & $5,7,9 \mathrm{wt}-\%$ \\
Regenerator Inlet Temperature & $900 \% \mathrm{~F}$ & Triangular & $850,900,910 \%$ \\
Absorber SO2 Removal Efficiency & $90 \%$ & Triangular & $70,90,95 \%$ \\
Copper Sulfate Regeneration Efficiency & $80 \%$ & Triangular & $70,80,95 \%$ \\
Copper Sulfite Regeneration Efficiency & $40 \%$ & Triangular & $40,40,80 \%$ \\
Copper Oxide Regeneration $\mathrm{Efficiency}_{\text {Conversion of CuO to CuSO }}$ & $80 \%$ & Triangular & $70,80,95 \%$ \\
Available Cu/S Ratio & $100 \%$ & Uniform & $0-100 \%$ \\
Excess Methane Ratio & 1.3 & Triangular & $1.5,2.0,3.0$ \\
\hline
\end{tabular}

a For uniform dist. actual ranges of values are shown. For triangular distrib., endpoints and mode are shown.

$$
\mathrm{k}_{\mathrm{s}, \mathrm{I}}=\left\{\begin{array}{c}
4.2 \times 10^{7} \cdot \mathrm{F}_{\mathrm{w}} \cdot \exp \left(\frac{-21,700}{\mathrm{~T}}\right) \text { if } \mathrm{T} \leq 1,355{ }^{\circ} \mathrm{R} \\
11.2 \times 10^{5} \cdot \mathrm{F}_{\mathrm{w}} \cdot \exp \left(\frac{-16,800}{\mathrm{~T}}\right) \text { if } \mathrm{T}>1,355 \text { oR }
\end{array}\right\}
$$

where the factor Fw is a correction based on the sorbent copper loading (Harriott, 1993):

$$
F_{w}=2.04 \exp \left(-14.23 W_{C u}\right)
$$

and the reaction rate is:

$$
\begin{gathered}
\mathrm{r}_{\mathrm{k}}=\frac{\mathrm{k}_{\mathrm{s}, \mathrm{R}, \mathrm{k}} \mathrm{P}_{\mathrm{CH}_{4, \mathrm{k}}}\left(\eta_{\mathrm{r} 2, \mathrm{eq}, \mathrm{k}}-\mathrm{k} \Delta \eta_{\mathrm{r} 2}\right)}{1+\mathrm{K}_{1} \mathrm{P}_{\mathrm{CH}_{4, \mathrm{k}}}+\mathrm{K}_{2} \mathrm{P}_{\mathrm{SO}_{2, \mathrm{k}}}+\mathrm{K}_{3} \mathrm{P}_{\mathrm{CO}_{2}, \mathrm{k}}} \\
\eta_{\mathrm{r} 2, \mathrm{eq}, \mathrm{k}}=1:-0.9 \mathrm{P}_{\mathrm{CH}_{4, \mathrm{k}}}
\end{gathered}
$$

The average reaction rate for each conversion interval is:

$$
\mathrm{I}_{\mathrm{k}, \text { ave }}=\frac{\mathrm{r}_{\mathrm{k}-1}+\mathrm{r}_{\mathrm{k}}}{2}
$$

and the total residence time required for regeneration of copper sulfate is:

$$
\mathrm{t}_{\mathrm{r}, \mathrm{CuSO}_{4}}=\sum_{\mathrm{k}=1}^{\mathrm{n}} \frac{\Delta \eta_{\mathrm{r} 2}}{\mathrm{r}_{\mathrm{k}, \text { ave }}}
$$

A simplified response surface model for residence time was developed based on statistical analysis of the residence time model. Eight of the residence time model input parameters were assigned probability distributions representing possible ranges of values that might be expected in future model applications. These assumptions are given in Table 3. These distributions were sampled using Latin Hypercube sampling, a variant of Monte Carlo simulation, and the paired sets 
of sample values were used to calculate the corresponding residence times. A total of 100 sets of calculations were made. Linear regression analysis was used to correlated the resulting distribution of residence time values to each of the input distributions. The simplified model for regenerator residence time is:

$\mathrm{t}_{\mathrm{r}, \mathrm{CuSO}_{4}}=1.01 \cdot \exp \left\{8.31+0.10 \mathrm{~W}_{\mathrm{Cu}^{-}}-0.009 \mathrm{t}_{\mathrm{s}, \mathrm{R}, \mathrm{i}}+0.90 \eta_{\mathrm{s}}+3.76 \eta_{\mathrm{r} 2}-0.44 \mathrm{x}_{1}-0.39 \mathrm{R}-1.03 \mathrm{R}_{\mathrm{CH}_{4}}\right\}$

This regression model has a coefficient of determination $\left(R^{2}\right)$ of 0.95 . The standard error of the estimate of residence time is 1 minute. This model should not be extrapolated.

\subsection{ByProduct Recovery}

The regenerator off-gas is sent to a byproduct recovery plant for processing. As previously noted, elemental sulfur recovery using a Claus plant is the design basis for this study. A two-stage Allied Chemical design is assumed, based on previous studies (Ratafia-Brown, 1983; Rubin et al., 1991). The sulfur recovery efficiency for this design is estimated to be 95 percent, with the unconverted sulfur emitted as $\mathrm{SO}_{2}$ in the Claus plant tailgas. Thus, the overall sulfur removal efficiency if the copper oxide process removes 90 percent of sulfur oxides from the flue gas would be only 85.5 percent. Such a design is likely to be unacceptable compared to conventional flue gas desulfurization systems, which are capable of 90 percent or greater sulfur capture.

Three approaches are possible to improve the overall system $\mathrm{SO}_{\mathrm{x}}$ removal efficiency. These are: (1) increase the copper oxide removal efficiency to compensate for the Claus plant tailgas emissions; (2) recycle the tailgas emissions to the flue gas upstream of the fluidized bed absorber, and adjust the copper oxide removal efficiency; or (3) increase the sulfur capture efficiency of the Claus plant. The third option is not considered here, due to the need to obtain detailed design information that is not readily available. However, the first two options are considered in the copper oxide process performance model.

The first approach is easily modeled by adjusting the copper oxide sulfur oxides capture efficiency based on the sulfur recovery plant efficiency:

$$
\eta_{\mathrm{s}}=\frac{\eta_{\mathrm{s}, \mathrm{overall}}}{\eta_{\text {Claus }}}
$$

For example, if an overall removal efficiency of 90 percent is required, and if the Claus plant recovers only 95 percent of the sulfur in the regenerator offgas, then the copper oxide process sulfur removal efficiency must be 94.7 percent. Such an increase in removal efficiency will substantially increase the sorbent requirement. Depending on the design assumptions, an increase 
sorbent circulation rate of over 40 percent may be required. Therefore, it is unlikely that this is the lowest cost approach.

The second approach is modeled by injecting into the flue gas just upstream of the fluidized bed absorber an amount of $\mathrm{SO}_{2}$ equivalent to the sulfur molar flow in the Claus plant tailgas:

$$
\mathrm{MSO}_{2, \text { recycle }}=\left\{\frac{\left(1-\eta_{\text {Claus }}\right) \eta_{\mathrm{s}}}{1-\left(1-\eta_{\text {Claus }}\right) \eta_{\mathrm{s}}}\right\} \mathrm{MSO}_{2, \mathrm{FG}}
$$

The required absorber sulfur removal efficiency is given by:

$$
\eta_{s}=\frac{\eta_{s, \text { overall }}}{\eta_{\text {Claus }}+\left(1-\eta_{\text {Claus }}\right) \eta_{\mathrm{s}, \text { overall }}}
$$

In contrast to the example given above, the sulfur removal efficiency in the absorber is only 90.45 percent. Combined with the increased sulfur loading to the absorber, the tailgas recycle approach results in a modest increase in the sorbent circulation rate of typically less than 10 percent.

As part of process integration, the regeneration offgas must be dried and cooled prior to entering the sulfur recovery plant (Ratafia-Brown, 1983). A typical regenerator offgas is at a temperature of 875 to $910 \mathrm{~F}$, with a moisture content of 40 to 45 percent. The design basis for gas inlet to the Claus plant calls for a temperature of $500 \mathrm{oF}$ with a moisture content of only 6 percent. The net effect of the gas treatment and cooling is to generate superheated steam, which may be used elsewhere in the power plant.

\subsection{Energy Penalties and Credits}

The copper oxide process consumes electrical energy to operate blowers and compressors associated with the pneumatic solids transport system and the combustor for the sorbent heater. Due to the flue gas pressure drop across the fluidized bed absorber, additional electrical energy is required to operate the power plant induced draft fan. The sulfur recovery system consumes a relatively small amount of power.

The electrical requirements of the various fans are estimated using the "fan equation" (McQuiston and Parker, 1982):

$$
\mathrm{EC}_{\mathrm{fan}}=\frac{\dot{\mathrm{Q}} \Delta \mathrm{P}}{8,512 \eta_{\mathrm{fan}}}
$$

The fan efficiencies are assumed to be 85 percent. For the induced draft fan, the incremental pressure drop is estimated based on the fluidized bed height. For a 48 inch bed height, the pressure drop is approximately 28 inches of water (Frey, 1987). For the dense phase solids 
transport system between the regenerator and the absorber, the pressure drop is 22 psi (Roberts and Schaeffer, 1992). The pressure drop across the sorbent transport system between the absorber and the solids heater is estimated at 4.3 psi (Ratafia-Brown, 1983). The pressure drop across the solids heater combustor is estimated at 90 inches of water (Ratafia-Brown, 1983).

The copper oxide process and the sulfur recovery plant utilize methane for solids heating, sorbent regeneration, and regenerator offgas reduction. The methane represents an energy input into the power plant system.

Due to the exothermic reactions occuring in the fluidized bed absorber, as well as to the thermal energy added to the sorbent during solids heating, the temperature of the flue gas exiting the absorber is substantially higher than the inlet temperature. The temperature increase is typically on the order of $100 \mathrm{~F}$. This additional energy may be recovered by the power plant air preheater, and used to increase the temperature of the combustion air entering the boiler. The calculation of this energy credit is described by Rubin et al. (1991, pp. 27, 44-46).

The copper oxide process uses steam for ammonia vaporization and injection. However, the offgas pretreatment section of the sulfur recovery plant produces steam, as previously described. Typically, the net effect is an energy credit. The thermal value of the steam is converted to an electricity equivalent basis using the power plant gross steam cycle heat rate (excluding the boiler, see Rubin et al., 1991, p. 45 for details). 


\subsection{COST MODEL}

This section presents the economic model developed for the fluidized bed copper oxide process. The source of economic data for this model includes previous work by Frey (1987; 1991) as well as new data developed by A.E. Roberts and Associates (1994). The cost model is comprised of a capital cost model and an annual cost model.

\subsection{Capital Cost Models}

The capital cost of a complete fluidized bed copper oxide system includes the following major equipment items:

- Fluidized bed absorbers

- Ammonia Injection System

- Regenerator

- Solids Heater

- Sorbent Transport System

- Byproduct Recovery System

For each of these major systems, a direct capital cost model is developed.

\subsubsection{Fluidized Bed Absorbers}

The direct capital cost of the fluidized bed absorbers includes the absorber vessel, structural supports, dampers and isolation valves, refractory lining for the inside of the absorber, ductwork, instrumentation and control, and installation costs.

The absorber vessels are refractory-lined carbon steel of minimum one-half inch thickness. Each absorber vessel may be approximated as a cylinder. The internal diameter of the absorber vessel is determined based on the superficial gas velocity requirement. The materials cost of the absorber are proportional to the surface area of the absorber vessel.

The absorber vessel internal radius is given by:

$$
r_{a}=\sqrt{\frac{G_{F G}}{60 \pi V_{s} N_{a, 0}}}
$$

The diameter of the absorber vessel must be larger than this internal radius to accomodate the thickness of refractory lining. The design basis developed by A.E. Roberts and Associates (AERA) for the absorber includes a two-inch thick base or inner refractory covering the internal 
surface of the absorber vessel. A second "hot base" refractory layer approximately six inches thick is placed over the first layer. Thus, the vessel internal diameter is:

$$
r_{v, a}=r_{a}+t_{i r}+t_{h r}
$$

The surface area of the absorber vessel is approximated by the following equation for the surface area of a cylinder.

$$
S A_{a}=2 \pi\left(r_{v, a}\right)^{2}+2 \pi r_{v, a} h_{a}
$$

The design height of the absorber vessel is approximately 70 feet, based on the AERA design basis. The total height of the absorber assembly is larger when flue gas outlet ductwork is taken into consideration. The straight wall portion of the absorber vessel that is covered with refractory lining is approximately 35 feet.

The direct cost for the steel absorber vessel is estimated based on the ratio of surface areas referenced to a base case design. The AERA design is predicated on a flue gas volumetric flowrate of $500,000 \mathrm{scfm}$ at $705 \mathrm{oF}$ and a superficial gas velocity of $4.5 \mathrm{ft} / \mathrm{sec}$. Therefore, the required internal radius is 36.4 feet. Accounting for the 8 inch total thickness of the refractory, the steel vessel's internal diameter must be 37 feet. Therefore, the approximate surface area of the absorber vessel is $24,875 \mathrm{ft}^{2}$. The base cost estimate is $\$ 1,434,000$ (in 1993 dollars) for a single absorber vessel of this size. Therefore, the direct cost model for the cost of the steel absorber vessel is given by:

$$
\mathrm{DC}_{\mathrm{a}, \mathrm{v}}=1,434 \mathrm{~N}_{\mathrm{a}, \mathrm{T}}\left(\frac{\mathrm{SA}_{\mathrm{a}}}{24,875 \mathrm{ft}^{2}}\right) \frac{\mathrm{PCI}}{1993 \mathrm{PCI}}
$$

Typically, there will be two $50 \%$ capacity absorber vessels with no spares. The cost of refractory is given by the refractory surface area, required to cover the sides of the absorber vessel, and a unit cost for refractory per square foot:

$$
\mathrm{DC}_{\mathrm{a}, \mathrm{r}}=2 \pi \mathrm{r}_{\mathrm{a}} \mathrm{h}_{\mathrm{a}, \mathrm{sw}} \mathrm{N}_{\mathrm{a}, \mathrm{T}} \mathrm{UC}_{\mathrm{r}}
$$

In 1993, the unit cost of the total of 8 inches of refractory required for the absorber was approximately $\$ 55 / \mathrm{ft}^{2}$.

Each absorber requires structural supports. In the base case design, these are estimated at $\$ 100,000$ per vessel. The structural support is assumed here to have some economy of scale with respect to size. As a default assumption, a six-tenths scaling rule is assumed:

$$
\mathrm{DC}_{\mathrm{a}, \mathrm{S}}=100 \mathrm{~N}_{\mathrm{a}, \mathrm{T}}\left(\frac{\mathrm{SA}_{\mathrm{a}}}{24,875 \mathrm{ft}^{2}}\right)^{0.6} \frac{\mathrm{PCI}}{1993 \mathrm{PCI}}
$$


The surface area of the absorber vessel is used as a surrogate variable for the size of the absorber system and, hence, the proportional size of the structural supports.

The costs for flue gas ductwork, flue gas isolation valves, and dampers are assumed to be proportional to the flue gas volumetric flow rate. Moreover, economies of scale are assumed. In the absence of more detailed information, the following direct cost model was developed:

$$
\mathrm{DC}_{\mathrm{a}, \mathrm{d}}=300 \mathrm{~N}_{\mathrm{a}, \mathrm{T}}\left(\frac{\mathrm{G}_{\mathrm{FG}}}{1.1 \times 10^{6} \mathrm{ft}^{3} / \min \mathrm{N}_{\mathrm{a}, \mathrm{O}}}\right)^{0.6} \frac{\mathrm{PCI}}{1993 \mathrm{PCI}}
$$

In this model, the cost of ductwork, isolation valves, and dampers is estimated for a single absorber vessel, and is multiplied by the total number of absorber vessels.

The total direct cost for the absorber process area is given by:

$$
\mathrm{DC}_{\mathrm{a}}=\left(1+\mathrm{f}_{\mathrm{ic}, \mathrm{a}}\right)\left(\mathrm{DC}_{\mathrm{a}, \mathrm{v}}+\mathrm{DC}_{\mathrm{a}, \mathrm{r}}+\mathrm{DC}_{\mathrm{a}, \mathrm{s}}+\mathrm{DC}_{\mathrm{a}, \mathrm{d}}\right)
$$

where $\mathrm{f}_{\mathrm{ic}, \mathrm{a}}$ is an installation cost factor for the absorber process area. A default value of 0.45 is suggested.

In addition to these direct costs, there is an incremental cost associated with increasing the pressure drop of the flue gas. The differential cost required to "modify" a new induced draft fan has been modeled by Frey (1994). The energy requirement required to overcome the absorber flue gas pressure drop is:

$$
\mathrm{EC}_{\mathrm{ID}, \mathrm{dif}}=\frac{\mathrm{G}_{\mathrm{FG}} \Delta \mathrm{P}_{\mathrm{CuO}}}{8,512 \eta_{\mathrm{fan}} \mathrm{N}_{\mathrm{a}, \mathrm{O}}}
$$

The fan efficiency is typically 85 percent. The cost of the ID fan differential is:

$$
\mathrm{DC}_{\mathrm{DD}, \mathrm{dif}}=180 \mathrm{~N}_{\mathrm{a}, \mathrm{T}}\left(\frac{\mathrm{EC}_{\mathrm{D}, \mathrm{dif}}}{4,600}\right)^{0.6}\left(\frac{\mathrm{PCI}}{357.3}\right)
$$

\subsubsection{Ammonia Injection System}

Ammonia is injected into the flue gas upstream of the absorber vessel. The ammonia injection system is comprised of the following equipment, based on the AERA design basis:

- One ammonia storage tank per absorber vessel, plus one common spare tank

- One air compressor per storage tank

- One vaporizer per absorber vessel

- Injection probes and nozzles for each absorber inlet

- Control panels 
The cost of the ammonia injection system is most sensitive to the ammonia flow rate requirement for each absorber vessel. The ammonia flow rate requirement depends on the $\mathrm{NO}_{\mathrm{x}}$ loading into the absorbers and the ammonia-to- $\mathrm{NO}_{\mathrm{x}}$ molar ratio required to achieve a given level of $\mathrm{NO}_{\mathrm{x}}$ control. The total ammonia mass flow rate is given by:

$$
\mathrm{m}_{\mathrm{NH}_{3}}=\mathrm{MW}_{\mathrm{NH}_{3}} \mathrm{R}_{\mathrm{NH}_{3}} \mathrm{M}_{\mathrm{NO}_{x}}
$$

Storage to provide 30 days supply of ammonia is required under the design basis. The total ammonia storage requirement is distributed among several tanks, depending on how many absorber vessels are used. Therefore, the storage capacity of each tank is given by:

$$
\mathrm{C}_{\mathrm{NH}_{3}}=\frac{\mathrm{m}_{\mathrm{NH}_{3}} 24 \mathrm{D}_{\mathrm{NH}_{3}}}{(8.34 \mathrm{lb} / \text { gallon })\left(\mathrm{N}_{\mathrm{2}, \mathrm{O}}+1\right)}
$$

Based on Perry's Chemical Engineer's Handbook (6th Ed., p. 25-69), the exponential factor appropriate for horizontal tanks is 0.57 . Based on a previous cost estimate developed by AERA, the cost of an 80,000 gallon ammonia storage tank is approximately $\$ 235,000$. Therefore, the storage tank cost is given by:

$$
\mathrm{DC}_{\mathrm{a}, \mathrm{S}}=\left(1+\mathrm{f}_{\mathrm{ic}, \mathrm{ai}}\right) 235\left(\mathrm{~N}_{\mathrm{a}, \mathrm{O}}+1\right)\left(\frac{\mathrm{C}_{\mathrm{NH}_{3}}}{80,000}\right)^{0.57} \frac{\mathrm{PCI}}{1993 \mathrm{PCI}}
$$

The detailed costs for other components of the ammonia injection system are not disaggregated in the AERA cost estimate. However, based on a previous AERA estimate, the total cost of the ammonia injection system was estimated as $\$ 2.3$ million. This estimate was for an ammonia flow rate of $1,751 \mathrm{lb} / \mathrm{hr}$, but involved three 80,000 gallon storage tanks. Assuming an installation cost factor of 45 percent for the storage tanks, the net installed cost of the ammonia vaporization and injection system is $\$ 1.28$ million. This cost should scale with the ammonia flow rate. Frey (1994) developed a direct cost model of an ammonia injection system for selective catalytic reduction (SCR) in which the scaling exponent was found to be 0.482 . Therefore, the direct cost for the ammonia vaporization and injection components is estimated as:

$$
\mathrm{DC}_{\mathrm{ai}, \mathrm{v}}=17.5\left(\mathrm{~N}_{\mathrm{a}, \mathrm{T}}\right)\left(\mathrm{m}_{\mathrm{NH}_{3}}\right)^{0.482} \frac{\mathrm{PCI}}{1993 \mathrm{PCI}}
$$

The direct cost of the ammonia injection system is therefore:

$$
\mathrm{DC}_{\mathrm{ai}}=\mathrm{DC}_{\mathrm{ai}, \mathrm{S}}+\mathrm{DC}_{\mathrm{ai}, \mathrm{v}}
$$

\subsubsection{Regenerator}

The regenerator is a carbon steel cylindrical vessel. The regenerator is sized to accomodate sorbent storage for a specified sorbent residence time. In the base case, AERA has designed a 
regenerator with a sorbent hold-up volume of $8,800 \mathrm{ft}^{3}$. The regenerator design features a 28 foot straight wall height. Here, it is assumed that the straight wall height is held fixed, and the radius is adjusted to accomodate various residence times.

The required regenerator radius is therefore given by:

$$
\mathrm{r}_{R}=\sqrt{\frac{\mathrm{m}_{s, R, i} \mathrm{t}_{R}}{60 \rho_{s} \mathrm{~N}_{R, 0} \pi \mathrm{h}_{\mathrm{R}, \mathrm{w}}}}
$$

The total height of the regenerator is the straight wall height plus inlet and outlet clearances for gas flows. These clearances add approximately 17 feet to the straight wall height. The inside of the regenerator vessel walls are covered with two layers of refractory totalling 8 inches in thickness. Therefore, the steel vessel diameter is

$$
r_{v, R}=r_{R}+t_{i r}+t_{h r}
$$

The surface area of the regenerator vessel is approximated by the surface area of a cylinder.

$$
S A_{R}=2 \pi\left(r_{v, R}\right)^{2}+2 \pi r_{v, R} h_{R}
$$

In the base case, the regenerator has an equivalent overall height of 78 feet and a radius of 10 feet. The direct cost of the regenerator vessel is:

$$
\mathrm{DC}_{\mathrm{R}, \mathrm{v}}=475 \mathrm{~N}_{\mathrm{a}, \mathrm{R}}\left(\frac{\mathrm{SA}_{\mathrm{R}}}{5,530 \mathrm{ft}^{2}}\right) \frac{\mathrm{PCI}}{1993 \mathrm{PCI}}
$$

The direct cost of refractory is given by:

$$
D C_{R, r}=2 \pi r_{R} h_{R} N_{R, T} U C_{r}
$$

Each regenerator requires structural supports. In the base case design, these are estimated at $\$ 42,500$ per vessel. The structural support is assumed here to have some economy of scale with respect to size. As a default assumption, a six-tenths scaling rule is assumed:

$$
\mathrm{DC}_{\mathrm{R}, \mathrm{s}}=42.5 \mathrm{~N}_{\mathrm{a}, \mathrm{T}}\left(\frac{\mathrm{SA}_{\mathrm{a}}}{5,530 \mathrm{ft}^{2}}\right)^{0.6} \frac{\mathrm{PCI}}{1993 \mathrm{PCI}}
$$

The surface area of the absorber vessel is used as a surrogate variable for the size of the regenerator system and, hence, the proportional size of the structural supports.

The costs for ductwork, isolation valves, and dampers are assumed to be proportional to the regenerator offgas volume flow rate. Moreover, economies of scale are assumed. In the base case analysis, approximately $1,300 \mathrm{lbmole} / \mathrm{hour}$ of offgas is evolved from the regenerator. At 900 oF, the volumetric flow rate is $21,900 \mathrm{ft}^{3} / \mathrm{min}$. Thus, in the absence of more detailed information, the following direct cost model was developed: 


$$
\mathrm{DC}_{\mathrm{R}, \mathrm{d}}=350 \mathrm{~N}_{\mathrm{R}, \mathrm{T}}\left(\frac{\mathrm{G}_{\mathrm{OG}}}{626 \mathrm{lbmolehr} \mathrm{N}_{\mathrm{R}, \mathrm{O}}}\right)^{0.6} \frac{\mathrm{PCI}}{1993 \mathrm{PCI}}
$$

In this model, the cost of ductwork, isolation valves, and dampers is estimated for a single absorber vessel, multiplied by the total number of absorber vessels.

A methane feed system and a booster compressor and motor is required for the inlet methane to overcome the pressure drop through the regenerator. The booster compressor cost is assumed to be proportional to the methane flow rate. The cost equation is thus:

$$
\mathrm{DC}_{\mathrm{R}, \mathrm{bf}}=350 \mathrm{~N}_{\mathrm{R}, \mathrm{T}}\left(\frac{\mathrm{M}_{\mathrm{CH}_{4}, \mathrm{R}, \mathrm{i}}}{187 \mathrm{lbmolehr} \mathrm{N}_{\mathrm{R}, \mathrm{O}}}\right)^{0.6} \frac{\mathrm{PCI}}{1993 \mathrm{PCI}}
$$

The total direct cost for the absorber process area is given by:

$$
D C_{R}=\left(1+f_{i c, R}\right)\left(D C_{R, v}+D C_{R, r}+D C_{R, s}+D C_{R, d}+D C_{R, b f}\right)
$$

where $f_{i c, R}$ is an installation cost factor for the absorber process area. A default value of 0.45 is suggested.

\subsubsection{Solids Heater}

The solids heater is a carbon steel cylindrical vessel. In the base case, AERA has designed a solids heater with an internal radius of 10 feet and a height of 50 feet. The side walls of the heater are lined with refractory material. The internal diameter of the solids heater is proportional to the mass flow of sorbent entering the vessel. The vessel contains two sorbent beds in which hot combustion gases from a methane combustor contact the sorbent in counter-current flow. Thus, for fixed bed heights in each stage, the solids heater internal radius varies with the sorbent mass flow rate as follows:

$$
\mathrm{r}_{\mathrm{SH}}=10 \sqrt{\frac{\mathrm{m}_{\mathrm{s}, \mathrm{SH}, \mathrm{i}}}{400,000 \mathrm{~N}_{\mathrm{SH}, \mathrm{O}}}}
$$

The inside of the solids heater vessel walls are covered with two layers of refractory totalling 8 inches in thickness. Therefore, the steel vessel diameter is

$$
r_{v, S H}=r_{S H}+t_{i r}+t_{h r}
$$

The surface area of the solids heater vessel is approximated by the surface area of a cylinder. Thus, for a single vessel, the surface area is:

$$
\mathrm{SA}_{\mathrm{SH}}=2 \pi\left(\mathrm{r}_{\mathrm{v}, \mathrm{SH}}\right)^{2}+2 \pi \mathrm{r}_{\mathrm{v}, \mathrm{SH}} \mathrm{h}_{\mathrm{SH}}
$$


In the base case, the solids heater has an equivalent overall height of 50 feet and an internal radius of 10 feet. The direct cost of the regenerator vessel is:

$$
\mathrm{DC}_{\mathrm{SH}, \mathrm{v}}=360 \mathrm{~N}_{\mathrm{SH}, \mathrm{T}}\left(\frac{\mathrm{SA}_{\mathrm{SH}}}{4,060 \mathrm{ft}^{2}}\right) \frac{\mathrm{PCI}}{1993 \mathrm{PCI}}
$$

The direct cost of refractory is given by:

$$
D C_{S H, r}=2 \pi r_{S H} h_{S H} N_{S H, T} U C_{r}
$$

Each solids heater requires structural supports. In the base case design, these are estimated at $\$ 72,500$ per vessel. The structural support is assumed here to have some economy of scale with respect to size. As a default assumption, a six-tenths scaling rule is assumed:

$$
\mathrm{DC}_{\mathrm{SH}, \mathrm{S}}=72.5 \mathrm{~N}_{\mathrm{SH}, \mathrm{T}}\left(\frac{\mathrm{SA}_{\mathrm{a}}}{4,060 \mathrm{ft}^{2}}\right)^{0.6} \frac{\mathrm{PCI}}{1993 \mathrm{PCI}}
$$

The surface area of the solids heater vessel is used as a surrogate variable for the size of the solids heater system and, hence, the proportional size of the structural supports.

The costs for ductwork, isolation valves, dampers, and booster fans and motors are assumed to be proportional to the solids heater exit gas volumetric flow rate. Moreover, economies of scale are assumed. In the base case analysis, approximately $6,500 \mathrm{lbmole} / \mathrm{hour}$ of gas exits the solids heater at $830 \mathrm{o}$. Thus, in the absence of more detailed information, the following direct cost model was developed:

$$
\mathrm{DC}_{\mathrm{SH}, \mathrm{d}}=608 \mathrm{~N}_{\mathrm{SH}, \mathrm{T}}\left(\frac{\mathrm{G}_{\mathrm{SH}, \mathrm{o}}}{6467 \mathrm{lbmolehr} \mathrm{N}_{\mathrm{SH}, \mathrm{O}}}\right)^{0.6} \frac{\mathrm{PCI}}{1993 \mathrm{PCI}}
$$

In this model, the cost of ductwork, isolation valves, dampers, booster fans, and booster fan motors is estimated for a single solids heater vessel, and multiplied by the total number of absorber vessels.

The total direct cost for the solids heater is:

$$
\mathrm{DC}_{\mathrm{SH}}=\left(1+\mathrm{f}_{\mathrm{ic}, \mathrm{SH}}\right)\left(\mathrm{DC}_{\mathrm{SH}, \mathrm{v}}+\mathrm{DC}_{\mathrm{SH}, \mathrm{r}}+\mathrm{DC}_{\mathrm{SH}, \mathrm{s}}+\mathrm{DC}_{\mathrm{SH}, \mathrm{d}}\right)
$$

where $f_{i c, R}$ is an installation cost factor for the absorber process area. A default value of 0.45 is suggested.

\subsubsection{Sorbent Transport System}

A dense phase pneumatic transport system is employed to transport sorbent from the regenerator outlet to the absorber inlet. The transport system includes valves, compressors, piping, filters, and surge bins. The total cost for this system reported by AERA is $\$ 6,580,000$. 
The dense phase transport system was sized for a sorbent circulation rate of $1,000,000 \mathrm{lb} / \mathrm{hr}$. The cost of the transport system is proportional to the sorbent circulation rate. Thus, the equipment cost for the dense phase transport system is:

$$
\mathrm{DC}_{\mathrm{ST}, \mathrm{e}}=6,580\left(\frac{\mathrm{m}_{\mathrm{s}, \mathrm{A}, \mathrm{i}}}{1,000,000}\right)^{0.6} \frac{\mathrm{PCI}}{1993 \mathrm{PCI}}
$$

In addition, a sorbent storage silo is required. The cost of these silos is proportional to the sorbent circulation rate and the sorbent attrition rate, which determine the sorbent make-up rate. The nominal sorbent makeup rate is $500 \mathrm{lb} / \mathrm{hr}$ in the base case design. Therefore, the cost of the storage silos with air locks is:

$$
\mathrm{DC}_{\mathrm{ST}, \mathrm{s}}=330\left(\frac{\mathrm{m}_{\mathrm{s}, \text { makeup }}}{500}\right)^{0.6} \frac{\mathrm{PCI}}{1993 \mathrm{PCI}}
$$

The total direct cost for the sorbent transport system is:

$$
D C_{S T}=\left(1+f_{i c, S T}\right)\left(D C_{S T, e}+D C_{S T, s}\right)
$$

where $f_{i c, S T}$ is an installation cost factor for the solids transport process area. A default value of 0.45 is suggested.

\subsubsection{Solids Heater Combustor}

The cost of the combustor for the solids heater is proportional to the methane requirement:

$$
\mathrm{DC}_{\mathrm{SH}, \mathrm{c}}=2,650\left(1+\mathrm{f}_{\mathrm{ic}, \mathrm{SH}, \mathrm{c}}\right)\left(\frac{\mathrm{m}_{\mathrm{CH}_{4}, \mathrm{SH}, \mathrm{i}}}{225}\right)^{0.6} \frac{\mathrm{PCI}}{1993 \mathrm{PCI}}
$$

: where $\mathrm{f}_{\mathrm{ic}, \mathrm{SH}, \mathrm{c}}$ is an installation cost factor for the solids heater combustor process area. A default value of 0.45 is suggested.

\subsubsection{ByProduct Recovery}

A performance and cost model of a byproduct recovery plant has been developed previously and is documented by Rubin et al (1991, pp. 143-147).

\subsubsection{Aị Preheater Modifications}

The copper oxide process affects the power plant air preheater due to the highly exothermic sulfation reactions. The flue gas temperature in the fluidized bed absorber may increase by $100 \mathrm{~F}$, depending on the flue gas sulfur content and the overall sorbent circulation rate. Thermal energy is added to the flue gas by exothermic sulfation and $\mathrm{NO}_{\mathrm{x}}$ control reactions, as well as by transfer of sensible heat from the inlet sorbent to the flue gas. The energy added to the flue gas may be recovered to the power plant boiler by increasing the size of the air preheater, thereby increasing 
the temperature of the combustion air entering the furnace. This energy credit is discussed in detail by Frey (1987). A cost model for the air preheater modifications associated with capturing this energy credit is also given by Frey (1987).

\subsubsection{Initial Sorbent Inventory}

The initial sorbent requirement is governed primarily by the amount of sorbent hold up in the fluidized bed absorber, the regenerator, and the solids heater. It is assumed that the quantity of sorbent hold up in the transport system is small by comparison. The cost for initial sorbent fill is therefore:

$$
C_{I S}=\left\{\rho_{s} Z_{A} A_{A}+\left(\frac{m_{s}}{60}\right) t_{R}+2 \rho_{s} Z_{S H} A_{S H}\right\} U C_{s}
$$

\subsection{Total Capital Requirement}

The total direct cost is the summation of the plant section direct costs. The cost of initial catalyst charge is also included here in the direct costs, because it is such a large and integral part of the copper oxide system. One cost area not included in the previous sections is that associated with general facilities and control systems. AERA estimates that the control system has a cost of approximately 10 percent of the other direct cost items. Therefore, the total direct cost is given by:

$\mathrm{TDC}=\left(1+\mathrm{f}_{\mathrm{GF}}\right)\left(\mathrm{DC}_{\mathrm{A}}+\mathrm{DC}_{\mathrm{AI}}+\mathrm{DC}_{\mathrm{R}}+\mathrm{DC}_{\mathrm{SH}}+\mathrm{DC}_{\mathrm{ST}}+\mathrm{DC}_{\mathrm{SH}, \mathrm{c}}+\mathrm{DC}_{\mathrm{BY}}+\mathrm{DC}_{\mathrm{APH}}\right)+\mathrm{C}_{\mathrm{IS}}$

Other capital costs include various indirect capital costs, as well as preproduction costs associated with startup and inventory costs associated with providing initial stocks of chemicals and fuels.

Engineering and home office fees are typically estimated as a percentage of the total direct cost:

$$
\mathrm{C}_{\mathrm{EHO}}=\mathrm{f}_{\mathrm{EHO}} \mathrm{TDC}
$$

AERA has estimated that "process engineering" costs are approximately 20 percent of the equipment costs, or approximately 14 percent of the installed direct capital costs. The engineering and home office costs include the costs associated with: (1) engineering, design, and procurement labor; (2) office expenses; (3) licensor costs for basic process engineering; (4) office burdens, benefits, and overhead costs; (5) fees or profit to the architect/engineer. EPRI recommends that a value of 7 to 15 percent of the total direct cost, indirect construction cost, and sales tax be used. Therefore, a value of 15 percent is used here as a default.

Project contingency costs reflect the expected increase in the capital cost estimate that would result from a more detailed cost estimate for a specific site. Usually, project contingency is 
Table 8. Project Contingency Factors Recommended by EPRI ${ }^{\mathrm{a}}$

Type of Estimate Design Information

Percentage of

Direct Cost

\begin{tabular}{lll}
\hline Simplified & General site, process flow diagram & 30 to 50 \\
Preliminary & $\begin{array}{l}\text { Major equipment, preliminary piping and } \\
\text { instrumentation diagrams }\end{array}$ & 15 to 30 \\
Detailed & $\begin{array}{l}\text { Complete process design, site-specific, } \\
\text { engineering design in progress, } \\
\text { construction contract and schedule. }\end{array}$ & 10 to. 20
\end{tabular}

Finalized Complete engineering of process plant 5 to 10 a Expressed as a percentage of the total of total direct, total indirect, and process
contingency.

Source: EPRI (1986)

assigned as a multiplier of the total direct cost and selected indirect capital costs (e.g, EPRI, 1986). For example:

$$
\mathrm{C}_{\text {ProjC }}=\mathrm{f}_{\text {ProjC }}\left(\mathrm{TDC}+\mathrm{C}_{\mathrm{EHO}}\right)
$$

A typical value for the project contingency for a preliminary level cost estimate, as defined by the EPRI Technical Assessment Guide, is 20 percent.

A major cost item for advanced technology plants is the process contingency. The process contingency is used in deterministic cost estimates to quantify the expected increase in the capital cost of an advanced technology due to uncertainty in performance and cost for the specific design application. In the EPRI cost method, the process contingency is estimated based on separate consideration of contingencies for each process section. The contingency is expressed as a multiplier of the sum of the direct and indirect capital costs for each plant section. Recommended ranges of process contingency factors are shown in Table 8 . The process contingency decreases as the commercial experience with a process area increases. For example, in a fully commercialized process, which has been used in similar applications, the process contingency may be zero. For a new concept early in the development stage, the process contingency may be over 40 percent of the process area cost. Experience has shown that cost estimates for innovative technologies early in the development phase tend to be low by a factor of two or more compared to the cost of the first commercial-size demonatration plant (EPRI, 1986; Merrow, Phillips, and Myers, 1981). However, the cost for subsequent plants tends to decrease, which is known as the "learning curve" effect. Process contingencies employed for innovative technologies are intended to represent the 
expected costs of a commercialized (e.g., fifth of a kind) plant (EPRI, 1986). The process contingency for each major plant section is estimated as follows:

$$
\mathrm{C}_{\text {ProcC }}=\sum_{\mathbf{i}} \mathrm{f}_{\text {ProjC }} D C_{i}
$$

Typical values for the project contingency employed in previous studies are 0.25 for the absorber, solids heater, and regenerator, 0.5 for the sorbent transport system, and 0.1 for the sulfur recovery system. AERA employed 20 percent for all process areas.

The total plant cost, or overnight construction cost, is given by:

$$
\mathrm{TPC}=\mathrm{TDC}+\mathrm{C}_{\mathrm{EHO}}+\mathrm{C}_{\mathrm{ProjC}}+\mathrm{C}_{\mathrm{Proc}}
$$

An allowance for funds during construction (AFDC) is calculated based on the TPC as a function of the amount of time it would take to construct a copper oxide system. A 36 month construction period for a new plant is assumed. Methods for computing the AFDC are documented elsewhere (e.g., EPRI, 1986) and are not repeated here. The total plant investment (TPI) represents the sum of the total plant cost and the AFDC.

The final measure of capital cost is the total capital requirement (TCR). The TCR includes the total plant investment plus costs for royalties, startup costs, and initial inventories of feedstocks. In this case, no costs are assumed for royalties. Preproduction costs typically include one month of both fixed and variable operating costs and two percent of total plant investment. Inventory capital is estimated as 0.5 percent of total process capital excluding catalyst. The costs for initial catalysts and chemicals is zero. The copper oxide initial sorbent requirement is included in the process capital costs. Thus, for a copper oxide system, the total capital requirement is:

$$
\mathrm{TCR}=\frac{\mathrm{VOC}+\mathrm{FOC}}{12}+\left(1+\mathrm{f}_{\mathrm{PP}}\right) \mathrm{TPI}+\mathrm{f}_{\mathrm{IC}} \sum_{\mathrm{i}} \mathrm{DC} \mathrm{C}_{\mathrm{i}}
$$

\subsection{Annual Costs}

The annual costs for copper oxide systems include fixed and variable operating costs. Fixed operating costs include operating labor, maintenance labor and materials, and overhead costs associated with administrative and support labor. Variable operating costs include consumables, such as ammonia and sorbent replacment. Costs for steam and electricity consumed from within the plant may also be estimated.

\subsubsection{Fixed Operating Costs}

Fixed operating costs include operating labor, maintenance labor and materials, and overhead costs associated with administrative and support labor. The operating labor cost is based 
on an estimate of the number of personnel hours required to operate the plant multiplied by an average labor rate. It is common to assume that four shifts per day are required for plant operation, allowing two hours overlap for transition between shifts. Furthermore, an allowance for personnel on sick leave or vacation can be incorporated into the "shift factor." A shift factor of 4.75 is assumed as a default in this study, based on Bechtel (1988).

The number of operators required per shift for the copper oxide process is estimated by AERA to be five. The total operating labor cost is estimated by summing the number of plant operators per shift for all process areas, applying the shift factor, and applying the average labor rate as follows:

$$
O C_{L}=\operatorname{ALR} \frac{2,080 \mathrm{hrs}}{\mathrm{yr}} \mathrm{SF}\left(1+2 \mathrm{~N}_{\mathrm{A}, \mathrm{O}}\right)
$$

The cost for maintenance material and labor for new technologies is typically estimated as a percentage of the installed capital cost for each process section. The total maintenance cost for the plant is given by:

$$
O C_{M}=f_{M} T P C
$$

where a typical value of the maintenance cost multiplier, $f_{M}$, is 0.045 for a solids handling system. The total maintenance operating cost may be disaggregated into material and labor components using the following approach:

$$
\begin{aligned}
O C_{M M} & =0.60 O C_{M} \\
O C_{M L} & =0.40 O C_{M}
\end{aligned}
$$

The administrative and support labor cost is assumed to be 30 percent of the operating and maintenance labor cost:

$$
\mathrm{OC}_{\mathrm{AS}}=0.30\left(\mathrm{OC}_{\mathrm{L}}+\mathrm{OC}_{\mathrm{ML}}\right)
$$

\subsubsection{Variable Operating Costs}

The variable operating costs include all consumable materials required for operation of the plant. These include the costs of sorbent for makeup of attrition losses, the cost of ammonia for injection into the fluidized bed absorber, and the cost of methane required for regeneration and solids heating. In addition, the electricity and steam consumption of the copper oxide process results in an energy penalty. However, the increased flue gas temperature in the fluidized bed absorber results in an energy credit.

The annual costs for sorbent makeup, ammonia, and methane consumption are given by: 


$$
\begin{gathered}
\operatorname{VOC}_{\mathrm{s}}=8,760 \mathrm{c}_{\mathrm{f}} \mathrm{m}_{\mathrm{s}, \mathrm{makeup}} \mathrm{UC}_{\mathrm{s}} \\
\operatorname{VOC}_{\mathrm{NH}_{3}}=8,760 \mathrm{c}_{\mathrm{f}} \mathrm{m}_{\mathrm{NH}_{3}, \mathrm{~A}, \mathrm{i}} \mathrm{UC}_{\mathrm{NH}_{3}} \\
\operatorname{VOC}_{\mathrm{CH}_{4}}=8,760 \mathrm{c}_{\mathrm{f}}\left(\mathrm{m}_{\mathrm{CH}_{4}, \mathrm{SH}}+\mathrm{m}_{\mathrm{CH}_{4}, \mathrm{R}}+\mathrm{m}_{\mathrm{CH}_{4}, \mathrm{BY}}\right) \mathrm{UC}_{\mathrm{CH}_{4}}
\end{gathered}
$$

Note that methane is required for solids heating, as a reducing gas for the regeneration reactions, and also as a reducing gas for off-gas pretreatment in the Claus plant.

The variable operating costs also include a byproduct credit for the sale of elemental sulfur produced by the Claus plant. The amount of this credit is given by:

$$
\mathrm{VOC}_{\mathrm{BY}}=8,760 \mathrm{c}_{\mathrm{f}} \eta_{\mathrm{BY}}\left(\frac{32 \mathrm{M}_{\mathrm{SO}_{2} \mathrm{R}, \mathrm{o}}}{2,000}\right) \mathrm{UC}_{\mathrm{S}}
$$

A variable operating cost credit is also taken for a reduction in coal consumption associated with the increased combustion air inlet temperature, which in turn results from the higher flue gas temperature entering the air preheater. This credit is discussed by Frey (1987). 


\subsection{SENSTIVITY ANALYSES OF THE FLUIDIZED BED COPPER OXIDE PROCESS}

The copper oxide process performance and economic models are applied to several case studies to identify key process sensitivities and to identify potentially robust design configurations. These analysis are predicated on "deterministic" analyses, in which point-estimates are used for all model input parameters. In the following chapter, uncertainties in the copper oxide process will be quantified and evaluated.

\subsection{Integration of copper oxide process and byproduct recovery system}

The copper oxide process performance model is applied here to three case studies to compare alternative approaches for dealing with the Claus plant tailgas. The design basis is a 500 MW power plant. The coal composition and the calculated flow rate are given in Table 9, the calculated flue gas composition and flow upstream of the copper oxide process are given in Table 10, and the key design assumptions and modeling results for the three cases are given in Table 11. These case studies are based on a single stage fluidized bed absorber. Case 1 represents a base case in which no measures are taken to correct for tailgas emissions. In Case 2 , the $\mathrm{SO}_{2}$ removal efficiency in the absorber is increased to compensate for the tailgas emissions. In Case 3, the tailgas emissions are recycled to the flue gas just upstream of the absorber, and the absorber sulfur removal efficiency is increased slightly to achieve an overall 90 percent removal efficiency. Cases 2 and 3 yield the same overall removal efficiency of 90 percent, while Case 1 achieves only 85.5 percent removal efficiency.

Table 9. Coal Composition and Model Results for Coal Input Flow Rate a

\begin{tabular}{|c||c|c|}
\hline Component & $\begin{array}{c}\text { Composition, } \\
\text { (wt-\% as fired) }\end{array}$ & $\begin{array}{c}\text { Flow Rate } \\
\text { (lb/hr) }\end{array}$ \\
\hline \hline Carbon & 57.56 & 246,686 \\
Hydrogen & 4.14 & 17,743 \\
Oxygen & 7.00 & 30,000 \\
Sulfur & 3.12 & 13,371 \\
Nitrogen & 1.44 & 61,714 \\
Ash & 16.00 & 68,571 \\
Moisture & 10.74 & 46,029 \\
\hline \hline TOTAL & 100.00 & 428,571 \\
\hline \hline
\end{tabular}

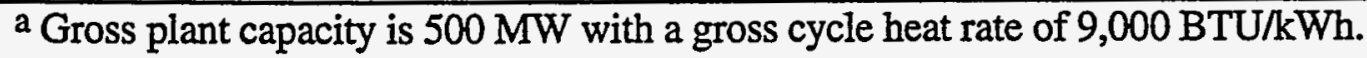


Table 10. Model Results for Flue Gas Composition and Flow Rate a

\begin{tabular}{|c||r|r|r|}
\hline Component & $\begin{array}{c}\text { Composition } \\
\text { (Volume \%) }\end{array}$ & $\begin{array}{c}\text { Flow Rate } \\
(\mathrm{lb} / \mathrm{hr})\end{array}$ & $\begin{array}{r}\text { Flow Rate } \\
(\mathrm{bmole} / \mathrm{hr})\end{array}$ \\
\hline \hline Nitrogen & 73.229 & $3,091,870$ & 110,371 \\
Oxygen & 3.217 & 155,175 & 4,849 \\
Water Vapor & 9.597 & 260,581 & 14,465 \\
Carbon Dioxide & 13.628 & 903,967 & 20,540 \\
Sulfur Dioxide & 0.260 & 25,129 & 393 \\
Sulfur Trioxide & 0.003 & 317 & 4 \\
Nitrogen Oxide & 0.062 & 2,810 & 10 \\
Nitrogen Dioxide & 0.003 & 227 & 5 \\
\hline \hline TOTAL & 100.000 & $4,440,070$ & 150,720 \\
\hline
\end{tabular}

a $95 \%$ of the coal sulfur is emitted, with $99 \%$ as $\mathrm{SO}_{2}$. Ambient air is at $80{ }^{\circ} \mathrm{F}$ and $65 \%$ relative humidity. Excess boiler air is $20 \%$, and air preheater leakage is $19 \%$.

While the design basis for Case 1 is likely to result in inadequate overall sulfur emissions control, Case 2 is likely to result in prohibitive costs. The sorbent circulation is increased by 28 percent to achieve the 94.74 percent absorber sulfur removal efficiency needed to compensate for the Claus plant tailgas emissions. Due to the higher sorbent circulation rate, the methane requirement for solids heating and regeneration is increased, contributing to a larger net energy penalty on the power plant. In contrast, Case 3 achieves an overall sulfur removal efficiency of 90 percent with a modest increase in sorbent circulation rate of only six percent. Thus, Case 3 is clearly preferred over Case 2 for 90 percent overall sulfur control. The design basis for Case 3 is employed here for sensitivity analyses regarding absorber bed height, sorbent copper loading, and regeneration efficiency.

A detailed economic evaluation of the three Claus plant integration schemes is shown in Table 12. The total capital cost for the tailgas recycle approach is approximately 3 percent higher than an approach in which the tailgas is emitted with recycle or any type of compensation for $\mathrm{SO}_{2}$ in the tailgas. The total capital cost increases by approximately 10 percent if the removal efficiency of the copper oxide process is substantially increased as a means to compensate for Claus plant tailgas emissions. The differences in total operating and maintenance (O\&M) costs among the three schemes are even more pronounced. The recycle approach increases $O \& M$ costs by three percent, but the compensation approach leads to a 17 percent increase in O\&M costs. Therefore, the tailgas recycle scheme appears to have relatively modest cost impacts while ensuring that overall sulfur control targets are achieved. 
Table 11. Copper Oxide Process Design Assumptions and Model Results

\begin{tabular}{|c|c|c|c|}
\hline \multirow[b]{2}{*}{ PARAMETER } & \multicolumn{3}{|c|}{ Values } \\
\hline & Case 1 & Case 2 & Case 3 \\
\hline Required $\mathrm{SO}_{2}$ Removal Efficiency, \% & 90.0 & $\overline{90.0}$ & $\overline{90.0}$ \\
\hline Absorber $\mathrm{SO}_{2}$ Removal Efficiency, \% & 90.0 & 94.7 & 90.5 \\
\hline Sulfur Plant Recovery Efficiency, \% & 95.0 & 95.0 & 95.0 \\
\hline Claus Tailgas Recycle to Flue Gas & No & No & Yes \\
\hline Overall $\mathrm{SO}_{2}$ Removal Efficiency, $\%$ & 85.5 & 90.0 & 90.0 \\
\hline Net $\mathrm{SO}_{2}$ Captured, lbmole/hr & 339 & 357 & 357 \\
\hline $\mathrm{NO}_{\mathrm{x}}$ Removal Efficiency, \% & 90.0 & 90.0 & 90.0 \\
\hline $\mathrm{NO}_{\mathrm{X}}$ Captured, $1 \mathrm{bmole} / \mathrm{hr}$ & 88.7 & 88.7 & 88.7 \\
\hline Flue Gas Inlet Temp., oF & 705 & 705 & 705 \\
\hline Flue Gas Outlet Temp., of & 797 & 812 & 801 \\
\hline Number of Absorbers & 2 & 2 & 2 \\
\hline Area per Absorber, $\mathrm{ft}^{2}$ & 3,898 & $3,89 \overline{8}$ & $3,89 \overline{8}$ \\
\hline CuO Regeneration Efficiency, \% & 80 & 80 & 80 \\
\hline 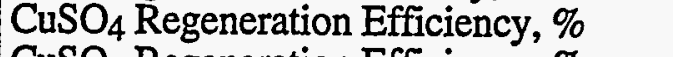 & 80 & 80 & 80 \\
\hline $\mathrm{CuSO}_{3}$ Regeneration Efficiency, \% & & 80 & 80 \\
\hline Conversion of $\mathrm{CuO}$ to $\mathrm{CuSO}_{3}$, frac. & & 1 & \\
\hline Absorber Sorbent Inventory, $\mathrm{lb}$ & 829,496 & 829,496 & 829,599 \\
\hline Sorbent Circulation Rate $(\mathrm{lb} / \mathrm{hr}$, fresh) & 714,811 & 913,387 & 757,940 \\
\hline Absorber Inlet Sorbent Flow (lb/hr) & 727,411 & 929,487 & 771,300 \\
\hline Sorbent Circ. Rate (lb fresh $/ 1,000$ scf) & 12.5 & 16.0 & 13.2 \\
\hline Sorbent Absorber Residence Time (min) & 70 & 54 & 66 \\
\hline Sorbent Copper Loading (wt-\%) & & 7 & 7 \\
\hline Available Cu/S Ratio & 1.59 & 2.03 & 1.61 \\
\hline Total Cu/S Ratio & 1.99 & 2.54 & 2.01 \\
\hline Copper Utilization (S rem./avail Cu) & 0.57 & 0.47 & 0.56 \\
\hline $\mathrm{NH}_{3} / \mathrm{NO}_{\mathbf{x}}$ Molar Ratio & 1.00 & 1.00 & 1.00 \\
\hline Ammonia (lb/hr) & 1,763 & 1,763 & 1,763 \\
\hline Ammonia Injection Steam $(\mathrm{lb} / \mathrm{hr})$ & 1,129 & 1,129 & 1,129 \\
\hline Superficial Flue Gas Velocity (ft/s) & 4.5 & 4.5 & 4.5 \\
\hline Expanded Bed Height (inches) & 48 & 48 & 48 \\
\hline Fluidized Bed Pressure Drop (in. $\mathrm{H}_{2} \mathrm{O}$ ) & 27.7 & 27.7 & 27.7 \\
\hline Bed Attrition ( $\%$ of bed inventory) & 0.020 & 0.020 & 0.020 \\
\hline Circ. Attrition (\% of circulation) & 0.047 & 0.047 & 0.047 \\
\hline Overall Attrition (\% of circulation) & 0.070 & 0.065 & 0.069 \\
\hline Makeup Sorbent (lb/hr) & 508 & 603 & 528 \\
\hline Methane (lb/hr) & 10,455 & 12,107 & 10,983 \\
\hline Net Energy Impact (kW) & 17,108 & 18,308 & 17,640 \\
\hline
\end{tabular}


Table 12. Capital, Annual, and Levelized Costs for the Fluidized Bed Copper Oxide Process: A Comparison of Three Claus Plant Tailgas Integration Schemes ${ }^{a}$

\begin{tabular}{|l|r|r|r|}
\hline & \multicolumn{2}{|c|}{ Tailgas } & \multicolumn{1}{c|}{ Integration } \\
\cline { 2 - 4 } Description & $\begin{array}{c}\text { No Recycle } \\
\text { (Case 1) }\end{array}$ & $\begin{array}{c}\text { Recycle } \\
\text { (Case 3) }\end{array}$ & $\begin{array}{c}\text { Compensate } \\
\text { (Case 2) }\end{array}$ \\
\hline NH $_{3}$ Handling and Injection, M\$ & 2.036 & 2.036 & 2.036 \\
\hline Fluidized Bed Absorber Capital, M\$ & 6.381 & 6.381 & 6.381 \\
\hline I Fan Differential, M\$ & 0.401 & 0.401 & 0.401 \\
\hline Solids Heater, M\$ & 3.472 & 3.565 & 3.888 \\
\hline Regenerator, M\$ & 3.410 & 3.516 & 3.719 \\
\hline Sorbent Transport System, M\$ & 8.375 & 8.669 & 9.728 \\
\hline Solids Heater Combustor, M\$ & 3.741 & 3.828 & 4.134 \\
\hline Sulfur Recovery Plant, M\$ & 13.316 & 13.831 & 14.664 \\
\hline Air Preheater Modifications, M\$ & 5.339 & 5.623 & 6.585 \\
\hline Sorbent Inventory, M\$ & 5.515 & 5.595 & 5.783 \\
\hline Total Direct Capital Cost, M\$ & 56.633 & 58.230 & 62.474 \\
\hline Eng'ring \& Home Office Fees, M\$ & 8.495 & 8.735 & 9.371 \\
\hline Process Contingency, M\$ & 13.026 & 13.393 & 14.369 \\
\hline Project Contingency, M\$ & 7.389 & 7.585 & 8.142 \\
\hline Total Plant Cost ("overnight"), M\$ & 85.542 & 87.943 & 94.357 \\
\hline Interest, M\$ (current dollars) & 8.088 & 8.315 & 8.922 \\
\hline Total Plant Investment, M\$ & 93.630 & 96.258 & 103.279 \\
\hline Startup (Preproduction) Cost, M\$ & 4.206 & 4.346 & 4.762 \\
\hline Working (Inventory) Capital, M\$ & 0.232 & 0.239 & 0.258 \\
\hline Land Cost, M\$ & 0.028 & 0.028 & 0.028 \\
\hline Total Capital Cost, M\$ & 98.096 & 100.871 & 108.327 \\
\hline \hline Total Capital, \$/kW & 207.5 & 213.1 & 227.9 \\
\hline Fixed Operating Cost, M\$/yr & 5.596 & 5.717 & 6.040 \\
\hline Sorbent Cost, M\$/yr & 14.485 & 15.075 & 17.307 \\
\hline Methane Cost, M\$yr & 6.686 & 7.023 & 7.778 \\
\hline Ammonia Cost, M\$/yr & 0.795 & 0.795 & 0.795 \\
\hline Miscellaneous, M\$/yr & 0.441 & 0.441 & 0.441 \\
\hline Variable Operating Cost, M\$/yr & 22.407 & 23.334 & 26.321 \\
\hline \hline Total O\&M Cost, M\$/yr & 22.399 & 23.161 & 26.254 \\
\hline Revenue wo Uti, M\$/yr & 32.541 & 33.590 & 37.454 \\
\hline Utilities, M\$/yr & 2.943 & 2.966 & 3.052 \\
\hline Total Revenue, M\$/yr & 35.484 & 36.556 & 40.505 \\
\hline Total Rev, mills/kWh & 13.173 & 13.552 & 14.955 \\
\hline
\end{tabular}

a All costs are reported in 1993 dollars. Variable operating costs and levelized costs are calculated using a 65 percent plant capacity factor. The three Claus plant integration schemes are: (1) release tailgas to the atmosphere, with no adjustment for SO2 emitted to the atmosphere in the tailgas; (2) recycle the tailgas to a point upstream of the fluidized bed absorber, to maintain an overall 90 percent sulfur removal efficiency; (3) increase the sulfur removal efficiency of the copper oxide process to compensate for tailgas $\mathrm{SO}_{2}$ emissions. 


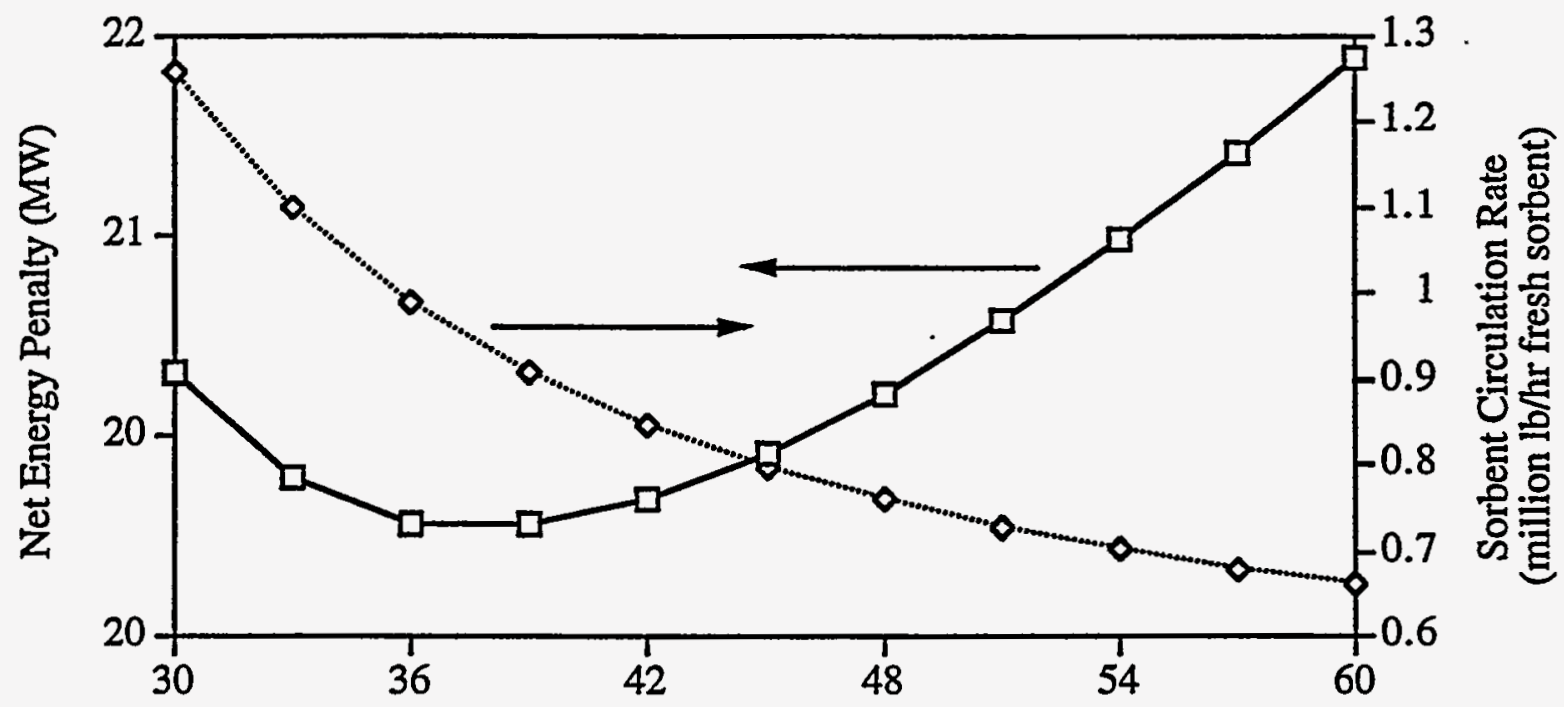

Expanded Fluidized Bed Height (inches)

Figure 10. Sensitivity of Energy Penalty and Sorbent Circulation Rate to the Expanded Fluidized Bed Height for a Single-Stage Absorber-Based Copper Oxide System.

\subsection{Sorbent Bed Height: Single Stage Fluidized Bed Absorber}

The sorbent bed height has a direct effect on the fluidized bed sorbent inventory. The bed inventory is in turn a determinant of sorbent residence time in the regenerator, which affects the $\mathrm{Cu} / \mathrm{S}$ molar ratio required to achieve a given removal efficiency. As the bed height increases, the sorbent circulation rate decreases, as shown in Figure 10. However, as the bed height increases, the flue gas pressure drop and the induced draft fan electricity requirements increase. Figure 10 indicates that a minimum net energy penalty is achieved at a fluidized bed height of approximately 36 to 39 inches. However, the energy penalty is not the sole determinant of cost. Much of the equipment in the copper oxide process, including the solids heater and regenerator, is sized based on the sorbent circulation rate. Therefore, a reduction in sorbent circulation rate can yield significant capital cost savings. Furthermore, operating costs are reduced due primarily to lower sorbent replacement costs and lower methane requirements to heat and regenerate the sorbent.

An economic analysis of the levelized cost for the copper oxide process versus expanded fluidized bed height is shown in Figure 11. The levelized cost for a single-stage absorber based system is shown to be highly sensitive to fluidized bed height, varying from 16.7 mills $/ \mathrm{kWh}$ at a 30 inch bed height to approximately 13.4 mills $/ \mathrm{kWh}$ at a 60 inch bed height. This analysis strongly suggests that the economics of the copper oxide process are favored by larger bed heights, larger sorbent residence time in the absorber, and reduced sorbent circulation rate, even though this is at the expense of increased flue gas pressure drop. The results also suggest that minimum costs 


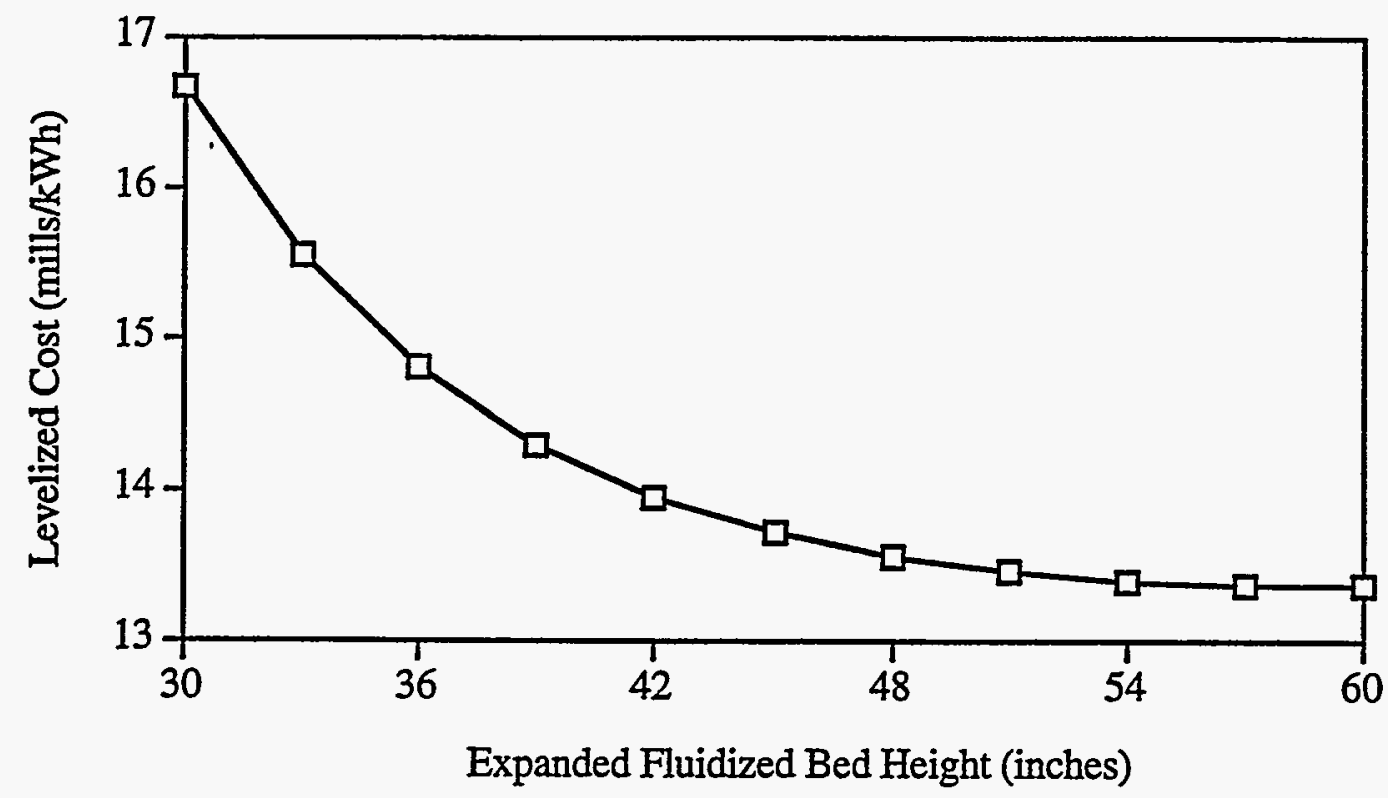

Figure 11. Sensitivity of Levelized Cost to the Expanded Fluidized Bed Height for a SingleStage Absorber-Based Copper Oxide System.

are realized in the range of 57 to 60 inches. (The costs begin to increase for bed heights larger than 60 inches). However, these results do not take into account any changes in sorbent attrition that might be associated with larger bed heights, nor does it account for the incremental structural costs for the absorber vessel associated with substantially increasing the sorbent inventory. Thus, while these results are suggestive of the merits of higher bed heights, they are not conclusive.

While the costs of a single-stage absorber design are highly sensitive to bed height, the costs of optimally designed two-stage absorber systems are more nearly the same with variations in key design parameters. This is illustrated in Figure 12. For a two-stage design, there are two independent design parameters. These are the height of the second stage, and the desired sulfur removal efficiency of the second stage. Specifying these two values determines the height and removal efficiency of the first stage of the absorber. A sensitivity analysis was performed in which the design height of the second stage absorber was varied from ten to forty inches, and in which four different values of sulfur removal efficiency were assumed for the second stage. The results in Figure 12 indicate that for any selected second stage bed height, there is an optimal (minimum total cost) second stage removal efficiency. While the levelized cost for any particular second stage bed height may be highly sensitive to the second stage removal efficiency (consider the different values of levelized cost obtained at a second stage bed height of 15 inches at removal efficiencies of $30,40,50$, and 60 percent as shown in the figure), the levelized cost is not very sensitive to designs based on optimal selection of second-stage removal efficiency given a second-stage bed height. The least-cost solutions over the entire range from ten to forty inch second stage bed 


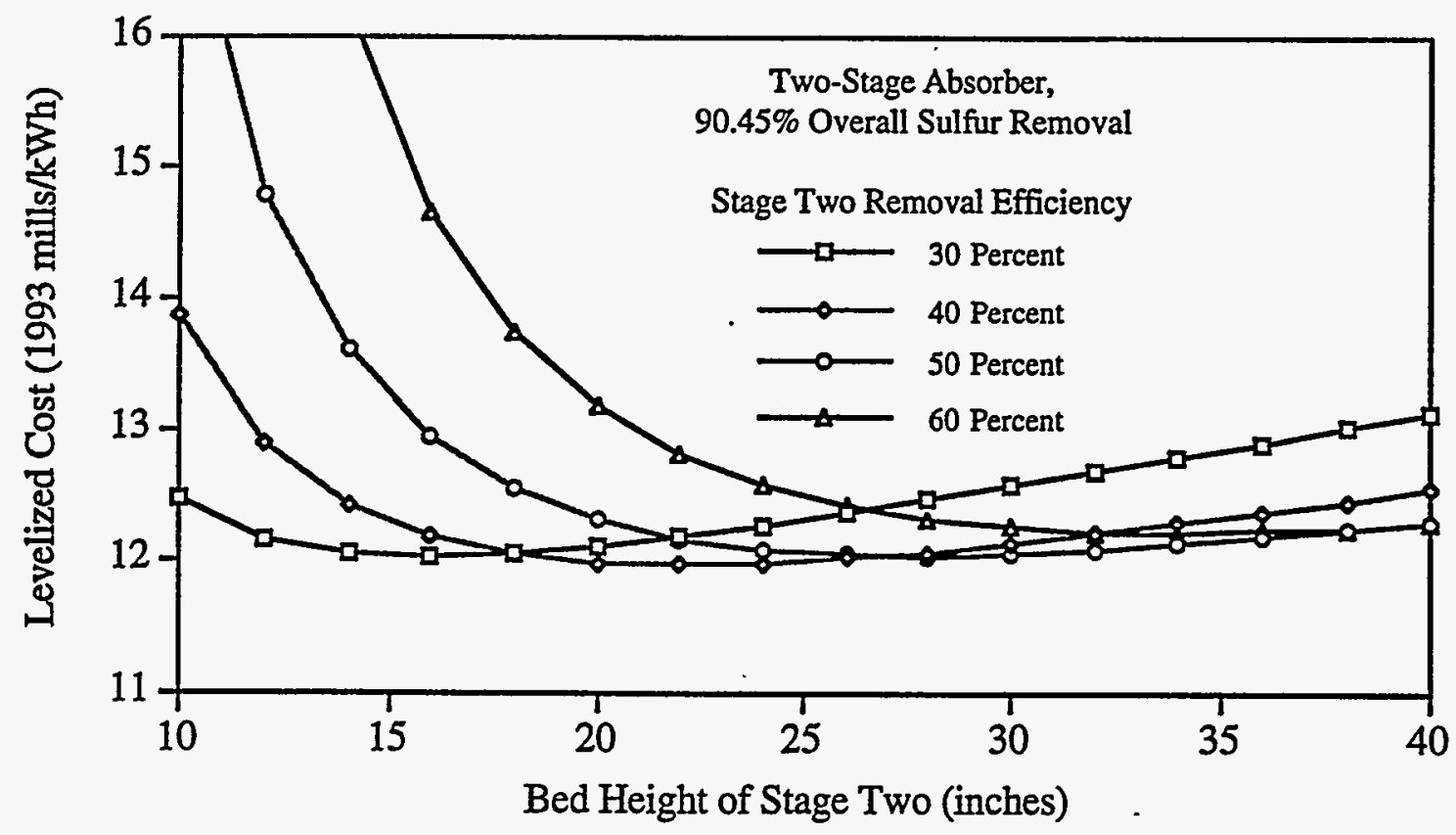

Figure 12. Sensitivity of Levelized Cost to the The Design of a Two-Stage Absorber-Based Copper Oxide System.

heights varies only between approximately $12 \mathrm{mills} / \mathrm{kWh}$ and $12.5 \mathrm{mills} / \mathrm{kWh}$. Thus, the use of a two-stage design offers the opportunity to select relatively robust optimal designs. The minimum cost solution in Figure 12 is a second stage bed height of 16 inches with an associated removal efficiency of 30 percent. However, selection of a 22 inch bed height with a 40 percent removal efficiency yields nearly the same levelized cost value.

A detailed economic comparison of the one and two stage absorber designs is given in Table 13. The two-stage design results in a substantial reduction in sorbent circulation rate compared to the one-stage design. Hence, the costs of equipment sized to accomodate the sorbent flow rate, such as the regenerator, solids heater, and sorbent transport system, are modestly reduced. There is an increase in sorbent inventory cost due to the large bed inventory in the twostage system. The major impact of the two-stage design is seen in the annual costs, where the costs associated with makeup sorbent are reduced by over two million dollars. The overall effect is a reduction in levelized costs of $1.5 \mathrm{mills} / \mathrm{kWh}$. Not taken into account in the cost model, however, are any additional costs for a two-stage absorber associated with the absorber vessel material or structural costs. The two-stage design is employed here in further senstivity studies. 
Table 13. Capital, Annual, and Levelized Costs for the Fluidized Bed Copper Oxide Process: $A$ Comparison of Singe and Two-Stage Absorber Designs ${ }^{\mathrm{a}}$

\begin{tabular}{|c|c|c|}
\hline \multirow[b]{2}{*}{ Description } & \multicolumn{2}{|c|}{ Absorber Design } \\
\hline & Single Stage & Two-Stage \\
\hline $\mathrm{NH}_{3}$ Handling and Injection, $\mathrm{M} \$$ & 2.036 & 2.036 \\
\hline Fluidized Bed Absorber Capital, M\$ & 6.381 & 6.381 \\
\hline D Fan Differential, M\$ & 0.401 & 0.413 \\
\hline Solids Heater, $\mathrm{M} \$$ & 3.565 & 3.101 \\
\hline Regenerator, M\$ & 3.516 & 3.219 \\
\hline Sorbent Transport System, $\mathrm{MS}$ & 8.669 & 7.255 \\
\hline Solids Heater Combustor, $\mathrm{M} \$$ & 3.828 & 3.357 \\
\hline Sulfur Recovery Plant, M\$ & 13.831 & 12.784 \\
\hline Air Preheater Modifications, M\$ & 5.623 & 4.437 \\
\hline Sorbent Inventory, M\$ & 5.595 & 5.741 \\
\hline Total Direct Capital Cost, M\$ & 58.230 & 53.022 \\
\hline Eng'ring \& Home Office Fees, M\$ & 8.735 & 7.953 \\
\hline Process Contingency, M\$ & 13.393 & 12.195 \\
\hline Project Contingency, M\$ & 7.585 & 6.833 \\
\hline Total Plant Cost ("overnight"), M\$ & 87.943 & 80.003 \\
\hline Interest, $\mathrm{M} \$$ ( current dollars) & 8.315 & 7.565 \\
\hline Total Plant Investment, M\$ & 96.258 & 87.568 \\
\hline Startup (Preproduction) Cost, M\$ & 4.346 & 3.869 \\
\hline Working (Inventory) Capital, M\$ & 0.239 & 0.215 \\
\hline Land Cost, MS & 0.028 & 0.028 \\
\hline Total Capital Cost, $\mathrm{M} \$$ & 100.871 & 91.680 \\
\hline Total Capital, \$/kW & 213.1 & 194.922 \\
\hline Fixed Operating Cost, $\mathrm{M} \$ / \mathrm{yr}$ & 5.717 & 5.317 \\
\hline Sorbent Cost, M\$/yr & 15.075 & 12.828 \\
\hline Methane Cost, M\$/yr & 7.023 & 6.034 \\
\hline Ammonia Cost, $\mathrm{M} \$ / \mathrm{yr}$ & 0.795 & 0.795 \\
\hline Miscellaneous, M\$/yr & 0.441 & 0.441 \\
\hline Variable Operating Cost, $\mathrm{M} \$ / \mathrm{yr}$ & 23.334 & 20.098 \\
\hline Total O\&M Cost, M\$/yr & 23.161 & 19.808 \\
\hline Revenue wo Uti, M\$/yr & 33.590 & 29.286 \\
\hline Utilities, $\mathrm{M} \$ / \mathrm{yr}$ & 2.966 & 2.975 \\
\hline Total Revenue, M\$/yr & 36.556 & 32.261 \\
\hline Total Rev, mills/kWh & 13.552 & 12.038 \\
\hline
\end{tabular}

a All costs are reported in 1993 dollars. Variable operating costs and levelized costs are calculated using a 65 percent plant capacity factor. The absorber capital cost for the two-stage design does not include any additional costs associated with a second stage distributor plate. The two-stage design is based on a lower stage with a 16-inch height operating at $30 \%$ sulfur capture efficiency. The upper stage is approximately 37 inches in height and operates at approximately 86 percent sulfur capture efficiency. 


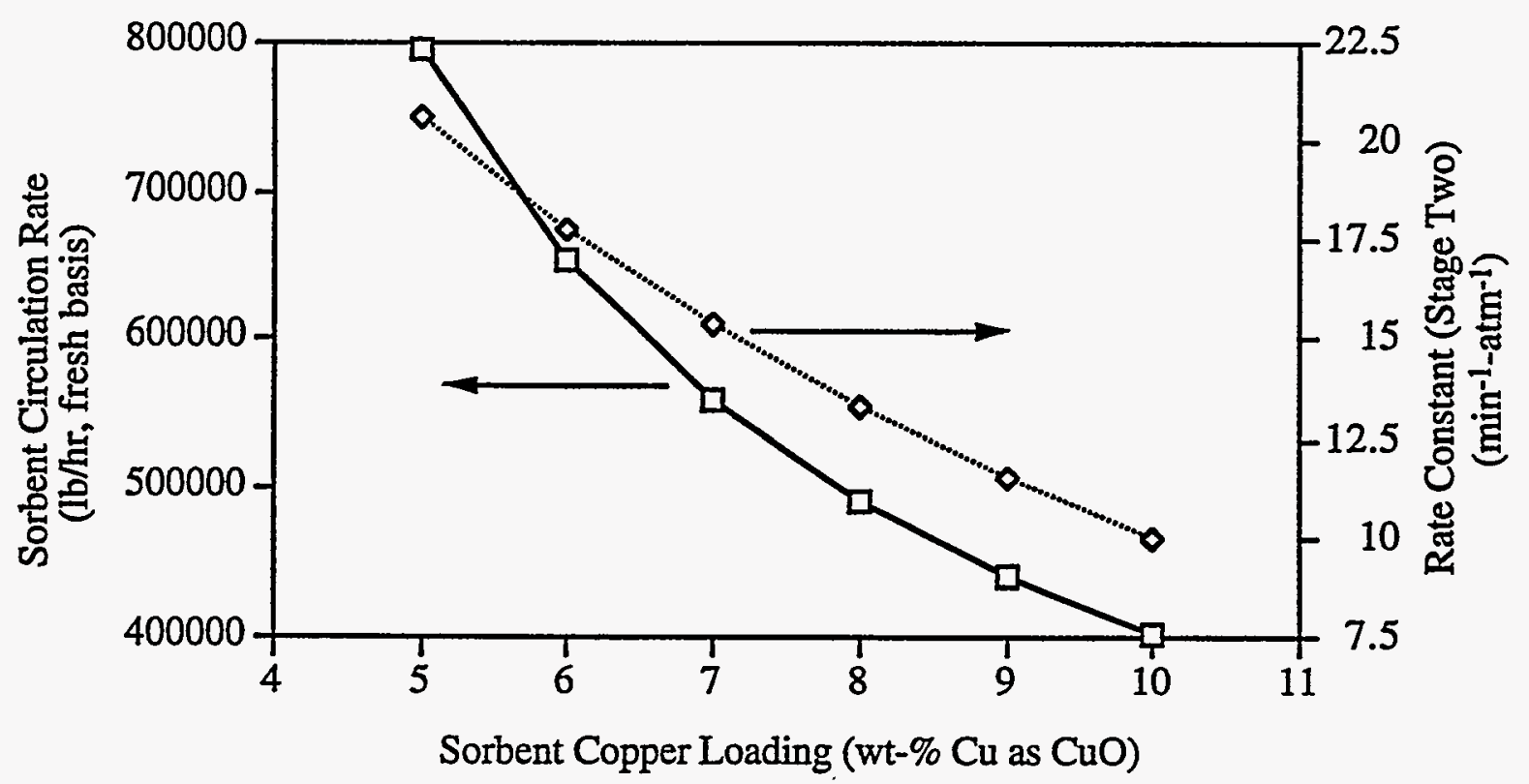

Figure 13. Sensitivity of Sorbent Circulation Rate and Second-Stage Kinetic Rate Constant to the Sorbent Copper Loading.

\subsection{Sorbent Copper Loading}

Optimization of the sorbent copper content is a key design issue. The primary trade-off is between sorbent mass flow rate and sorbent attrition; however, the attrition characteristics of high copper sorbents are not well characterized. Data in Figure 13 for a two-stage absorber system point to the potential advantages of high copper loadings. Although the reaction rate constant (Equation 38) decreases with increased copper loading, the net effect is a substantial reduction in the sorbent circulation rate. A change in sorbent copper loading of one percent from the base case value of seven weight-percent results in a change in sorbent circulation rate of approximately $100,000 \mathrm{lb} / \mathrm{hr}$. However, there is little experience or data with highly loaded sorbents.

Neglecting possible changes in sorbent attrition rate, the economic implications of alternative sorbent copper loadings are show in Figure 14. Over the range from five to ten weight percent copper loading, capital cost varies by approximately $\$ 30 / \mathrm{kW}$, while levelized costs vary by approximately $3 \mathrm{mills} / \mathrm{kWh}$. The possible substantial reductions in cost associated with higher sorbent copper loadings suggest that there may be a considerable pay-off from research to improve sorbent copper loading or, alternatively, improve overall sorbent activity. 


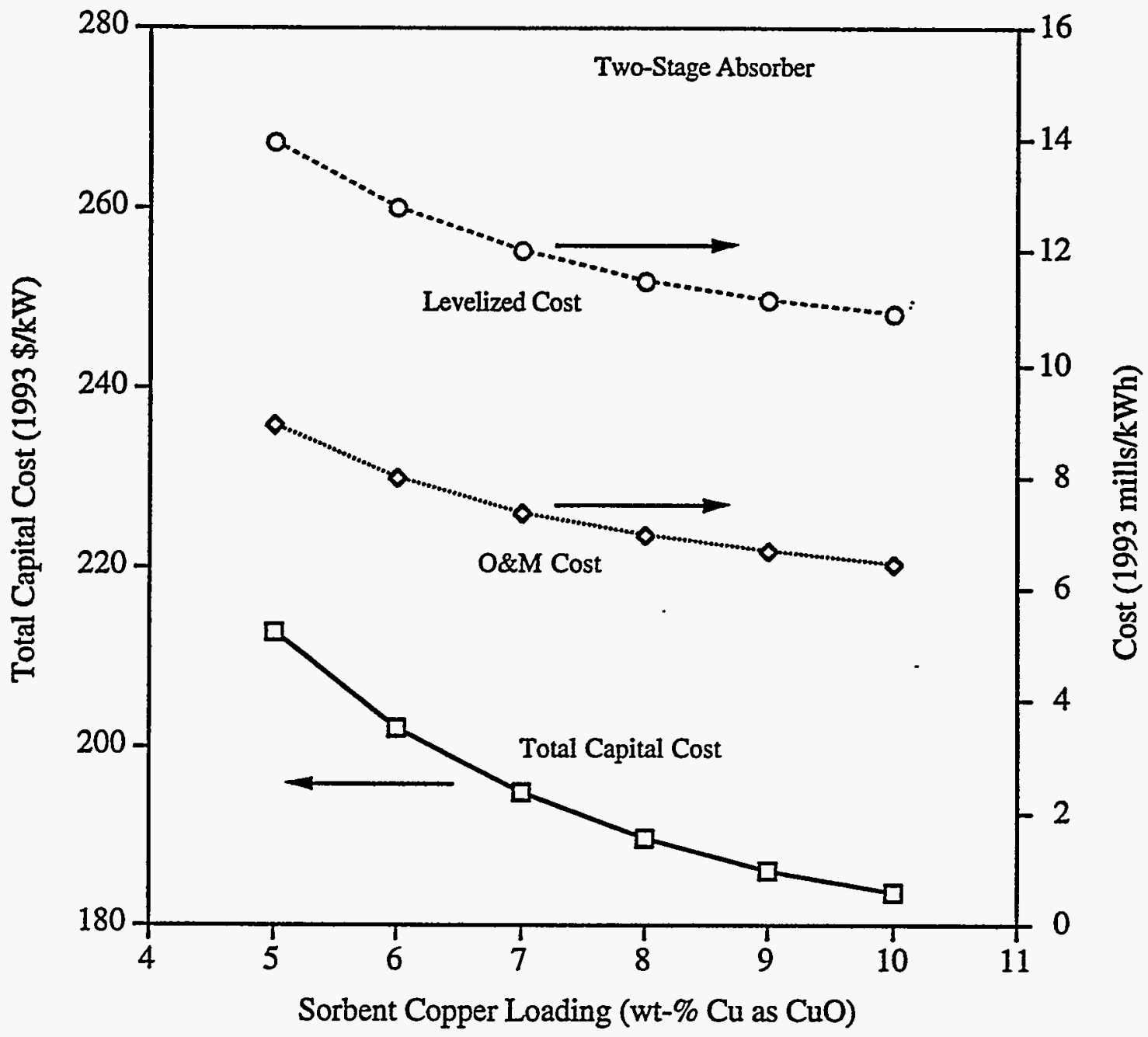

Figure 14. Sensitivity of Capital, O\&M, and Levelized Costs to the Sorbent Copper Loading.

\subsection{Regeneration Efficiency}

A third area for process optimization is the sorbent regeneration efficiency. Three case studies are considered in Figure 15. The first is a case in which none of the copper oxide entering the regenerator is coverted to copper sulfite. Thus, the only reactions occuring are Equations (6) and (8). In the second case, all of the copper oxide entering the regenerator is assumed to be converted to copper sulfite. The regeneration efficiencies for copper sulfate and copper sulfite are assumed to be the same. This case yields results that approach those of the first case as the regeneration efficiency approaches 100 percent. Finally, in the third case, the copper sulfite regeneration efficiency is assumed to be one-half that for copper sulfate. In this case, even at very high copper sulfate regeneration efficiencies, the unregenerated copper sulfite leads to a higher . spent sorbent loading to the absorber and a correspondingly higher total $\mathrm{Cu} / \mathrm{S}$ ratio than the other 


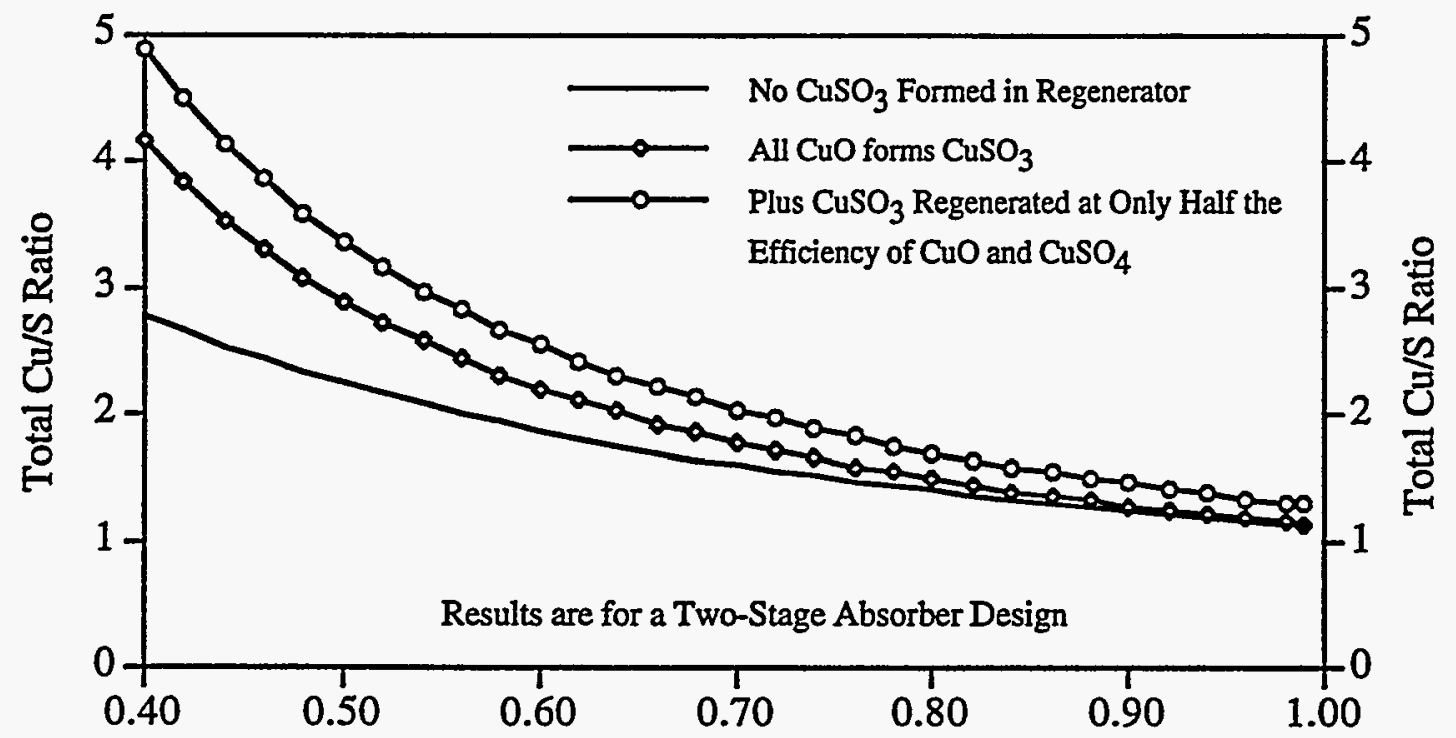

Regeneration Efficiency for $\mathrm{CuO}$ and $\mathrm{CuSO}_{4}$

Figure 15. Sensitivity of the Total Cu/S Molar Ratio to Regeneration Efficiencies.

cases. These three cases illustrate that attention must be focused on understanding regeneration and its implications for process performance and economics.

The economic implications of poor regeneration are shown in Figure 16. At low regeneration efficiencies, typical of those believed to have occurred in life cycle testing, the levelized costs may be as much as double or more the costs based on base case assumptions of 80 percent regeneration.

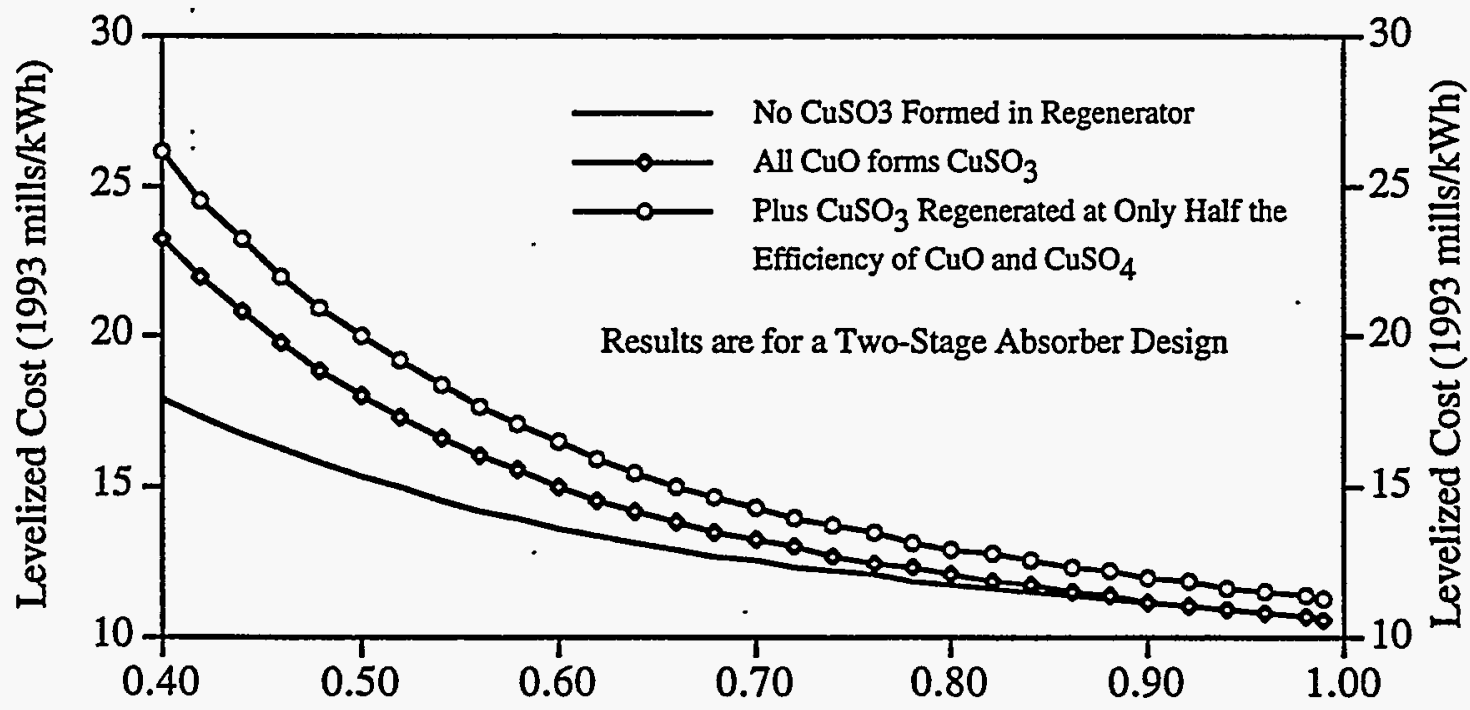

Regeneration Efficiency for $\mathrm{CuO}$ and $\mathrm{CuSO} 4$

Figure 16. Sensitivity of Levelized Cost to Regeneration Efficiencies. 


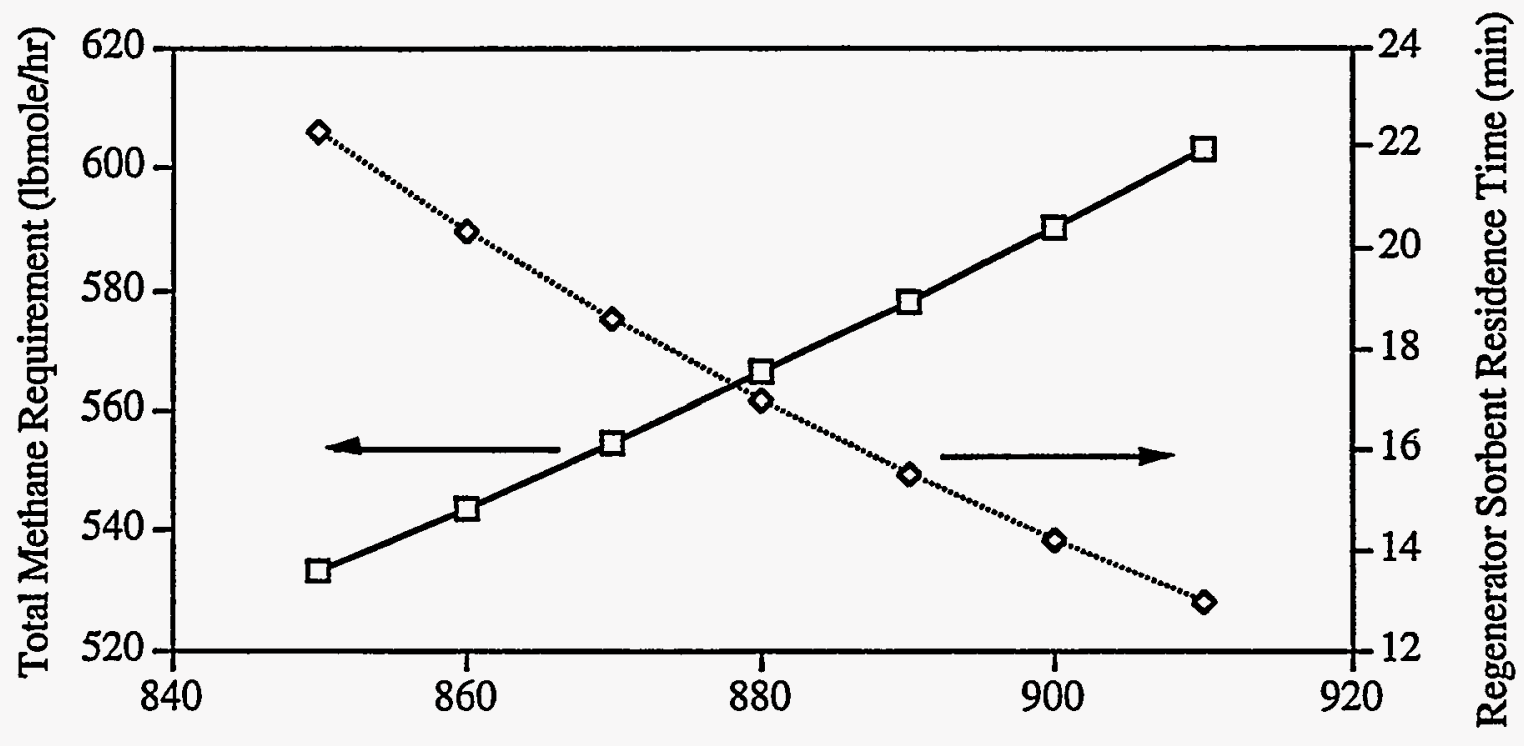

Regenerator Inlet Temp (oF)

Figure 17. Sensitivity of Total Methane Requirement and Regenerator Residence Time to the Regenerator Inlet Temperature.

\subsection{Regenerator Inlet Temperature}

The regenerator sorbent residence required to achieve a given regeneration efficiency is a function of the temperature of the inlet sorbent. This sensitivity is shown in Figure 17, together with a sensitivity analysis for the total methane required for the copper oxide process. As the sorbent inlet temperature is reduced, the kinetics of the regeneration reactions slow, leading to a requirement for a longer sorbent residence time to achieve a given copper sulfate conversion efficiency to copper. As temperature is reduced, however, less methane is required in the solids heater combustor to provide hot gases for sorbent heating.

The net effect of varying the regenerator sorbent inlet temperature on the levelized cost of the copper oxide process is shown in Figure 18. As the inlet temperature is reduced, the levelized costs are also reduced. The previous base case assumption was an inlet temperature of $900 \mathrm{oF}$, which results in a levelized cost of 12.04 mills $/ \mathrm{kWh}$. Reducing the inlet temperature to $850 \mathrm{oF}$ results in a levelized cost of 11.82 mills/kWh. While this is a modest savings on a percentage basis, for a $500 \mathrm{MW}$ power plant operating at a 65 percent capacity factor this represents a savings of over $\$ 600,000 /$ year. Further savings may be possible through additional reductions in the regenerator inlet temperature. However, such savings cannot be investigated with the current version of the residence time model. A simplified residence time model, Equation (103), is employed in the integrated performance and cost model of the copper oxide process. This model 


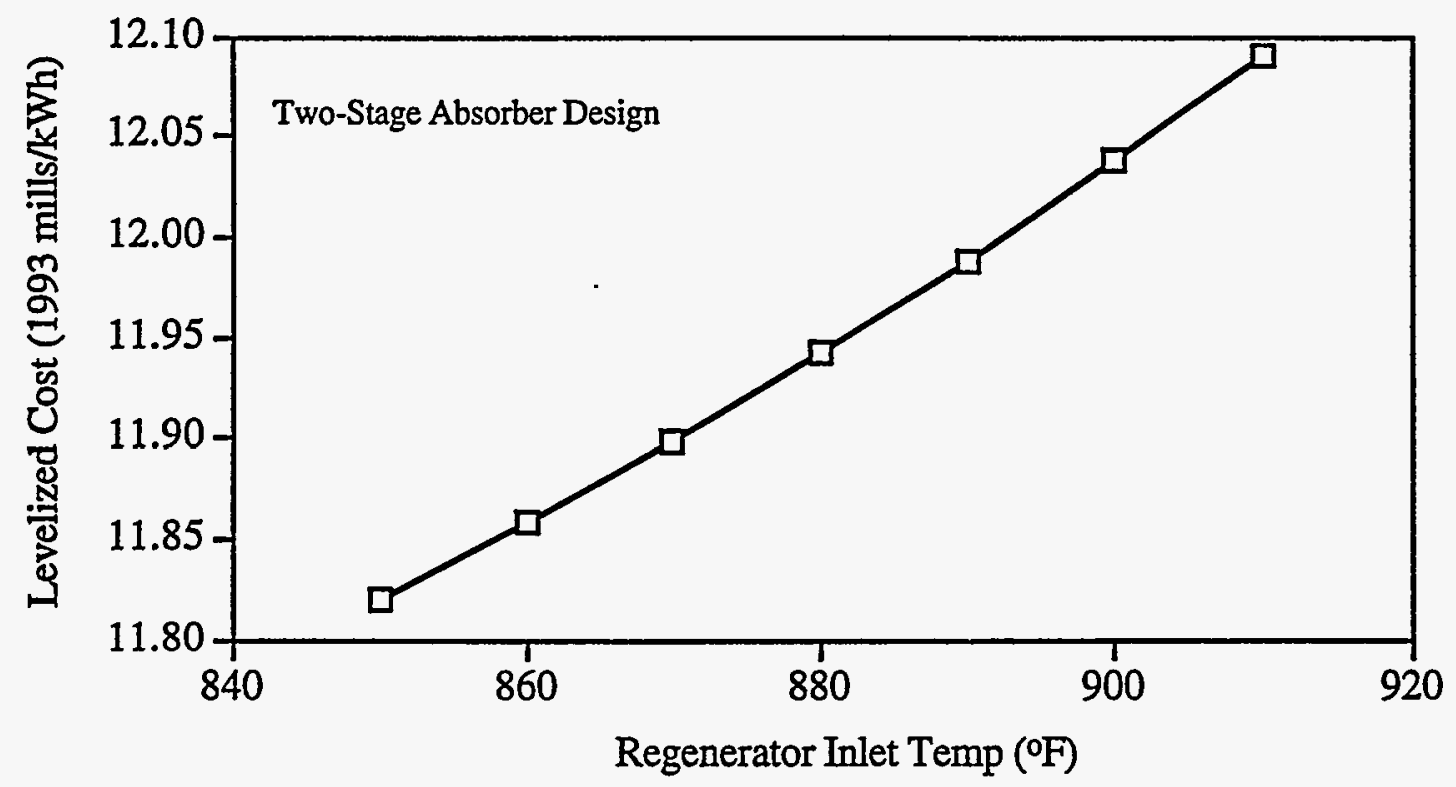

Figure 18. Sensitivity of Total Methane Requirement and Regenerator Residence Time to the Regenerator Inlet Temperature.

was developed based on the range of temperatures shown in Figure 18, and cannot be extrapolated. Development of a new response surface model sensitive to a wider range of temperatures is a need for future work.

A detailed comparison of a two-stage based absorber design with regenerator sorbent inlet temperatures of $900 \mathrm{~F}$ and $850 \mathrm{~F}$ is given in Table 14. The lower regenerator inlet temperature is used as the basis for further evaluation studies. 
Table 14. Capital, Annual, and Levelized Costs for the Fluidized Bed Copper Oxide Process: Effect of Regeneration Temperature on Costs ${ }^{a}$

\begin{tabular}{|c|c|c|}
\hline \multirow[b]{2}{*}{ Description } & \multicolumn{2}{|c|}{ Regenerator Temperature } \\
\hline & $900^{\circ} \mathrm{F}$ & $850^{\circ} \mathrm{F}$ \\
\hline $\mathrm{NH}_{3}$ Handling and Injection, $\mathrm{MS}$ & 2.036 & 2.036 \\
\hline Fluidized Bed Absorber Capital, M\$ & 6.381 & 6.381 \\
\hline ID Fan Differential, M\$ & 0.413 & $\overline{0.414}$ \\
\hline Solids Heater, M\$ & 3.101 & 2.756 \\
\hline Regenerator, M\$ & 3.219 & 3.540 \\
\hline Sorbent Transport System, M\$ & 7.255 & 7.258 \\
\hline Solids Heater Combustor, $\mathrm{M} \$$ & 3.357 & 2.668 \\
\hline Sulfur Recovery Plant, M\$ & 12.784 & 12.785 \\
\hline Air Preheater Modifications, MS & 4.437 & 3.784 \\
\hline Sorbent Inventory, M\$ & 5.741 & 6.170 \\
\hline Total Direct Capital Cost, M\$ & 53.022 & 51.956 \\
\hline Eng'ring \& Home Office Fees, M\$ & 7.953 & 7.793 \\
\hline Process Contingency, M\$ & 12.195 & 11.950 \\
\hline Project Contingency, M\$ & 6.833 & 6.626 \\
\hline Total Plant Cost ("overnight"), MS & 80.003 & 78.326 \\
\hline Interest, M\$ ( current dollars) & 7.565 & 7.406 \\
\hline Total Plant Investment, MS & 87.568 & 85.732 \\
\hline Startup (Preproduction) Cost, M\$ & 3.869 & 3.782 \\
\hline Working (Inventory) Capital, M\$ & 0.215 & 0.208 \\
\hline Land Cost, M\$ & 0.028 & 0.028 \\
\hline Total Capital Cost, M\$ & 91.680 & 89.749 \\
\hline Total Capital, $\$ / \mathrm{kW}$ & $\overline{194.922}$ & $\overline{191.428}$ \\
\hline Fixed Operating Cost, $\mathrm{M} \$ / \mathrm{yr}$ & 5.317 & 5.232 \\
\hline Sorbent Cost, $\mathrm{M} \$ / \mathrm{yr}$ & 12.828 & 12.884 \\
\hline Methane Cost, M\$/yr & 6.034 & 5.451 \\
\hline Ammonia Cost, $\mathrm{M} \$ / \mathrm{yr}$ & 0.795 & 0.795 \\
\hline Miscellaneous, M\$/yr & 0.441 & 0.441 \\
\hline Variable Operating Cost, M\$/yr & 20.098 & 19.571 \\
\hline Total O\&M Cost, $\mathrm{M} \$ / \mathrm{yr}$ & $\overline{19.808}$ & $\overline{19.345}$ \\
\hline Revenue wo Uti, M\$/yr & 29.286 & 28.624 \\
\hline Utilities, $\mathrm{M} \$ \mathrm{yr}$ & 2.975 & 2.954 \\
\hline Total Revenue, M\$/yr & 32.261 & 31.578 \\
\hline Total Rev, mills/kWh & 12.038 & 11.821 \\
\hline
\end{tabular}

a All costs are reported in 1993 dollars. Variable operating costs and levelized costs are calculated using a 65 percent plant capacity factor. The absorber capital cost for the two-stage design does not include any additional costs associated with a second stage distributor plate. The two-stage design is based on a lower stage with a 16-inch height operating at $30 \%$ sulfur capture efficiency. The upper stage is approximately 37 inches in height and operates at approximately 86 percent sulfur capture efficiency. The first case is for a regenerator sorbent inlet temperature of $900^{\circ} \mathrm{F}$. The second case is for a regenerator sorbent inlet temperature of $850^{\circ} \mathrm{F}$. 


\subsection{PROBABILISTIC ANALYSIS}

A probabilistic analysis was performed to evaluate uncertainties in the copper oxide process. This technology has been tested on only a small-scale, with no large-scale commercial experience that is required to verify expectations of performance and cost. Therefore, any estimate of performance or cost for this technology is subject to uncertainty.

A probabilistic analysis requires input assumptions or data regarding the uncertainties in key process and economic parameters. There are several types of uncertainty in trying to predict the commercial-scale performance and cost of a new process technology. These include statistical error, systematic error, variability, and lack of an empirical basis for concepts that have not been tested. Uncertainties may apply to different aspects of the process, including performance variables, equipment sizing parameters, process area capital costs, requirements for initial catalysts and chemicals, indirect capital costs, process area maintenance costs, requirements for consumables during plant operation, and the unit costs of consumables, byproducts, wastes, and fuel. Model parameters in any or all of these areas may be uncertain, depending on the state of development of the technology, the level of detail of the performance and cost estimates, and future market conditions for new chemicals, catalysts, byproducts, wastes, and other process components.

It may not always be possible to develop estimates of uncertainty based on classical statistical analysis, nor would such an approach be appropriate in many cases. Particularly for new process technologies, data may be lacking regarding some types of uncertainty. For example, the effect of scale-up on process performance may not be fully understood. Thus, analysis of benchscale test data alone may be an insufficient basis for estimating the total uncertainty in a variable. When data are lacking, estimates of uncertainty must rely on the informed judgments of technical experts. Judgments regarding uncertainties can be encoded as probability distributions, using techniques discussed elsewhere (see Appendix A for an overview).

\subsection{Input Uncertainty Assumptions.}

Uncertainties in specific performance and cost parameters were explicitly characterized using probability distributions. Identification of parameters that should be treated probabilistically, and the estimates of uncertainties for these parameters, were based on literature review, data analysis, and elicitation of expert judgments from DOE/PETC process engineers involved in technology development. This approach has also been applied by Frey et al. (1994) for evaluating an integrated gasification combined cycle (IGCC) system. 
Table 15. Summary of Deterministic and Uncertainty Assumptions for the Fluidized Bed Copper Oxide Process. ${ }^{\mathrm{a}}$

\begin{tabular}{|c|c|c|c|c|c|c|}
\hline \multirow[b]{2}{*}{ DESCRIPTION AND UNITS } & \multirow{2}{*}{$\begin{array}{l}\text { DET. } \\
\text { VAL. }\end{array}$} & \multicolumn{5}{|c|}{$\begin{array}{l}\text { DISTRIBUTIONS AND } \\
\text { THEIR PARAMETERS }\end{array}$} \\
\hline & & Type & Min & & Max & Mode \\
\hline $\begin{array}{l}\text { Sorbent Attrition in Fluidized Bed, wt-\% of } \\
\text { total bed inventory }\end{array}$ & 0.02 & $\mathrm{~T}$ & 0.01 & to & 0.02 & $(0.011)$ \\
\hline $\begin{array}{l}\text { Sorbent Attrition in Transport, wt-\% of } \\
\text { sorbent flow rate }\end{array}$ & 0.047 & $\mathbf{T}$ & 0.02 & to & 0.047 & $(0.047)$ \\
\hline $\mathrm{CuO}$ Converted to $\mathrm{CuSO}_{3}$ in Reg., fraction & 1 & $\mathbf{T}$ & 0.45 & to & 1 & $(0.6)$ \\
\hline Regeneration Efficiency for $\mathrm{CuSO}_{3}$, frac. & 0.8 & $\overline{\mathrm{U}}$ & 0.4 & to & 0.8 & \\
\hline $\begin{array}{l}\text { Standard Error of Estimate for Avail. } \mathrm{Cu} / \mathrm{S} \\
\text { ratio, fraction of model estimate }\end{array}$ & 1 & $\mathbf{N}$ & 0.9 & to & 1.1 & (1) \\
\hline Expanded Sorbent Density, lb/ft ${ }^{3}$ & 26.6 & $\bar{T}$ & 24.5 & to & 28.7 & $(26.6)$ \\
\hline $\begin{array}{l}\text { Relative Enthalpy of } \mathrm{CuSO}_{3} \text { Compared to } \\
\text { CuSO }_{4} \text {, fraction }\end{array}$ & 0.8 & $\mathrm{~T}$ & 0.7 & to & 0.9 & $(0.8)$ \\
\hline $\begin{array}{l}\text { Standard Error of Estimate of Regenerator } \\
\text { Residence Time, min }\end{array}$ & 0 & $\mathrm{~N}$ & -2 & to & 2 & (U) \\
\hline Ammonia Cost, \$/ton & 158 & $\overline{\mathrm{U}}$ & 158 & to & 237 & $(158)$ \\
\hline Natural Gas Cost, \$/mscf & 4.75 & $\mathbf{N}$ & 4.35 & to & 5.15 & $(4.75)$ \\
\hline Sorbent Cost, $\$ / \mathrm{lb}$ & 5.00 & $\mathrm{~T}$ & 2.50 & to & 5.00 & $(5.00)$ \\
\hline Sulfur Sales Price, $\$ /$ ton & 132 & $\bar{T}$ & 66 & to & 132 & (132) \\
\hline Indirect Cost Factor, fraction of direct cost & 0.45 & $\mathbf{N}$ & 0.36 & to & 0.54 & $(0.45)$ \\
\hline General Facilities Cost Factor, fraction & 0.10 & $\mathbf{N}$ & 0.08 & to & 0.12 & $(0.10)$ \\
\hline Engr. \& Home Office Fees cost, fraction & 0.15 & $\bar{N}$ & 0.12 & to & 0.18 & $(0.15)$ \\
\hline Project Contingency, fraction & 0.20 & $\bar{N}$ & 0.12 & to & 0.28 & $(0.20)$ \\
\hline \begin{tabular}{|l} 
Absorber Direct Cost Contingency and \\
Uncertainty, fraction
\end{tabular} & 0.20 & $\mathbf{N}$ & 0.08 & to & 0.32 & $(0.20)$ \\
\hline Ammonia Inj. DC Cont. and Unc., frac. & 0.20 & $\mathbf{N}$ & 0.08 & to & 0.32 & $(0.20)$ \\
\hline ID Fan Differ. DC Cont. and Unc., frac. & 0.10 & $\mathbf{N}$ & 0.04 & to & 0.16 & $(0.10)$ \\
\hline Regenerator DC Cont. and Unc., frac. & 0.20 & $\overline{\mathrm{N}}$ & 0.08 & to & 0.32 & $(0.20)$ \\
\hline Solids Heater DC Cont. and Unc., frac. & 0.20 & $\mathbf{N}$ & 0.08 & to & 0.32 & $(0.20)$ \\
\hline Sorbent Trans. DC Cont. and Unc., frac. & 0.20 & $\mathbf{N}$ & 0.08 & to & 0.32 & $(0.20)$ \\
\hline Solids Htr Comb. DC Cont. \& Unc., frac. & 0.20 & $\overline{\mathrm{N}}$ & 0.08 & to & 0.32 & $(0.20)$ \\
\hline Sulfur Plant DC Cont. and Unc., frac. & 0.10 & $\mathbf{N}$ & 0.04 & to & 0.16 & $(0.10)$ \\
\hline Air Preheater Mod. DC Cont. \& Unc., frac. & 0.10 & $\bar{N}$ & 0.04 & to & 0.16 & $(0.10)$ \\
\hline Total Direct Cost Uncertainty, factor & 1 & $\overline{\mathrm{N}}$ & 0.8 & to & 1.2 & (1) \\
\hline Pre-Production Cost Factor, frac. & 0.02 & $\mathbf{N}$ & 0.016 & to & 0.024 & $(0.02)$ \\
\hline Inventory Capital Cost Factor, frac & 0.005 & $\mathbf{N}$ & 0.004 & to & 0.006 & $(0.005)$ \\
\hline Maintenance Cost Factor, frac. & 0.045 & $\bar{N}$ & 0.036 & to & 0.054 & $(0.045)$ \\
\hline
\end{tabular}

${ }^{a}$ DET. VAL. = deterministic (point-estimate) value. Five columns are shown to define probability distributions. The first indicates the type of distribution, where $T=$ triangular, $N=$ normal, and $U=$ uniform. The remaining four columns provide the parameters of the distribution. For the uniform, the lower and upper bounds are given. For the triangular, the lower and upper bounds, and the mode (most likely) value are given. For the normal, the lower and upper bounds of the 95 percent confidence interval, and the mode, are given. 


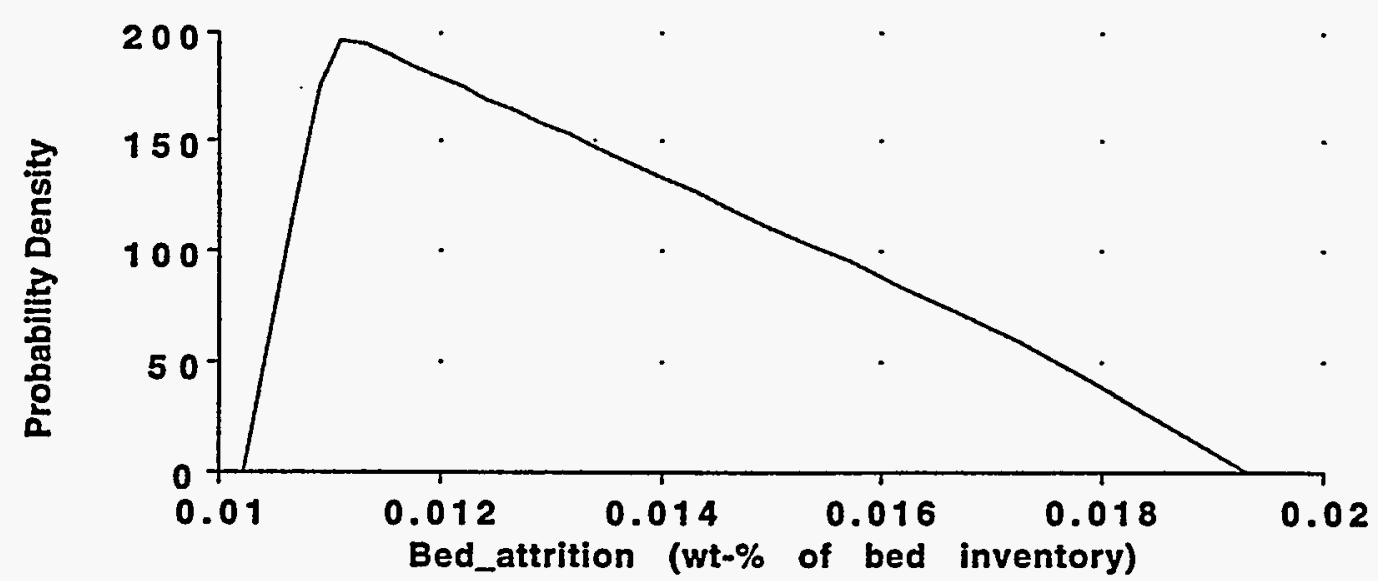

Figure 19. Uncertainty Assumption for the Sorbent Bed Attrition Rate.

The characterization of performance uncertainties focused on sorbent attrition, sorbent regeneration, and parameters affecting sulfation in the absorber. Uncertainties in additional cost model parameters also were characterized, including direct and indirect capital costs, operating and maintenance costs, and the unit costs of consumables, byproducts, and wastes. These assumptions are given in Table 15.

Several of the input assumptions are shown graphically. The uncertainties for sorbent bed attrition and circulation attritrition were assigned triangular distributions, as shown in Figures 19 and 20, respectively. In the case of bed attrition, experts at DOE/PETC believed that the performance of the copper oxide sorbent would be similar to that of the NOXSO sorbent, for which more test data and experience has been accumulated. While the default assumption is 0.02 weight-percent attrition as a percentage of the absorber bed inventory, it was felt that the attrition rate would improve with better sorbent formulations and improved absorber design. Thus, a "most likely" value representative of NOXSO experience was employed. For the circulation attritrion rate, the default assumption is believed to be conservative. It was assumed that this value may actually be highly uncertain, and may be able to attain significantly lower values than the default. However, the distribution is weighted toward higher values.

The uncertainty in the fractional conversion of $\mathrm{CuO}$ to $\mathrm{CuSO}_{3}$ at the regenerator inlet is shown in Figure 21. This distribution is based on a judgment by DOE/PETC engineers for a regenerator sorbent inlet temperature of $850^{\circ} \mathrm{F}$. The distribution is considerably broad due to the scarcity of data for characterizing this parameter. There is also considerable uncertainty as to whether $\mathrm{CuSO}_{3}$ is formed, versus some other possible compounds containing copper and oxygen. 


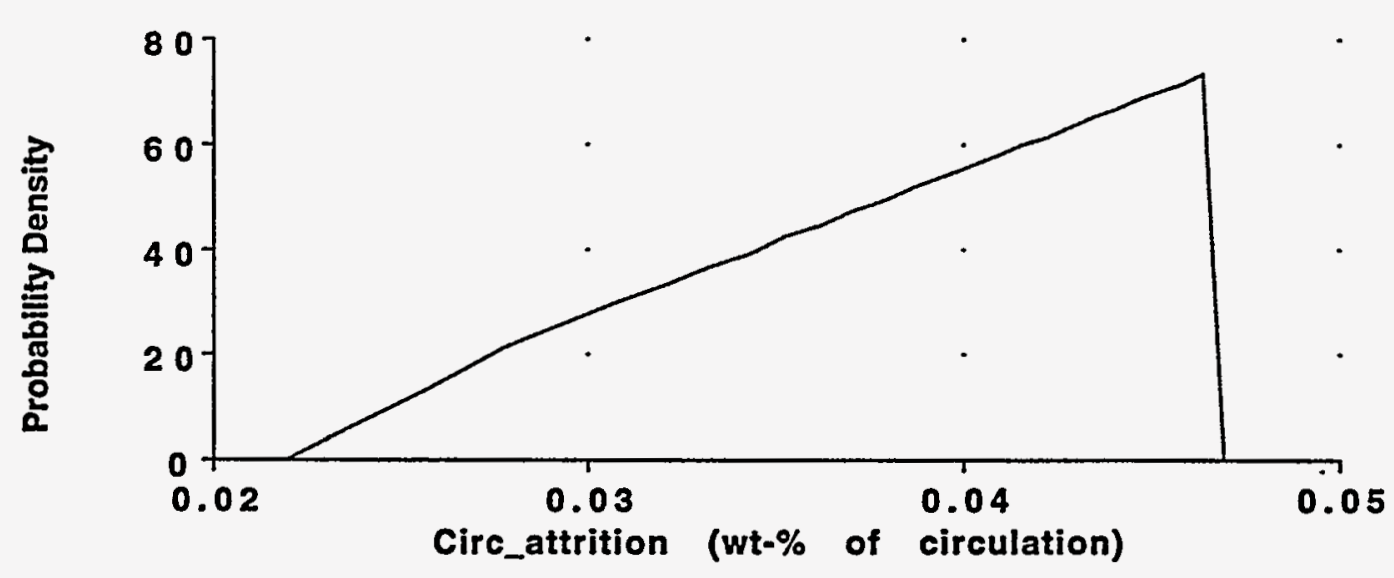

Figure 20. Uncertainty Assumption for the Sorbent Circulation Attrition Rate.

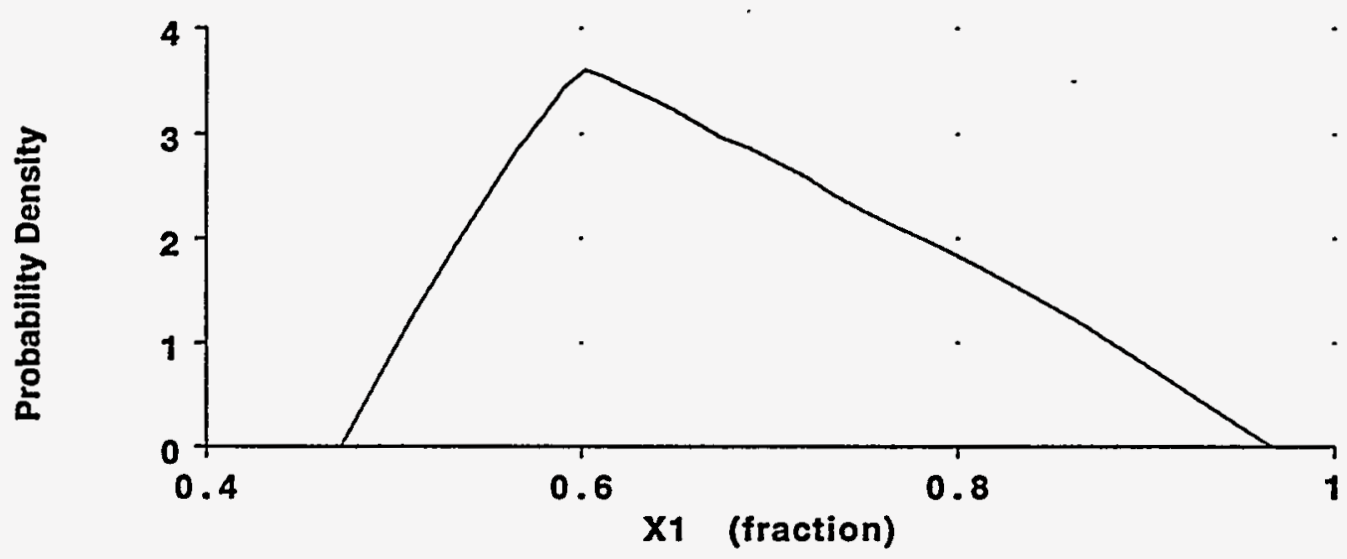

Figure 21. Uncertainty Assumption for the Fractional Conversion of $\mathrm{CuO}$ to $\mathrm{CuSO}_{3}$ at the Regenerator Inlet.

The uncertainty in the regeneration efficiency for $\mathrm{CuSO}_{3}$ is characterized as uniform distribution (see Figure 22), based on a judgment by DOE/PETC personnel. The lower end of the range represents a tentative observation in some preliminary experimental work on the kinetics of copper oxide sorbent regeneration. The upper end represents expectations for the regeneration of copper sulfate in a commercial scale regenerator.

The sorbent expanded density has exhibited considerable variability. in previous experimental work. This variability is represented by the triangular distribution shown in Figure 23.

The uncertainty in sorbent unit cost is shown in Figure 24. DOE/PETC personnel believe that the sorbent cost will be reduced from its nominal value of $\$ 5 / \mathrm{lb}$ with commercialization of the technology and mass production of the sorbent. 


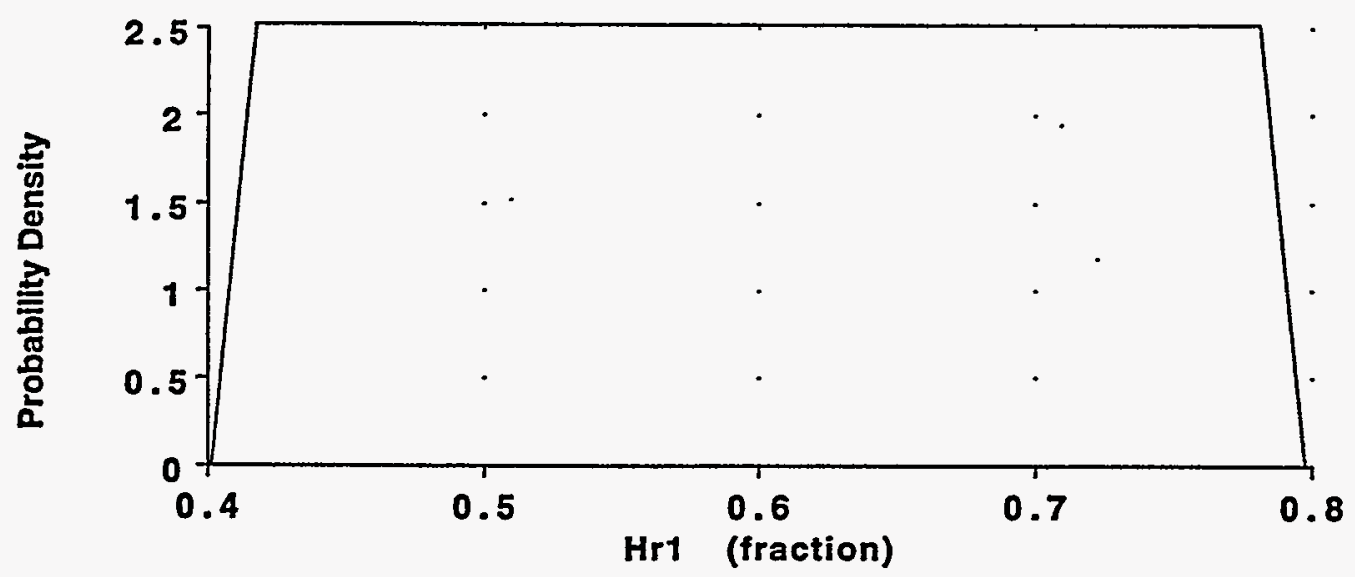

Figure 22. Uncertainty Assumption for the Regeneration Efficiency of $\mathrm{CuSO}_{3}$.

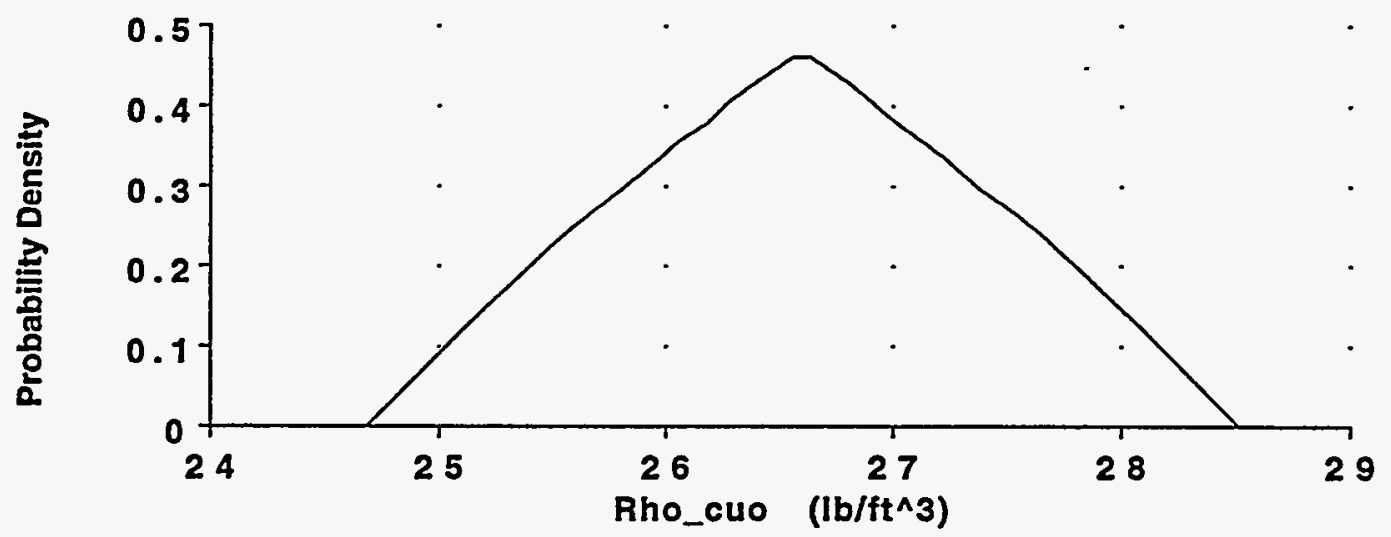

Figure 23. Uncertainty Assumption for the Sorbent Expanded Density.

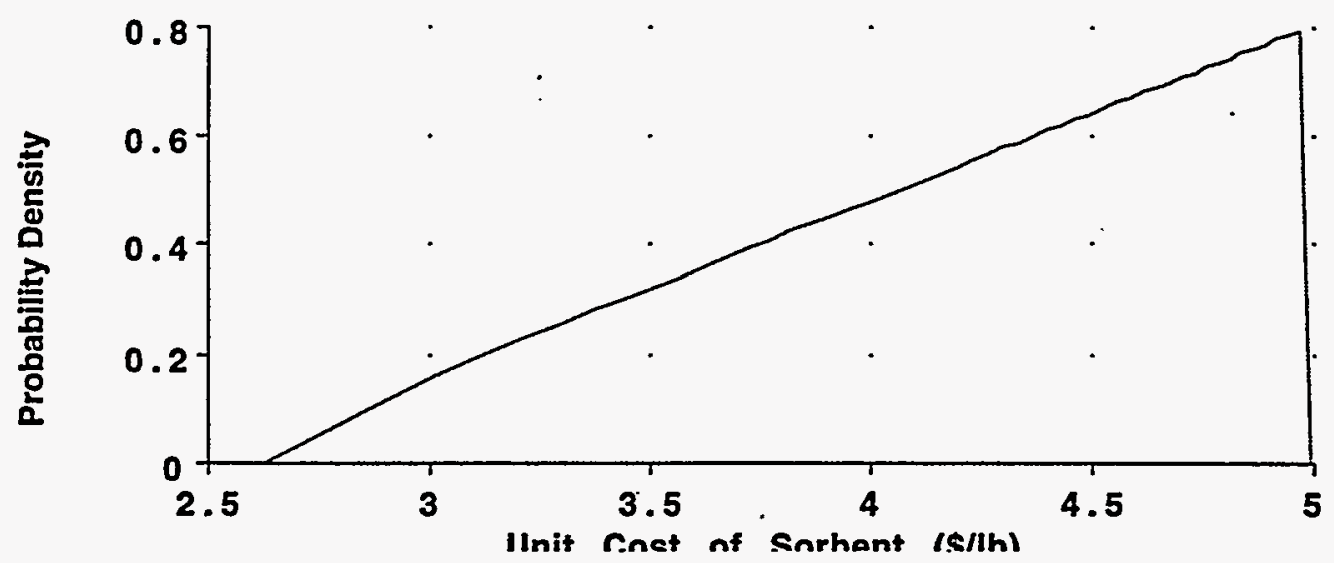

Figure 24. Uncertainty Assumption for the Sorbent Unit Cost. 
Uncertainties in the cost parameters of the model are based on nominal assumptions and previous analyses of this and other power generation and environmental control technologies. For . example, many of the multipliers used in capital cost models, such as engineering and home office fees, are estimated based on rules-of-thumb from recommended ranges of data. In such cases, the entire recommended range, rather than a single point estimate, is employed and represented as a distrubution. In the case of contingency factors, uncertainty distributions were assigned to these to represent the lack of a detailed basis for selecting a single point value. These direct capital cost uncertainty distributions represent both the systematic error and uncertainty in predicted direct capital costs for each process area. See Frey and Rubin $(1991,1992)$ and Frey (1991) for more details on previous case studies.

\subsection{Characterizing Uncertainty in Performance and Cost}

The uncertainties in Table 15 were propagated through the performance and cost model of the copper oxide model using the probabilistic modeling features of the IECM. Selected examples of output results are shown in Figure 25 through Figure 34.

The first example is the regenerator residence time, which varies from approximately 22 minutes to 29 minutes as a result of uncertainties in factors such as the fractional conversion of copper oxide to copper sulfite at the regenerator inlet, and the standard error of the estimate for the residence time response surface model. Another example of a performance-related uncertainty is the copper-to-sulfur molar ratio. This varies from approximately 1.05 to 1.35 , as shown in Figure 26. The copper-to-sulfur molar ratio is a key factor affecting the sorbent circulation rate, which is shown in Figure 27. The sorbent circulation rate varies from approximately $500,000 \mathrm{lb} / \mathrm{hr}$ to $700,000 \mathrm{lb} / \mathrm{hr}$. This uncertainty in circulation rate results in uncertainty in the size and, hence, cost, of many equipment items in the copper oxide process.

An example of a capital cost uncertainty is shown in Figure 28 for the direct capital cost of the fluidized bed absorber. This varies from approximately six to seven million dollars, with 95 percent confidence. The uncertainty in regenerator residence time and sorbent circulation rate directly affect the sizing and cost of the regenerator vessel. The uncertainty in the cost of this vessel is shown in Figure 29. The 95 percent confidence interval for this vessel encloses a range of approximately $\$ 100,000$. The uncertainty in the direct cost for all components of the regeneration process area is shown in Figure 30. The 95 percent confidence interval for the entire process area encloses a range of $\$ 500,000$.

A performance uncertainty which affects the $O \& M$ cost is the make-up sorbent flow rate, shown in Figure 31. This flow rate is uncertain by a factor of approximately two. 


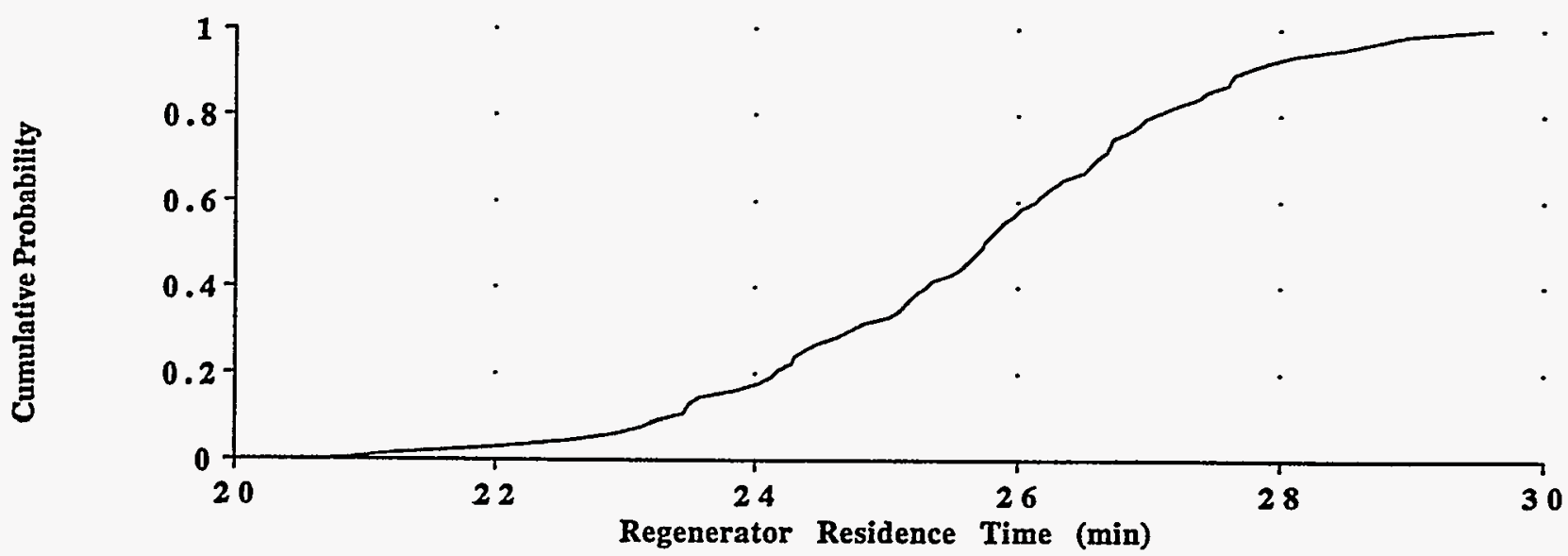

Figure 25. Uncertainty Result for Regenerator Residence Time.

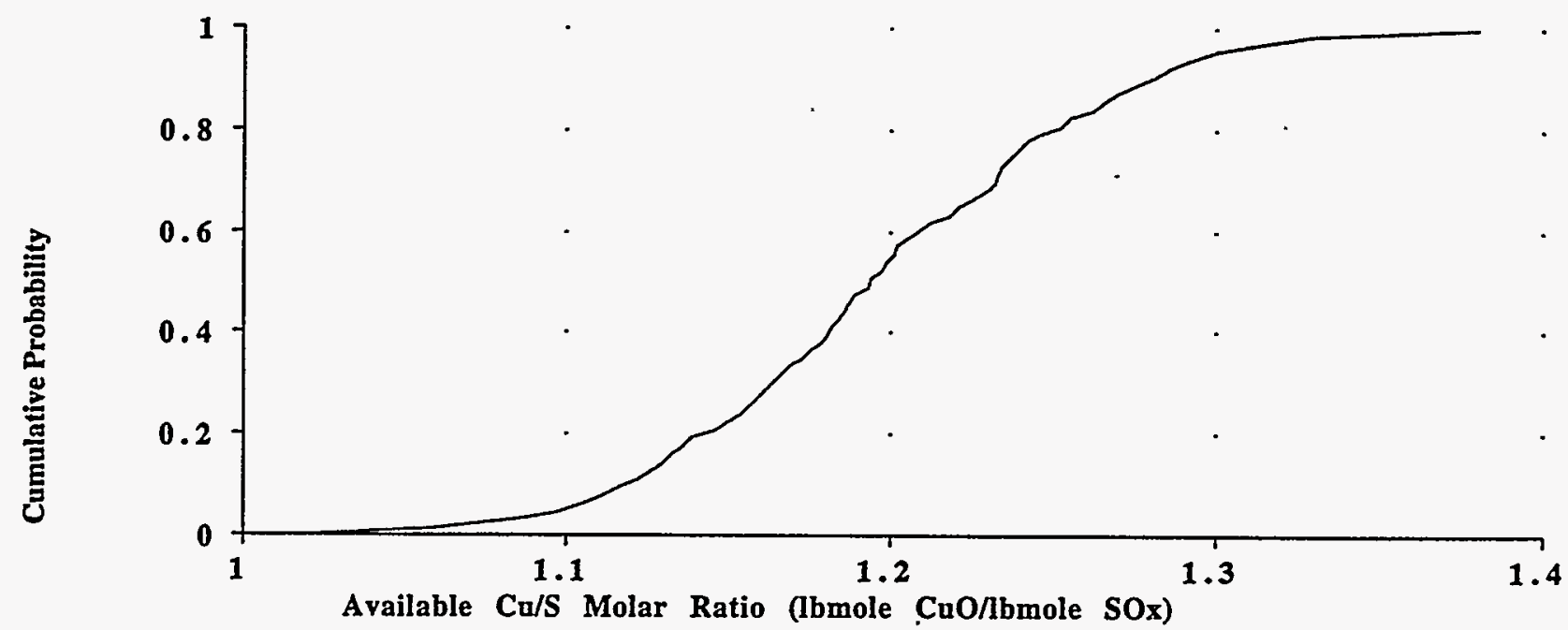

Figure 26. Uncertainty Result for Available Copper-to-Sulfur Molar Ratio.

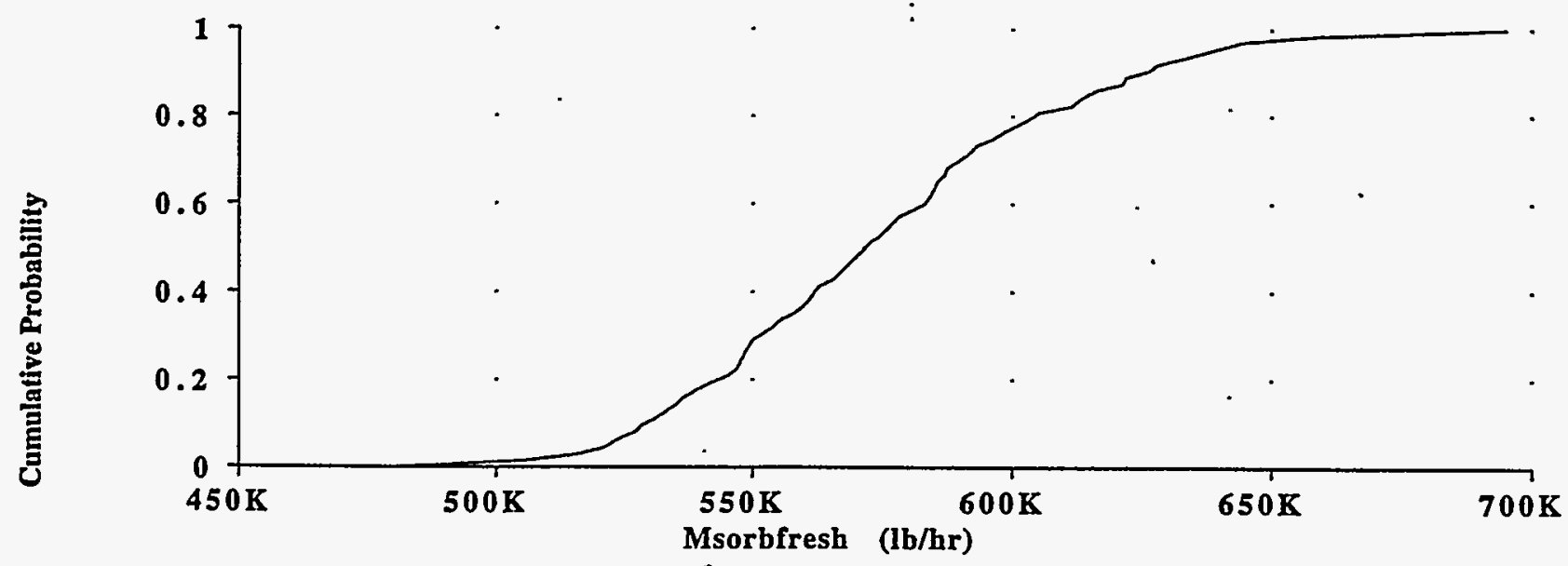

Figure 27. Uncertainty Result for Sorbent Circulation Rate (on a Fresh Basis). 


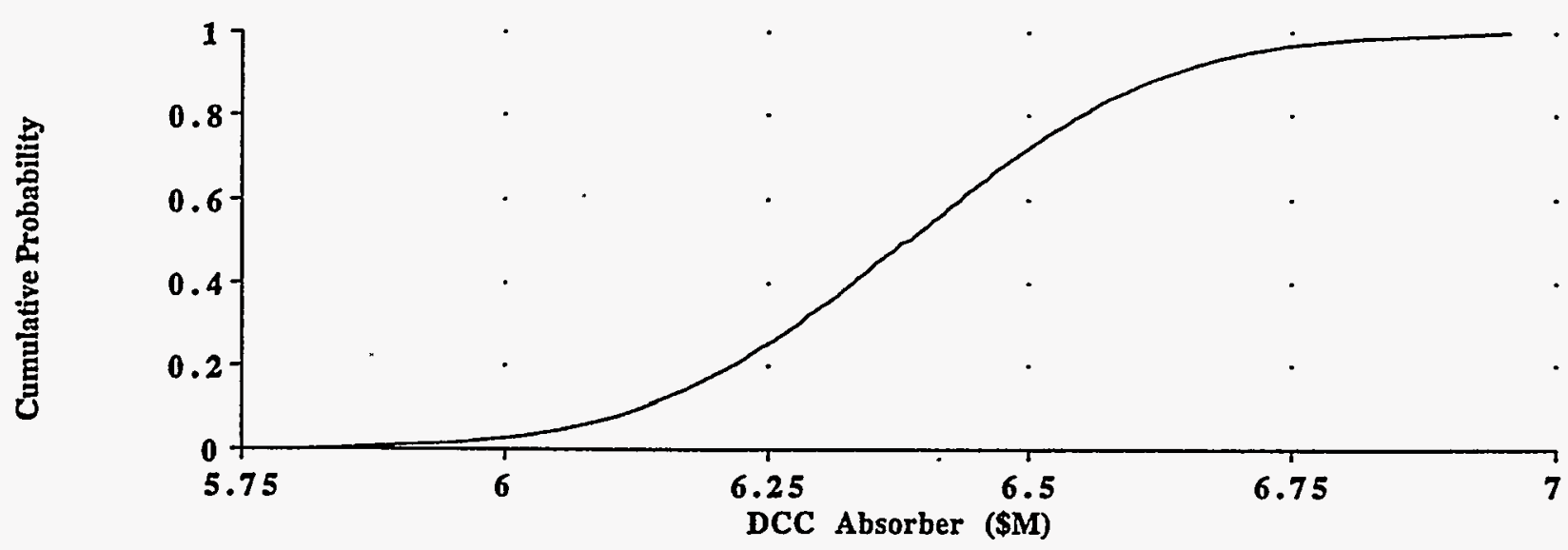

Figure 28. Uncertainty Result for the Direct Cost of the Absorber Process Area.

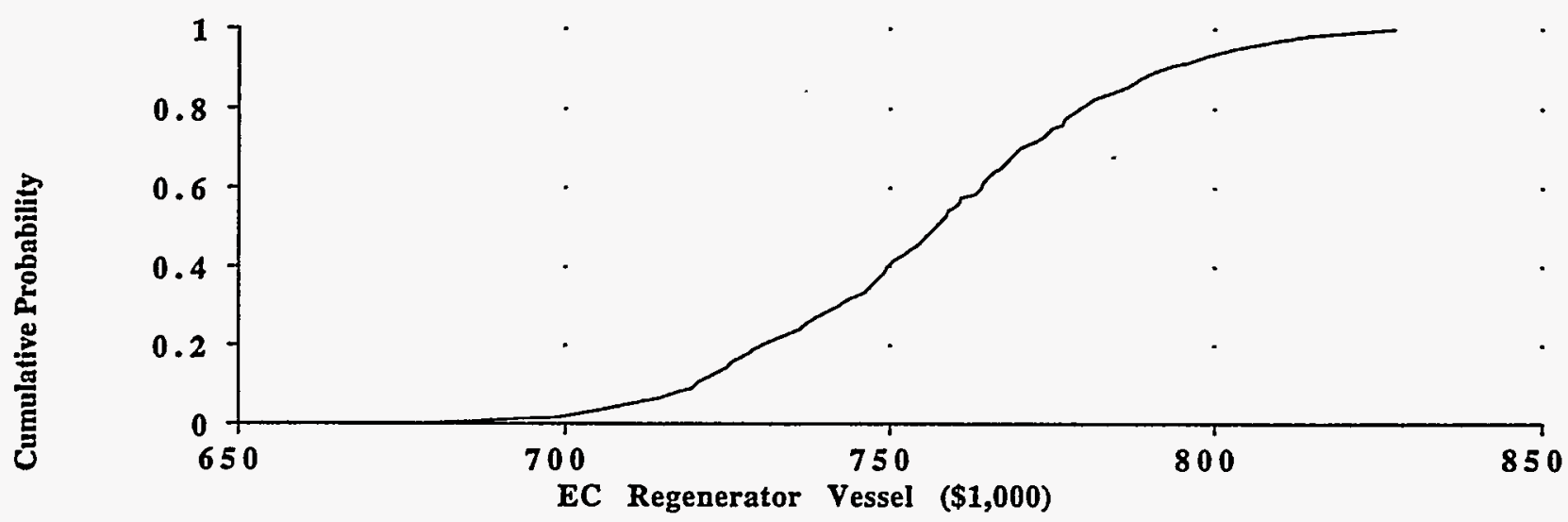

Figure 29. Uncertainty Result for the Equipment Cost of the Regenerator Vessel.

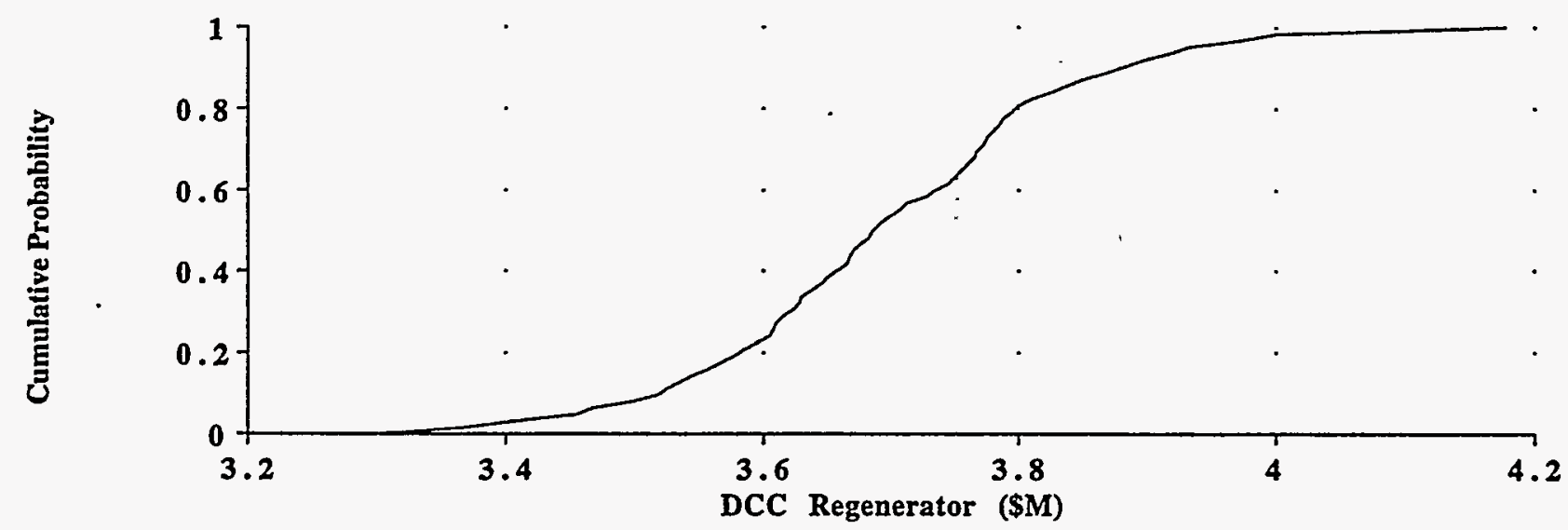

Figure 30. Uncertainty Result for the Direct Capital Cost of the Regenerator Process Area. 


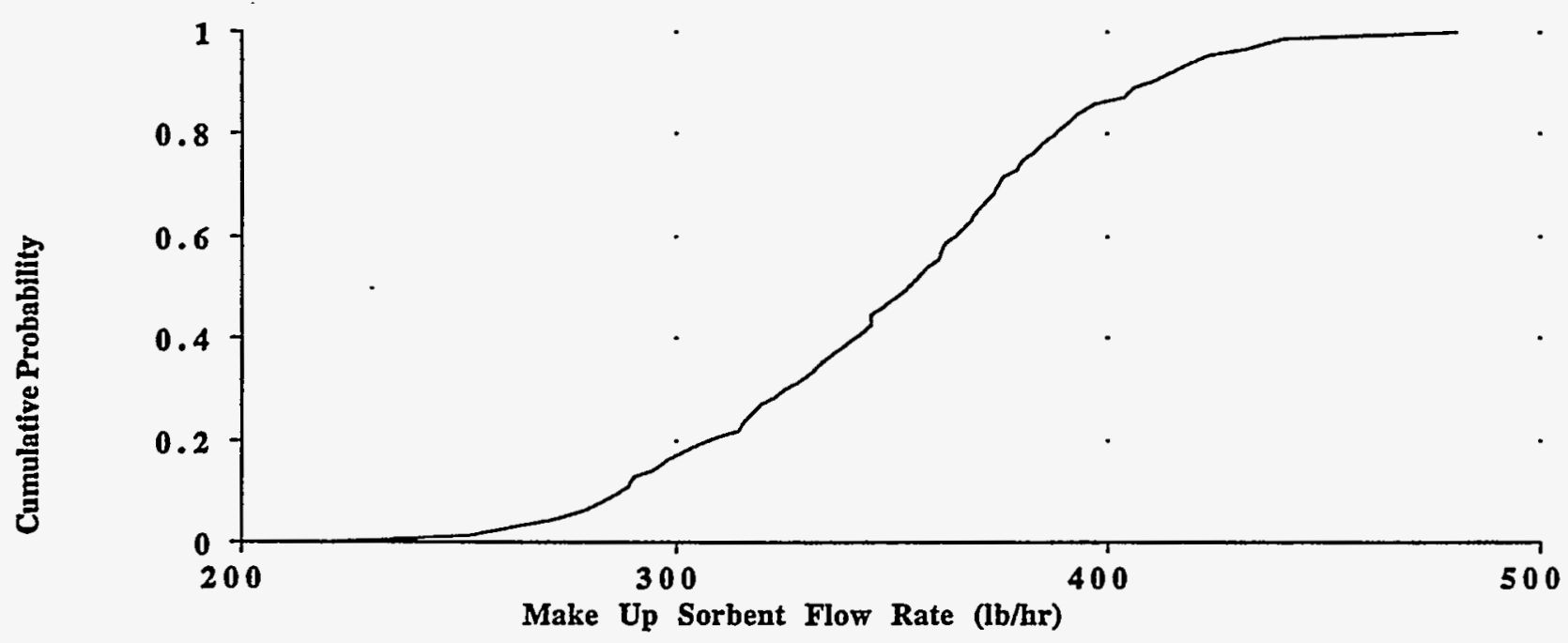

Figure 31. Uncertainty Result for the Make-Up Sorbent Flow Rate.

The ultimate measures of process viability are the total capital, annual, and levelized costs. The uncertainty in these parameters are shown in Figures 32,33, and 34, respectively. Recall from Table 14 that the estimated deterministic capital cost was $\$ 191 / \mathrm{kW}$, taking into account typical values of contingency factors employed in previous analyses. This corresponds closely to the mean value from the probabilistic simulation, which is $\$ 189 / \mathrm{kW}$. The probabilistic analysis, however, indicates that there is a substantial probability that the capital cost could be higher than the nominal deterministic value, and may in fact by higher by $\$ 50 / \mathrm{kW}$.

The deterministic estimate of 11.8 mills/kWh for the levelized cost of the copper oxide process is at the upper end of the distribution from the probabilistic simulation. Thus, it appears that potentially overly conservative assumptions may have been made in the deterministic estimate with regard to factors such as sorbent attrition and sorbent unit cost, which were assigned skewed . distributions based on judgments by and discussions with process experts. The mean estimate for the levelized cost is 10.4 mills $/ \mathrm{kWh}$, or approximately 1.4 mills $/ \mathrm{kWh}$ lower than the deterministic estimate.

In some ways, these results are contrary to general trends observed for cost estimates developed for technologies in early stages of development. Often, the cost of technologies are underestimated, and the performance is overestimated (e.g., Merrow et al., 1981). This trend has been observed in similar analyses of other process technologies (e.g., Frey and Rubin, 1992a). However, in this case, it appears at least somewhat plausible that the deterministic estimate may . actually overestimate average costs, due to the importance of only a handful of parameters in influencing the uncertainty in levelized costs. The sensitivity of the results to specific uncertainty assumptions is considered in the next section. 


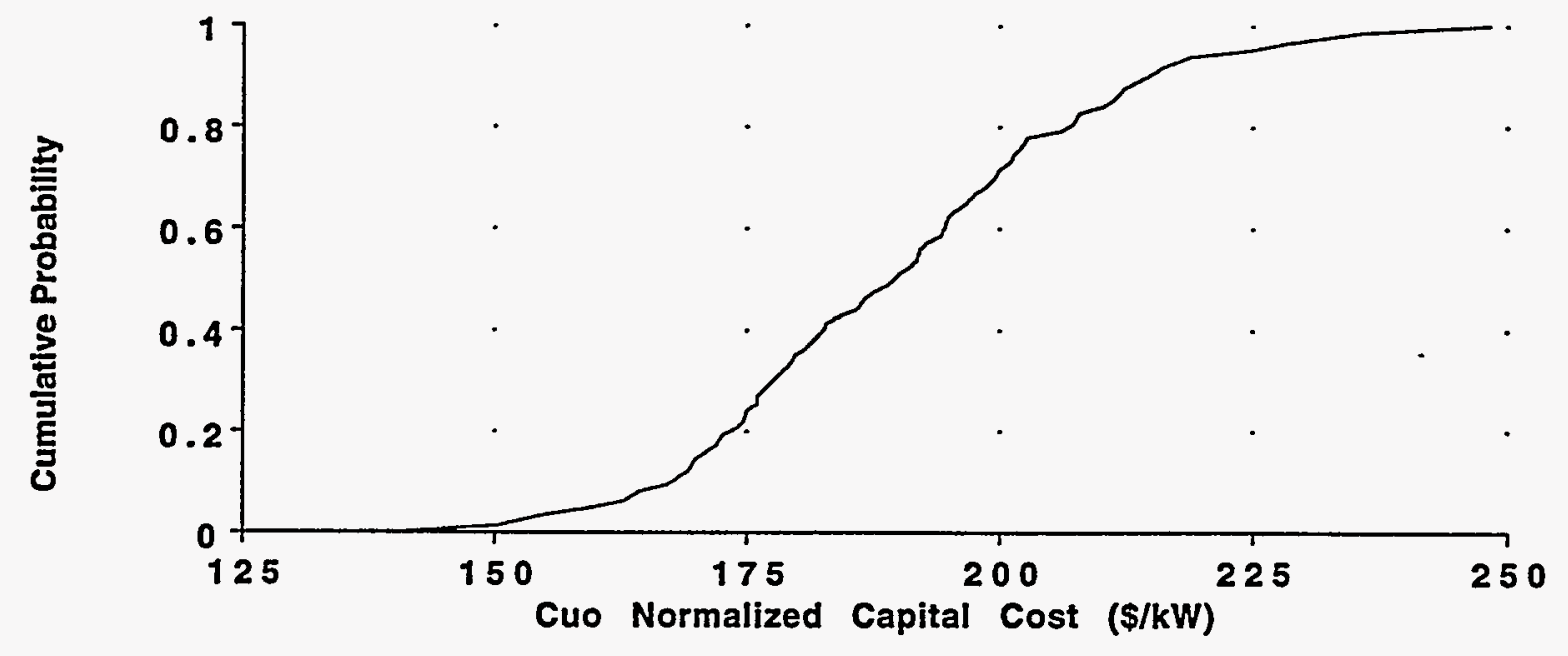

Figure 32. Uncertainty Result for the Copper Oxide Process Total Capital Cost.

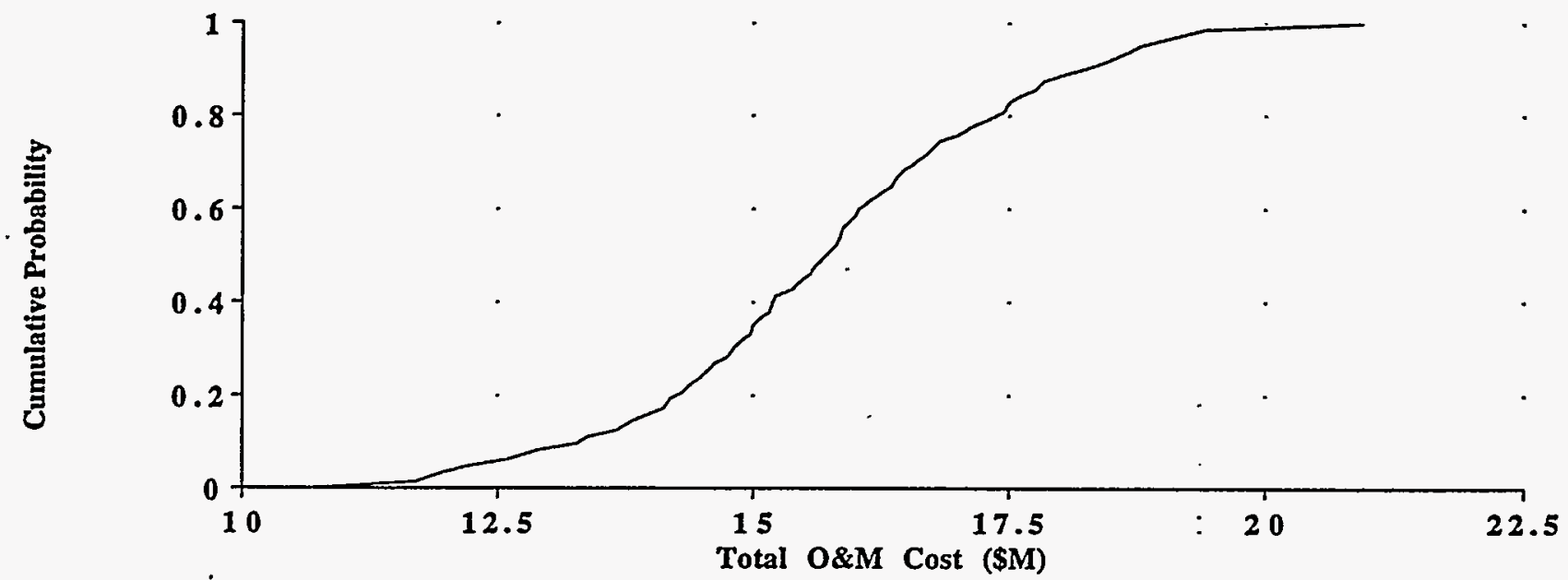

Figure 33. Uncertainty Result for the Copper Oxide Process Total Operating and Maintenance Cost. 


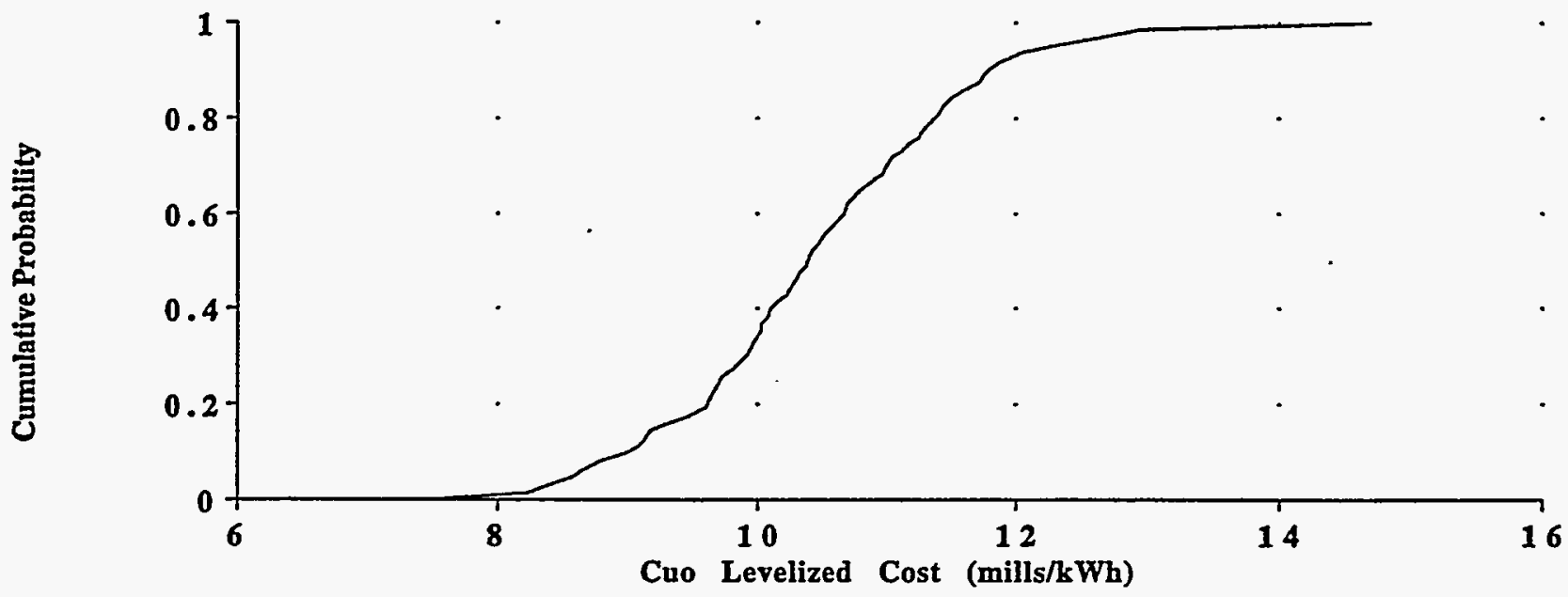

Figure 34. Uncertainty Result for the Copper Oxide Process Total Levelized Cost.

\subsection{Identifying Key Sources of Uncertainty}

One of the key advantages of probabilistic modeling is the capability to identify the key sources of uncertainty in model results when many model input variables are simultaneously uncertain. One technique for identifying key uncertainties is the use of rank correlation coefficients. The rank correlation coefficient provides a measure of the strength of the linear dependence between the rank ordering of sample values for model outputs (e.g., capital cost) to the rank ordering of sample values for model inputs (e.g., uncertainty in regeneration efficiency).

Five model output variables were selected for statistical analysis to identify key input sources of uncertainty. These are the available copper-to-sulfur molar ratio, sorbent circulation rate, total capital cost, total O\&M cost, and levelized cost. Approximately 30 inputs to the copper oxide process performance and economic models were specified as probability distributions. Therefore, the senstivity of each of these five model output variables were evaluated with respect to each of the thirty input uncertainties, except in cases where no dependence exists. For example, the $\mathrm{Cu} / \mathrm{S}$ ratio is not dependent on any of the economic uncertainty input assumptions.

A summary of the rank correlation results is given in Table 16. Strong correlations are highlighted with bold text. The uncertainty in the $\mathrm{Cu} / \mathrm{S}$ ratio is most highly correlated with uncertainty in the standard error of the estimate of the $\mathrm{Cu} / \mathrm{S}$ ratio, regeneration efficiency for copper sulfite, and the expanded sorbent density. The uncertainty in sorbent circulation rate is also most highly correlated with the standard error of the estimate of the $\mathrm{Cu} / \mathrm{S}$ ratio. However, the input uncertainties which most influenced uncertainty in the $\mathrm{Cu} / \mathrm{S}$ ratio and sorbent flow rate have little impact on the uncertainties in process costs. The capital cost uncertainty is most highly correlated with uncertainties in parameters of the capital cost model itself. Thus, uncertainty in capital cost is 
not driven, in this case, by uncertainties in performance parameters. This result is somewhat atypical of technologies which are not yet commercialized, for which many performance uncertainties must be resolved as a condition for developing more robust capital cost estimates. However, it is important to note that one effect of the adoption of a two-stage absorber design, versus the single-stage design employed in many previous evaluations, is a substantial reduction in overall sorbent circulation rates. This leads to a substantial reduction in the influence of sulfationrelated uncertainties on uncertainties in process economics, and leads to a proportionally larger contribution from equipment cost uncertainties.

The $O \& M$ uncertainty is driven by both performance and cost parameter uncertainties. The sorbent attrition rate uncertainty, as represented by uncertainties in both bed and circulation attrition, results in substantial uncertainty in the sorbent make-up rate (a factor of two, as previously illustrated). Combined with the uncertainty in the future cost of commercially produced copper oxide sorbent, the O\&M cost uncertainty is closely linked to sorbent replacement cost uncertainty. Uncertainties in sulfur byproduct markets also significantly influence O\&M cost uncertainty.

The key factors driving uncertainty in levelized cost illustrate a key advantage of probabilistic analysis over conventional point-estimate approaches using contingency factors and other multipliers to account for uncertainty. The uncertainty in levelized cost is driven by a performance-related uncertainty (sorbent attrition), a capital cost related uncertainty (total direct cost), and an annual cost uncertainty (sorbent unit cost). These three sources of uncertainty interact to significantly affect uncertainty in levelized cost. This type of simultaneous interaction among performance and cost uncertainties is not addressed in traditional cost estimating approaches.

An alternative approach to identifying key uncertainties is to use a technique that might be described as "probabilistic sensitivity analysis". This approach is illustrated in Figure 35. The contributions of various groups of uncertain parameters to the uncertainty in levelized cost is evaluated by running the copper oxide process models with probabilistic values for selected groups of variables, while holding all other variables at their nominal (deterministic) values. The results of this sensitivity analysis indicate that the range of values for levelized costs is determined mostly by the range of values from the economic-related uncertainties, but that the performance and economic uncertainties interact to shift the total costs of the process downward. This effect results from the negative skewness of many of the distributions and to differences between the deterministic assumptions, which may be overly conservative in some cases, and the most likely values in the probabilistic assumptions. 
Table 16. Absolute Values of Rank Correlations Between Key Model Outputs and Input Uncertainties.

\begin{tabular}{|c|c|c|c|c|c|}
\hline \multirow[b]{2}{*}{ DESCRIPTION AND UNITS } & \multicolumn{5}{|c|}{ SELECTED MODEL OUTPUTS } \\
\hline & $\mathrm{Cu} / \mathrm{S}$ & $\mathrm{m}_{\mathrm{s}}$ & TCC & O\&M & $\overline{\mathrm{COE}}$ \\
\hline $\begin{array}{l}\text { Sorbent Attrition in Fluidized Bed, wt-\% of } \\
\text { total bed inventory }\end{array}$ & & & $\overline{0.04}$ & 0.28 & 0.14 \\
\hline $\begin{array}{l}\text { Sorbent Attrition in Transport, wt-\% of } \\
\text { sorbent flow rate }\end{array}$ & & & $\overline{0.12}$ & 0.53 & $\overline{\mathbf{0 . 3 8}}$ \\
\hline $\mathrm{CuO}$ Converted to $\mathrm{CuSO}_{3}$ in Reg., fraction & 0.04 & $\mathbf{0 . 1 9}$ & 0.03 & 0.03 & 0.02 \\
\hline Regeneration Efficiency for $\mathrm{CuSO}_{3}$, frac. & 0.21 & 0.47 & 0.19 & 0.18 & $\overline{0.16}$ \\
\hline $\begin{array}{l}\text { Standard Error of Estimate for Avail. } \mathrm{Cu} / \mathrm{S} \\
\text { ratio, fraction of model estimate }\end{array}$ & $\overline{0.96}$ & 0.86 & $\overline{0.16}$ & $\overline{0.14}$ & 0.15 \\
\hline Expanded Sorbent Density, $\mathrm{lb} / \mathrm{ft}^{3}$ & $\overline{\mathbf{0 . 1 9}}$ & $\overline{0.18}$ & $\overline{0.09}$ & 0.04 & 0.00 \\
\hline $\begin{array}{l}\text { Relative Enthalpy of } \mathrm{CuSO}_{3} \text { Compared to } \\
\mathrm{CuSO}_{4} \text {, fraction }\end{array}$ & $\overline{0.09}$ & $\overline{0.12}$ & 0.06 & 0.10 & $\overline{0.11}$ \\
\hline $\begin{array}{l}\text { Standard Error of Estimate of Regenerator } \\
\text { Residence Time, } \min \end{array}$ & & & 0.04 & 0.07 & 0.09 \\
\hline Ammonia Cost, \$/ton & & & 0.05 & 0.06 & 0.02 \\
\hline Natural Gas Cost, $\$ / \mathrm{mscf}$ & & & 0.08 & 0.12 & 0.03 \\
\hline Sorbent Cost, $\$ / \mathrm{lb}$ & & & 0.09 & 0.60 & 0.39 \\
\hline Sulfur Sales Price, $\$ /$ ton & & & 0.05 & 0.28 & $\overline{0.15}$ \\
\hline Indirect Cost Factor, fraction of direct cost & & & $\overline{0.16}$ & 0.01 & $\overline{0.01}$ \\
\hline General Facilities Cost Factor, fraction & & & 0.04 & $\overline{0.04}$ & $\overline{0.04}$ \\
\hline Engr. \& Home Office Fees cost, fraction & & & 0.07 & 0.03 & $\overline{0.00}$ \\
\hline Project Contingency, fraction & & & $\mathbf{0 . 3 0}$ & 0.06 & $\overline{0.08}$ \\
\hline $\begin{array}{l}\text { Absorber Direct Cost Contingency and } \\
\text { Uncertainty, fraction }\end{array}$ & & & 0.03 & $\overline{0.08}$ & $\overline{0.02}$ \\
\hline Ammonia Inj. DC Cont. and Unc., frac. & & & 0.01 & $\overline{0.12}$ & 0.07 \\
\hline ID Fan Differ. DC Cont. and Unc., frac. & & & 0.04 & $\overline{0.02}$ & $\overline{0.02}$ \\
\hline Regenerator DC Cont. and Unc., frac. & & & 0.02 & 0.09 & 0.05 \\
\hline Solids Heater DC Cont. and Unc., frac. & & & 0.02 & 0.03 & $\overline{0.01}$ \\
\hline Sorbent Trans. DC Cont. and Unc., frac. & & & $\overline{0.06}$ & 0.01 & $\overline{0.01}$ \\
\hline Solids Htr Comb. DC Cont. \& Unc., frac. & & & 0.05 & 0.08 & $\overline{0.06}$ \\
\hline Sulfur Plant DC Cont. and Unc., frac. & & & $\overline{0.06}$ & 0.02 & 0.03 \\
\hline Air Preheater Mod. DC Cont. \& Unc., frac. & & & 0.01 & 0.05 & 0.05 \\
\hline Total Direct Cost Uncertainty, factor & & & 0.89 & 0.19 & $\overline{0.38}$ \\
\hline Pre-Production Cost Factor, frac. & & & 0.18 & 0.04 & 0.00 \\
\hline Inventory Capital Cost Factor, frac & & & 0.05 & 0.13 & $\overline{0.04}$ \\
\hline Maintenance Cost Factor, frac. & & & $\overline{0.06}$ & $\overline{0.12}$ & 0.05 \\
\hline
\end{tabular}




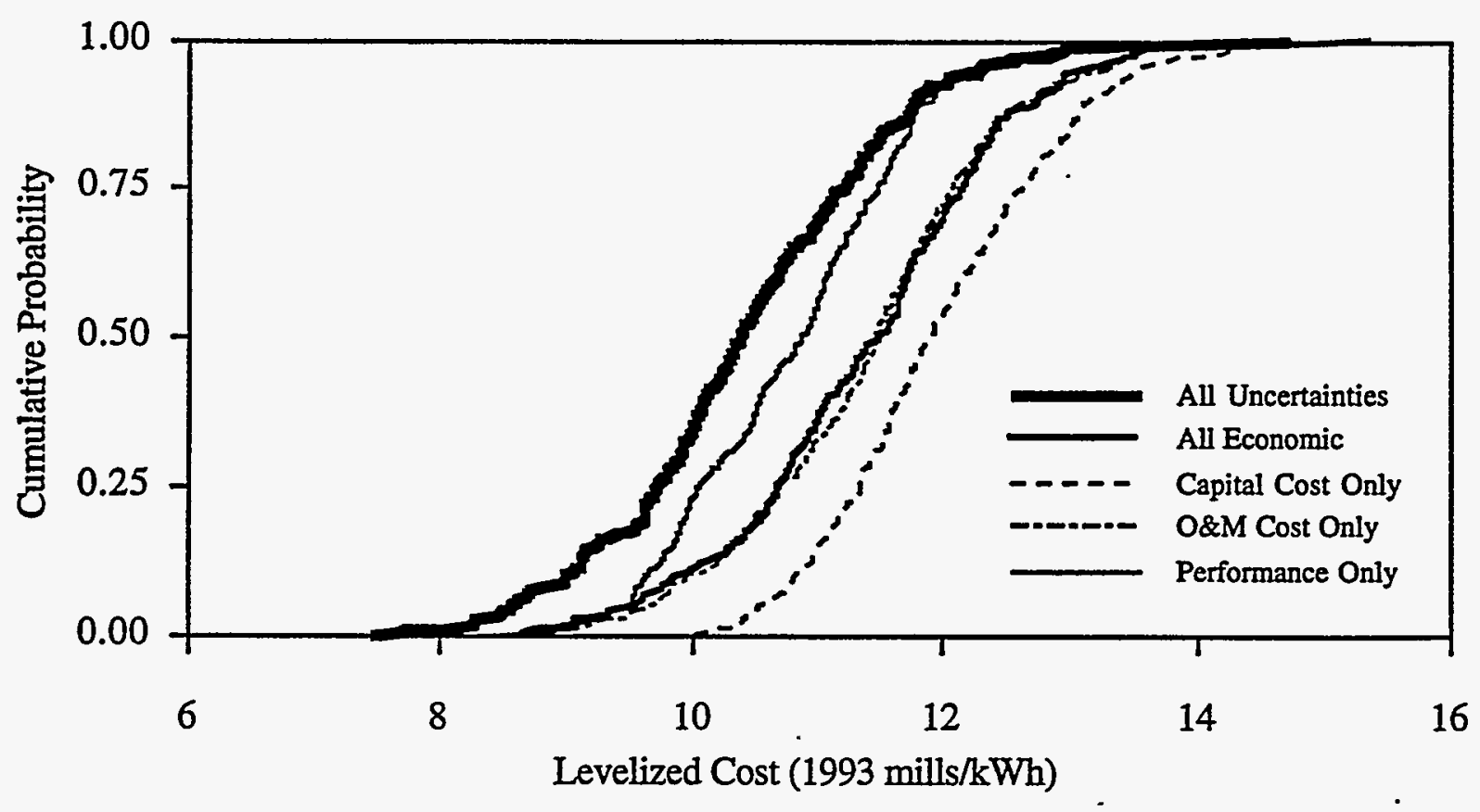

Figure 35. Uncertainty Result for the Copper Oxide Process Total Levelized Cost.

\subsection{Evaluating Design Trade-Offs Probabilistically}

The significant levels of uncertainty identified in key measures of process performance suggest that comparisons of design alternatives should be evaluated taking into account uncertainties. For example, a key result from the deterministic sensitivity analyses in the previous chapter was that the cost of a two-stage absorber-based system would offer substantial cost savings compared to a single-stage absorber based system. A nominal cost savings of 1.4 mills/kWh was estimated. This result is revisited using probabilistic assumptions.

The results of a comparison based on the difference in levelized cost for a one-stage absorber system versus a two-stage absorber system is shown in Figure 36. The difference is carefully calculated by pairing samples values from two probabilistic simulations, one for each design option. Because the input uncertainties are correlated between the two systems, this pairing is required. The sample values from the two-stage simulation were subtracted from the corresponding paired sample values for the one-stage system.

The results show considerable uncertainty in the total savings, ranging by a factor of approximately four from 0.7 to 2.8 mills $/ \mathrm{kWh}$. However, these results do illustrate that there is certain to be a cost savings, and that the cost savings may be substantially higher than the deterministic estimate. 


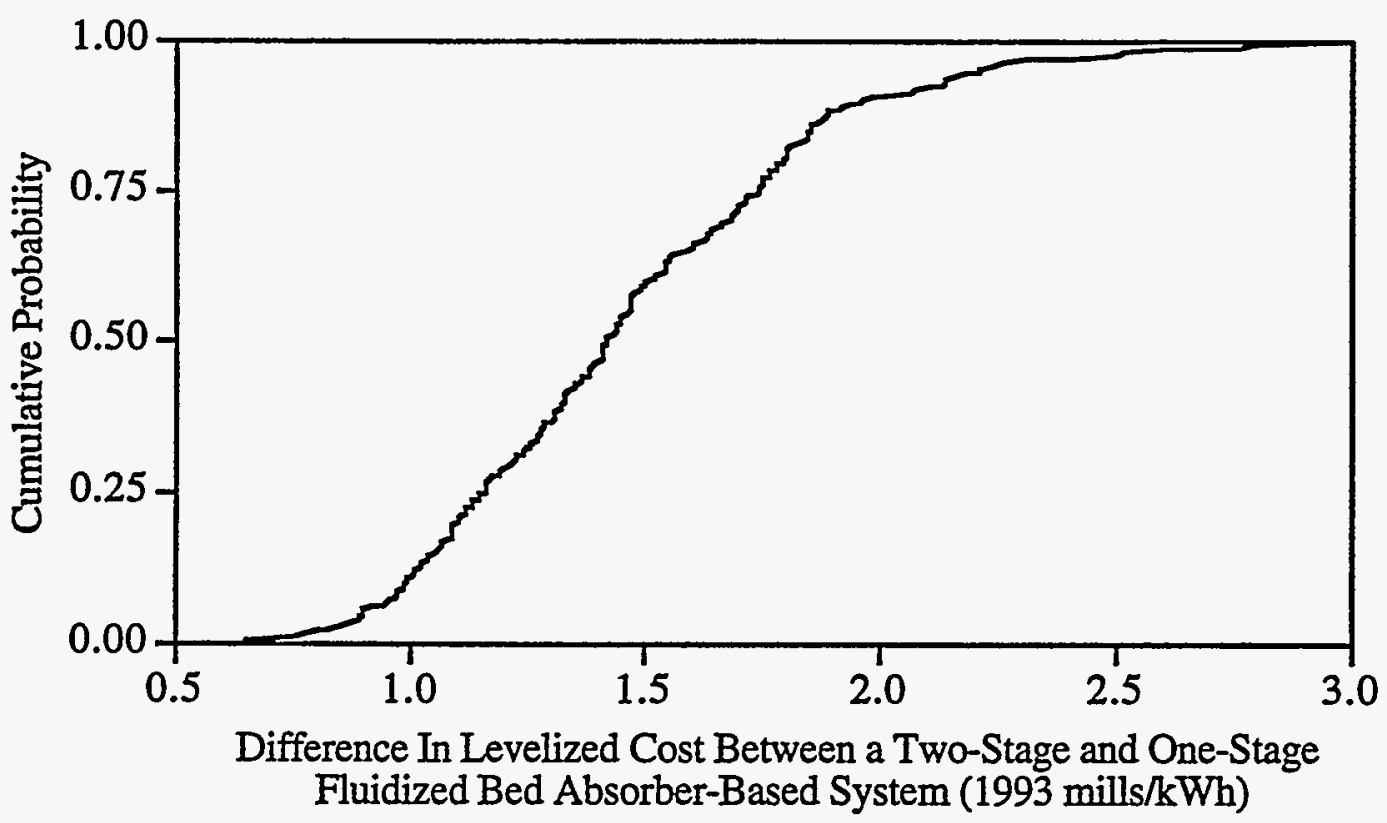

Figure 36. Uncertainty in the Cost Savings for a Two-Stage Absorber System Versus a One-Stage Absorber System. 


\subsection{DISCUSSION AND FUTURE WORK}

A detailed performance and cost model of the copper oxide process has been developed. This model was applied in a series of key sensitivity and probabilistic analyses to identify key factors which affect process uncertainties and which merit further investigation. However, to determine the priority of further work on this technology requires additional comparative evaluations of the copper oxide process with respect to competing options such as flue gas desulfurization and selective catalytic reduction, and other combined $\mathrm{SO}_{\mathrm{x}} / \mathrm{NO}_{\mathrm{x}}$ processes such as the NOXSO process. Such analyses are planned for future work. In addition, other variants of the copper oxide process, such as the moving bed process, may offer cost savings compared to the fluidized bed process. These, too, will be investigated in future work.

The results here provide a road map for further refinement of the model and the uncertainty estimates. Other applications of the probabilistic evaluation method not discussed here include: (1) evaluation of the reductions in uncertainty that may be obtained from further process research; (2) evaluation of alternative judgments regarding model parameter uncertainties by different experts as they affect model results; (3) evaluation of the importance of correlation structures in model parameter uncertainties; (4) comparative analysis of competing technologies under uncertainty; and (5) the use of decision analysis techniques to interpret modeling results. These types of applications are discussed elsewhere (e.g, Frey, 1991).

Significant uncertainties inevitably surround advanced environmental control technologies in the early stages of development. Thus, engineering performance and cost models developed to evaluate process viability must be capable of adequately analyzing and displaying the consequences of these uncertainties. Toward this end, the probabilistic modeling capability described here allows the effect of uncertainties in multiple performance and cost parameters to be evaluated explicitly. The results give a measure of overall uncertainty in key model outputs, such as cost, and serve to identify the key process variables that contribute most to overall uncertainty.

As shown in the case studies of the copper oxide process, probabilistic analysis provides explicit insights into the range and likelihood of outcomes for key measures of plant performance and cost. In many cases, there is a probability of obtaining extreme outcomes, such as low performance or high cost, that would result in technology failure. The characterization of uncertainties in performance and cost results from the simultaneous interaction of uncertainties in many input parameters. These types of insights cannot be obtained from deterministic analysis. 
Case studies for the fluidized bed copper oxide process illustrated potential applications of an integrated environmental control system framework for process design and comparative analyses. Interactions among various components of the environmental control system, which are frequently overlooked in many process studies, were found to significantly influence overall system costs. This is true, for example, in the case of air preheater modifications to capture the energy released to the flue gas in the absorber for use in heating the boiler combustion air. Probabilistic comparisons between advanced and conventional technologies can also provide quantitative assessments of the potential benefits and risks of new technology in various market situations. The potential payoff from process research and development also may be evaluated using the methods described here.

Of course, as with any other modeling approach, probabilistic methods rely on data and judgments that must be provided by the user. To be sure, different judgments or assumptions can alter the results. But forcing process developers and evaluators to consider uncertainties explicitly (rather than ignore them) in probabilistic engineering models can help improve research planning and management by allowing the implications of alternative judgments to be tested. Indeed, experience to date suggests that the process of thinking about key parameter uncertainties, as inputs to a model, often is the most valuable component of this approach that fosters improved understanding of the systems being modeled. 


\section{Nomenclature}
$\mathrm{A}=$ Fluidized bed area, $\mathrm{ft}^{2}$
$\mathrm{F}_{\mathrm{s}} \quad=$ Sorbent feed rate at absorber inlet, fresh sorbent basis, $\mathrm{lb} / \mathrm{min}$
$\mathrm{G}_{\mathrm{FG}}=$ Volumetric flue gas flow rate at absorber inlet, $\mathrm{ft}^{3} / \mathrm{min}$
$\mathrm{I}_{\mathrm{b}} \quad=$ Bed inventory, $\mathrm{lb}$
$\mathrm{k}_{\mathrm{S}} \quad=$ Reaction rate constant, $1 /($ min॰atm $)$
$\mathrm{m}_{\mathrm{s}} \quad=$ Sorbent mass flow rate, $\mathrm{lb} / \mathrm{hr}$
$\mathrm{M}_{\mathrm{i}} \quad=$ Molar flow rate of species $\mathrm{i}, \mathrm{lbmole} / \mathrm{hr}$
$\mathrm{M}_{\mathrm{i}, \mathrm{j}, \mathrm{k}}=$ Molar flow rate of species $\mathrm{i}$ at process area $\mathrm{j}$ 's inlet or outlet $\mathrm{k}$ (e.g., $\mathrm{MSO}_{2, \mathrm{a}, \mathrm{i}}=$ molar flow of SO2 at the absorber inlet), $1 \mathrm{bmole} / \mathrm{hr}$
$\mathrm{MW}_{\mathrm{Cu}}=$ Molecular weight of copper, $63.54 \mathrm{lb} / \mathrm{lbmole}$
$\mathrm{MW}_{\mathrm{CuO}}=$ Molecular weight of copper oxide, $79.54 \mathrm{lb} / \mathrm{lbmole}$
$\mathrm{MW}_{\mathrm{CuSO}_{3}}=$ Molecular weight of copper sulfite, $143.54 \mathrm{lb} / \mathrm{lbmole}$
$\mathrm{MW}_{\mathrm{CuSO}}{ }_{4}=$ Molecular weight of copper sulfate, $159.54 \mathrm{lb} / \mathrm{bmole}$
$\mathrm{P} \quad=$ Absorber inlet pressure, atm
$\mathrm{r}_{\mathrm{abs}}=$ Internal radius of absorber, feet
$\mathrm{r}_{\mathrm{ves}} \quad=$ Radius of steel absorber vessel, feet
$\mathrm{R}=\mathrm{Absorber}$ Inlet Available $\mathrm{Cu}$ to inlet $\mathrm{SO}_{2}$ molar ratio, lbmole CuO/bmole $\mathrm{SO}_{2}$
$\mathrm{t}_{\mathrm{hr}}=$ Thickness of hot refractory, feet
$\mathrm{t}_{\mathrm{ir}}=$ Thickness of inner or base refractory, feet
$\mathrm{t}_{\mathrm{r}, \mathrm{a}}=$ Absorber solids residence time, $\min$
$\mathrm{T}=$ Absorber bed temperature, $\mathrm{K}$
$\mathrm{V}_{\mathrm{s}} \quad=$ Superficial flue gas velocity at absorber inlet, $\mathrm{ft} / \mathrm{sec}$
$\mathrm{W}_{\mathrm{Cu}}=$ Weight fraction $\mathrm{Cu}$ as $\mathrm{CuO}$ in fresh sorbent, $\mathrm{lb} \mathrm{Cu} / \mathrm{lb}$ sorbent 


$$
\begin{array}{ll}
\mathrm{x} & =\text { molar fraction of copper as copper sulfate at the regenerator inlet } \\
\mathrm{x}_{1} & =\begin{array}{l}
\text { molar fraction of copper oxide converted to copper sulfite just inside } \\
\text { regenerator }
\end{array} \\
\mathrm{y}_{\mathrm{i}} & =\mathrm{SO}_{2} \text { inlet flue gas concentration, } 1 \mathrm{bmoles} \mathrm{SO}_{2} / \mathrm{lbmole} \text { flue gas } \\
\mathrm{y}_{0} & =\mathrm{SO}_{2} \text { outlet flue gas concentration, } 1 \mathrm{bmoles} \mathrm{SO}_{2} / \mathrm{lbmole} \text { flue gas } \\
\mathrm{Z} & =\text { Fluidized bed height, } \mathrm{ft}
\end{array}
$$

Greek Letter Symbols

$$
\begin{array}{ll}
\alpha & =\text { Kinetic parameter (dimensionless) } \\
\eta_{\mathrm{r}} & =\text { Overall sorbent regeneration efficiency, fraction } \\
\eta_{\mathrm{r} 1} & =\text { Regeneration efficiency for copper sulfite, fraction } \\
\eta_{\mathrm{r} 2} & =\text { Regeneration efficiency for copper sulfate, fraction } \\
\eta_{\mathrm{r} 3} & =\text { Regeneration efficiency for copper oxide, fraction } \\
\eta_{\mathrm{s}} & =S O_{2} \text { removal efficiency, fraction } \\
\rho_{\mathrm{s}} & =\text { Sorbent density (expanded bed), } 1 \mathrm{~b} / \mathrm{ft}^{3}
\end{array}
$$

Subscripts

$$
\begin{aligned}
& \mathrm{A}=\text { Absorber } \\
& \mathrm{Cu}=\text { Copper }: \\
& \mathrm{CuO}=\text { Copper Oxide } \\
& \mathrm{CuSO}_{3}=\text { Copper Sulfite } \\
& \mathrm{CuSO}_{4}=\text { Copper Sulfate } \\
& \text { fresh }=\text { Sorbent on a fresh basis } \\
& \mathrm{i} \quad=\text { Inlet } \\
& \mathrm{O} \quad=\text { Outlet } \\
& \mathrm{R} \quad=\text { Regenerator } \\
& \mathrm{s} \quad=\text { Sorbent }
\end{aligned}
$$


$\mathrm{SO}_{2}=$ Sulfur dioxide

$\mathrm{SO}_{3}=$ Sulfur trioxide

$\mathrm{SO}_{\mathrm{x}}=$ All sulfur oxide species 


\subsection{REFERENCES}

A.E. Roberts and Associates, Inc. (1994). Conceptual Design and Economic Evaluation of the Fluidized Bed Copper Oxide Process. Prepared for UOP, Inc. and the U.S. Department of Energy. March.

Barin, I., and O. Knacke (1973). Thermochemical Properties of Inorganic Substances. SpringerVerlag, New York.

Barin, I., O. Knacke, and O. Kubaschewski (1977). Thermochemical Properties of Inorganic Substances: Supplement. Springer-Verlag, New York.

Chase., M.W., et al. (1985). "JANAF Thermochemical Tables, Third Edition, Part 11, Cr-Zr," Journal of Physical and Chemical Reference Data, Vol. 14, Supplement No. 1.

Demski, R.J., S.J. Gasior, E.R. Bauer, Jr., J.T. Yeh, J.P. Strakey, and J.I. Joubert (1982). "Simultaneous Removal of $\mathrm{SO}_{2}$ and $\mathrm{NO}_{\mathrm{x}}$ From Flue Gas Employing a Fluidized-Bed Copper Oxide Process," 1982 Summer Session of AIChE, August 29 to September 1.

Drummond, C.J., J.T. Yeh, J.I. Joubert, and J.A. Ratafia-Brown (1985). The Design of a Dry, Regenerative Fluidized Bed Copper Oxide Process for the Removal of Sulfur Dioxide and Nitrogen Oxides from Coal-Fired Boilers. Presented at the 78th Annual Meeting of the Air Pollution Control Association, June 16-21.

Frey, H.C. (1987). Performance and Economic Model of the Fluidized Bed Copper Oxide Process. Master's Thesis. Department of Mechanical Engineering, Carnegie-Mellon University. Pittsburgh, PA. May.

Frey, H.C., E.S. Rubin, and J.S. Salmento (1989), "Evaluation of the Fluidized Bed Copper Oxide Process Using A Probabilistic Engineering Model," Proceedings of the Sixth Annual International Pittsburgh Coal Conference, Pittsburgh, Pennsylvania, p. 356-365.

Frey, H.C., and E.S. Rubin (1991), "Probabilistic Evaluation of Advanced $\mathrm{SO}_{2} / \mathrm{NO}_{\mathrm{X}}$ Control Technology," Journal of the Air and Waste Management Association, 41(12):1585-1593 (December).

Frey, H.C., and E.S. Rubin (1992), "An Evaluation Method for Advanced Acid Rain Compliance Technology," Journal of Energy Engineering, 118(1):38-55 (April).

Frey, H.C., and E.S. Rubin (1992a), "Evaluation of Advanced Coal Gasification Combined-Cycle Systems Under Uncertainty," Industrial and Engineering Chemistry Research, 31(5):1299-1307.

Frey, H.C., E.S. Rubin, and U.M. Diwekar (1994), "Modeling Uncertainties in Advanced Technologies: Application to a Coal Gasification System with Hot Gas Cleanup," Energy 19(4):449-463.

Harriott, P. (1992a). Personal Communication to D. Henzel, June 3.

Harriott, P. (1992b). Personal Communication to D. Henzel, August 4.

Harriott, P. (1992c). Personal Communication to C. Frey, August 14.

Harriott, P., and J.M. Markussen (1992), "Kinetics of Sorbent Regeneration in the Copper Oxide Process for Flue Gas Cleanup," Industrial and Engineering Chemistry Research, 31(1):373-379. 
Merrow, E.W., K.E. Phillips, and C.W. Myers (1981). Understanding Cost Growth and Performance Shortfalls in Pioneer Process Plants. Prepared by Rand Corporation for U.S. Department of Energy.

Plantz, A.R., C.J. Drummond, S.W. Hedges, and F.N. Gromicko (1986). Performance of the Fluidized Bed Copper Oxide Process in an Integrated Test Facility. Presented at the 79th Annual Meeting of the Air Pollution Control Association, Minneapolis, Minnesota. June 22-27.

Rubin, E.S., J.S. Salmento, J.G. Barrett, C.N. Bloyd, and H.C. Frey (1986). Modeling and Assessment of Advanced Processess for Integrated Environmental Control of Coal-Fired Power Plants. Prepared by the Center for Energy and Environmental Studies, Carnegie-Mellon University, for the U.S. Department of Energy, Pittsburgh Energy Technology Center. July.

Rubin, E.S., J.S. Salmento, and H.C. Frey (1988). Cost-Effective Emission Controls for CoalFired Power Plants. Chemical Engineering Communications, 74. pp. 155-167. December

Rubin, E.S., J.S. Salmento, and H.C. Frey (1989), "Evaluating Combined $\mathrm{SO}_{2} / \mathrm{NO}_{\mathrm{x}}$ Processes," Proceedings: Fourth Symposium on Integrated Environmental Control, Electric Power Research Institute, Palo Alto, California, EPRI Report No. GS-6519, September, p. 6-1 to 6-15.

Rubin, E.S., J.S. Salmento, H.C. Frey, A. Abu-Baker, and M. Berkenpas (1991), Modeling of Integrated Environmental Control Systems for Coal-Fired Power Plants, Final Report (draft), submitted by Carnegie-Mellon University to the U.S. Department of Energy, Pittsburgh, Pennsylvania, DOE Contract No. DE-AC22-87PC79864, April, 214p.

Rubin, E.S., H.C. Frey, and M.B. Berkenpas (1992), "Development of the Integrated Environmental Control Model," Proceedings, Eighth Annual Coal Preparation, Utilization, and Environmental Control Contractor's Conference, U.S. Department of Energy Pittsburgh Energy Technology Center, Pittsburgh, Pennsylvania, July 27-30, pp. 619-626.

SMC (1983a). Technical and Economic Evaluation of the Fluidized Bed Copper Oxide Flue Gas Treatment Process and Integrated Sulfur-Producing Plants. Prepared by Science Management Corporation for the U.S. Department of Energy, Pittsburgh Energy Technology Center, Pittsburgh, PA. June.

SMC (1983b). Technical and Economic Evaluation of Design Optimization Issues Associated With the Fluidized Bed Copper Oxide Flue Gas Treatment Process. Prepared by Science Management Corporation for the U.S. Department of Energy, Pittsburgh Energy Technology Center, Pittsburgh, PA. November.

SMC (1983c). Economic Evaluation of the Fluidized Bed Copper Oxide Flue Gas Treatment Process and Integrated Sulfuric Acid Plant. Prepared by Science Management Corporation for the U.S. Department of Energy, Pittsburgh Energy Technology Center, Pittsburgh, PA. April.

SMC (1984). Modeling of the Regenerator Reactor for the Fluidized Bed Copper Oxide Flue Gas Treatment Process. Prepared by Science Management Corporation for the U.S. Department of Energy, Pittsburgh Energy Technology Center, Pittsburgh, PA. May.

Williamson, R.R., J.A. Morici, and T.L LaCosse (1987). Sorbent Life Cycle Testing, Fluidized Bed Copper Oxide Process. Prepared by UOP, Inc., for the U.S. Department of Energy, Pittsburgh Energy Technology Center.

Yeh, J.T., C.J. Drummond, and J.I. Joubert (1987), "Process Simulation of the Fluidized-Bed Copper Oxide Process Sulfation Reaction," Environmental Progress, 6(2):44-50. 
Yeh, J.T., R.J. Demski, J.P. Strakey, and J.I. Joubert (1984). "PETC Fluidized-Bed Copper Oxide Process for Combined $\mathrm{SO}_{2} / \mathrm{NO}_{\mathrm{x}}$ Removal from Flue Gas," AIChE 1984 Winter National Meeting, Atlanta, March 11-14. 


\section{BRIEFING PAPER PART 1: An Introduction to Uncertainty Analysis}

\section{INTRODUCTION}

Nearly all analyses of energy and environmental control technologies that are still in the research phase involve uncertainties. The most common approach to handling uncertainties is either to ignore them or to use simple "sensitivity" analysis. In sensitivity analysis, the value of one or a few model input parameters are varied, usually from "low" to "high" values, and the effect on a model output parameter is observed. Meanwhile, all other model parameters are held at their "nominal " values. In practical problems with many input variables which may be uncertain, the combinatorial explosion of possible sensitivity scenarios (e.g., one variable "high", another "low," and so on) becomes unmanageable. Furthermore, sensitivity analysis provides no insight into the likelihood of obtaining any particular result.

A more robust approach is to represent uncertainties in model parameters using probability distributions. Using probabilistic simulation techniques, simultaneous uncertainties in any number of model input parameters can be propagated through a model to determine their combined effect on model outputs. The result of a probabilistic simulation includes both the possible range of values for model output parameters and information about the likelihood of obtaining various results. This provides insights into the risks or potential pay-offs of a new technology. Statistical analysis on the input and output data can be used to identify trends (e.g., key input uncertainties affecting output uncertainties), without need to re-run the analysis. Thus, probabilistic analysis can be used as a research planning tool to identify the uncertainties in a process that matter the most, thereby focusing research efforts where they are most needed. You may have seen probabilistic analysis referred to elsewhere as "range estimating" or "risk assessment."

The development of ranges and probability distributions for model input parameters can be based either on statistical data analysis and/or engineering judgments. The approaches to developing probability distributions for model parameters are similar in may ways to the approach you might take to pick a single "best guess" number for deterministic (point-estimate) analysis or to select a range of values to use in sensitivity analysis.

The purpose of this briefing paper is to serve as a foundation for eliciting probability estimates from selected engineers at DOE/PETC to characterize uncertainties in the fluidized bed copper oxide process. The particular systems and process areas of interest are described in detail in Part 2 of this packet.

The information on uncertainties will be used in case studies being prepared for PETC under contract DE-AC22-85PC81004, "Conceptual Design and Economic Evaluation of the Fluidized Bed Copper Oxide Process." The contractor has developed detailed performance and cost models for the fluidized bed copper oxide process. These models are included in the Integrated Environmental Control Model (IECM) developed by Carnegie Mellon for PETC. The IECM is implemented in a software environment that enables any madel parameter to be represented as a probability distribution. Probabilistic results are obtained using a variant of Monte Carlo simulation.

You have been selected to help provide technical input for the development of probability distributions for performance parameters of the copper oxide model. This briefing paper (Part 1), and the accompanying technical description (Part 2), will highlight:

- Some of the typical problems encountered in making estimates of uncertainty

- Some of the technical issues related to uncertainty in the copper oxide process. 
The technical review accompanying this Introduction is intended only as a starting point for your own thinking about uncertainties for this system. In Part 3 of this briefing packet, you are requested to provide some information, such as:

1) A list of the parameters which you think are uncertain (regardless of whether you or someone else can provide estimates of the uncertainties);

2) For those parameters about which you are knowledgeable, the range of possible values that the parameters could have in a commercial-scale fifth-of-a-kind system, based on your understanding of the system as it currently stands;

3) A discussion of the basis for your assessment for each parameter, indicating any technical arguments or considerations.

4) A list of other experts who you think are competent to make judgments about uncertainties for this process, including their phone numbers and affiliations, if available.

\section{PHILOSOPHY OF UNCERTAINTY ANALYSIS}

If you have had a course in probability theory, you were probably taught what is termed the "classical" approach. This approach requires that estimates for probability distributions must be based on empirical data. However, in many practical cases, the available data may not be relevant to the problem at hand. For example, test results from a process development unit (PDU) under a given set of conditions may not be directly applicable to estimating the performance of a fifth-of-akind commercial scale plant under a different set of operating conditions. Thus, statistical manipulation of data may be an insufficient basis for estimating uncertainty in a real system of interest. Engineering analysis or judgments about the data may be required.

An alternative approach differs in how probability distributions are interpreted. In the socalled "Bayesian" view, the probability of an outcome is your "degree of belief" that the outcome will occur, based on all of the relevant information you currently have about the system. Thus, the probability distribution may be based on empirical data and/or other considerations, such as your own technically-informed judgments or predictions. People with different information may estimate different distributions for the same variable. The assessment of uncertainties requires you to think about all possible outcomes and their likelihoods, not just the "most likely" outcome. This is an advantage for you, because by thinking systematically and critically about uncertainties, you are more likely to anticipate otherwise overlooked problems, or to identify otherwise overlooked potential pay-offs of a system.

\section{TYPES OF UNCERTAIN QUANTITIES}

There are a number of types of uncertainty that you might consider when developing a probability distribution for a variable. Some of these are summarized briefly here.

Statistical error is associated with imperfections in measurement techniques. Statistical analysis of test data is thus one method for developing a representation of uncertainty in a variable.

Empirical measurements also involve systematic error. The mean value of a quantity may not converge to the "true" mean value because of biases in measurement and procedures. Such biases may arise from imprecise calibration, faulty reading of meters, and inaccuracies in the assumptions used to infer the actual quantity of interest from the observed readings of other quantities. Estimating the possible magnitude of systematic error may involve an element of engineering judgment. For example, data on sorbent attrition in a PDU may be used to estimate the sorbent attrition in a fifth-of-a-kind commercial-scale system. The conditions in the PDU differ from that in the commercial scale unit; therefore, there may be a systematic error involved in using the PDU data for design purposes. 


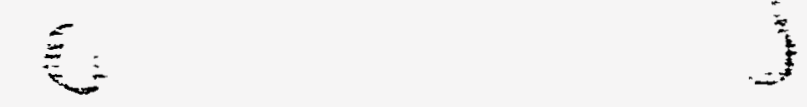

Variability can be represented as a probability distribution. Some quantities are variable over time. For example, the composition of a coal (or perhaps a sorbent) may vary over time.

Uncertainty may also arise due to lack of actual experience with a process. This type of uncertainty often cannot be treated statistically, because it requires predictions about something that has yet to be built or tested. This type of uncertainty can be represented using technical estimates about the range and likelihood of possible outcomes. These judgments may be based on a theoretical foundation or experience with analogous systems.

\section{ENCODING UNCERTAINTIES AS PROBABILITY DISTRIBUTIONS}

As indicated in the previous sections, there are two fundamental approaches for encoding uncertainty in terms of probability distributions. These include statistical estimation techniques and engineering judgments. A combination of both methods may be appropriate in many practical situations. For example, a statistical analysis of measured test data may be a starting point for thinking about uncertainties in a hypothetical commercial scale system. You must then consider the effect that systematic errors, variability, or uncertainties about scaling-up the process might have on interpreting test results for commercial scale design applications.

\section{Statistical Techniques}

Statistical estimation techniques involve estimating probability distributions from available data. The fit of data to a particular probability distribution function can be evaluated using various statistical tests. For example, the cumulative probability distribution of a set of data may be plotted on "probability" paper. If the data plot as a straight line, then the distribution is normal.

Procedures for fitting probability distribution functions are discussed in many standard texts on probability and are not reviewed here. Rather, the focus of this briefing paper is on the situations where statistical analysis alone may be insufficient, because your own engineering insights may be required to interpret whatever limited data are available.

\section{Judgments about Uncertainties}

In making judgments about a probability distribution for a quantity, there are a number of approaches (heuristics) that people use which psychologists have observed. Some of these can lead to biases in the probability estimate. Three of the most common are briefly summarized. ${ }^{1}$

1) Availability. The probability that experts assign to a particular possible outcome may be linked to the ease (availability) with which they can recall past instances of the outcome. For example, if tests have yielded high sorbent durability, it may be easier to imagine obtaining a high sorbent durability in the future than obtaining lower durabilities. Thus, one tends to expect experts to be biased toward outcomes they have recently observed or can easily imagine, as opposed to other possible outcomes that have not been observed in tests.

2) Representativeness has also been termed the "law of small numbers." People may tend to assume that the behavior they observe in a small set of data must be representative of the behavior of the system, which may not be completely characterized until substantially more data are collected. Thus, one should be cautious in inferring patterns from data with a small number of samples.

\footnotetext{
1 The discussion here is taken from Morgan and Henrion, Uncertainty: A Guide to Dealing with Uncertainty in Quantitative Risk and Policy Analysis, Cambridge University Press, in press.
} 
3) Anchoring and adjustment involves using a natural starting point as the basis for making adjustments. For example, an expert might choose to start with a "best guess" value, which represents perhaps an average or most likely (modal) value, and then make adjustments to the best guess to achieve "worst" and "best" outcomes as bounds. The "worst" and "best" outcomes may be intended to represent a 90 percent probability range for the variable. However, the adjustment from the central "best guess" value to the extreme values is often insufficient, with the result that the probability distribution is too tight and biased toward the central value. This phenomena is overconfidence, because the expert's judgment reflects less uncertainty in the variable than it should. The "anchor" can be any value, not just a central value. For example, if an expert begins with a "worst" case value, the entire distribution may be biased toward that value.

Judgments also may be biased for other reasons. One common concern is motivational bias. This bias may occur for reasons such as: a) a person may want to influence a decision to go a certain way; b) the person may perceive that they will be evaluated based on the outcome and might tend to be conservative in their estimates; c) the person may want to suppress uncertainty that they actually believe is present in order to appear knowledgeable or authoritative; and d) the expert has taken a strong stand in the past and does not want to appear to contradict himselves by producing a distribution that lends credence to alternative views.

\section{Designing an Elicitation Protocol}

From studies of how well calibrated judgments about uncertainty are, it appears that the most frequent problem encountered is overconfidence. Knowledge about how most people make judgments about probability distributions can be used to design a procedure for eliciting these judgments. The appropriate procedure depends on the background of the expert and the quantity for which the judgment is being elicited. For example, if you have some prior knowledge about the shape of the distribution for the quantity, then it may be appropriate to ask you to think about extreme values of the distribution and then to draw the distribution yourself. On the other hand, if you have little statistical background, it may be more appropriate to ask a you series of questions. For example, you might be asked the probability of obtaining a value less than or equal to some value $\mathrm{x}$, and then the question is repeated for a few other values of $\mathrm{x}$. Your judgment can then be graphed by an elicitor, who would review the results of the elicitation with you to see if you are comfortable with your answers.

To overcome the typical problem of overconfidence, it is usual to begin by thinking about extreme high or low values before asking about central values of the distribution. In general, experts' judgments about uncertainties tend to improve when: (1) the expert is forced to consider how things could turn out differently than expected (e.g., high and low extremes); and (2) the expert is asked to list reasons for obtaining various outcomes.

While the development of expert judgments may be flawed in some respects, it does permit a more robust analysis of uncertainties in a process when limited data are available. Furthermore, in many ways, the assessment of probability distributions is qualitatively no different than selecting single "best guess" values for use in a deterministic estimate. For example, a "best guess" value often represents a judgment about the single most likely value that one expects to obtain. The "best guess" value may be selected after considering several possible values. The types of heuristics and biases discussed above may play a similar role in selecting the value. Thus, even when only a single "best guess" number is used in an analysis, a seasoned engineer usually has at least a "sense" for "how good that number really is." This may be why engineers, more so than scientists, are usually better able to make judgments about uncertainties, because they implicitly make these types of judgments routinely. 


\section{Some Types of Probability Distributions}

Examples of several types of probability distributions are shown in Figure 1 as both probability density functions (pdf's) and cumulative distribution functions (cdf's). The pdf is a graphical means of representing the relative likelihood or frequency with which values of a variable may be obtained. The pdf also clearly illustrates whether a probability distribution is symmetric or skewed. In a symmetric unimodal distribution, the mean (average), median (50th percentile), and mode (peak) coincide. In a positively skewed distribution (e.g., lognormal), the mean is greater than the median, and both are greater than the mode.

An alternative way to represent a probability distribution is the cdf. The cdf shows probability fractiles on the $y$-axis and the value of the distribution associated with each fractile on the $\mathrm{x}$-axis. The cdf is a way to represent any probability distribution when there is information about various fractiles of the distribution (e.g., the values of the 5th, 50th and 95th percentiles). given here:

A brief description of several types of probability distributions and their applications is

- Uniform: Uniform probability of obtaining a value between upper and lower limits. Use when you are willing to specify a finite range of possible values, but are unable to decide which values in the range are more likely to occur than others. The use of the uniform distribution is also a signal that the details about uncertainty in the variable are not known. Useful for screening studies.

- Triangle: Similar to uniform except a mode is also specified. Use when you are willing to specify both a finite range of possible values and a "most likely" (mode) value. The triangle distribution may be symmetric or skewed (as in Figure 1). Like the uniform, this distribution indicates that additional details about uncertainty are not yet known. The triangle distribution is excellent for screening studies and easy to obtain judgments for.

- Normal: A symmetric distribution with mean, mode, and median at the same point. Often assumed in statistical analysis as the basis for unbiased measurement errors. The normal distribution has infinite tails; however, over 99 percent of all values of the normal distribution lie within plus or minus three standard deviations of the mean. Thus, when used to represent uncertainty in physical quantities which must be greater than zero, the standard deviation should not be more than about 20 or 30 percent of the mean.

- Lognormal: A positively skewed distribution (it has a long tail to the right). This distribution is usually used to represent uncertainty in physical quantities which must be non-negative and are positively skewed, such as the size of an oil spill or the concentration of a pollutant. This distribution may be used when uncertainties are expressed on a multiplicative orderof-magnitude basis (e.g., factor of 2 ) or when there is a probability of obtaining extreme large values.

- Loguniform: A uniform distribution in log space (each decade has equal probability, not shown in Figure 1).

- Fractile: The finite range of possible values is divided into subintervals. Within each subinterval, the values are sampled uniformly according to a specified frequency for each subinterval. This distribution looks like a histogram and can be used to represent any arbitrary data or judgment about uncertainties in a parameter, when the parameter is continuous. Explicitly shows detail of the judgments about uncertainties.

- Chance: This is like the fractile distribution, except that it applies to discrete, rather than continuous, variables. An example of a discrete variable is the number of trains of equipment, which must be an integer (e.g., 30\% chance of one train, $70 \%$ chance of two). 

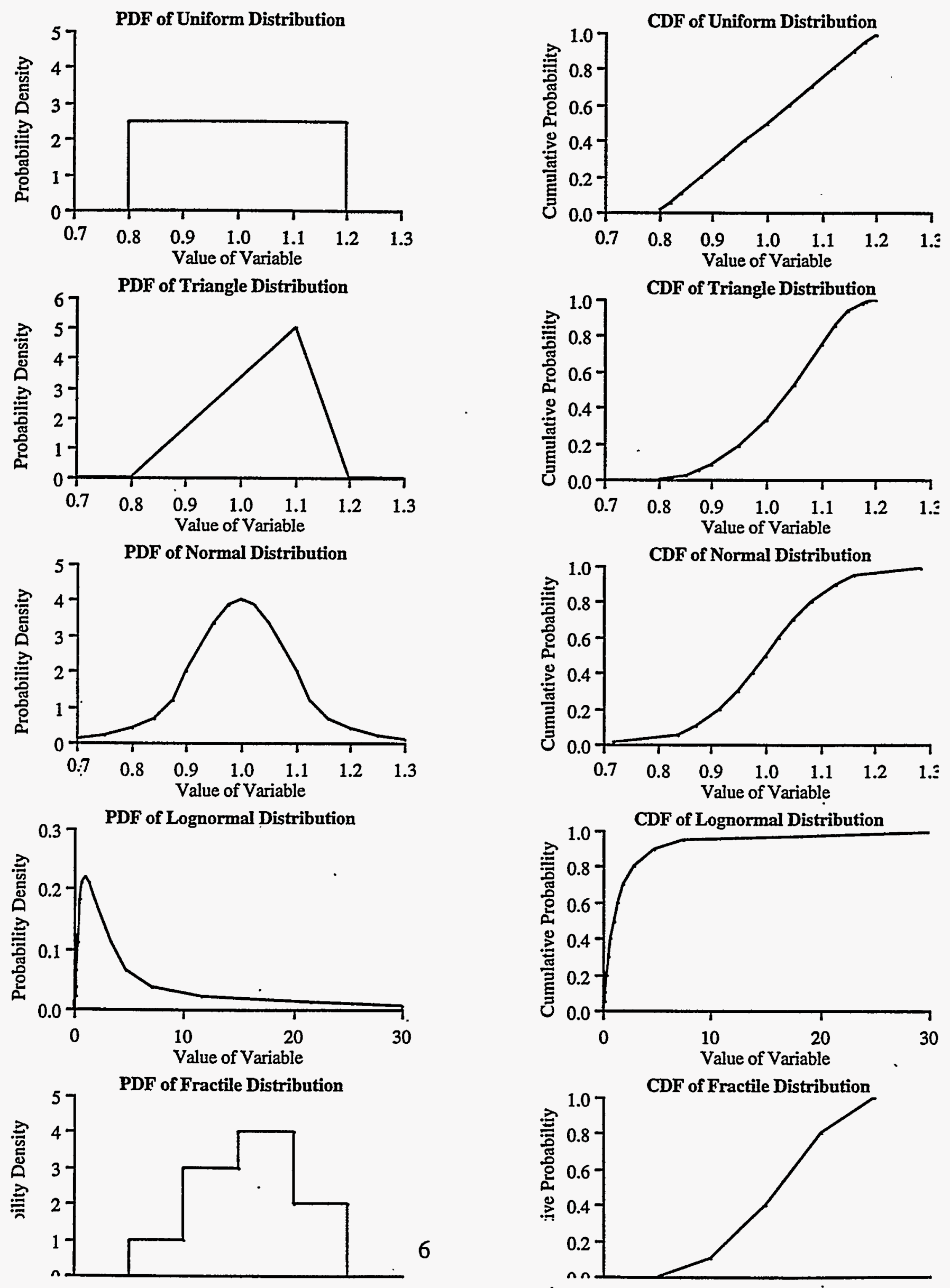


\section{The Use of Judgments in This Project}

A single probability distribution is not an appropriate means for representing disagreements between two or more experts. In this research, judgments will not be "combined" using weights; instead, the ramifications of alternative judgments on model results will be analyzed by separately running the model with each set of judgments. In some cases, disagreements between experts on a specific variable may have little effect on the results of an analysis. In cases where disagreements yield significantly different results, the analysis should focus on differences in the underlying assumptions. In such a case, the modeling is the means to focus engineering discussion on those parameters which matter the most.

In reporting the results from this research, the contractor will refer to experts only by arbitrarily assigned numbers, rather than by name.

\section{A NONTECHNICAL EXAMPLE}

To illustrate the process of eliciting subjective probability distributions, let's turn to a simple example. How long does it take from the time you enter the PETC cafeteria to the time you pay the cashier? Assume that you enter at $12: 05 \mathrm{pm}$ on Tuesdays and that you purchase your entire meal at the cafeteria. The answer you give may depend on your recent experiences in the cafeteria. Think about the shortest possible time that it could take (suppose nobody else is getting lunch) or the longest possible time (every PETC employee, every contractor simultaneous involved in project review meetings, etc). What is the probability that it will take 2 minutes or less? 45 minutes or less? Is the probability that it takes 10 minutes or less greater than 50 percent? etc. After asking a number of questions such as these, it should be possible to draw a distribution for your judgment regarding the time require to obtain and purchase lunch at the cafeteria. A hypothetical assessment about the time to obtain lunch is given on the following page to illustrate the procedure for developing uncertainty estimates..

\section{A TECHNICAL EXAMPLE}

A second example focuses on a performance parameter for an advanced pollution control system. This parameter has an important effect on system performance and cost. 


\section{Example 1: Probability Assessment of Time to Get Lunch at the PETC Cafeteria}

This example is intended to illustrate a possible thought process for someone estimating the time to obtain and pay for lunch at the PETC cafeteria. A key element of this example is the development of alternative scenarios for possible outcomes. These scenarios provide a basis for justifying the range of outcomes. The assessor makes a judgment the probability of each scenario. Finally, the the probability distribution is drawn and reviewed for reasonableness.

"First, I will consider the best possible case. No one is in line for food, what I want is already prepared or easily obtained, I have exact change ready, no one is in line at the cashier, and the cafeteria employees and cashier respond promptly. In this case, I think it would take only one minute from the time I enter the cafeteria until the time I pay for lunch. However, the probability of this happening is low, given that it is $12: 05 \mathrm{pm}$ on a Tuesday. I think there is only a 1 percent chance that it will take a minute or less.

"Next, I consider the worst possible outcome. Everyone at PETC, including visitors, decides to go to the cafeteria. Some of them will turn away when they see the line, so not everyone who goes to the cafeteria will stay to get lunch. Even so, when I enter the cafeteria, there is a line of about 25 people at the food counter. By the time it is my turn to order food, they have just run out of the entree I want and I have to wait for the next batch (I won't eat that other stuff). After I finally get my food, I go to the soft drink island. The first machine I go to is empty; so I have to go to the other side of the island to use the other drink machine, for which there is a line of about eight people. I look for ice but there is none left. I take my food and drink to the line of fifteen people for the cashier (only one register is open). All I have is a $\$ 20$ and the cashier does not have the correct change. I have to wait while the cashier gets change. It takes 25 minutes or more for me to get lunch. I expect that this or an equivalent scenario can happen 5 percent of the time.

"I think that 50 percent of the time, it will take about 10 minutes or less to get lunch, because there will generally be smaller lines and I usually order something that is already prepared. This is closer to what I usually experience at the cafeteria.

"The probability that it will take 15 minutes or more is about 25 percent. The probability that it will take 5 minutes or less is about 10 percent. From these assessments, I can draw a cumulative distribution function. I assume that the distribution is continuous.

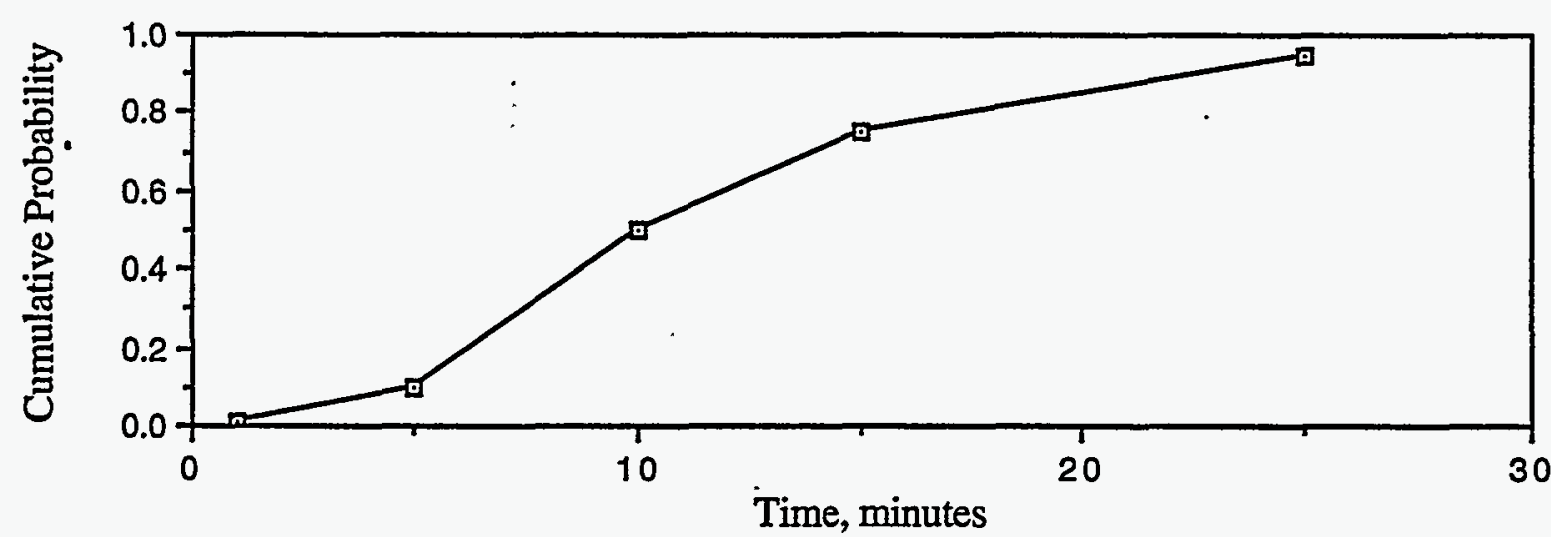

Figure 2. Example of Judgment About Uncertainty in Time to Get Lunch at METC Cafeteria

"This is an arbitrary distribution function. It is positively skewed, reflecting my assessment that it can possibly take a long time to get lunch at this time. I am comfortable that this distribution reflects the range and likelihood of all possible outcomes." 


\section{Example 2: Probability Assessment of a Technical Parameter}

This example focuses on an assessment of uncertainty in the performance of an innovative emission control system for coal-fired power plants. It is meant to be illustrative only. In this system, a sorbent circulates between a fluidized bed reactor, where $\mathrm{SO}_{2}$ in the flue gas is removed by chemical reaction with the sorbent, and a regenerator, in which $\mathrm{SO}_{2}$ is evolved in a reaction of the sulfated sorbent with methane. There is no commercial experience with this system; the largest test unit has been sized to handle $100 \mathrm{scfm}$ of flue gas. Furthermore, the test units have used batch, rather than continuous, regeneration. The last complete series of tests was completed several years ago.

One of the key parameters affecting the performance and cost of this system is the . regeneration efficiency, which is defined as the fraction of the spent sorbent which is regenerated. In small scale tests in which the regeneration efficiency has been estimated, the efficiency was found to be roughly 30 to 50 percent. In a more recent test, the regeneration efficiency was not measured due to instrumentation difficulties; however, it may have been lower than the previously obtained values. Regeneration residence times were typically greater than 30 minutes.

About 10 years ago a consultant developed a detailed model of the regenerator, and estimated that a properly sized and designed regenerator, coupled with heating of the sorbent to a sufficiently high reaction temperature, would result in a regeneration efficiency of just over 99 percent at a 30 minute residence time.

A potential problem that may be occuring in the test units is that regenerated sorbent in the regenerator may be re-absorbing some of the evolved $\mathrm{SO}_{2}$. However, this was not considered in the 1984 modeling study of the regenerator.

Based on this information, it appears that it may be possible to achieve the design target of over 99 percent regeneration efficiency. Clearly, however, it is possible that the actual efficiency may be substantially less than this target value. As a worst case, we might consider the known test results as a lower bound. Thus, there is a small chance the regeneration efficiency may be less than 50 percent. We expect the regeneration efficiency to tend toward the target value of 99.2 percent. Thus, to represent the expectation that the efficiency will be near the target value, but may be substantially less, we can use a negatively skewed distribution. In this case, we assume a triangle with a range from, say, 50 to 99.2 percent with a mode at 99.2 percent. The triangle in this case gives us a distribution with a mean of about 83 percent and a median of about 85 percent.

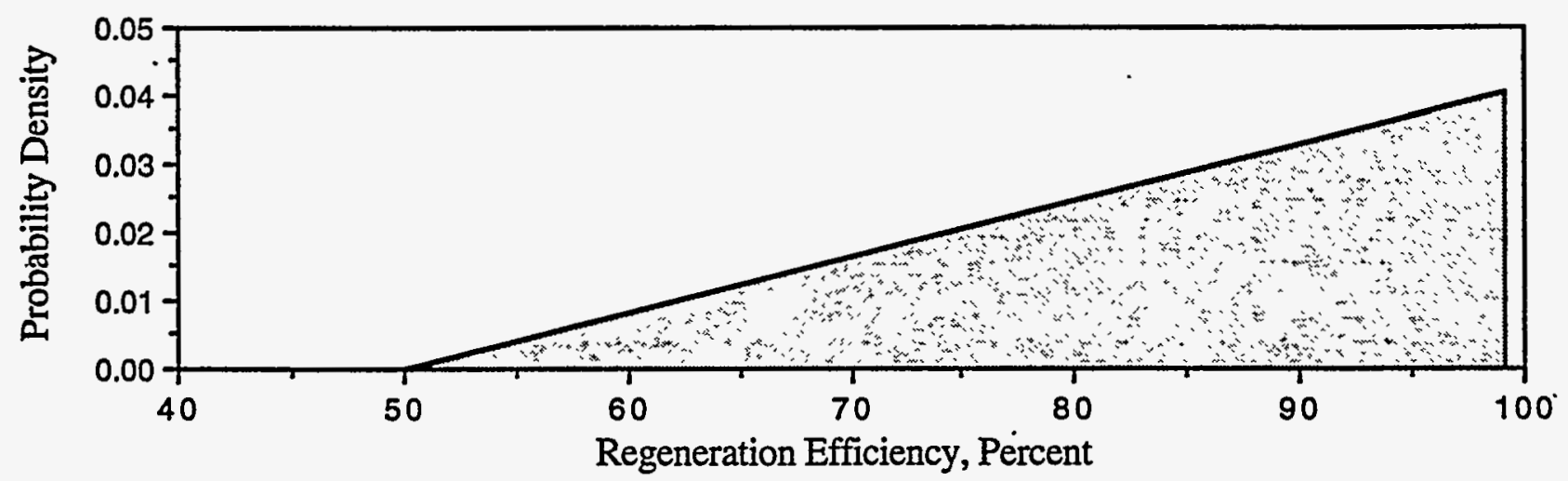

Figure 3. Example Uncertainty Judgment for a Performance Parameter 


\section{BRIEFING PAPER PART 2: Technical Background on the CuO Process}

This section provides a brief overview of the fluidized bed copper oxide process to familiarize you with the system we are modeling and to help ensure that we all have a common framework for discussing uncertainties in the process. More detail about the process and the models we employ can be found in the following papers and reports, which you may already have:

Frey, H.C., "Performance Model of the Fluidized Bed Copper Oxide Process for $\mathrm{SO}_{2} / \mathrm{NO}_{\mathrm{x}}$ Control," Paper 93-WA-79.01 presented at the 86th Annual Meeting of the Air \& Waste Management Association, Denver, CO, June 13-18, 1993.

Frey, H.C., and E.S. Rubin, "An Evaluation Method for Advanced Acid Rain Compliance Technology," Journal of Energy Engineering, 118(1):38-55 (April 1992).

Frey, H.C., and E.S. Rubin, "Probabilistic Evaluation of Advanced $\mathrm{SO}_{2} / \mathrm{NO}_{\mathrm{x}}$ Control Technology," Journal of the Air and Waste Management Association, 41(12):1585-1593 (December 1991).

Rubin, E.S., M.B. Berkenpas, and H.C. Frey, "Development of the Integrated Environmental Control Model," Proceedings, Ninth Annual Coal Preparation, Utilization, and Environmental Control Contractor's Conference, U.S. Department of Energy Pittsburgh Energy Technology Center, Pittsburgh, Pennsylvania, July 19-22, 1993, pp. 447-454.

Rubin, E.S., J.S. Salmento, H.C. Frey, A. Abu-Baker, and M. Berkenpas, Modeling of Integrated Environmental Control Systems for Coal-Fired Power Plants, Final Report, Prepared by Carnegie-Mellon University for the U.S. Department of Energy, Pittsburgh, Pennsylvania, DOE Contract No. DE-AC2287PC79864, April 1991, 214p.

Rubin, E.S., J.S. Salmento, J.G. Barrett, C.N. Bloyd, and H.C. Frey, Modeling and Assessment of Advanced Processes for Integrated Environmental Control of Coal-Fired Power Plants, prepared by Carnegie-Mellon University for the U.S. Department of Energy, Pittsburgh, Pennsylvania, NTIS DE86014713, July 1986.

Of these, the first paper cited here is the most relevant. It contains documentation of the newest version of the copper oxide performance model, and several illustrative deterministic case studies. It is assumed here that you are already thoroughly familiar with the fluidized bed copper oxide. Furthermore, it is also assumed that you have access to the first paper referenced above and can review it to familiarize yourself with the performance model.

A process schematic is included on the follow page. Some key design assumptions are given in the next section. 


\section{BRIEFING PAPER PART 3: \\ Questions About Performance Uncertainties in the Fluidized Bed Copper Oxide Process}

Here, you are asked to provide technically-informed judgments about probability distributions for parameters of a performance model for the fluidized bed copper oxide process. You are asked to consider the possibilities of potentially poor performance as well as the probability of obtaining favorable performance, based on current information about the system. The preceding sections provide an overview of uncertainty analysis and sources of technical information about the process and the models we employ.

We are interested in your technically-based judgments about uncertainties in key performance parameters related primarily to absorption, regeneration, sorbent transport and attrition, and process design. We intend to model the uncertainty in performance and cost associated with a fifth-of-a-kind, or mature, system. Thus, we are asking you to make predictions about systems that have not yet been built or operated. We are asking you to express the range of possible outcomes for these systems using probability distributions, as discussed in Part 1.

Several questions follow. These are the types of questions which we will discuss on Friday. If you would like, you may respond to the questions on these pages, or use additional paper as needed. Alternatively, you could provide your responses more informally during our meeting on Friday. See the Introduction for examples of how you might estimate uncertainty in each parameter.

\section{Design Assumptions} in Table 1.

A number of key design assumptions for the fluidized bed copper oxide process are shown

In previous work reported by Frey at the last AWMA meeting, three integration strategies are considered for the copper oxide process and a sulfuric acid plant. Case 1 represents a base case in which no measures are taken to correct for Claus plant tailgas emissions. In Case 2, the $\mathrm{SO}_{2}$ removal efficiency in the absorber is increased to compensate for the tailgas emissions. In Case 3, the tailgas emissions are recycled to the flue gas just upstream of the absorber, and the absorber sulfur removal efficiency is increased slightly to achieve an overall 90 percent removal efficiency. Cases 2 and 3 yield the same overall removal efficiency of 90 percent, while Case 1 achieves only 85.5 percent removal efficiency. The design assumptions for $\mathrm{SO}_{2}$ removal efficiencies in Table 1 are based on Case 3. 
Table 1. Key Copper Oxide Process Design Assumptions

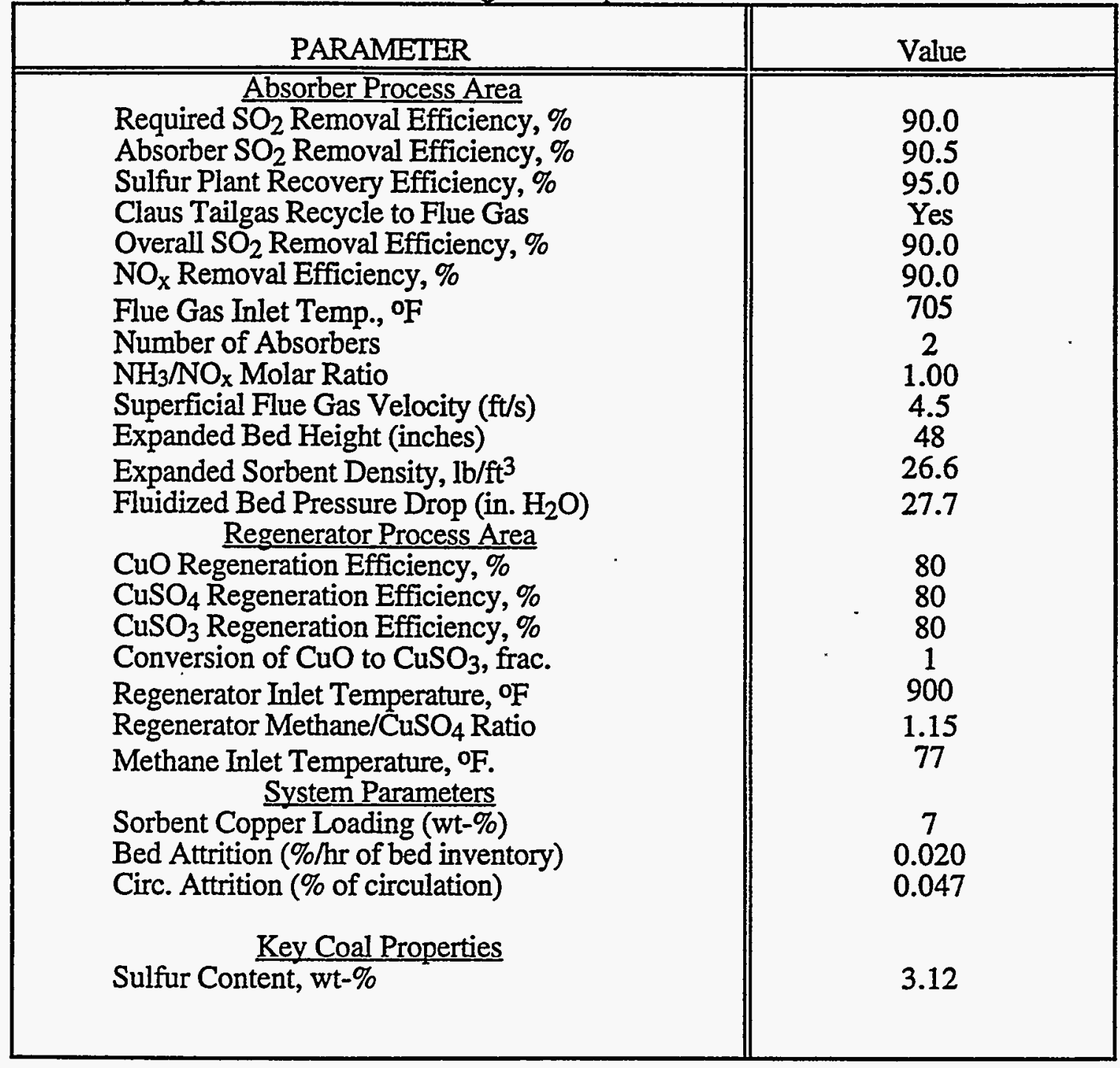

\section{Question \#1: Comments on Default Assumptions}

Do the default assumptions seem reasonable? If not, adjust accordingly and explain the basis for the changes. Are there additional assumptions that should be specified for these systems? If so, please add these assumptions and explain why they are needed. Use your updated set of assumptions as the basis for answering the following questions. 


\section{Question \#2. Uncertain Parameter Identification}

desired.

The following is a list of the specific parameters for which uncertainty distributions are

\section{Absorber-Related Uncertainties}

- Sulfation Rate Constant Model Error

- Cu/S Model Error

- Fluidized Bed Sorbent Density

- Fluidized Bed Flue Gas Pressure Drop dependency on fluidized bed height (over a range of 36 to 72 inches)

- Ammonia Stoichiometry and Ammonia Slip

\section{Regeneration-Related Uncertainties}

- Formation of $\mathrm{CuSO}_{3}$ in the regenerator

- Regeneration Efficiencies for Different Copper Species

- Copper Oxide

- Copper Sulfite

- Copper Sulfate

- Regenerator Residence Time Model Error

- Regenerator Rate Constant for $\mathrm{CuSO}_{4}$

- Regenerator Reaction Rate for $\mathrm{CuSO}_{4}$

\section{Other Uncertainties}

- Sorbent Attrition Rate

- dependency on sorbent copper loading (over a range of 5 to $10 \mathrm{wt}-\% \mathrm{Cu}$ as $\mathrm{CuO}$ )

- dependency on fluidized bed height (over a range of 36 to 72 inches)

- Sorbent Unit Cost

Are you comfortable making estimates of uncertainty for these parameters?

Are there other parameters which you believe also should be treated probabilistically (whether or not you feel comfortable making the judgment yourself) that are not included in the above list? If so, please specify what these parameters are and supply your judgments about them if you are comfortable doing so (see the following questions for examples of the types of judgments we are looking for). If not, who can we ask to estimate uncertainties for these additional parameters? 


\section{Absorber-Related Uncertainties}

\section{Uncertainty in Sulfation Rate Constant Model}

The expression used in the model to calculate the rate constant is:

$$
k_{s}=1,573 \exp \left(-14.23 W_{C u}\right) \exp \left(-\frac{2,417.6}{T}\right)
$$

where $\mathrm{k}_{\mathrm{s}}$ is the reaction rate constant $(1 /(\min * a t m)), \mathrm{W}_{\mathrm{Cu}}$ is the sorbent copper loading (wtfraction $\mathrm{Cu}$ as $\mathrm{CuO}$ ), and $\mathrm{T}$ is the absorber bed temperature $(\mathrm{K})$. Clearly, this model provides an estimate of the actual rate constant under different conditions of sorbent copper loading and temperature. How accurate and precise is the model? Accuracy refers to random error in predicting the rate constant, whereas precision refers to any biases (e.g., a systematic tendency to under-predict or over-predict). How likely is it that the rate constant could be higher than the estimated value? How much higher could the rate constant be (as a percentage of the estimated value)? Could it by lower? By how much?

\section{Uncertainty in the Estimated Cu/S Molar Ratio}

The uncertainty in this parameter can be estimated by comparing model results with experimental results. This is done in the following figure:

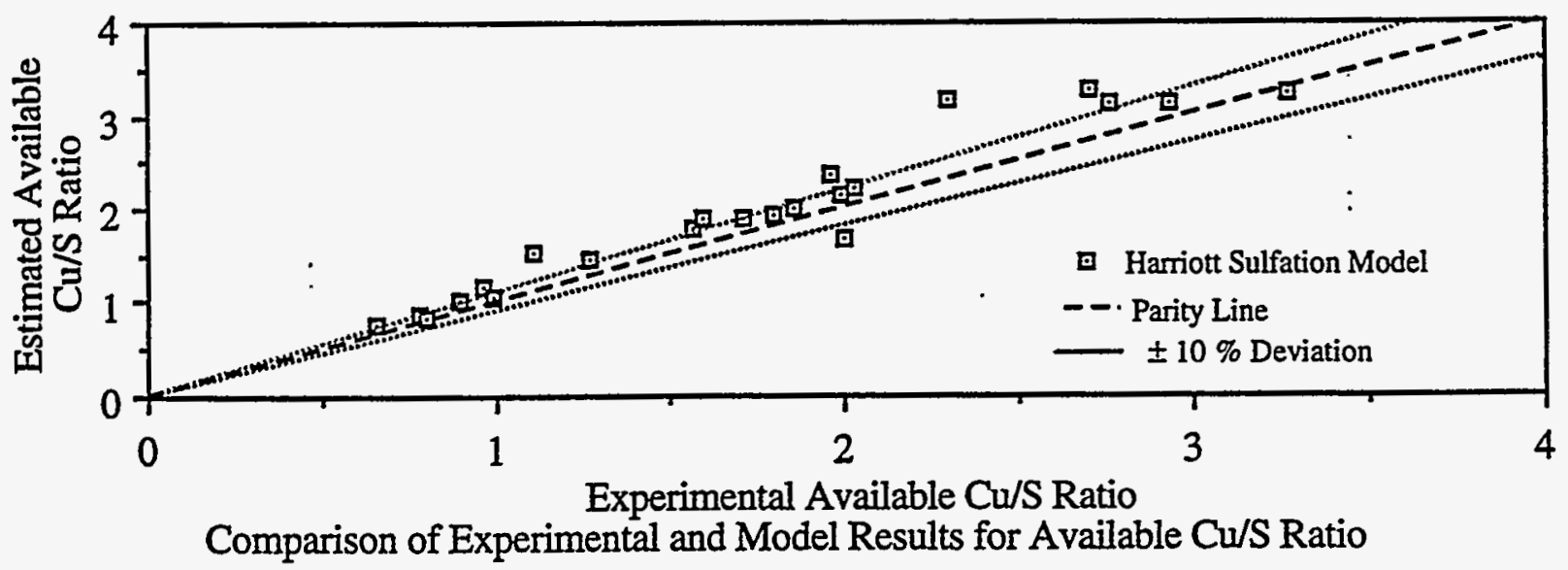

The limitation of this approach is that the experimental data may not be representative of the operating conditions for a full-scale commercial plant, either due to different design assumptions or to scale-up effects. In your opinion, do these data provide a reasonable indication of the uncertainty for predicting $\mathrm{Cu} / \mathrm{S}$ ratios for a commercial size unit (which may be larger than the 40 inch by 48 inch test unit from, which the data were taken, by a factor of 300 in terms of sorbent bed inventory)? What is your estimate of uncertainty in the predicted value of the $\mathrm{Cu} / \mathrm{S}$ ratio, especially for ratios in the range of 1.5 to 2.0 ? 


\section{Fluidized Bed Sorbent Density}

Analysis of data from the 40 by 48 inch tests conducted at PETC in the mid-1980s indicates that there is variability in the expanded sorbent density across the tests. While the average sorbent density was approximately $26 \mathrm{lb} / \mathrm{ft}^{3}$, it varied by about $\pm 17 \%$. This variation was not explainable by differences in superficial gas velocity, although there appears to be a weak dependence on bed height (density increases with bed height). Even accounting for differences in bed height, the variation is $\pm 12 \%$. What is the source of this variation? Is it likely to average out over time for a given absorber?

\section{Fluidized Bed Pressure Drop}

The flue gas pressure drop across the absorber has implications for induced draft fan electrical requirements. A simple linear model of pressure drop versus bed height has been employed based on PETC test results:

$$
\text { Pressure Drop (inches of } \mathrm{H}_{2} \mathrm{O} \text { ) }=10.2+0.365 \mathrm{H} \text { (inches of bed height) }
$$

Does this model provide a reasonable approximation over a range of bed heights in excess of those from the PETC test results (e.g., for bed heights of 48 to 72 inches)?

\section{Ammonia Stoichiometry and Ammonia Slip}

The ammonia-to-nitrogen oxides stoichiometric ratio required for a given NOx removal efficiency can be estimated empirically using regression models developed based on PETC test data. The scatter in these data appear to be on the order of approximately $\pm 5 \%$ or $\pm 10 \%$. The data indicate that ammonia removal efficiency increases with bed height for a given $\mathrm{NH}_{3} / \mathrm{NO}_{\mathrm{x}}$ molar ratio. While the performance and cost of the copper oxide process are not particularly sensitive to differences in ammonia injection rates, the issue of ammonia slip is not well understood for this system. One study by UOP in 1987 reported that ammonia slip appeared to be less than $50 \mathrm{ppmv}$. However, such levels could be excessive. For 90 percent $\mathrm{NO}_{\mathrm{x}}$ removal, what is your best estimate as to best case, worst case, and most likely ammonia slip levels? 


\section{Regenerator-Related Uncertainties}

\section{Formation of $\mathrm{CuSO}_{3}$ in the Regenerator}

Some studies have suggested that potentially many other copper species besides $\mathrm{Cu}, \mathrm{CuO}$, and $\mathrm{CuSO}_{4}$ may play an important role, particularly with regard to regeneration. For example, $\mathrm{CuSO}_{3}$ may be formed by the reaction of $\mathrm{SO}_{2}$ in the exiting off-gas with $\mathrm{CuO}$ in the incoming sorbent. The question here is: how much (if any) $\mathrm{CuSO}_{3}$ is formed in this manner?

\section{Regeneration Efficiencies}

A key input to the regenerator kinetic model used to estimate required sorbent residence time is the regeneration efficiency of $\mathrm{CuSO}_{4}$. This parameter is assumed to have a value of 80 percent in the default design basis.

What is the relationship between the regeneration efficiency of $\mathrm{CuSO}_{3}$ and that of $\mathrm{CuSO}_{4}$ ? For example, Harriott and Markussen (IECR, 31:1, p.378) indicate that the regeneration efficiency of $\mathrm{CuSO}_{3}$ could be substantially less than that of $\mathrm{CuSO}_{4}$.

What is the relationship between the regeneration of $\mathrm{CuO}$ and $\mathrm{CuSO}_{4}$ ? What are reasonable assumptions to make? What ranges of values can be used? For example, is the regeneration efficiency for $\mathrm{CuO}$ the same as for $\mathrm{CuSO}_{4}$ ?

\section{Regenerator Residence Time Model}

How accurate and precise are predictions made by the regenerator residence time model described in Frey's paper (the model itself was developed by Harriott based on experimental work done by Harriott and Markussen). Assuming that all inputs to the model were known with certainty, how much scatter could we expect to see between model predictions and actual process performance? What are some sources of descrepancies (e.g., channeling of flow with the regenerator bed, masking by contaminants, unaccounted for chemical reactions, etc.)? How much longer could the residence time be, as a percentage of the model estimate? How much lower? 


\section{Regenerator Rate Constant}

How accurate and precise are the predictions of the rate constant for the regeneration of copper sulfate? These predictions are given by the following model:

$$
\mathrm{k}_{\mathrm{s}, \mathrm{r}}=\left\{\begin{array}{l}
4.2 \times 10^{7} \cdot \mathrm{F}_{\mathrm{w}} \cdot \exp \left(\frac{-21,700}{\mathrm{~T}}\right) \text { if } \mathrm{T} \leq 1,355 \circ \mathrm{R} \\
11.2 \times 10^{5} \cdot \mathrm{F}_{\mathrm{w}} \cdot \exp \left(\frac{-16,800}{\mathrm{~T}}\right) \text { if } \mathrm{T}>1,355{ }^{\circ} \mathrm{R}
\end{array}\right\}
$$

where the factor $F_{w}$ is a correction based on the sorbent copper loading:

$$
F_{\mathrm{w}}=2.04 \exp \left(-14.23 \mathrm{~W}_{\mathrm{Cu}}\right)
$$

For example, as a percentage of the value estimated by the model, how much higher might the actual rate constant be? How much lower might it be?

\section{$\underline{\text { Regenerator Reaction Rate }}$}

The copper sulfate regeneration reaction rate is estimated using the following expression, based on a memo by Harriott. The reaction rate is estimated for each of a number of increments within the regenerator (the nomenclature used here is defined in the recent paper by Frey):

where:

$$
\mathrm{r}_{\mathrm{k}}=\frac{\mathrm{k}_{\mathrm{s}, \mathrm{R}, \mathrm{k}} \mathrm{P}_{\mathrm{CH}_{4}, \mathrm{k}}\left(\eta_{\mathrm{r} 2, \mathrm{eq}, \mathrm{k}}-\mathrm{k} \Delta \eta_{\mathrm{r} 2}\right)}{1+\mathrm{K}_{1} \mathrm{P}_{\mathrm{CH}_{4, \mathrm{k}}}+\mathrm{K}_{2} \mathrm{P}_{\mathrm{SO}_{2}, \mathrm{k}}+\mathrm{K}_{3} \mathrm{P}_{\mathrm{CO}_{2}, \mathrm{k}}}
$$

The partial pressures for each gas are estimated throughout various increments in the regenerator. The average reaction rates are calculated for each increment based on the inlet and outlet partial pressures. The parameters of the reaction rate equation, $\mathrm{K}_{1}, \mathrm{~K}_{2}$, and $\mathrm{K}_{3}$, are estimated by Harriott to be 5,16 , and 6 , respectively.

Date reported by Harriott and Markussen (IECR, 31(1):373-379) in Table 1 provide some quantitative indication of uncertainty in the reaction rate. However, it is not clear that these data translate directly to a commercial scale absorber, which may have flow distribution problems and in which other gases not included in the tests (e.g., water vapor) may be present. How likely is it that the reaction rate will be higher? Lower? By how much? 


\section{Other Uncertainties}

\section{Sorbent Attrition Rate}

Sorbent attrition rate can be characterized in a number of ways. One approach used in the current study is to separately consider attrition occuring from sorbent particle motion in the fluidized bed absorber from that associated with sorbent transport. The new design basis for the copper oxide process employs a dense phase transport system. What are your estimates of worst case, best case, and most likely sorbent attrition rates for the absorber bed and the sorbent transport system, assuming a base case $7 \mathrm{wt}-\% \mathrm{Cu}$ (as $\mathrm{CuO}$ ) sorbent?

How will attrition rates change for different sorbent copper loadings? Consider a sorbent with 5 wt-\% $\mathrm{Cu}$ versus one with $10 \mathrm{wt}-\% \mathrm{CuO}$.

\section{$\underline{\text { Sorbent Unit Cost }}$}

A common assumption in economic evaluations of the copper oxide process is that sorbent will cost $\$ 5.00 / \mathrm{lb}$ for a $7 \mathrm{wt}-\% \mathrm{Cu}$ formulation. This assumption has been used for a number of years now. Is it still reasonable? How likely is the cost to be higher than this? To be lower? How low could it be? How high could it be?

How would the sorbent cost be different for a $5 \mathrm{wt}-\%$ formulation versus that of a $10 \mathrm{wt}-\%$ formulation? 


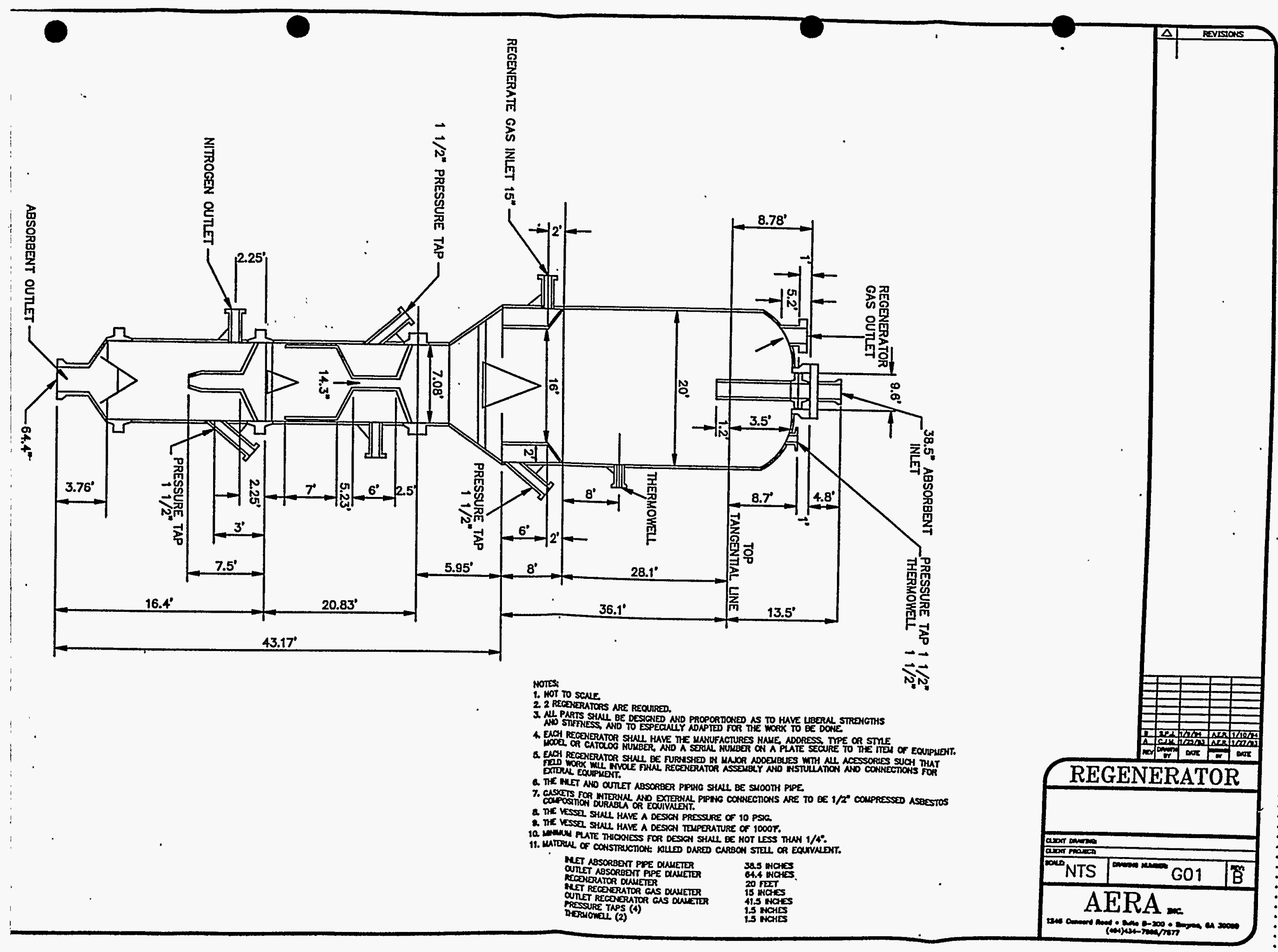




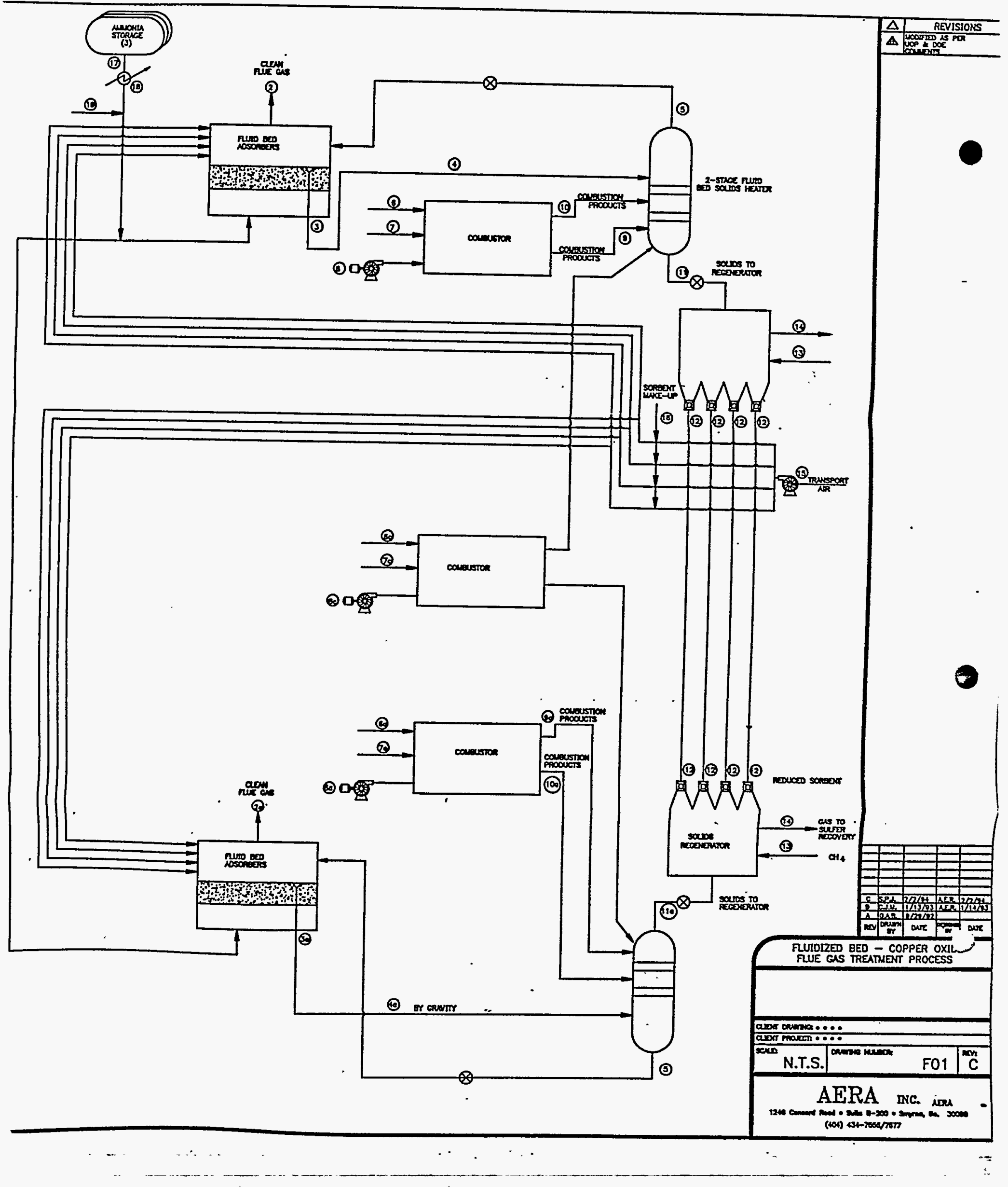




\section{REFERENCES}

1. D.H. McCrea, AJ. Forney, and J.G. Myers, "Recovery of Sulfur from Flue Gases Using a Copper Oxide Absorbent" Journal of the Air Pollution Control Association, Vol. 20, No. 12, (1970).

2. A.E. Arneson, F.M. Nooy, and J.B. Pohlenz, "The Shell FGD Process: Pilot Plant Experience at Tampa Electric," Fourth Symposium on Flue Gas Desulfurization, EPA, Hollywood, FL, Nov. 1977.

3. A.O. Braun and J.B. Pohlenz, "Shell NOx/ $/ \mathrm{SO}_{2}$ Flue Gas Treatment Process: Pilot Plant Evaluation," EPA Report 600/7-83/048, Sept. 1983.

4. J.P. Strakey, E.R. Bauer, and W.P. Haynes, "Removal of SO2 and NOx from Flue Gas in a Fluidized-Bed Copper Oxide Process," presented at the Sixth National Conference on Energy and the Environment, Pittsburgh, PA, May 21-24, 1979.

5. R.J. Demski, S.J. Gasior, E.R. Bauer, J.T. Yeh, J.P. Strakey, and J.I. Joubert, "Simultaneous Removal of SO2 and NOx from Flue Gas in a Fluidized-Bed Copper Oxide Process" Presented at the Summer Session of the American Institute of Chemical Engineers, Cleveland, OH, August 29-September 1, 1982.

6. J.A. Ratafia-Brown, "General Technical Review of the Fluidized-Bed Copper Oxide Removal Process," Science Management Corporation, February 12, 1982.

7. J.A. Ratafia-Brown, and R.L. Hershey, "Technical and Economic Evaluation of The Fluidized-Bed Copper Oxide Flue Gas Treatment Process and Integrated Sulfur Producing Plants" prepared by Scientific Management Corporation for Mr. James Jourbert of the Pittsburgh Energy Technology Center, June 1983.

8. J.T. Yeh, R.J. Demski, J.P. Strakey, and J.I. Joubert, "PETC Fluidized-Bed Copper Oxide Process for Combined Removal from Flue Gas," presented at the AICHE Winter National Meeting, Atlanta, GA, March 11-14, 1984.

9. R.R. Williamson, J.A. Morici, and T.L. LaCrosse, "Phase I-Sorbent Life Cycle Testing: Fluidized-Bed Copper Oxide Process," prepared by UOP for the Pittsburgh Energy Technology Center under DOE and DE-AC22-85PC81004, Apr. 1987.

10. J.T. Yeh "A Pilot-Scale Test of the NOXSO Flue Gas Treatment Process" prepared by NOXSO Corporation under DOE contract number DE-FC22-85PC81503, June, 1988. 
A. E. ROBERTS \& ASSOCIATES, INC.

11. J.A. Ratafia-Brown "Technical/Cost Comparison of the Moving Bed \& Fluidized-Bed Copper Oxide Processes," prepared by Sciences Applications International Corporation, under DOE contract number DE-AC22-89PC88400, June, 1991.

12. Ibid 9.

13. H.C. Frey "Performance and Economic Model of the Fluidized-Bed Copper Oxide Process," Masters Thesis, Department of Mechanical Engineering, Carnegie Mellon University, Pittsburgh, May 1987.

14. E.S. Rubin, J.S. Salmento, H.C. Frey, et al, "Modeling and Assessment of Advanced Processes for Integrated Environmental Control of Coal-Fired Power Plants," DOE, Pittsburgh, July, 1986.

15. Ibid 13.

16. E.S. Rubin, J.S. Salmento, H.C. Frey, et al., "Modeling of Integrated Environmental Control Systems for Coal-Fired Power Plants," DOE, Pittsburgh, April, 1991.

17. P. Harriott, personal communications, Cornell University, Ithica, NY, June 6, 1992, Aug. 4, 14, and 25, 1992, and Dec. 14, 1992.

18. P. Harriott and J.M. Markussen "Kinetics of Sorbent Regeneration in the Copper Oxide Process for Flue Gas Cleanup," Industrial and Engineering Chemistry Research, Vol. 31, No. 1, pp. 373-379, 1992.

19. P.O. Shah, G.S. Takahashi, and D.G. Leshock "Fluidized-Bed Copper Oxide Process Proof-of-Concept Unit Design," Sept. 1992.

20. P. Harriott, personal communications, Cornell University, Ithica, NY, Aug. 25, 1992, and Dec. 14, 1992.

21. Ibid 19.

22. H.C. Frey "Performance Model of the Fluidized Copper Oxide Process for $\mathrm{SO}_{2} / \mathrm{NO}$ Control" 86th Annual Meeting of the Air and Waste Management Association, Denver, CO, June 14-18, 1993.

23. P. Harriott, personal communications, Cornell University, Ithica, NY, June 3, 1992.

24. Ibid 12.

25. Ibid 12. 


\title{
FLUIDIZED-BED COPPER OXIDE PROCESS
}

PHASE IV

CONCEPTUAL DESIGN AND ECONOMIC EVALUATION

Volume II
Appendices

\begin{abstract}
Prepared for the
United States Department of Energy

Pittsburgh Energy Technology Center

under

Contract Number DE-AC22-85PC81004
\end{abstract}

Prepared by

A.E. Roberts \& Associates, Inc.

(under a subcontract from UOP)

Atlanta, Georgia

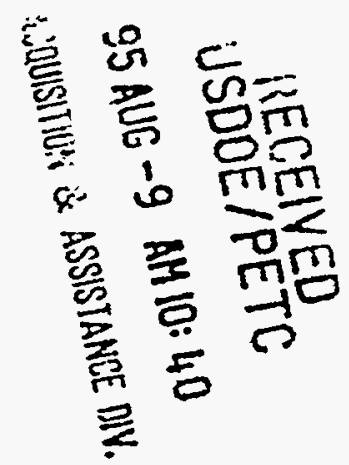

November 30, 1994 


\title{
FLUIDIZED-BED COPPER OXIDE PROCESS \\ PHASE IV \\ CONCEPTUAL DESIGN AND ECONOMIC EVALUATION
}

\author{
Volume II \\ Appendices
}

\begin{abstract}
Prepared for the
United States Department of Energy

Pittsburgh Energy Technology Center

under

Contract Number DE-AC22-85PC81004
\end{abstract}

Prepared by

A.E. Roberts \& Associates, Inc. (under a subcontract from UOP)

Atlanta, Georgia

November 30, 1994

PATENT CLEARED BY CHICAGO

OPC ON: JANUARY 25, 1995 


\section{TABLE OF CONTENTS}

\section{Volume II}

\subsection{Appendices}

I Conceptual Design and Economic Evaluation of the Fluidized Bed Copper Oxide Process

II Material Balances

III Absorber Specification

IV Ammonia Injection System

V Regenerator Specification

VI Two Stage Solids Heater Sizing 


\section{APPENDIX I}


Establishment Of The Design Basis For Application To A 500 MW Powerplant

By

A. E. Roberts

D. S. Henzel

J. M. Whitmer

of A. E. Roberts \& Associates, Inc.

Atlanta, Georgia

For

UOP of DesPlaines, llinois

Dr. Hemant B. Gala, Project Manager

September 29, 1992

Revised Based on UOP/DOE Comments January 12, 1993 
Establishment of the Design Basis for Application to a 500 MW Power Plant

I. Introduction

A. E. Roberts \& Associates, Inc. has extensively evaluated all of the past work that collectively defines the Fluidized-Bed Copper Oxide Process. This review included all seven reports authored by Jay Ratafia-Brown, principal investigator, the LCTU Phase I results authored by UOP, and the designs presented by UOP in Phase II for a $5 \mathrm{MW}$ and finally a 2,500 SCFM pilot plant demonstration unit. The key reference to our selection process was the "Proof-of-Concept Unit Design Report", authored by UOP in September 1990 to support the engineering design for the proposed 2,500 SCFM demonstration unit at Plant Kincaid.

Beyond reviewing the published record, A. E. Roberts \& Associates, Inc. contracted with Professor Peter Harriott of Cornell University to review the record and to define as an expert the kinetics to use for both the absorption and regeneration reactions. Professor Harriott has done an excellent job and has defined and refined the critical regeneration design basis to fit a realistic interpretation of the kinetics involved in absorbing $\mathrm{SO}_{2}$ on to the CuO catalyst and then regenerating the $\mathrm{CuO}$ from the $\mathrm{CuSO}_{4}$ reaction product. The results of Professor Harriott's work are presented in Appendix A. 
Additionally, it is planned to use the Integrated Environmental Computer Model that has been developed by Carnegie Mellon University (CMU) and that rests in the care of Dr. H. Christopher Frey to incorporate Professor Harriott's algorithms in order to establish the base case process performance for the selected criteria. This base case will verify that the selected process criteria can be successfully used as the design basis for application of the FBCO process to the $500 \mathrm{MW}$ powerplant. Appendix $B$ presents a schematic process flow diagram that $\mathrm{CMU}$ will use to perform this modeling. 
II. Review of A. E. Roberts' Process Evaluations

The evaluation of the Fluidized-Bed Copper Oxide Flue Gas Treating Process enabled A. E. Roberts to identify the key process criteria and operating parameters and to verify that the system characteristics presented in Table 1 as derived by the development effort to date are optimum and can be used in an engineering design for application to a $500 \mathrm{MW}$ powerplant.

The $500 \mathrm{MW}$ powerplant for the conceptual design basis is a new $500 \mathrm{MW}$ coalfired boiler, with an assumed state of llinois location (for purposes of preparing cost estimates). The fuel for the plant is coal having a heating value of 10,500 Btu/lb and containing 3.12\% sulfur and $16 \%$ ash (on an as-fired basis). The coal composition and the input coal requirements (based on a heat rate of 9,000 Btu/KWh) for the 500-MW boiler are listed in Table 2.

The composition of the flue gas at the exit of the economizer will be processed by the fluidized-bed copper oxide process since the temperature desired in the reactor is close to the economizer exit temperature. This flue gas composition is presented in Table 3 and was calculated based on the assumption that 95 percent of the sulfur in the coal is emitted in the flue gas as $\mathrm{SO}_{x}$ with an $\mathrm{SO}_{2}$ to $\mathrm{SO}_{3}$ ratio of 99 to 1. It is also assumed that 80 percent of the fly ash is emitted with the flue gas stream. The $\mathrm{NO}_{x}$ concentration of the flue gas was calculated to be 650 PPM and consists of approximately $95 \%$ nitric oxide (NO) and 5 percent nitrogen dioxide $\left(\mathrm{NO}_{2}\right)$ 
Table 1.

SYSTEM CHARACTERISTICS SELECTED FOR THE DESIGN BASIS OF THE FLUIDIZED-BED COPPER OXIDE PROCESS

Svstem Characteristics

Option Selected

\begin{tabular}{l|l}
\hline $\mathrm{SO}_{2} / \mathrm{NO}_{x}$ Sorbent Reactors & Fluidized Bed \\
\hline Sorbent Heater & Two-Stage Fluidized-Bed Solids Heater \\
\hline $\begin{array}{l}\text { Source of Hot Gas Required for Solids } \\
\text { Heating }\end{array}$ & Methane Combustion \\
\hline Sorbent Regenerator Reactor & Counter-Current Gravitating Bed \\
\hline Reducing Gas Used & Methane \\
\hline By-Product Sulfur Recovery & $\begin{array}{l}\text { The concentrated } \mathrm{SO}_{2} \text { stream produced } \\
\text { in the regenerator reactor is sent to a } \\
\text { sulfur-producing plant using Allied } \\
\text { Chemical's SO }\end{array}$ \\
\hline Solids Transport System Process. \\
\hline & $\begin{array}{l}\text { A semicontinuous, dense-phase solids } \\
\text { transport system using surge hoppers } \\
\text { and blow tanks as designed by } \\
\text { Macawber Equipment Company. }\end{array}$
\end{tabular}


III. Fluidized-Bed Copper Oxide Process Design Results

The design of the fluidized-bed reactor will provide the optimum size, bed height and solids circulation rate based on the kinetic results of all the past work. This presents a dilemma because UOP in the LCTU test program derived CU/S mole ratios in the 4 to 6 range, while Professor Harriott has calculated a value of 1.7 for $80 \%$ sorbent regeneration. Jay Ratafia-Brown's recent work used a value of 1.08 for an assumed $98 \%$ sorbent generation. Discussions with both Professor Harriott and Jay Ratafia-Brown and observation of recent demonstration results of the NOXSO process, a somewhat similar process, leads A. E. Roberts to agree with the collective belief that in the LCTU, incomplete regeneration of the sorbent led to operation with very high solid circulation rates (4 to 6 times the minimum) in order to achieve $90 \% \mathrm{SO}_{2}$ removal. If nearly complete regeneration of the sorbent $(80 \%)$ is obtained, then $90+\% \mathrm{SO}_{2}$ removal can be achieved in the fluidized-bed absorber, with only a moderate excess of methane. However, in consideration of the practicality of combining the actual physical LCTU results with the theoretical model expected results and in view of the more reasonable $80 \%$ regeneration versus the models assumed $98 \%$ regeneration, A. E. Roberts has chosen to use as a design basis a $\mathrm{Cu} / \mathrm{S}$ mole ratio of 2.0. The need for providing a targeted one second residence time in the expanded bed lead to the selection of a bed of 4 feet in depth with a superficial gas velocity of 4.5 fps. Recent cost-optimization comparison evaluation made with the Integrated Environmental Computer. Model by CMU have shown that a 4 feet expanded bed height has lower total levelized 
process costs. Table 4 presents the critical fluidized-bed reactor design parameters that will be used to establish the engineering design basis.

The sorbent material is a proprietary UOP developed catalyst, and was found in the LCTU to present the best results, and has been designated as UOP catalyst SOX-3. Table 5 presents this materials' physical properties.

Fresh sorbent must be added to the FBCO process to make up for sorbent lost through attrition. The sorbent make up rate was chosen to be $0.067 \mathrm{wt.} \%$ of the circulation rate, but is calculated based on using $0.02 \mathrm{wt}$ \% of the bed inventory and $0.047 \mathrm{wt} . \%$ of the actual circulated sorbent rate. These numbers are based on the recent pilot demonstration experience of the NOXSO Process, a similar process to FBCO that uses sodium impregnated on a gamma alumina oxide carrier. Also, the results from the Macawber test program, which was a non-ideal duplication of the FBCO indicated that after 100 cycles only $3 w t . \%(0.03 w t . \%$ per cycle) of the alumina oxide catalyst was lost to attrition as dust collected in the bag house. However, another $11 \mathrm{wt}$. \% was found to be attrited to below 30 mesh in size during the Macawber test. From discussions held with Professor Harriott, L. G. Neal, and John Haselbeck of the NOXSO Corporation, it is our collective belief that this minus 30 mesh fraction of catalyst will still be available for capture of $\mathrm{SO}_{2}$ in the FBCO process. Again, the NOXSO process demonstration experience to date is proof of the usefulness of this smaller sized catalyst fraction. 
A. E. ROBERT? \& ASSOCIATES, INC.

Table 2.

COAL COMPOSITION AND INPUT FLOW RATE

\begin{tabular}{|c|c|c|c|}
\hline $\begin{array}{l}\text { - Power Plant Capacity, MW } \\
\text { Heating Rate, Btu/Kwh }\end{array}$ & & $\begin{array}{r}500 \\
9,000\end{array}$ & . \\
\hline Coal & Flow rat & $\mathrm{lb} / \mathrm{hr}$ & 428,571 \\
\hline Component & $\begin{array}{l}\text { Wt-\% } \\
\text { as-fired }\end{array}$ & $\begin{array}{l}\text { Wt-\% } \\
\text { dry }\end{array}$ & $\mathrm{lb} / \mathrm{hr}$ \\
\hline C & 57.56 & 64.49 & 246,686 \\
\hline $\mathrm{H}$ & 4.14 & 4.64 & 17,743 \\
\hline $\mathrm{N}$ & 1.29 & 1.45 & 5,529 \\
\hline 0 & 7.00 & 7.84 & 30,000 \\
\hline$S$ & 3.12 & 3.50 & 13,371 \\
\hline $\mathrm{Cl}$ & 0.15 & 0.17 & 643 \\
\hline Ash & 16.00 & 17.93 & 68,571 \\
\hline $\mathrm{H}_{2} \mathrm{O}$ & 10.74 & - & 46,029 \\
\hline TOTAL & 100.00 & 100.00 & 428,571 \\
\hline
\end{tabular}


A. E. ROBERT? ASSOCIATES, INC.

Table 3.

FLUE GAS COMPOSITION AND FLOW RATE

S emitted as SOx in flue gas, \% of coal S

95

Ratio of $\mathrm{SO} 2 / \mathrm{SO} 3$

99

Flow Rate, SCFM

957,871@60F, atm pressure

\begin{tabular}{|c|c|c|c|c|}
\hline Component & Vol-\% & $\begin{array}{c}\text { Vol-\% } \\
\text { (Dry) } \\
\end{array}$ & $\mathrm{lb} / \mathrm{hr}$ & Mol. wt. \\
\hline Nitrogen & 73.390 & 81.076 & $3,114,070$ & 28.0134 \\
\hline Oxygen & 3.230 & 3.568 & 156,553 & 31.9988 \\
\hline $\begin{array}{l}\text { Carbon } \\
\text { Dioxide }\end{array}$ & 13.560 & 14.980 & 903,933 & 44.0100 \\
\hline Sulfur Dioxide & 0.260 & 0.287 & $25,229 r$ & 64.0628 \\
\hline Sulfur Trioxide & 0.003 & 0.003 & $364 r$ & 80.0622 \\
\hline Nitric Oxide & 0.062 & 0.068 & 2,818 & 30.0061 \\
\hline $\begin{array}{l}\text { Nitrogen } \\
\text { Dioxide }\end{array}$ & 0.003 & 0.003 & 209 & 46.0055 \\
\hline $\begin{array}{l}\text { Hydrochloric } \\
\text { acid }\end{array}$ & 0.012 & 0.013 & 645 & 35.4657 \\
\hline Water & 9.480 & & 258,686 & 18.0152 \\
\hline TOTAL & 100.000 & 100.000 & $4,462,507$ & 29.4614 \\
\hline
\end{tabular}


A. E. ROBERTS ASSOCIATES, INC.

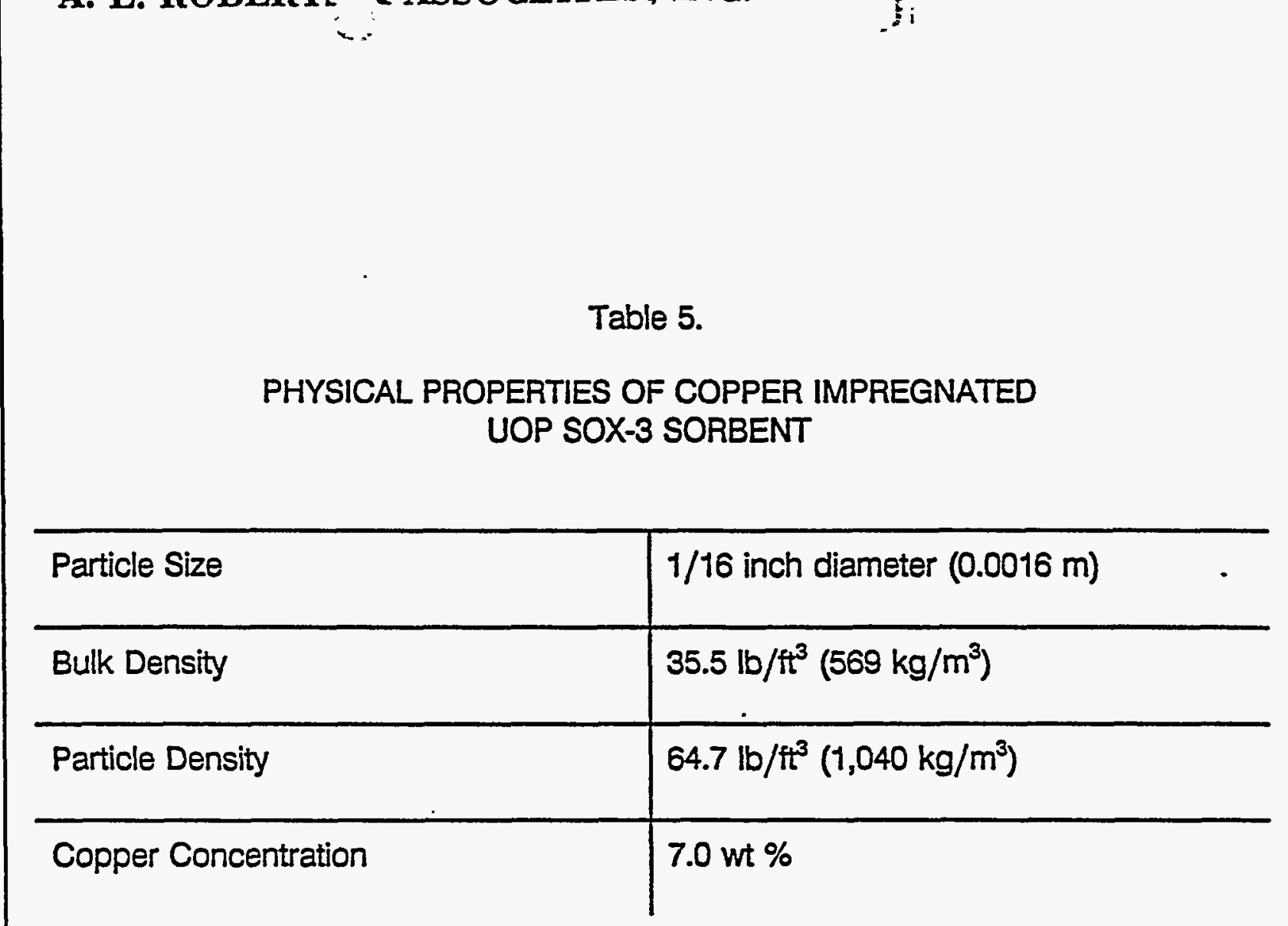


Table 6 presents the material balance for the sorbent circulating loop in pounds per hour, based on the Cu/S molar ratio of 2.0.

The selection of the regenerator design parameters reflects the recent work by Professor Harriott to provide a minimum of $80 \% \mathrm{CuSO}_{4}$ to $\mathrm{CuO}$ conversion at $480 \mathrm{C}(900 \mathrm{~F})$. Realizing that the endothermic reduction reaction will lower the solids temperature top to bottom by $35 \mathrm{~F}$, special considerations will be provided in the engineering design to maintain an average bed temperature of 900 F. Table 7 presents the regenerator design parameters.

Figure 1 presents a process flow schematic of the fluidized-bed copper oxide process as it will be used in the engineering design. Figure 1 also contains the mass balance data that is associated with the circled process stream numbers. The mass balance shown reflects the $\mathrm{Cu} / \mathrm{S}$ mole ratio of 2.0 and its associated $752,821 \mathrm{lbs} / \mathrm{hr}$ absorber circulation rate.

Process energy requirements for a $500 \mathrm{MW}$ application were calculated based on the process flow diagram and mass balance. The energy requirements consist of the following inputs (and outputs):

- Methane reducing gas

- Methane for solids heating 
Table 6.

FLUIDIZED BED COPPER OXIDE PROCESS

500 MW CONCEPTUAL DESIGN

SORBENT CIRCULATING LOOP

MATERIAL BALANCE, lb/hr

\begin{tabular}{l|r|r|r|r}
\hline \hline Component & $\begin{array}{c}\text { Oxidized } \\
\text { Sorbent to } \\
\text { Fluid Bed }\end{array}$ & $\begin{array}{c}\text { Spent } \\
\text { Sorbent to } \\
\text { Regenerator }\end{array}$ & $\begin{array}{c}\text { Reduced } \\
\text { Sorbent to Lift } \\
\text { Engager }\end{array}$ & \multicolumn{1}{c}{$\begin{array}{c}\text { Sorbent From } \\
\text { Lift Engager }\end{array}$} \\
\hline \hline Al203 & $673,419.5$ & $673,419.5$ & $673,419.5$ & $673,419.5$ \\
Cu & $50,687.5$ & $22,153.5$ & & 34,903 \\
CuO & & 57,248 & & $6,995.5$ \\
CuSO4 & 724,107 & 752,821 & $713,905.7$ & 715,318 \\
\hline \multicolumn{1}{r|}{ TOTAL } & & & & \\
\hline \hline
\end{tabular}

Basis:

1) 2 to $1 \mathrm{Cu} / \mathrm{S}$ ratio

2) Dry Basis; $\mathrm{H} 2 \mathrm{O}$ level presumked constant through sorbent loop.

3) Circulation rate as $7 \% \mathrm{CuO}$ for available $\mathrm{Cu}$ as oxidized. 
Table 7.

REGENERATOR DESIGN PARAMETERS

TO OBTAIN $80 \%$ SORBENT REGENERATION

\begin{tabular}{|c|c|}
\hline PARAMETER & DESIGN VALUE \\
\hline Bed Temperature & $900 \mathrm{~F}$ \\
\hline Operating Pressure & $5^{\prime \prime}$ of W.c. \\
\hline Sorbent Residence Time & 25 Minutes \\
\hline Methane Injection & 15\% Excess \\
\hline
\end{tabular}


然.

UOP MLTERAL BUUACE

Curs - 20 par cos

$1-2-03$

\begin{tabular}{|c|c|c|c|c|c|c|}
\hline$\approx \quad-$ & COABUSTOA EULANCE & & & & & \\
\hline & STREM & 81 & 7 & 81 & g & 10 \\
\hline & COMPONENT & & & & & \\
\hline & MASS FLOWIOMn & 20001 & 870911 & 170121 & E18s5 & 20000 \\
\hline & & & & & & \\
\hline & VCLUME FLOW (SCM) & 15181 & 100821 & 3031 & 12225 & 8433 \\
\hline \multirow{3}{*}{ • } & TЕМРERATURE(F) & 801 & का & 121 & 1200 & 1200 \\
\hline & & & 1 & & & \\
\hline & PAESSURE IPaX) & $-\infty$ & $=-\infty$ & $=-$ & $=-$ & $-\infty$ \\
\hline
\end{tabular}

\begin{tabular}{|c|c|c|c|c|c|c|c|}
\hline \multicolumn{8}{|c|}{ SECOND STACE SOUDS HEATER } \\
\hline STREMA & ग1 & in & 4 & 91 & ग1 & III & \\
\hline \multicolumn{8}{|l|}{ COMPONENT } \\
\hline WASSFLOWIOMH & 732921 & E15s0 & 830701 & BIQ45! & 200081 & 7528211 & 172000 \\
\hline & & & & & & & \\
\hline VOUME FLOWISFM) & $=-$ & 1023 & -- & 120251 & 8031 & $=-\infty$ & $-\infty$ \\
\hline & & & & & & & \\
\hline TEMPGRTUAEW & 730 & $\infty$ & 7201 & 1200 & 12001 & $\infty$ & $=-$ \\
\hline & & & I & 1 & 1 & & \\
\hline PRESSURE (pent) & $-\infty$ & $=-$ & 2131 & $-\infty$ & $=$ & $=-$ & $-\infty$ \\
\hline
\end{tabular}
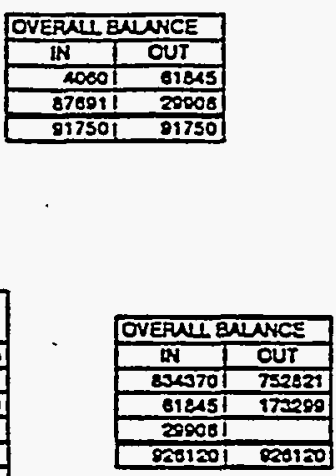
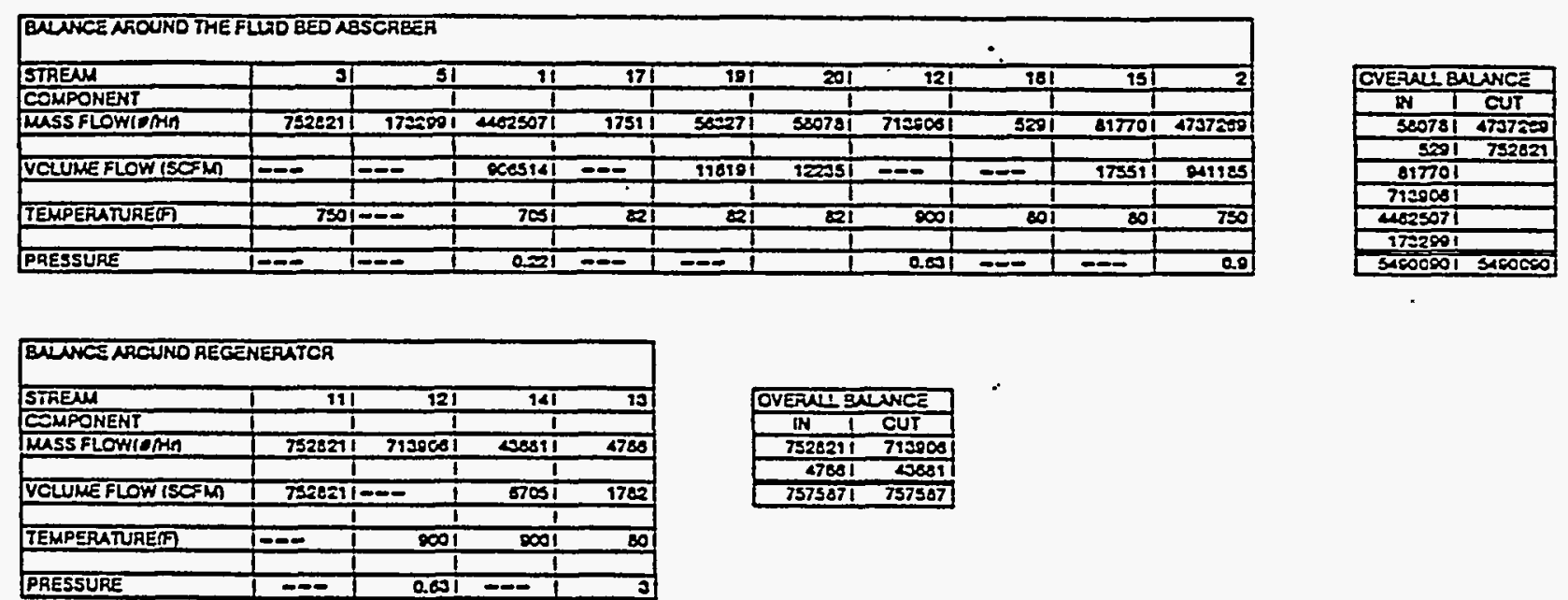
- Methane for solids transport air heating if heat is unavailable from the sulfuric acid plant

- Electrical energy for fans, blowers, compressors, and valves including the solids dense phase transport

- $\quad$ Energy credits associated with process.

Table 8 summarizes the energy requirements for the process base case application. It should be pointed out that the total energy requirement shown in Table 7 does not reflect any additional heat recovery in the air preheater due to reduction in the sulfuric acid dew point of the flue gas by removal of suliur tricxide $\left(\mathrm{SO}_{3}\right)$ in the reactor.

Table 9 summarizes the raw material requirements for the process application. The sorbent make-up requirements are based on an attrition rate of $0.067 \% / \mathrm{hr}$ of the required circulation rate. Steam is used in the process to vaporize the ammonia.

Appendix $C$ presents the proposed general layout arrangement for the FBCO process integrated with the grass roots $500 \mathrm{MW}$ powerplant located in the state of Illinois. The drawings reflect an initial effort to define the space requirements for the FBCO process as now conceptualized. 
Table 8.

PROCESS ENERGY REQUIREMENTS

\begin{tabular}{|c|c|c|c|}
\hline ENERGY TYPE & $\begin{array}{c}\text { ENERGY } \\
\text { REQUIREMENT } \\
\text { (GIVEN UNITS) }\end{array}$ & $\begin{array}{c}\text { CONVERTED } \\
\text { ENERGY } \\
\text { REQUIREMIENT } \\
(\mathrm{KW}) \\
\end{array}$ & $\begin{array}{c}\text { PERCENT OF } \\
\text { BOIIER OUTPUT } \\
(500 \mathrm{MW})\end{array}$ \\
\hline Electricity $_{3}$ & $\begin{array}{r}50.52 \times 10^{6} \\
\mathrm{BTU} / \mathrm{HR}\end{array}$ & 5,600 & 1.11 \\
\hline Steam $_{1}$ & $\begin{array}{l}1.22 \times 10^{6} \\
\mathrm{BTU} / \mathrm{HR}\end{array}$ & 145 & 0.03 \\
\hline Methane $_{5}$ & $\begin{array}{r}192.5 \times 10^{6} \\
\text { BTU/HR }\end{array}$ & 14,400 & 2.88 \\
\hline Heat Credit 6 & $\begin{array}{r}\left(47.0 \times 10^{6}\right) \\
\text { BTU/HR } \\
\end{array}$ & $(5,200)$ & (1.05) \\
\hline TOTAL & $\begin{array}{r}197.24 \times 10^{6} \\
\text { BTU/HR }\end{array}$ & 14,945 & 2.97 \\
\hline
\end{tabular}

NOTES:

1. Calculated energy requirement for the process.

2. Each energy form has been put on the basis of electricity output from the power plant. For steam, a thermal efficiency of 88 percent was used to determine the energy input required to generate a Btu of steam energy - then the energy requirement was converted to electricity output at the plant heat rate. Both the heat credit and methane were assumed to replace heat input to the boiler on a 1-to-1 basis and then converted to electricity output @ 9,000 Btu/Kwhr.

3. Includes induced draft fans, solids transport air blowers, rotary valves and combustor/solids heater blower.

4. Based on a datum of saturated water at $32 \circ \mathrm{F}$.

5. Based on a heating value of $21,500 \mathrm{Btu} / \mathrm{lb}$. Includes methane for solids heating, solids regeneration and transport air heating.

6. Based on added process energy removed in the air heater and returned to the boiler. 
A. E. ROBERTS \& ASSOCIATES, INC.

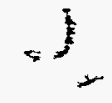

IV. Summary

The selected process criteria will be used as the basis for calculating major equipment design specifications. This information will be turned into performance specifications that will include, for each piece of equipment, the following data:

- Equipment functional description

- Number of pieces required

- Equipment type

- Equipment operating conditions

- $\quad$ Equipment budgetary cost (from specified manufacturer).

This report concludes the establishment of the design basis phase of A. E. Roberts's work effort to engineer the FBCO flue gas treatment unit. 


\section{Cornell University}

OLIN HALL, ITHACA, N.Y. 14853.5201

Tel. $607-255-8656$

EAX: $607-255-9166$

December 14, 1992

Mr. A.E. Roberts

A.E. Roberts and Associates, Inc. 1246 Concord Road, Suite B-20

Atlanta (Smyma), GA 30080

Dear Mr. Roberts:

I reviewed the December 4, 1992 letter from UOP, the November 25, 1992 letter from DOE to UOP, and the November 23 memo by Dr. James T. Yeh.

The DOE letter recommends a value of 2.0 for the $\mathrm{Cu} / \mathrm{SO}_{2}$ ratio rather than the value of 3.0 given in the Design Basis Report. I strongly favor this change, since I thought the optimum ratio might be in the range 1.5-2.0, and I used 1.7 for my sample calculations. I hope that the sensitivity analysis done by Chris Frey at $\mathrm{CMU}$ will include calculations for several $\mathrm{Cu} / \mathrm{SO}_{2}$ ratios near the design basis of 2.0 .

Dr. Yeh says that the Hirriott model gives about the same results as the 1985 PETC model for $90 \% \mathrm{SO}_{2}$ removal, but his analysis was based only on the 40 " by 48 " fluidized bed tests. The PETC model is based on plug flow of solids, which is unrealistic for a fluidized bed, whereas my model assumes complete mixing of the solid, which is certainly closer to the true situation when the average solids residence time is $1-3$ hours. I am sure that these models will give significantly different results when the coper oxide conversion is high, and I am glad that DOE is willing to base the design cases on my model. .

The rate instant $\mathrm{k}_{\mathrm{S}}$ for the $\mathrm{SO}_{2}$ removal reaction can be modified to account for changes in copper concentrations. My value for $\mathrm{k}_{\mathrm{S}}=840 \exp (-2460 / \mathrm{T}) \mathrm{min}^{-1}$, atm $\mathrm{am}^{-1}$ was based on the results for $5.1 \% \mathrm{Cu}$. I haven't seen the data that $\mathrm{Dr}$. Yeh used for other copper concentrations, but his recommended equation is reasonable and agrees with my value for $k_{S}$ when $x=5.1 \%$ Cu. 
Mr. A.E. Roberts

December 14, 1992

Page 2

However, assuming the decrease in $k_{S}$ with $\mathrm{x}$ is caused by partial blocking of the pores or larger crystals of $\mathrm{CuO}$, I think a similar correction factor should be applied to the rate constants for regeneration. I suggest adding the following factor to the equations for regeneration given in my : August 4, 1992 letter

$$
\begin{aligned}
& F=2.04 \exp (-0.14 x) \\
& \text { where } \quad x=w t \% \mathrm{Cu}
\end{aligned}
$$

I enclose an invoice for work done this month.

Sincerely,

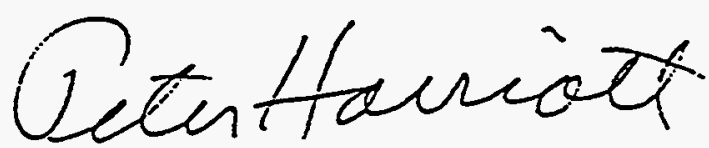

Peter Harriott

Professor

\section{c.c.: Dr. Chris Frey}

Carnegie Mellon University

Center for Energy Studies

Pittsburgh, PA 152i3-3890

Hemant B. Gala

UOP

25 East Algonquin Rd.

Des Plaines, II 60017 
Dr. Chris Frey

Center for Energy Sudies

Cannegie Mellon University

Fitssourgh, PA 15213-3890

Desr Chris:

Enclosed are some notes on a model for regenezation of spent $\mathrm{CuO}_{2} \mathrm{Al}_{2} \mathrm{O}_{3}$ sorident I calculated a few cases based on this model using concitions that I thcugit worid be reasonable.

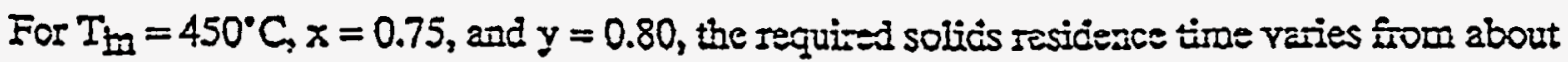
24 minutes to 43 minutes as the excess methane goes tion $15 \%$ to $-9 \%$ (ine percent of methane fed . that is actually consumed goes from 7090 to 88\%). increasing the degree of regeneration from $y=0.8$ to $y=0.9$ greatly increases the required residence time. I hope you can use this model to show more completely the efiects of $T_{i n}, x_{1} y_{1}$ and excess methane on the residence time needed.

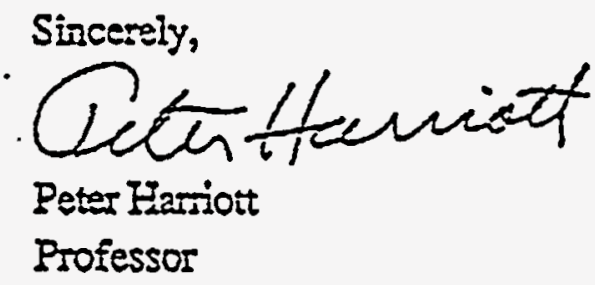

c.c. D. Fienzel 


\section{Regeneration of Spent Sorbent in the CuO Process for $\mathrm{SO}_{2}$ Removal}

In the $\mathrm{CuO}$ process, $\mathrm{SO}_{2}$ is removed trom flue gas in a fluidized bed of $\mathrm{CuO} / \mathrm{Al}_{2} \mathrm{O}_{3}$ particles. The parially-sulfated soroent is carried to a moving-bed reactor where it is regenerated with natural . gas. The razin regeneration reaction is:

$$
\begin{aligned}
\mathrm{CuSO}_{4}+1 / 2 \mathrm{CH}_{4} \rightarrow \mathrm{Cu}+\mathrm{SO}_{2}+\mathrm{H}_{2} \mathrm{O}+1 / 2 \mathrm{CO}_{2} \\
\text { at } 25^{\circ} \mathrm{C}, \Delta \mathrm{HI}=17,880 \mathrm{cal} / \mathrm{mol} \\
\Delta \mathrm{G}=-9,080 \mathrm{cal} / \mathrm{mol} \\
\overline{\mathrm{A}}_{\text {eq }}=4.5 \times 10^{5}
\end{aligned}
$$

Reacion (A) is modeately exdotherric bot quite favcrable at $25^{\circ} \mathrm{C}$, and it should be wnch more fayorable at 450 to $500^{\circ} \mathrm{C}$, the probable range of regenenator temperatures. Fowever, the above values are basad on themocynamic dam for the bulk or crystalline soitcis, and the values for Enely aispersed $\mathrm{Cu}$ or $\mathrm{CuSO}_{4}$ on $\mathrm{Al}_{2} \mathrm{O}_{3}$ may be sigoinicantly difierent.

Kinetic tests in a therwal balance showed that reaction $(A)$ is fractional order to CH4 and siongly inhibited by $\mathrm{SO}_{2}$ and $\mathrm{CO}_{2}$ (Hiwrior, P. and J.M. Makussen, Ind. Eng. Chem. Res. 11 373, 1992). With $\mathrm{SO}_{2}$ present, the reacion appeared to siop at between 70 and 90 percent convesion, even though the predicted equilibrium conversion was alrosi 100 perent. An approxionate eqquation for the pseucio-equilioition conversion is:

$$
y_{e q} \cong 1-0.9 P_{\mathrm{SO}_{2}}
$$

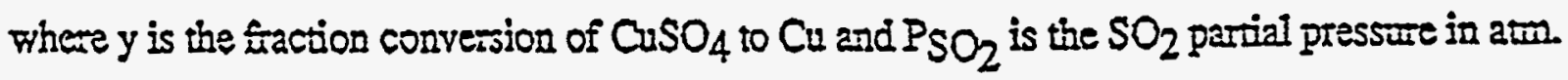

In the previous kinetic sucily, the rate constants were evainated mainly from initial reaction rates, and the limiting conversion was not taken into account. However in a commercial unit, nearly complete regeneration is needed, and the previous kinetic correiations are therefore modified to better predict the reaction rate at bigh convesions. The driving force term is changed from $(1-y)$ to $(y$ eq $-y)$, and the numerator constant is increased by a factor of 1.5 to give about the same rates as before for low conversions. The recormmended equation for the rate of regeneration is then:

$$
r=\frac{d y}{d t}=\frac{k_{2} P_{\mathrm{CH}_{4}}\left(1-0.9 \mathrm{P}_{\mathrm{SO}_{2}}-y\right)}{1 \div 5 \mathrm{P}_{\mathrm{CH}_{1}}+16 \mathrm{P}_{\mathrm{SO}_{2}}+6 \mathrm{P}_{\mathrm{CO}_{2}}}
$$


Tests at $450^{\circ} \mathrm{C}$ to $510^{\circ} \mathrm{C}$ showed a decresse in activation energy with increasing temperature, and the following equations can be used for $\mathrm{k}_{2}$.

Up to $480^{\circ} \mathrm{C}, \mathrm{k}_{2}=4.2 \times 10^{7} \exp (-12,080 / \pi) \min ^{-1}$, am-1

Above $480^{\circ} \mathrm{C}, \mathrm{k}_{2}=11.2 \times 10^{5} \exp (-9,350 / \mathrm{I}) \mathrm{min}^{-1}, 2 \mathrm{~m}-1$

At $450^{\circ} \mathrm{C}(\mathrm{T}=723 \mathrm{~K}), \mathrm{k}_{2}=2.33 \min ^{-1}$, atmo ${ }^{-1}$

At $480^{\circ} \mathrm{C}(T=753 \mathrm{~K}), \mathrm{k}_{2}=4.53 \mathrm{~min}^{-1}, \mathrm{~atm}^{-1}$

The regenerator will operate in the counterilow made ai 1 ams with about 30 to $40 \% \mathrm{SO}_{2}$ in the exit gas. Uinde these concitions, Yeg is onity about 0.6 to 0.7 ai the sop of the regenerator, but at the bottom, $\mathrm{PSO}_{2}=0$, and $\mathrm{Yeq}_{\mathrm{eq}}=1.0$. Therefore a high conveasion of $\mathrm{CuSO}_{4}$ to $\mathrm{Cu}$ can sill be obrained if enough excess wethrne is used to aroid a "pinch" region near the ridale of the regenowator. (A pinch would exist if the term (1 - 0.9 PSO$_{2}-y$ ) beovines aimost zero at some internediate region.) Steprise calculations are required to detenoine ise parial pressures, conversions, and reaction rates at internediate points in the regenenator, because an explicit solution for conversion is not possible even if an average reie consiant is used.

Because the main reaction is endothenmic, the solios temperante will decrease as $\mathrm{CaSO}_{4}$ is converted to $\mathrm{Cu}$. For fully suliated sorbent with $6 \% \mathrm{Cu} / \mathrm{Al}_{2} \mathrm{O}_{3}$, comolete regenemation in an aciabatic reactor would result in a temperature change of about $-70^{\circ} \mathrm{C}$, as shown below.

Sample Calculation of $\Delta T$, the change in solids temperaure.

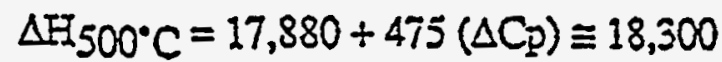

Basis: 1 mol Cu or $63.57 \mathrm{gCu}$

$F_{S}=63.57 / 0.06=1060 \mathrm{~g}$ sorbent .

$c_{s}=0.27 \mathrm{cal} / \mathrm{g} ;{ }^{\circ} \mathrm{c}$ (based on $\left.\mathrm{Al}_{2} \mathrm{O}_{3}\right)$

For complete conversion and no excess $\mathrm{CH}_{4}$

$\mathrm{N}=$ moles of gas proauced $=1 \mathrm{SO}_{2}+1 \mathrm{H}_{2} \mathrm{O} \div 1 / 2 \mathrm{CO}_{2}=2.5$

$\overline{C P} \equiv 11.0$ at $500^{\circ} \mathrm{C}$

$Q=18,300-F_{s} c_{s}\left(T_{\text {in }}-T_{\text {out }}\right) \div N \bar{C}_{p}\left(T_{\text {g, in }}-T_{g, \text { out }}\right)$

Assume gas enters at the solid exit temperature and leaves at the solid inlet remperature. 


$$
\begin{aligned}
& T_{g, \text { in }}-T_{g, \text { out }}=T_{\text {out }}-T_{\text {in }} \\
& 18,300=\left(F_{s} c_{s}-N_{C p}\right)\left(T_{\text {in }}-T_{\text {out }}\right) \\
& -\Delta T=T_{\text {in }}-T_{\text {out }}=\frac{18, \hat{300} \cdot}{1060(.27)-2.5(11)}=70.7^{\circ} \mathrm{C}
\end{aligned}
$$

In actual operation, the terperature change will be much less than $70^{\circ} \mathrm{C}$ because of incomplete regeneration. The optimum extent of regeneration depends on many factors, but it is expected to be in the range of 70 to 90 percent. Furhermore, the solicis fed to the regenerator will contain some $\mathrm{CuO}_{\mathrm{O}}$ well as $\mathrm{CuSO}_{4}$. The $\mathrm{CuO}$ in the spent sorient will react exothermically and very rapidly with $\mathrm{SO}_{2}$ in the top of the regenerator.

$$
\begin{aligned}
& \mathrm{CuO} \div \mathrm{SO}_{2} \rightarrow \mathrm{CaSO}_{3} \\
& \Delta \mathrm{HH} \equiv-51,800 \mathrm{cal} / \mathrm{mol}
\end{aligned}
$$

Thermodynamic cata for $\mathrm{CuSO}_{3}$ were not availabie, so $\triangle \mathrm{F}$ was esimaied using cava for $\mathrm{SO}_{2}$ oxidation and for $\mathrm{CuSO}_{4}$ formation.

As the soriont with a wixiste of $\mathrm{CuSO}_{4}$ and $\mathrm{CuSO}_{3}$ moves down through bed, the $\mathrm{CuSO}_{3}$ is reduced at about the same rate as the $\mathrm{CuSO}_{4}$.

$$
\mathrm{CuSO}_{3}+1 / 4 \mathrm{CH}_{4} \rightarrow \mathrm{Ca}+\mathrm{SO}_{2}+1 / 2 \mathrm{~F}_{2} \mathrm{O}+1 / 4 \mathrm{CO}_{2}
$$

$$
\Delta F \equiv 42,300 \mathrm{cal}
$$

The net efiect of reactions $(B)$ and $(C)$ is silightly exotherwic.

$$
\mathrm{CuO} \div 1 / 4 \mathrm{CH}_{4} \rightarrow \mathrm{Cu}+1 / 2 \mathrm{~F}_{2} \mathrm{O} \div 1 / 4 \mathrm{CO}_{2}
$$

$$
\Delta F=-9,500 \mathrm{cal}
$$

If solid entering the regenerator is $75 \%$ converted to $\mathrm{CuSO}_{4}(x=0.75)$, and $25 \%$ is $\mathrm{CuO}$, and if $80 \%$ regeneration is achieved $(y=0.80)$, the overall ternperature change is predicted to be a decrease of about $30^{\circ} \mathrm{C}$ depending on the amount of excess CH4 used. For exampie, with $20 \%$ ercess $\mathrm{CH}_{4}$, there are 1.7 moles of gas in the exit stream per mole of $\mathrm{Cu}$ fed, and the temperature change is $-34^{\circ} \mathrm{C}$. 


$$
T_{\text {in }}-T_{\text {out }}=\frac{0.75(18,300)(0.8)-0.25(9,500)(.8)}{1060(0.27)-1.7(11)}=34^{\circ} \mathrm{C}
$$

The temperature profile in the regenerator depends on the rates of Reactons (A), (B), and (C). Since Reaction (B) is very fast and exotheraic, the solics temperature is expected to rapidily increase and then gradually decrease as the solicis move through the reactor, giving a temperature profile of the following shape.

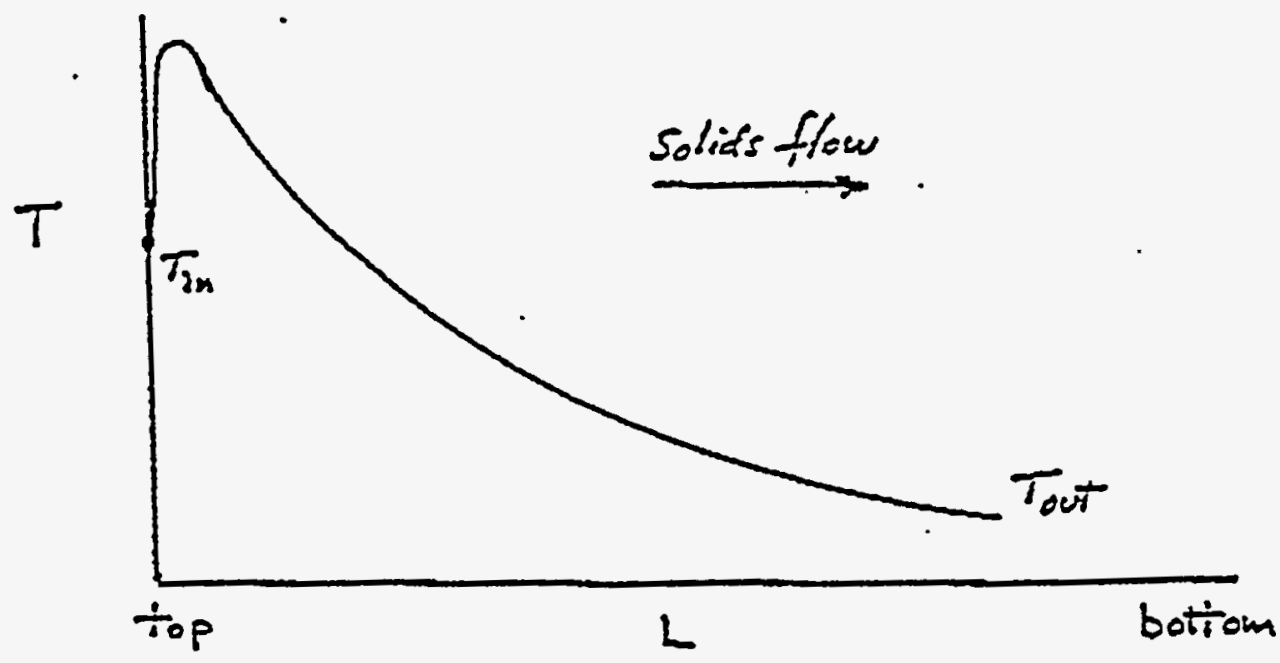

The higher reaction rates in the region above $T_{\text {in }}$ tend to compensate for low rates near the bottom of the reactor. A simple analysis could be based on the rate constants at $T_{\text {in }}$. Fiowever since numerical analysis is needed to deternine the required residence time for each combination of $x, y, T_{\text {in }}$, and $\%$ excess $C F 4$, the temperature change for each increment of convesion $\Delta y$, can be easily deternisied.

\section{Regenerator Calculation}

Assumotions:

1. No hear loss.

2. Plug flow of solids downard.

3. Plug flow of gas upward.

4. Constant pressure, $P$ atm.

5. Reducing gas is pure $\mathrm{CH}_{4}$.

6. Instantaneous conversion of $\mathrm{CuO}_{\text {to }} \mathrm{CuSO}_{3}$ at the top of the reactor (Reaction $\mathrm{B}$ ).

7. Reduction of $\mathrm{CuSO}_{4}$ and $\mathrm{CuSO}_{3}$ follow the same lineties given by Eq. (2), (3), (4).

8. Solid temperature equals gas tempesaure everywhere in the reactor. 
Suggested Basis: $1 \mathrm{~g} \mathrm{~mol} \mathrm{Cu}$ or $1060 \mathrm{~g} \mathrm{Cu} / \mathrm{Al}_{2} \mathrm{O}_{3}(6 \% \mathrm{Cu})$

Select 4 parameters: $T_{0}=$ feed tempesature of solids

$x=$ fraction conversion in adsorber

$$
x=\mathrm{CuSO}_{4} /\left(\mathrm{CuO}+\mathrm{CuSO}_{4}\right)
$$

$y=$ fraction regeneration to be obtained

$$
\mathrm{y}=\frac{\mathrm{Cu}}{\mathrm{CuSO}_{4} \div \mathrm{CuSO}_{3}}
$$

$\mathrm{N}_{\mathrm{CH}} 4$, in $\mathrm{N}^{*} \mathrm{CH}_{4}=$ excess methane ratio

From hancbooks, $c_{s}=0.27 \mathrm{cal} / \mathrm{g} \cdot{ }^{\circ} \mathrm{C}$ (constant)

$\mathrm{Cp}$ at $450^{\circ} \mathrm{C}, \mathrm{Ca} / \mathrm{mol},{ }^{\circ} \mathrm{C}$

$\begin{array}{ll}\mathrm{SO}_{2} & 12.2\end{array}$

$\mathrm{E}_{2} \mathrm{O} \quad 9.0$

$\mathrm{CO}_{2} \cdot 12.0$

$\mathrm{CF}_{4} 4 \quad 14.0$

Typical $\bar{C}_{\bar{D}}=11.3 \mathrm{C}$ (2)/rool, ${ }^{\circ} \mathrm{C}$

Nieglect ciarse in $C p$ witit temperature

Calculate minimum $\mathrm{CE}_{4}=\mathrm{N}^{*} \mathrm{CH}_{4}$

$$
\mathrm{N}^{*} \mathrm{CH}_{4}=1 / 2 \mathrm{x}+1 / 4(1-\pi)
$$

Get corsposition at top of reactor.

$$
\begin{aligned}
& \mathrm{NSO}_{2}=\mathrm{CuSO}_{4} \mathrm{in} \cdot\left(\mathrm{CuSO}_{4}+\mathrm{CuSO}_{3}\right)_{\text {out }} \\
& =x-(1-y)=x+y-1 \\
& \text { (or } \left.\mathrm{NSO}_{2}=x y(\text { Reaction } A)-(1-x)(\text { Reaction } Z)+(1-x) \text { y (Reaction } C\right) \\
& \left.\mathrm{Nin}_{2} \mathrm{O}=x y(\text { Reaction } A)+(1-x) y / 2 \text { (Reaction } C\right) \\
& =x y / 2 \div y / 2=y(1 \div x) \\
& \mathrm{NCO}_{2}=1 / 2 \mathrm{~N}_{2} \mathrm{O} \\
& 2 \\
& \mathrm{~N}_{\mathrm{CH}_{4}}=\mathrm{N}_{\mathrm{CH}_{4}, \mathrm{in}}-\mathrm{NCO}_{2} \\
& \text { at exir, } \quad \mathrm{P}_{\mathrm{SO}_{2}}=\left(\mathrm{N}_{\mathrm{SO}_{2}} \mathrm{~N}\right) \mathrm{P} \\
& \mathrm{P}_{\mathrm{CO}_{2}}=\left(\mathrm{N}_{\mathrm{CO}_{2}} \mathrm{~N}\right) P \\
& \mathrm{P} \mathrm{CH}_{4}=\left(\mathrm{NCH}_{4} \mathrm{~N}\right) \mathrm{P}
\end{aligned}
$$


Get gas composition just insice top of reactor, betore $(1-x) \mathrm{CuO}_{\text {has }}$ been convented to $\mathrm{CuSO}_{3}$ by Reacion B

ai starion $1 \mathrm{NSO}_{2}=\mathrm{NSO}_{2}$,top $+1-x$

Other gases are unchanged

Calculate $\mathrm{N}$ and $\mathrm{PSO}_{2}, \mathrm{PCO}_{2}, \mathrm{PCF}_{4}$

Calculate $T_{1}$, temperatrse at top of reactor

$$
\begin{gathered}
Q_{I}=(I-x)(51,800) \\
I_{1}-T_{0}=\frac{Q_{1}}{F_{s} c_{s}}=\frac{Q_{1}}{1060(0.27)}
\end{gathered}
$$

Evaluare $k_{2}$ tom Eq. (3) or Eq. (4)

$$
\left.I=\frac{k_{2} P_{\mathrm{CH}_{4}}\left(1-0.9 P_{\mathrm{SO}_{2}}-y\right)}{1+5 P_{\mathrm{CH}_{4}} \div 16 P_{\mathrm{SO}_{2}} \div 6 P_{\mathrm{CH}_{4}}} \text { (at station } 1, y=0\right)
$$

Choose a swall inciement of conyersion, $\Delta y$, to calculate $T_{2}, k_{2}$ and $\Sigma_{2}$

$$
\begin{aligned}
& -\Delta Q=\Delta y(x)(18,300) \div \Delta y(1-x)(42,300) \\
& T_{2}-T_{1}=\frac{\Delta Q}{1060(0.27)-\Sigma N C p} .
\end{aligned}
$$

Evaluate $k_{2}$ at $T_{2}$

Calculate $\mathrm{NSO}_{2}, \mathrm{~N}_{\mathrm{F}_{2} \mathrm{O}}, \mathrm{N}_{\mathrm{CO}_{2}}, \mathrm{NCH}_{4}$ at station 2

$$
\begin{aligned}
& \Delta \mathrm{NSO}_{2}=-\Delta \mathrm{y} \\
& \Delta \mathrm{NH}_{2} \mathrm{O}=-\Delta \mathrm{y}\left(x+\frac{1-x}{2}\right) \\
& \Delta \mathrm{N}_{\mathrm{CO}_{2}}=\Delta \mathrm{NH}_{2} \mathrm{O} / 2
\end{aligned}
$$

$$
\Delta \mathrm{NCH}_{4}=-\Delta \mathrm{NCO}_{2} \quad\left(\Delta \mathrm{NCH}_{4} \text { is positive }\right)
$$


$\mathrm{N}=\mathrm{N}_{\mathrm{SO}_{2}}+\mathrm{N}_{\mathrm{F}_{2} \mathrm{O}}+\mathrm{N}_{\mathrm{CO}_{2}}+\mathrm{N}_{\mathrm{CH}}$
get $\mathrm{PSO}_{2}, \mathrm{PCO}_{2}, \mathrm{P}_{\mathrm{CH}_{4}}$

Calculate If $_{2}$ from Eq. 2

$I_{2 v e}=\left(I_{1}+I_{2}\right) / 2$
$\Delta t=\Delta y / I_{\text {ave }}$

Continue until set conversion is reached. Get $t=\Sigma \Delta_{t}$, 
Sample Calculation

$$
\begin{aligned}
& I_{0}=450^{\circ} \mathrm{C} \\
& x=0.75 \\
& y=0.80 \\
& p=1 \text { atson } \\
& \mathrm{NCH}_{4, \text { in }}=1.15 \mathrm{~N}^{*} \mathrm{CLH}_{4} \\
& \mathrm{NiCH}_{4}^{*}=\frac{0.75}{2}+\frac{0.25}{4}=0.4375 \\
& \mathrm{NCH}_{4, \text { in }}=1.15(0.4375)=0.503 \\
& \mathrm{~N}_{\mathrm{SO}_{2}}=0.75+0.80-1=\quad 0.55 \quad 31.4 \\
& \mathrm{~N}_{\mathrm{E}_{2} \mathrm{O}}=\frac{0.75(0.80)}{2} \div \frac{0.80}{2}=0.70 \\
& \begin{array}{lll}
\mathrm{N}_{\mathrm{CO}_{2}}=0.70 / 2= & 0.35 \quad 20.0
\end{array} \\
& \mathrm{~N}_{\mathrm{Cs}_{4}}=0.503-0.35=\quad \underline{0.153} \quad 8.7 \\
& N=1.753
\end{aligned}
$$

Iust inside reacior

$\begin{array}{lrr}\mathrm{NSO}_{2}=0.55+0.25= & \frac{\%}{\%} \\ \mathrm{~N}_{2} \mathrm{O}= & 0.30 & 39.9 \\ \mathrm{~N}_{\mathrm{CO}_{2}}= & 0.35 & 35.0 \\ \mathrm{NCH}_{4}= & \underline{0.153} & 17.5 \\ & 2.003 & 7.6\end{array}$

$$
\begin{aligned}
& Q_{1}=0.25(51,800)=12,950 \\
& T_{1}-T_{0}=\frac{12,950}{1060(0.27)}=45^{\circ} \mathrm{C} \\
& T_{1}=450 \div 45=495^{\circ} \mathrm{C}=768 \mathrm{~K} \\
& k_{2}=11.2 \times 10^{5} \exp (-9350 / 768)=5.78 \mathrm{~min}^{-2}, 2 \mathrm{mon}^{-1} \\
& I_{1}=\frac{5.78(0.076)(1-0.9(0.399)-0)}{1+5(0.076)+16(0.399)+6(0.175)}=0.0319 \mathrm{~min}^{-1}
\end{aligned}
$$


Pick $\Delta y=0.08, y_{2}=0.08$

$$
\begin{aligned}
& -\Delta Q=0.08(.75)(18,300) \div 0.08(.25)(42,300) \\
& =1944 \text { cal } \% \\
& \mathrm{~N}_{\mathrm{SO}_{2}}=0.80-0.08=\quad 0.72 \quad 38.9 \\
& \Delta N_{E_{2} O}=-0.08(.75 \div .25 / 2)=-0.07 \\
& \mathrm{~N}_{\mathrm{E}_{2} \mathrm{O}}=0.70-0.07=\quad 0.63 \quad 34.0 \\
& \Delta \mathrm{N}_{\mathrm{CO}_{2}}=0.07 / 2=\quad-0.035 \\
& \mathrm{~N}_{\mathrm{CO}_{2}}=0.35-0.035=\quad 0.315 . \quad 17.0 \\
& \mathrm{~N}_{\mathrm{CH}_{4}}=0.153 \div 0.035=\quad \underline{0.188} \quad 10.1 \\
& N=1.853 \\
& \sum N_{C_{p}}=0.72(12.2)+0.63(0.0) \div 0.315(12) \div 0.188(14)=20.87 \\
& C p=11.3 \\
& I_{2}-T_{1}=-\frac{1944}{286.2-20.87}=-7.3 \\
& \mathrm{~T}_{2}=495-7.3=488.7^{\circ} \mathrm{C} \text { or } 760.7 \mathrm{~K} \\
& k_{2}=11.2 \times 10^{5} \mathrm{exp}(-9350 / 760.7)=5.14 \\
& I_{2}=\frac{5.14(.101)(1-0.9(0.389)-0.08)}{1+5(.101) \div 16(0.389) \div 6(0.170)}=0.0338 \mathrm{~min}^{-1} \\
& \tau_{\mathrm{avg}}=\frac{0.0319+0.0338}{2}=0.0328 \mathrm{~min}^{-1} \\
& \Delta t=\frac{0.08}{0.0328}=2.44 \min
\end{aligned}
$$

Calculations continued to $y=0.8$ give $t=24$ min., the required solids residence time. - 
Mr. David Henzel

AE Roberts \& Associates

1246 Concord Road B-200

Atlanta (Smyrana), GA 30080

Dear Dave:

After reviewing the data for $\mathrm{SO}_{2}$ removal, I suggest the following equation for the rate constant to be used in the model outined in my memo of June 3:

$$
k_{S}=840 \exp (-2,460 / T) \min ^{-1} ; \operatorname{atm}^{-1}
$$

The design of the regeneration should be based on the kinetic data of Harriott and Marlussen, but a change should be made in the rate expression to more accurately describe the rates at high values of $\mathrm{PSO}_{2}$ and high conversions. The diving force for reduction should be $x^{1}$ eq - $x$ rather than $1-x$, and $x^{1}$ eq $\equiv 1-0.9 \mathrm{PSO}_{2}$. The recommended equation is

$$
\frac{\mathrm{dx}}{\mathrm{dt}}=\frac{\mathrm{k}_{2} \mathrm{P}_{\mathrm{CH}_{4}}\left(1-0.9 \mathrm{P}_{\mathrm{SO}_{2}}-\mathrm{x}^{1}\right)}{1+5 \mathrm{P}_{\mathrm{CH}_{4}}+6 \mathrm{P}_{\mathrm{SO}_{2}}+6 \mathrm{P}_{\mathrm{CO}_{2}}}
$$

$\mathrm{x}^{1}$ is the faction conversion of $\mathrm{CuSO}_{4}$ to $\mathrm{Cu}$ $\mathrm{P}=$ parial pressure in atm 
Mr. David Henzel

August 4, 1992

Page 2

Up to $480^{\circ} \mathrm{C}, \mathrm{k}_{2}=4.2 \times 10^{7} \exp (-12,080 / \mathrm{T}) \mathrm{min}^{-1}$, atm -1

Above $480 \mathrm{C}^{\circ}, \mathrm{k}_{2}=11.2 \times 10^{5} \exp (-9,350 / \mathrm{T}) \mathrm{min}^{-1}, \mathrm{~atm}^{-1}$

I am preparing a memo on the method of calculating temperature and concentration profiles in the regenerator and will send it to you later this month.

Sincerely,

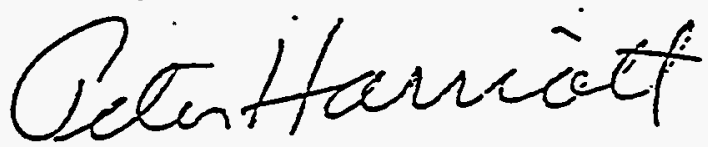

Peter Farriott

Professor

c.c. Dr. Chris Frey

Carnegie Mellon University

Center for Energy Studies

Pittsburgh, PA 15213-3890 
7

5

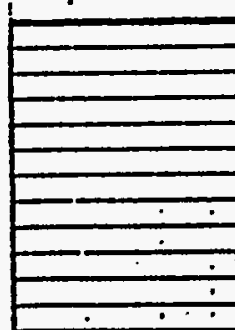

(1) $1 \cdot 1$
1
1
1
1
1

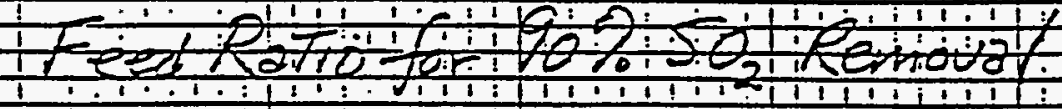

6

3

4

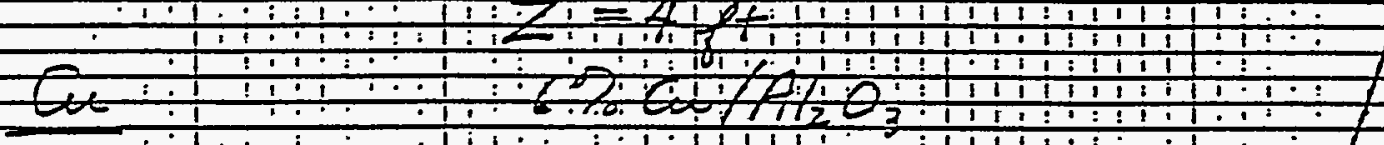
U.

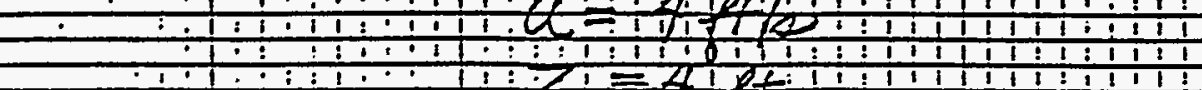
52 $\frac{1+1 ;}{1+1}$

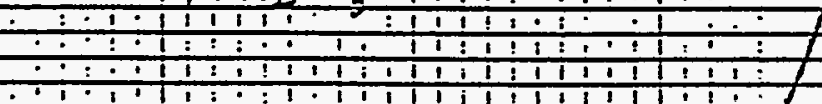

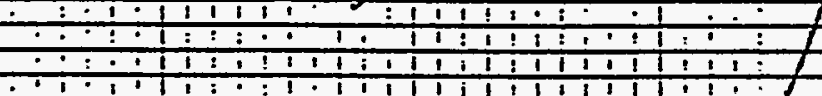
$\frac{1}{1}$

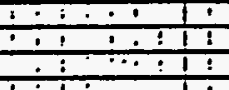

.

2

1

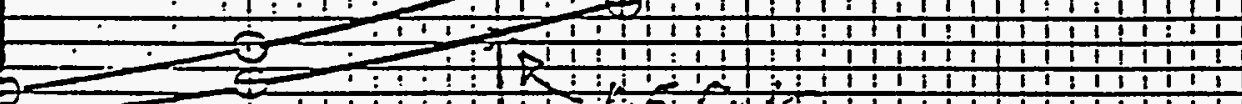
$\frac{11,111}{1,1111}$ $\frac{1+1}{1+1}$

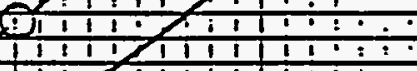

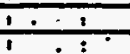

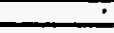

$1,1+1,111$

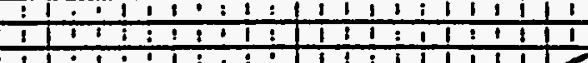

1111:1111!

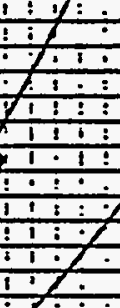

$111 \mathrm{i} / 111,111,1 \%$

\begin{tabular}{l}
\hline \\
\hline \\
\hline
\end{tabular}

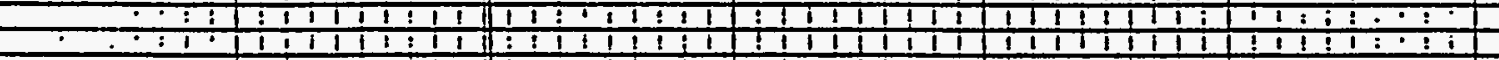
\begin{aligned} \hline \\ \hline\end{aligned}

0

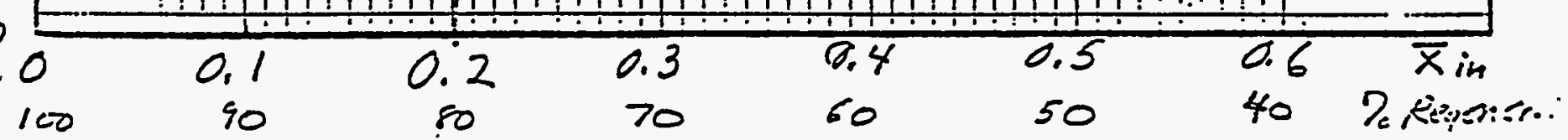

Effect of Incomplete Regencration on Perfurmance of Flurigiga-Bed Recitor for $\mathrm{SO}_{2}$ Removal 
Model for $\mathrm{SO}_{2}$ Removal by $\mathrm{CuO} / \mathrm{Al}_{2} \mathrm{O}_{3}$ in a Fluidized Bed

Assume plug flow of gas perfect mixing of solid uniform temperature

$$
u_{0} \rho_{m} d y=-k_{\Delta} \rho_{b} N_{t}(1-\bar{x}) P_{y} d z
$$

stoichiometric ratio, $R \equiv \frac{F_{\nu} N_{t}\left(1-\bar{x}_{\text {in }}\right)}{u_{0} A C_{\text {m }} y_{\text {in }}}=\frac{\text { motes } C_{\text {OO }}}{\text { motes } \mathrm{SO}_{2}}$

kinetic pordmeter, $\alpha \equiv \frac{k_{\nu} \rho_{b} A Z P}{\frac{E}{2}}=k_{\nu} P \bar{E}_{\text {salic }}$

$$
\ln \left(\frac{y_{\text {in }}}{y_{\text {oct }}}\right)=(\alpha R) y_{\text {in }}-\alpha\left(y_{\text {in }}-y_{\text {out }}\right)
$$

$2-10-92$ 


\section{Mr. Dave Henzel}

AE Roberts \& Associates

1246 Concord Road B-200

Atlanta (Smyma), GA 30080

Dear Dave:

I have reviewed the adsorber model used by Jay Rataifa-Brown for the 1983 SMC report and the model published by Yeh, Drummond, and Joubert in Environmental Progress, February 1987, p. 44. The model used by Frey and Rubin at CMU is essentially the same at Yeh's model. None of these models is satisiactory for design studies, as explained below.

The SMC model gives the sorbent circularion rate as a function of $\mathrm{SO}_{2}$ removal and other parameters, as shown below:

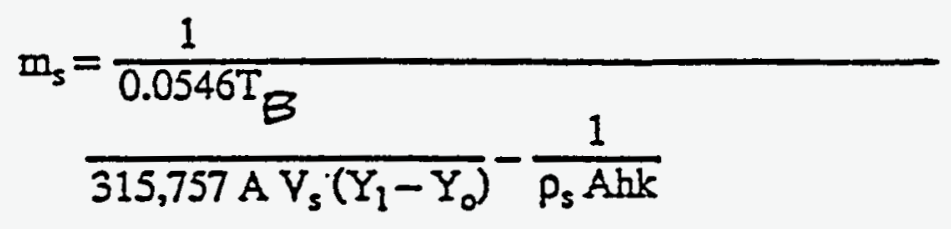

where $\mathrm{m}_{\mathrm{S}}=$ sorbent bed circularion rate, $\mathrm{lb} / \mathrm{hr}$

$k=$ chemical reaction rate constant, $\mathrm{hr}^{-1}$

$V_{S}=$ flue gas superificial velocity, $\mathrm{f} / \mathrm{sec}$

$\mathrm{A}=$ fluidized bed cross-sectional area, $\mathrm{ft}^{2}$

$\mathrm{T}_{\mathrm{B}}=$ bed temperature, $^{\circ} \mathrm{R}$

$\mathrm{Y}_{\mathrm{I}}=\mathrm{SO}_{2}$ inlet flue gas concentration, $\mathrm{Ib}$-moles $\mathrm{SO}_{2} / \mathrm{b}$-moles gas

$\mathrm{Y}_{\mathrm{O}}=\mathrm{SO}_{2}$ outlet flue gas concentration, $\mathrm{lb}$-moles $\mathrm{O}_{2} / \mathrm{b}$-mole gas

$\rho_{S}=$ soribent bulk density (settled), $1 \mathrm{~b} / \mathrm{ft}^{3}$

$\mathrm{h}=$ bed height (serted), $\mathrm{ft}$

This model does not account for the decrease in reaction rate with increasing $\mathrm{SO}_{2}$ conversion or the effects of total pressure and inlet $\mathrm{SO}_{2}$ concentration on the rate. The model might be suitable for design studies if all cases had the same $\mathrm{SO}_{2}$ conversion, say $90 \%$, and the same 
inlet partial pressure of $\mathrm{SO}_{2}$. For other cases, the rate constant $\mathrm{k}$ would have to be adjusted based on the change in the effective mean partial pressure of $\mathrm{SO}_{2}$.

The model of Yeh et al. allows for the change in parial pressure of $\mathrm{SO}_{2}$ as flue gas passes through the bed, and it assumes plug flow of the gas. This is a reasonable assumption, though it somewhat overestimates the reacion rate. However the concentration of $\mathrm{CuO}$ at àny point in the bed is expressed as a function of the $\mathrm{SO}_{2}$ concentration through a material balance, which is correct only if the solid also moves in plug flow through the bed, in parallel with the gas flow. Since the solids in the fluidized bed have a long residence time (30-60 minutes), the solids are probably nearly perfectly mixed, so the average CuO concentration is the same throughout the bed. Individual sorbent particles have a wide range of residence times and thus a wide range of $\mathrm{CuO}$ concentration, but the average concentration is the appropriate concentration to use in the model. The Yeh equation is given below using the notation developed later for the recommended model. It predicts considerably higher conversions than the recommended model, except when the stoichiometric ratio, $R$, is very large.

$$
\text { For } \mathrm{SO}_{2}, \frac{\mathrm{y}_{\text {out }}}{\mathrm{y}_{\text {in }}}=\frac{1-1 / \mathrm{R}}{\exp \left[\alpha \mathrm{R} \mathrm{y}_{\text {in }}(1-1 / \mathrm{R})\right]-1 / \mathrm{R}}
$$

where $\mathrm{R}=$ stoichiometric ratio, $\mathrm{CuO} / \mathrm{SO}_{2}$

$\alpha=$ kinetic parameter

The recommended model is derived assuming plug flow of gas through a perfectly mixed bed of sorbent. The reaction is first order to $\mathrm{SO}_{2}$ and to $\mathrm{CuO}$, and the change in number of moles is assumed negligible. The parial pressure of $\mathrm{SO}_{2}$ is based on the average total pressure $P$ in the bed and the mole fraction $\mathrm{SO}_{2}, y$.

$$
v_{0} \rho_{m} d y=-k_{s} \rho_{b} N_{t}(1-\bar{x}) P y d z
$$

where $v_{0}=$ superficial velocity

$\rho_{m}=$ molar gas density .

$k_{s}=$ rate constant, $\min ^{-1}, \operatorname{atm}^{-1}$

$\mathrm{P}_{\mathrm{b}}=$ density of expanded bed

$\mathrm{N}_{\mathrm{t}}=$ total moles $\mathrm{Cu} / \mathrm{kg}$ sorbent

$\bar{x}=$ average conversion of $\mathrm{CuO}$ to $\mathrm{CuSO}_{4}$

$z=$ bed height 
Integration of Equation (3) gives

$$
\ln \left(\frac{y_{\text {out }}}{y_{\text {in }}}\right)=\frac{-k_{s} \rho_{b} N_{t}(1-\bar{x}) P Z}{v_{0} \rho_{m}}
$$

A material balance over the reactor is made for $F_{s}$ feed rate of sorbent and a bed area, $A$.

$$
F_{s} N_{z}\left(\bar{x}_{\text {out }}-\bar{x}_{\text {in }}\right)=v_{0} A \rho_{\text {m }}\left(y_{\text {in }}-y_{\text {out }}\right)
$$

The unconverted $\mathrm{CuO}$ concentration is $\left(1-\bar{x}_{\text {out }}\right)$

$$
(1-\bar{x})_{\text {out }}=1-\bar{x}_{\text {in }}-\frac{v_{0} A P_{m}\left(y_{\text {in }}-y_{\text {out }}\right)}{F_{s} N_{t}}
$$

Substituting $(1-\bar{x})_{\text {out }}$ from Eq. (ด) into Eq. (4) gives

$$
\begin{aligned}
& \ln \left(\frac{y_{\text {out }}}{y_{\text {in }}}\right)=\frac{-k_{s} P_{b} N_{t} P Z}{v_{0} P_{\text {m }}}\left(1-\bar{x}_{\text {in }} \frac{-v_{0} A P_{\text {m }}\left(y_{\text {in }}-y_{\text {out }}\right)}{F_{s} N_{t}}\right) \\
& \text { Let } R=\frac{F_{s} N_{t}\left(1-\bar{x}_{\text {in }}\right.}{V_{0} A \rho_{m} y_{\text {in }}}=\text { stoichiometric ratio } \\
& \text { Let } \alpha=\frac{k_{s} \rho_{b} P Z A}{F_{s}}=\text { kinetic parameter } \\
& \alpha R=\frac{k_{s} P_{b} P Z N_{\mathfrak{l}}\left(1-\bar{x}_{\text {in }}\right)}{v_{0} P_{m} y_{\text {in }}}
\end{aligned}
$$

Then Equation (7) becomes

$$
\ln \left(\frac{y_{\text {out }}}{y_{\text {in }}}\right)=-\alpha R y_{\text {in }}+\alpha\left(y_{\text {in }}-y_{\text {out }}\right)
$$

or 

- $\quad$ A. E. ROBERTS \& ASSOCIATES, INC.

APPENDIX B

CMU's CuO Process Model 


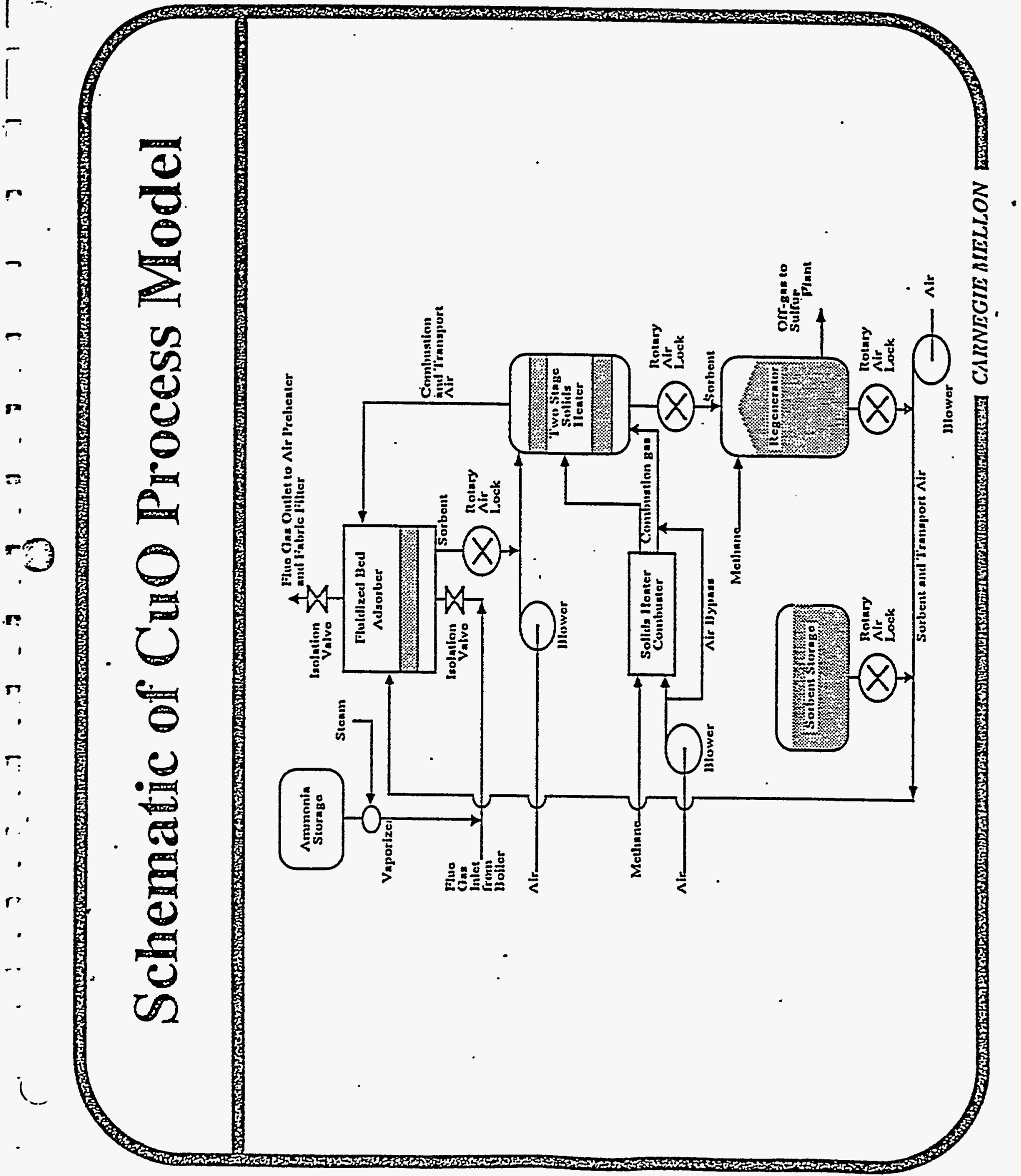




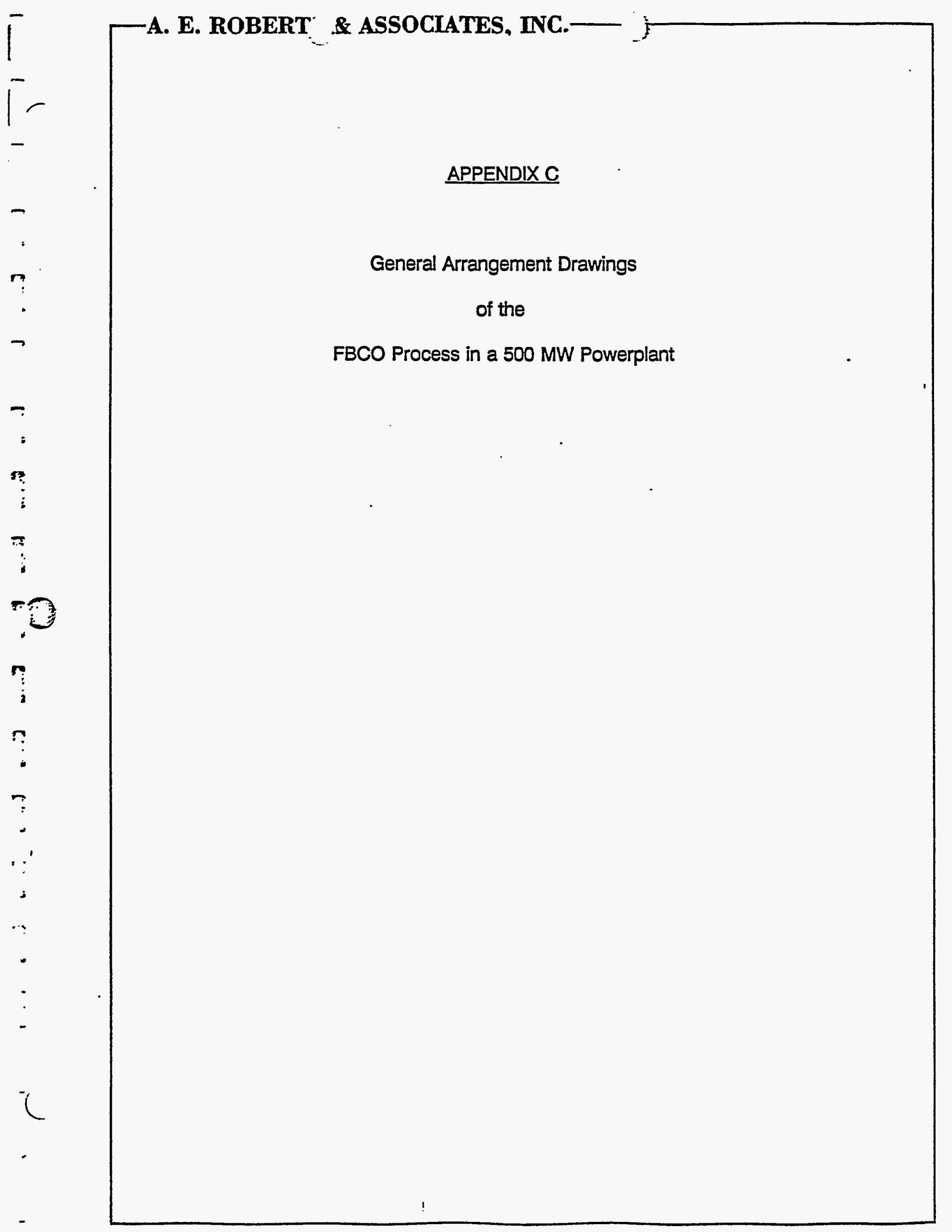




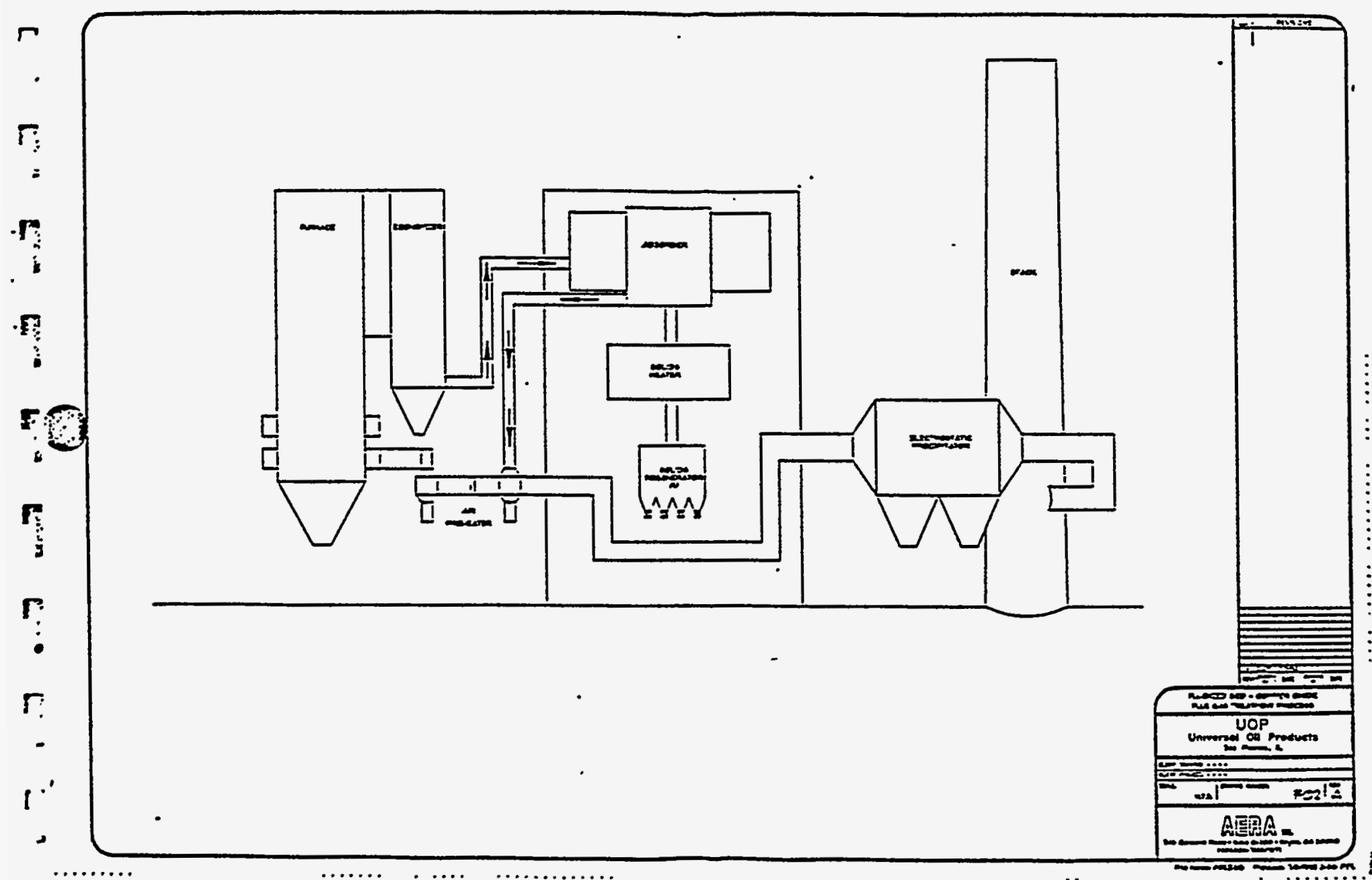




\begin{tabular}{|c|c|c|c|c|c|}
\hline \multicolumn{3}{|l|}{$\begin{array}{l}\text { WOP MTTEPUL BULANCE } \\
\text { CUT = } 20 \text { RW DOI }\end{array}$} & \multicolumn{3}{|c|}{$1-2-\infty$} \\
\hline & & & . & & \\
\hline STAEM & 6 & 7 & 8 & 2 & 10 \\
\hline COMPONENT & & & & & \\
\hline MUSSFLOW(GNA) & 2000 & 87001 & 17812 & 81805 & 20000 \\
\hline VOULE FLOW (SCFM) & 1518 & 18002 & 3634 & 12825 & 60 \\
\hline TEMPEEATUREAT & 80 & $\infty$ & 19 & 1200 & 1200 \\
\hline & & & & & \\
\hline PAESSURE (paid) & $=$ & $=-$ & $-\infty$ & $-\infty$ & $=-\infty$ \\
\hline
\end{tabular}

\begin{tabular}{|c|c|c|c|c|c|c|c|}
\hline \multicolumn{8}{|c|}{ [BECONO STAGE SOJOS HEATEA } \\
\hline STAENA & 3 & in & 4 & ] & 10 & III & 3 \\
\hline COMPONENT & & & & & & & \\
\hline MUSSFLOW(OMA) & 732121 & 01560 & 80970 & G845 & 20000 & 732321 & 17200 \\
\hline VouV EFLW/SCFM & $=$ & 10023 & $=$ & 12023 & 0 & $=$ & $=-$ \\
\hline & & & & & & & \\
\hline TEMPERUTURE(T) & 750 & $\infty$ & 730 & 1200 & 1200 & $\infty$ & $=$ \\
\hline & & & & & & & \\
\hline SURE & $=-$ & $-\infty$ & 315 & $=$ & $=$ & $=$ & $=$ \\
\hline
\end{tabular}

\begin{tabular}{|c|c|}
\hline \multicolumn{2}{|c|}{ OYERUII EULNCE } \\
\hline WN & OUT \\
\hline 4000 & 61845 \\
\hline 87001 & 2000 \\
\hline 01750 & 01730 \\
\hline
\end{tabular}

\begin{tabular}{|c|c|c|c|c|c|c|c|c|c|c|}
\hline \multicolumn{11}{|c|}{ BWWCE NFOUNO THE FLUD BED ABSOFBERA } \\
\hline STREAM & 5 & 5 & 1 & 17 & 10 & 20 & 12 & 10 & 15 & 2 \\
\hline COMPONENT & & & & & & & & & & \\
\hline MASSFLOW(OFH) & 732821 & 173200 & 4602507 & 1751 & $\operatorname{Bg} 27$ & 50070 & 773000 & 520 & 81770 & -4757200 \\
\hline VOUMEFLOW (SCFM) & $\ldots$ & 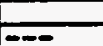 & 800514 & $\infty$ & 11610 & 12235 & -- & -- & 17351 & siritos \\
\hline & & & & & & & & & & \\
\hline TEMPERATUAERT & 730 & $-\infty$ & 705 & 82 & $\underline{2}$ & 2 & $\infty \infty$ & $\Phi$ & $\boldsymbol{E}$ & 750 \\
\hline PRESSURE & 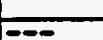 & -- & $0.22+13+1$ & $\ldots$ & $=-$ & & 0,0 & $\cdots$ & $\cdots$ & 0.0 \\
\hline
\end{tabular}

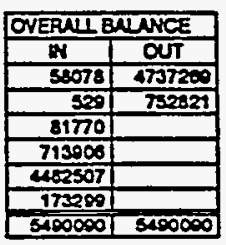

\begin{tabular}{|c|c|c|c|c|}
\hline \multicolumn{5}{|c|}{ BUWACE AROUND REGENERATOA } \\
\hline STREM & 71 & 12 & .94 & 13 \\
\hline VENT & & & & \\
\hline MUSS FLOWLOMA & 732821 & 713000 & 203851 & 4706 \\
\hline VOUUME FLOW (SCFM) & 752821 & -- & 6705 & 1782 \\
\hline TEMPEPUTAEF & $=$ & $\infty$ & $\infty$ & $\infty$ \\
\hline & & & & \\
\hline PRESSURE & $=-$ & 0.00 & $=-$ & $\overline{3}$ \\
\hline
\end{tabular}
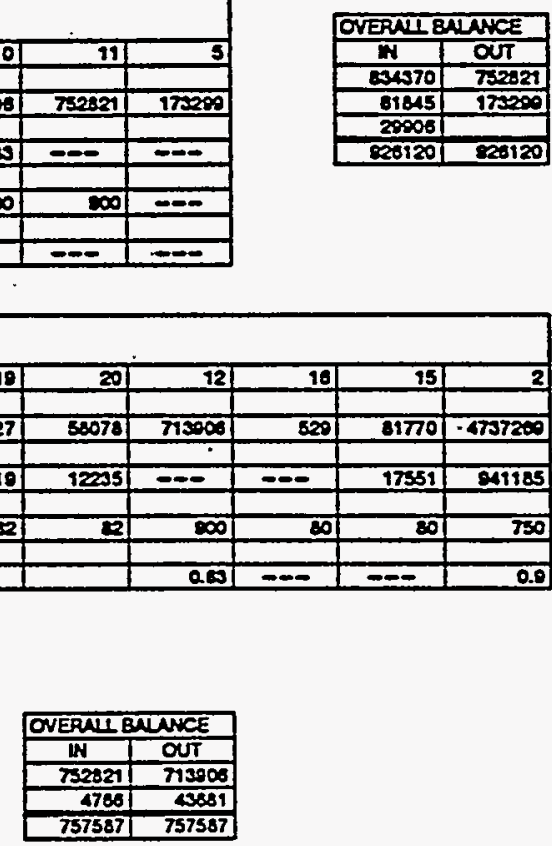

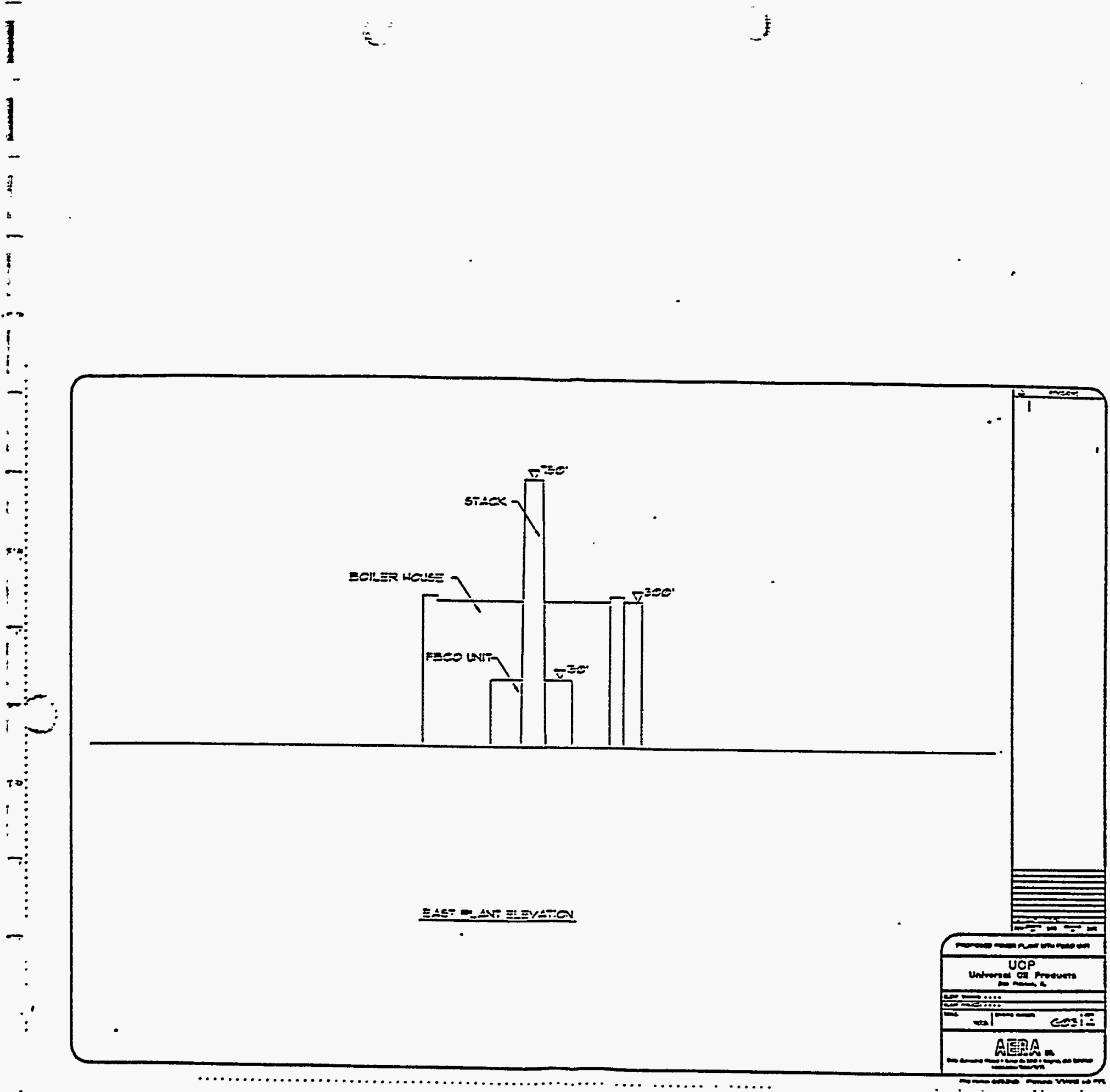


\section{APPENDIX II}




\section{SECTION 1}

Calculation for AERA CuO Process Material Balance

Purpose: Perform Material Balance for CuO Process (4 Sections)

Section 1: $\quad$ Absorber Balance

Exhaust Gas

From Heater (5)

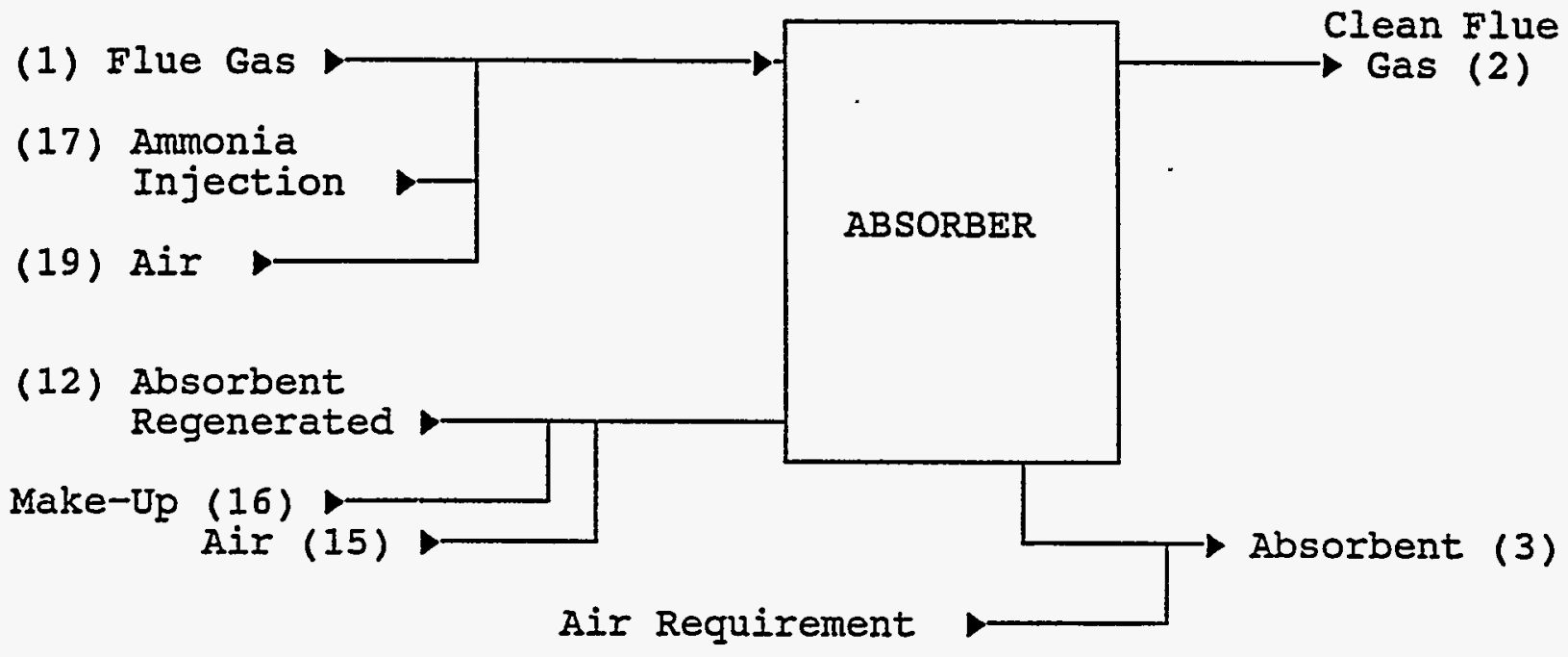

Flue Gas Flow Rate (Stream 1):

Flow Rate:

4,462,507 \#/Hr

957,871 SCFM @ 60 F

$\mathrm{P}=1 \mathrm{ATM}$

(Reference Table 3)

$\mathrm{SO}_{2}=25,229 \# / \mathrm{Hr}$

$\mathrm{SO}_{3}=364 \# / \mathrm{Hr}$

$\mathrm{NO}_{x} \rightarrow \quad \mathrm{NO}: 2,818 \# / \mathrm{Hr}$

$\mathrm{NO}_{2}: 209 \# / \mathrm{Hr}$ 
Ammonia Injection Requirements (Stream 17):

Assumptions $\quad$ Ratios: $\quad \mathrm{NH}_{3} / \mathrm{NO}=1.0$

$$
\mathrm{NH}_{3} / \mathrm{NO}_{2}=2.0
$$

$209 \# \mathrm{NO}_{2} / \mathrm{Hr} \times 1 \mathrm{Mole} \mathrm{NO} \mathrm{N}_{2} / 46 \# \mathrm{NO}_{2} \times 2 \mathrm{Mole} \mathrm{NH}_{3} / 1 \mathrm{Mole} \mathrm{NO}_{2}=9.09 \mathrm{Mole} \mathrm{NH}_{3} / \mathrm{Hr}$

2818 \# NO/Hr x 1 Mole/30 \# NO x 1 Mole $\mathrm{NH}_{3} / 1$ Mole NO $=93.93 \mathrm{Mole} \mathrm{NH}_{3} / \mathrm{Hr}$

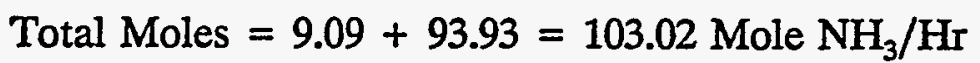

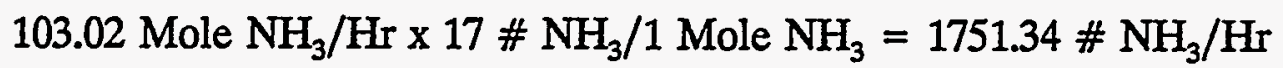

Sulfur Dioxide and Nitrogen Oxide Removal

$\left(\right.$ Inlet $\left.: \mathrm{SO}_{x}\right)=25,229+364=25,593 \# \mathrm{SO}_{x} / \mathrm{Hr}$

Capture $90 \%=0.9\left(25,593 \# \mathrm{SO}_{x} / \mathrm{Hr}\right)=23,033.7$

Out with Flue Gas $=25,593-23,033.7=2559.3$

$\left(\right.$ Inlet $\left.: \mathrm{NO}_{x}\right)=2818+209=3027 \# \mathrm{NO}_{x} / \mathrm{Hr}$

Capture $90 \%=0.9(3027)=2724.3 \# \mathrm{NO}_{x} / \mathrm{Hr}$

NOx out with flue gas $=3027.3-2724.3=303 \# \mathrm{NO}_{x} / \mathrm{Hr}$

Air with Ammonia Injection

103.2 Moles $\mathrm{NH}_{3} / \mathrm{Hr} \times 1$ Mole $\mathrm{O}_{2} / 4$ Moles $\mathrm{NH}_{3}$ x 1 Mole Air/0.21 Mole $\mathrm{O}_{2}$

122.6 Moles Air/Hr x 29 \# Air/1 Mole Air = 3556.6 \# Air/Hr

Injection System Requirements

$(3556.6+1751.34)=5307.94 \# / \mathrm{Hr}$

II -2 
Absorbent Requirements

$$
\mathrm{Cu} / \mathrm{S}=2.0
$$

$\mathrm{SO}_{2} \rightarrow 25,229 \# \mathrm{SO}_{2} / \mathrm{Hr} \times 1 \mathrm{Mole} / 64 \# \mathrm{SO}_{2}=394.2$

$\mathrm{SO}_{3} \rightarrow 364 \# \mathrm{SO}_{3} / \mathrm{Hr} \times 1 \mathrm{Mole} / 80 \# \mathrm{SO}_{3}=4.6$

$398.8 \mathrm{Moles} \mathrm{SO}_{x} / \mathrm{Hr}$

Assuming $100 \%$ Requirement

398.8 Moles $\mathrm{SO}_{x} / \mathrm{Hr} \times 1$ Mole S/1 Mole $\mathrm{SO}_{x} \times 2$ Mole Cu/ 1 Mole S

x 63.55 \# Cu/1 Mole $\mathrm{Cu}=50,687.5$

Utilizing 7\% Cu absorbent (Table 3 AERA Report)

50,687.5 \# Cu/Hr x \# Absorbent/0.07 \# Cu = 724,107 \# Absorbent $/ \mathrm{Hr}$

Absorbent $\quad 724,107$ \#/Hr

$93 \% \mathrm{Al}_{2} \mathrm{O}_{3} \quad 673,419.5 \# / \mathrm{Hr}$

$7 \% \mathrm{CuO} \quad 50,687.5 \# / \mathrm{Hr}$

$\mathrm{CuO}+\mathrm{SO}_{2}+1 / 2 \mathrm{O}_{2} \rightarrow \mathrm{CuSO}_{4}$

$\mathrm{CuO}+\mathrm{SO}_{3} \rightarrow \mathrm{CuSO}_{4}$

CuO Used $(0.9 \approx 90 \%$ Removal Efficiency)

23,033.7 \# $\mathrm{SO}_{x} / \mathrm{Hr}$ captured

$\mathrm{SO}_{2}$

25,229 \# $\mathrm{SO}_{2} / \mathrm{Hr} \times 1 \mathrm{Mole} \mathrm{SO}_{2} / 64$ \# $\mathrm{SO}_{2} \times 1 \mathrm{Mole} \mathrm{CuO} / 1 \mathrm{Mole}_{2} \times$

79.5 \# CuO/1 Mole CuO x 0.9 = 28,205.2 \# CuO/Hr

$\mathrm{SQ}_{3}$

$364 \#_{\mathrm{SO}_{3}} / \mathrm{Hr} \times 1 \mathrm{Mole} \mathrm{SO}_{3} / 80$ \# $\mathrm{SO}_{3} \times 1 \mathrm{Mole} \mathrm{CuO} / 1 \mathrm{Mole} \mathrm{SO}_{3} \times$

79.5 \# CuO/1 Mole CuO x $0.9=325.6$ \# CuO $/ \mathrm{Hr}$

$$
\text { II }-3
$$




\section{Used 28,530.8 \# CuO/Hr}

CuO Remaining $=50,687.5-28,530.8=22,156.7 \# \mathrm{CuO} / \mathrm{Hr}$

$\mathrm{CuO}$ used 28,530.8 \# $\mathrm{CuO} / \mathrm{Hr}$

$\mathrm{CuSO}_{4}$ Formed

28,530.8 \# CuO/Hr x $1 \mathrm{Mole} / 79.5$ \# CuO x $1 \mathrm{Mole} \mathrm{CuSO}_{4} / \mathrm{Mole} \mathrm{CuO}$ x

159.5 \# CuSO $4 / 1 \mathrm{Mole} \mathrm{CuSO}_{4}=57,241$

Total out of absorber: $\quad 57,241+22,156.7+673,419.5$

Stream (3) $\quad 752,817.2 \# / \mathrm{Hr}$

Absorbent $\quad 724,107$ \#/Hr

$7 \% \mathrm{Cu} \quad(50,688)$

\# $\mathrm{CuO} / \mathrm{HR} \quad 50,688$ \# Cu/Hr x 79.55 \# CuO/63.55 \# Ca = 63,449.7 \# $\mathrm{CuO} / \mathrm{Hr}$

$724,107 \# / \mathrm{Hr}-63,449 \# \mathrm{CuO} / \mathrm{Hr}=660,658 \# \mathrm{Al}_{2} \mathrm{O}_{3} / \mathrm{Hr}$

$\mathrm{CuO}$ Used

$\mathrm{CuSO}_{4}$ Formed 57,241 \# $\mathrm{CuSO}_{4} / \mathrm{Hr}$

Unreacted CuO:

$$
63,449-28,530.8=34,918.2 \# \mathrm{CuO} / \mathrm{Hr}
$$

Solids out of Absorber:

$$
\begin{aligned}
& 57,241 \\
& \mathrm{CuSO}_{4}
\end{aligned}+\begin{aligned}
& 660,658 \\
& \mathrm{Al}_{2} \mathrm{O}_{3}
\end{aligned} \quad \begin{aligned}
& 34,918.2=752,817 \\
& \mathrm{CuO}
\end{aligned}
$$

Transport Air Stream (3A)

Air Mass Requirements $10.8 \%$

$$
0.108 \times 752,817.2=81,304 \# / \mathrm{Hr}
$$

Stream (4) $=$ Stream (3)

$752,817.2$

(3A)

$81,304.0$

$834,121.2$

$$
\text { II }-4
$$


Stream (5) $238,281.5$ \#/Hr

Stream (12) $713,891.9$ \#/Hr - Section 4, pg. 3

Stream (16) 0.02 (Bed Inventory) +0.047 (Circulation Rate)

Flue Gas Flow Rate=957,871 SCFM @ 60 $\mathrm{F}$

@750․ F

$957,871 \operatorname{SCFM} \times(750+460) /(60+460)=957,871 \times 1210 / 520=2,228,892$ CFM @ 75

Bed Supervicial Gas Velocity $=4.5 \mathrm{ft} / \mathrm{sec}$

$2,228,892 \mathrm{ft}^{3} / \min \times 1 \mathrm{~min} / 60 \mathrm{sec} \times \sec / 4.5 \mathrm{ft}=8,255.1 \mathrm{ft}$

If one absorber: diameter area $=\pi D^{2} / 4$

$D=\sqrt{ } 4 / \pi(8255.1)$

$\mathrm{D}=102.52 \mathrm{ft}^{2}$

If two absorbers: $\quad$ diameter $\quad 72.49 \mathrm{ft}$

Bed Solids Volume

$8255.1 \mathrm{ft}^{2} \times 4 \mathrm{ft} \times 26.6 \# / \mathrm{ft}^{3}=878,342.6 \#$

Circulating Volume $752,817.2$ \#/Hr

$\Theta_{\mathrm{AB}}=878,342.6 \# / 752,817.2=1.17$ Hrs (70 minutes)

(16) Attrition Loss

$0.02 / 100(878,342.6)+0.047 / 100(752,817.2)=529.5 \# / \mathrm{Hr}$

Stream (15)

Air Requirements

$\mathrm{Cu}=22,783.8+17,633.6=40,472.4 \# / \mathrm{Hr}$

See Section 4, page 3 of 3

II -5 
Stream (2)

Absorber

In

(1) 4,462,507 \# Flue Gas/Hr

(17) $1,751.34 \# \mathrm{NH}_{3} / \mathrm{Hr}$

(19) 3,556.6 \# Air/Hr

(12) $713,891.9$ \#/Hr

(16) $529.5 \# / \mathrm{Hr}$

(15) $50,609.5 \# / \mathrm{Hr}$

(5) $238,281.5 \# / \mathrm{Hr}$

Subtotal $=5,471,127.3 \# / \mathrm{Hr}$

$(2)=5,471,127.3-752,817.2=4,718,310.1 \# / \mathrm{Hr}$
Out

(3) $752,817.2 \# / \mathrm{Hr}$

(3A) $81,304 \# / \mathrm{Hr}$

(2)

$$
\text { II }-6
$$




\section{REVISION FOR APPENDIX II \\ SECTION 2}

Two-Stage Absorber

$$
\begin{aligned}
& M_{s} \# 752817 \# / \mathrm{Hr} \quad T=738 \cdot \mathrm{F} \\
& \text { Combustion Gas } T=1200 \cdot \mathrm{F} \\
& C_{p s}=0.29 \mathrm{Btu} / \# \cdot \mathrm{F} \\
& C_{p g}=C_{p 1}=C_{p 2}=0.24 \mathrm{Btu} / \# \cdot \mathrm{F} \\
& M_{s} C_{p s}=218316.9
\end{aligned}
$$

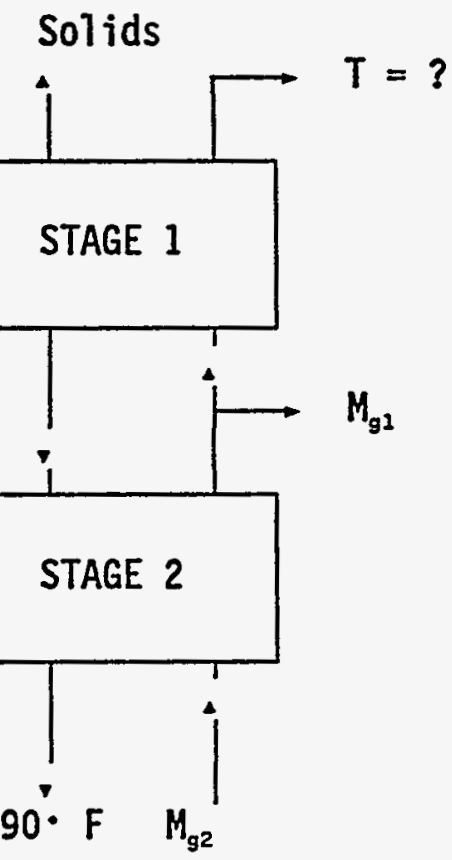

Energy Batance:
(1) $M_{s} C_{p s} \Delta T_{s}=M_{g 1} C_{p 1} \Delta T_{1}+M_{g 2} C_{p 2} \Delta T_{2}$
(2) $M_{\mathrm{g} 1}+M_{\mathrm{g} 2}=M_{\mathrm{g}}$
(3) $M_{g 2}=2.068 M_{a 1}$ (from model)
(4) $M_{s} C_{p s}(900-T)=M_{g 2} C_{p 2}(1200-900)$
(5) $M_{s} C_{p s}(T-738)=M_{g 2} C_{p 2}(900-T)+M_{g 2} C_{p 1}(1200-T)$

(4) $\quad M_{s} C_{p s}(900-T)=M_{g 2} C_{p 2}(1200-900)$

$$
\begin{aligned}
& M^{5} 18,316.9(900-T)=M_{g 2}(0.24)(300) \\
& M_{g 2}=3,032.18(900-T)
\end{aligned}
$$

(5) $\quad M_{s} C_{p s}(T-738)=M_{g 2} C_{p 2}(900-T)+M_{g 1} C_{p 1}(1200-T)$

$909,653.75(T-738)=M_{g 2}(900-T)+M_{g 1}(1200-T)$

$M_{91}=\left[909,653.75(T-738)-3,032.18(900-T)^{2}\right] 1 /(1200-T)$

(3) $\quad M_{g 2}=2.068 M_{g 1}$

$3,032.18(900-T)=2.068[909,653.75(T-738)-3,032.18(900-T)] * 1 /(1200-T)$

Solve for $T=$ ?

$T=815 \cdot F$ (Trial and Error)

$$
\text { II }-7
$$


$\mathrm{Mg}_{2}=3032.18(900-\mathrm{T})$

$\mathrm{Mg}_{2}=3032.18(900-815.2)$

$\mathrm{Mg}_{1}=256970 \# / \mathrm{Hr}$

$\mathrm{Mg}_{1}=\mathrm{Mg}_{2} / 2.068=124260 \# / \mathrm{Hr}$ 


\section{SECTION 3}

\section{Second Stage Solids Heater}

Stream (10) Section $2 \quad 28,765$ \#/Hr

Stream (9) Section $2 \quad 128,212.5$ \#/Hr

Stream (4) Section $1 \quad 834,121.2$ \#/Hr

Stream (11) Same as Stream (3)

Balance

$$
\begin{aligned}
& \text { Streams } 4+9+10=11+5 \\
& \text { Stream } 5=10+9+4-11
\end{aligned}
$$

$\begin{array}{ccl}\text { Stream (5) }= & 28,765 & (10) \\ 128,212.5 & (9) \\ 834,121.2 & (4) \\ & \frac{-752,817.2}{463,762.5} & (3)=(11) \\ & & (5)\end{array}$

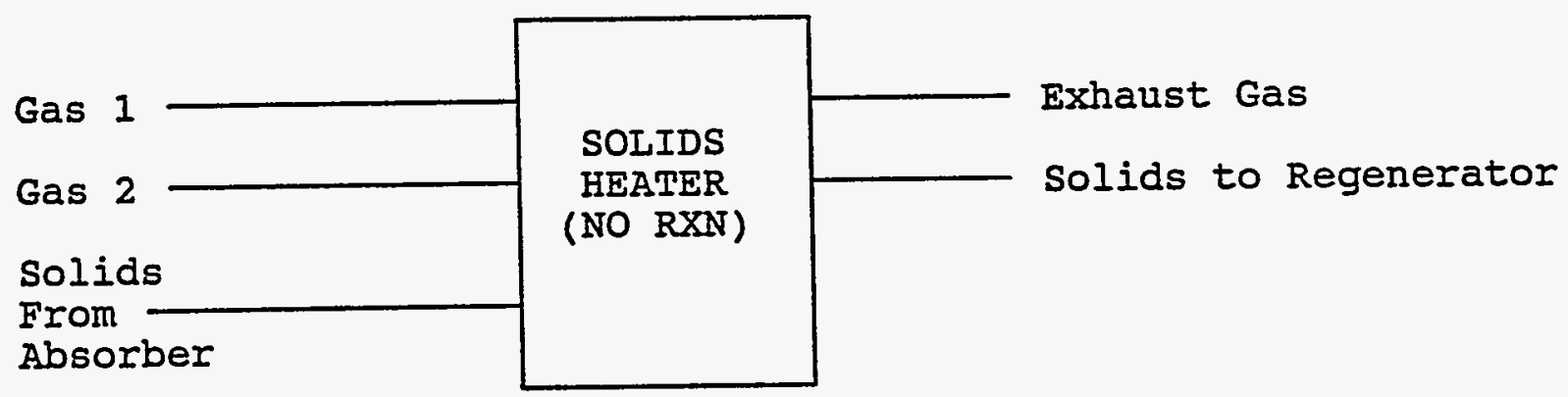




\section{SECTION 4}

\section{Regenerator Balance}

Stream (11) - Reference Section 3 - 752,817.2 \#/Hr

CuO Reacted 28,530.8 \#/Hr - Section 1, pg. 4
$\mathrm{Al}_{2} \mathrm{O}_{3}$
$673,419.5 \# \mathrm{Al}_{2} \mathrm{O}_{3} / \mathrm{Hr}$
(11)
$\mathrm{CuO} \rightarrow 22,156.7$ \# $\mathrm{CuO} / \mathrm{Hr}$
$\mathrm{CuSO}_{4} \rightarrow 57,241.0$ \# CuO/Hr

CuO Into System - 50,687.5 \# CuO/Hr

$\mathrm{Cu}$ (In) 50,687.5 \# CuO/Hr x $1 \mathrm{Mole} \mathrm{CuO} / 79.5$ \# CuO x 1 Mole CO/1 Mole CuO x 63.5/1 Mole

40,486.2 \# Cu/Hr (In)

(Mass)
(11) 752,817 \#/Hr

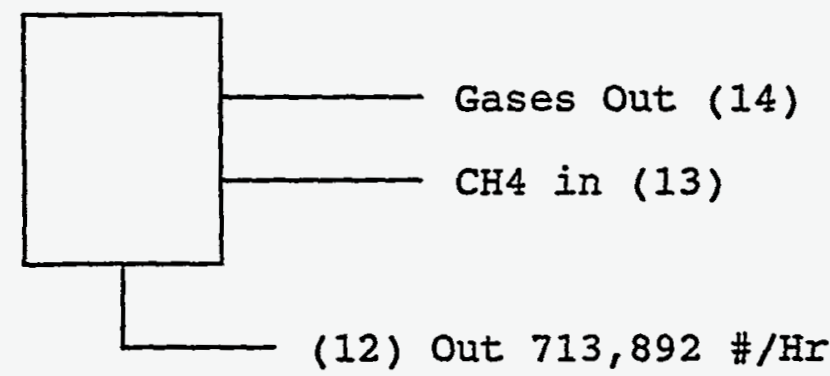

Stream (11)

$$
\begin{aligned}
& \text { 57,241 \# } \text { CuSO }_{4} / \mathrm{Hr} \\
& 22,156.7 \text { \# } \mathrm{CuO} / \mathrm{Hr} \\
& 673,419.5 \# \mathrm{Al}_{2} \mathrm{O}_{3} / \mathrm{Hr} \\
& 752,817.2 \# / \mathrm{Hr}
\end{aligned}
$$

(Methane Requirements) $\mathrm{CuSO}_{4}(100 \%$ Reduction)

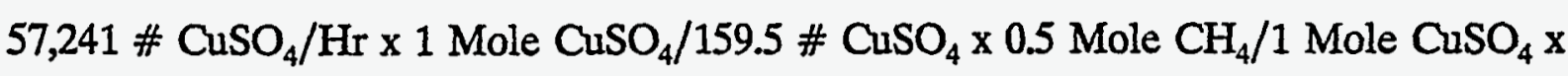
16 \# $\mathrm{CH}_{4} / 1$ Mole $\mathrm{CH}_{4}=2871.0 \# \mathrm{CH}_{4} / \mathrm{Hr}$ 
CuO Reduction (100\% Reduction)

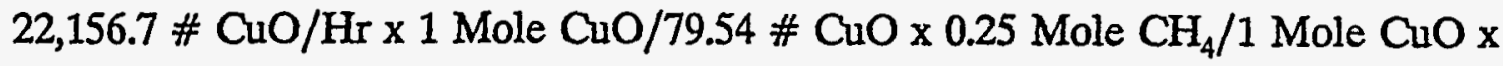

$16 \# \mathrm{CH}_{4} / 1$ Mole $\mathrm{CH}_{4}=1114.24$

$1114.24 \# \mathrm{CH}_{4} / \mathrm{Hr}$

Regenerator Requirements Methane Stream (13)

$2871.0+1114.24=3985.24 \# \mathrm{CH}_{4} / \mathrm{Hr}$

Assuming a $15 \%$ Excess: 3985.24 \# $\mathrm{CH}_{4} / \mathrm{Hr} \times 1.15=4583$ \#

Excess $\mathrm{CH}_{4} / \mathrm{Hr}=4583-3985.24=597.76 \# \mathrm{CH}_{4}$

Exhaust Gas Generation (14) $\mathrm{SO}_{2}, \mathrm{CO}_{2}, \mathrm{H}_{2} \mathrm{O}$ (generation) .

$\mathrm{CuSO}_{4}$ Regeneration Exhaust Gas

$\mathrm{SO}_{2}: 358.8 \mathrm{Mole} \mathrm{CuSO}_{4} / \mathrm{Hr} \times 1 \mathrm{Mole} \mathrm{SO}_{2} / 1 \mathrm{Mole} \mathrm{CuSO}_{4} \times 64 \mathrm{SO}_{2} / 1 \mathrm{Mole} \mathrm{SO}_{2}$ $=22,963.2 \# / \mathrm{Hr}$

$\mathrm{CO}_{2}: 358.8 \mathrm{Mole} \mathrm{CuSO}_{4} / \mathrm{Hr}$ x $0.5 \mathrm{Mole} \mathrm{CO}_{2} / 1 \mathrm{Mole} \mathrm{CuSO}_{4}$ x $44 \# \mathrm{CO}_{2} / 1 \mathrm{Mole}$ $\mathrm{CO}_{2}=7,893.6 \# \quad / \mathrm{Hr}$

$\mathrm{H}_{2} \mathrm{O}$ : $358.8 \mathrm{Mole} \mathrm{CuSO}_{4} / \mathrm{Hr} \times 1$ Mole $\mathrm{H}_{2} \mathrm{O} / 1 \mathrm{Mole} \mathrm{CuSO}_{4} \times 18 \# \mathrm{H}_{2} \mathrm{O} / 1$ Mole $\mathrm{H}_{2} \mathrm{O}=6,458.4 \# / \mathrm{Hr}$

Exhaust from regenerator $=37,315.2 \# / \mathrm{Hr}\left(\mathrm{CuSO}_{4}\right)$

\section{CuO Regeneration Exhaust Gas}

$\mathrm{SO}_{2}: \quad 278.56 \mathrm{Mole} \mathrm{CuO} / \mathrm{Hr} \times 0 \mathrm{Mole} \mathrm{SO}_{2} / 1 \mathrm{Mole} \mathrm{CuO}=0$

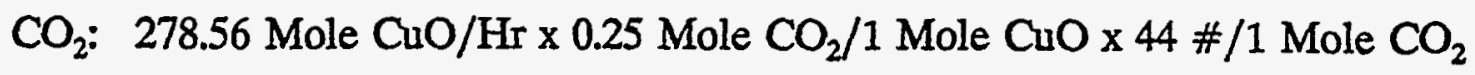
$=3064.16 \# \mathrm{CO}_{2} / \mathrm{Hr}$

II - 11 
$\mathrm{H}_{2} \mathrm{O}: 278.56$ Mole CuO/Hr x 0.5 Mole $\mathrm{H}_{2} \mathrm{O} / 1$ Mole CuO x 18 \#/1 Mole $=2507.04 \# \mathrm{H}_{2} \mathrm{O}$

Total $=5571.2 \#$ Total $\mathrm{Hr}$

$2871 \# \mathrm{CH}_{4} / \mathrm{Hr}$ for $\mathrm{CuSO}_{4}$

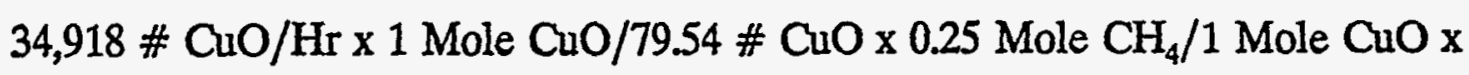
16 \# $\mathrm{CH}_{4} / 1$ Mole $\mathrm{CH}_{4}=1,756$ \# $\mathrm{CH}_{4} / \mathrm{Hr}$

$2871+1756=4627 \# \mathrm{CH}_{4} / \mathrm{Hr}$

$15 \%$ Excess $1.15 \times 4627=5321 \# \mathrm{CH}_{4} / \mathrm{Hr}$

(Not used - Sulfur Recovery System can not handle excess $\mathrm{CH}_{4}$ )

4627 \# $\mathrm{CH}_{4} / \mathrm{Hr} \times 21,500 \mathrm{Btu} / \# \mathrm{CH}_{4} 99.5 \times 10^{6} \mathrm{Btu} / \mathrm{hr}$ 
APPENDIX III 


\section{SECTION 13000 \\ ABSORBER}

PART 1 - GENERAL

\subsection{1 summary:}

This specification is provided as a generic specification for the purchasing and cost estimating of two absorbers for the removal of sulfur dioxide and nitrogen oxides from the flue gas from a pulverized coal fired furnace. The absorbers will use copper oxide as the absorbing media. The regenerator is utilized for the regeneration of the copper oxide with methane. The design basis for the absorber is provided in the design basis report "Establishment of the Design Basis for Application to a $500 \mathrm{MW}$ Power Plant," by A.E. Roberts \& Associates, Inc.

Based on the design provided in Drawing No. G02, the contractor is to furnish all material, equipment, and incidentals required to install, ready for service, piping, fittings, supports, gauges (temperature and pressure) and appurtenances for the absorbers as specified herein. Based upon the size of the absorbers as discussed in the specification, it is anticipated that the absorbers are to be field erected in multiple stages.

\subsection{Quality Assurance:}

The absorber shall be manufactured using highest industry standards.

\subsection{Submittals:}

A) The contractor shall submit shop drawings of each absorber including material of construction, location of inlet and outlet flue gas lines, absorbent inlet and outlet lines, interconnection details, weight of each absorber, dimensions, fittings, wall thickness (shells and head), pressure taps, thermowelds, locations of fittings, location and weights of auxiliary equipment. Included with the submittal shall be a complete set of detail instructions on the installation of the absorbers.

B) Contractor shall submit mounting details for the installation of the absorbers.

$$
\text { III }-1
$$


C) Contractor shall provide necessary structural details for the absorbers.

D) For this specification, the contractor shall provide a layout drawing of both absorbers assuming that the absorbers are to be mounted out side by side. For the design of the absorber and the regenerator, the contractor shall assume that each of the absorber and regenerator are to be provided as an "A" and "B" train.

E) The contractor is not to provide the absorbent needed for the absorber.

\subsection{Guarantee:}

Contractor's guaranteed for items furnished covers and includes:
A) Material and equipment, guaranteed for a period of 12 months after final acceptance.
B) Defective workmanship and materials.
C) Leakage, breakage, or other failure.

\subsection{Measurement and payment:}

Absorber equipment and installation will not be measured separately for payment.

\section{PART 2 - GENERAL}

\subsection{General:}

A) All parts shall be designed and proportioned as to have liberal strength and stiffness, and to be especially adapted for the work to be done. Ample room and facilities shall be provided for access.

B) Each absorber shall have the manufacturer's name, address, type or style model or catalog number, and serial number on a plate secured to the item of equipment.

C) Each absorber shall be furnished in major assemblies with all accessories such that field work will involve final absorber assembly and installation and connection of external equipment. 
D) The contractor shall be responsible for the design and structural integrity of the absorber.

E) The contractor shall be familiar with all details of the work, verify all dimensions in the field, and shall advise owner of any discrepancy before performing any work.

F) The absorbers will contain granular solids having a bulk density of 35 pounds per cubic foot. The design pressure (10 psig) does not include solid static head, but the maximum granular solids level during shut down should be eight feet above the grid.

G) Each absorber should be designed to withstand a 500,000 pound load from a 35 pound per cubic foot material.

H) For the inlet and outlet flue gas piping the piping shall be smooth pipe where possible.

I) The fluidizing velocity inside the absorber is 4.5 feet per second.

\section{pbsorbers}

As shown in Drawing No. G02 the characteristics of the absorber, excluding controls, should be:

A. Quantity 2

B. Inlet Air Flow Rate (SCFM e 705 Deg. F) 500,000

C. Effluent Air Flow Rate (SCFM \& 705 Deg. F) 500,000

D. Radius of Curvature Flue Gas outlet (feet) 16.4'

E. Design Pressure (PSIG). . 10

F. Design Temperature (Deg. F) 1,000

G. Diameter of Absorber (Ft.) 72.5

H. Overall Iength $\quad 116.7$

- Straight Wall (feet) 66.4

- Top Wall (feet) 20.3

- Bottom Wall (feet) 32.0

- Support Grid (between top and middle wall) 10'

- Absorbent Discharge 22.0 
I. Gas Velocities

- Inlet Gas Velocity (ft/sec)

39.7

- Outlet Gas Velocity (ft/sec)

39.7

- Superficial Flue Gas Velocity (ft/sec)

4.5

J. Grid support

Average slot Opening
Maximum Slot opening
Minimum slot Opening

K. Flue Gas Inlet Pipe (Bottom of second section, smooth pipe)

I. Flue Gas Exit Pipe (Top, smooth pipe)

M. Annul Distribution Diameter (feet)

N. Absorbent Feed Inlet (TOp)

o. Absorbent outlet (Bottom)

P. Absorbent Removal Pipe in Top and Middle section (feet)

Q. Flue Gas Distribution Diameter in Top Section (feet)

R. Flue Gas Distribution Height in Top Section (feet)

S. Flue Gas Distribution Diameter in Middle Section (feet)

T. Flue Gas Distribution Height in Middle Section (feet)

U. Expanded Bed Height (feet)

V. Manways (inches, four should provided, two for each section)

w. Material of Construction

X. Pressure Taps (2 per section, 6 total)

Y. Temperature Taps (2 per section, 6 total)
Johnson

Wire Mesh

or

equivalent

$0.24^{\prime \prime}=0.002$

$0.02^{\prime \prime}$

$0.018^{\prime \prime}$

$16.4^{\prime}$

$22^{\prime}$

$32^{\prime \prime}$

$22^{\prime \prime}$

$36^{\prime \prime}$

$32.3^{\prime}$

$11^{\prime} 1^{\prime \prime}$

$35.3^{\prime}$

$9^{\prime}$

$4^{\prime}$

$18-24^{\prime \prime}$

Killed Carbon steel (or equivalent)

$1.5^{\prime \prime}$

$1.5^{\prime \prime}$ 
Z. Absorbent Feed Rate to the Absorber (\#/hr) 500,000

AA. Overflow Pipes Should be Used to Control Fluidized Level 6"

AB. Number of Overflow Pipes per stage (two stages) 9

AC. Additional Level Sensors Differential or Nuclear Level Sensor

Pressure

PART 3 - EXECUTION

\subsection{Inspection:}

The contractor is to verify that the piping, ductwork, and materials of construction are compatible with the flue gas stream and sorbent.

\subsection{Installation:}

A) Equipment installation according to manufacturer's instructions.

B) Provide all valving, dampers, piping and fittings, and structural details required to install the absorbers.

\subsection{Adjust:}

A) Operational Test: Prior to acceptance, an operational test of both absorbers and control systems shall be performed to determine if the installed equipment meets the purpose and intent of the specifications. Tests shall demonstrate that the equipment is not electrically, mechanically, structurally, or otherwise defective; is in safe and satisfactory operating condition; and conforms with the specified operating characteristics. Tests shall include checks for excessive vibration, leaks in all piping and seals, correct operation of control systems and equipment, proper alignment, excessive noise levels, and power consumption.

B) Retesting: If any deficiencies are revealed during any test, such deficiencies shall be corrected and the tests shali be reconducted at the contractor expense.

C) Manufacturer or supplier's Installation check: Representative shall be experienced, competent, and authorized to inspect work. 


\section{APPENDIX IV}


AMMONIA INJECTION FOR AERA

Ammonia Injection:

(untreated)

$\mathrm{NO}_{x}=209 \# \mathrm{NO}_{2} / \mathrm{Hr}+2818 \# \mathrm{NO} / \mathrm{Hr}=3027 \# \mathrm{NO}_{x} / \mathrm{Hr}$

For $500 \mathrm{MW}$ coal fired power plant per AERA conceptual report - pg. Table 2

428,571 \# Coal $/ \mathrm{Hr} \times 10,500 \mathrm{Btu} / \#=4,499,995,500 \mathrm{Btu} / \mathrm{Hr}$

$4,499,995,500 \mathrm{Btu} / \mathrm{Hr} \times 1 \mathrm{M} / 10^{6}=4500 \mathrm{MBtu} / \mathrm{Hr}$

$\frac{\text { NO }}{(\mathrm{M}}=\frac{\text { Untreated }}{1 \text { Million })}=0.673 \# \mathrm{NO}_{\mathrm{x}} / \mathrm{MBtu}$

Collection Efficiency $=90 \%$

Treated: $\mathrm{NO}_{\mathrm{x}}=302.7 \# \mathrm{NO}_{x} / \mathrm{Hr}$ (90\% Removal)

$$
\mathrm{NO}_{x}=0.067 \text { \# } \mathrm{NO}_{x} / \text { MBtu (90\% Removal) }
$$

Ammonia Rate $=1751.3 \# \mathrm{NH}_{3} / \mathrm{Hr}$

(Material Balance)

Storage Requirements of Ammonia $=30$ days

$1751.3 \# / \mathrm{Hr} \times 24 \mathrm{Hrs} /$ Day $\times 30$ days $=1,260,936$

Approximately 1,300,000 \# of Ammonia stored

e 1,300,000 \# FuIl

Gallons of Ammonia Required

$1,300,000$ Full $\times$ gallon $/ 5.01 \#=259,455$ gallons \& $80^{\circ} \mathrm{F}$

Density References: Handbook of Chemistry and Physics, 62nd Edition

$$
5.02 \text { \# per gallon }
$$

Provide 3 tanks $\rightarrow$ volume $=259,455 / 3=86,482$ gallons

Use approximate volume 90,000 gallons per tank

Need 3 tanks (supply ammonia)

Capacity - 90,000 gallons

Each weight full - 603,334 \# (full)

Empty weight $\approx 170,000$ \# (empty) 
Use Diameter/Height $=0.37$

$$
\begin{aligned}
& \pi D^{2} / 4 H=-90,000 \times 1 / 7.48=12032 \mathrm{ft}^{3} \\
& D^{2} H=4 / \pi-12032 \mathrm{ft}^{3}=15299 \mathrm{ft}^{3} \\
& D^{2} \mathrm{H}=(0.37 \mathrm{H}){ }^{2} \mathrm{H}=0.137 \mathrm{H}^{3}=15299 \\
& \mathrm{H}^{3}=111,669 \\
& H=48.2 \text { feet } \\
& D=0.37 \mathrm{H}=17.8 \text { feet }
\end{aligned}
$$

Ammonia Rate $=1751.3 \# \mathrm{NH}_{3} / \mathrm{Hr}$

Carrier $=$ steam $\quad 60.5 \#$ steam $/ \# \mathrm{NH}_{3}$

$1751.3 \# \mathrm{NH}_{3} / \mathrm{Hr} \times 60.5 \#$ Steam/\#NH $3=106,024 \#$ steam $/ \mathrm{Hr}$

Power for Vaporizer $=6.17 \# \mathrm{NH}_{3} / \mathrm{Hr} \mathrm{KW}$

$1751.3 \# \mathrm{NH}_{3} / \mathrm{Hr} \times \mathrm{HR} \mathrm{KW} / 6.17 \# \mathrm{NH}_{3}=284 \mathrm{KW}$

Ammonia Vaporizer Power $=284 \mathrm{KW}$

Air Compressor Power $=1.486 \mathrm{~kW} / \# \mathrm{NH}_{3} / \mathrm{Hr}$

$1.486 \mathrm{KW} / \# \mathrm{NH}_{3} / \mathrm{Hr} \times 1751.3 \# \mathrm{NH}_{3} / \mathrm{Hr}=2603.3 \mathrm{KW}$

Carrier Gas $=16.2 \mathrm{SCFM} / \# \mathrm{Air} / \mathrm{Hr}$

Carrier Gas $=1751.3 \#$ Air $/ \mathrm{Hr} \times 16.2 \mathrm{SCFM} / \# \mathrm{Air} / \mathrm{Hr}=28,371 \mathrm{SCFM}$

Compressor size (3) 10,000 SCFM Each

Ammonia Tank size $=90,000$ gallons each

Vaporizer Size (3) × $95 \mathrm{KW}$ each

Estimated Ammonia Breakthrough $<5$ ppm

\section{For $90 \%$ Efficiency}

$\mathrm{NO}_{\mathrm{x}}$ untreated $=0.673 \# \mathrm{NO}_{\mathrm{x}} / \mathrm{MBtu}$

$\mathrm{NO}_{x}$ treated $=0.067 \# \mathrm{NO}_{x} / \mathrm{MBtu}$

Collection efficiency $=90 \%$

Ammonia rate $=1751.3 \# \mathrm{NH}_{3} / \mathrm{Hr}$

Ammonia vaporizer $=284 \mathrm{KW}$

Air compressor power $=2604 \mathrm{KW}$

$$
\text { IV }-2
$$




\section{Vaporizers \\ 3 Compressors \\ 8 Injection Probes}

Equipment \& Material (ammonia tank, compressors, vaporizer, injection probes, piping inst. [wiring, tubing and royalty])

$\$ 3,347.7 / \# \mathrm{NH}_{3} / \mathrm{Hr} \times 1751.3 \# \mathrm{NH}_{3} / \mathrm{Hr}=$

Installation $\quad \$ 3,124.32 / \# \mathrm{NH}_{3} / \mathrm{Hr}$

$\$ 3,124.32 / \# \mathrm{NH}_{3} / \mathrm{Hr} \times 1751.3 \# \mathrm{NH}_{3} / \mathrm{Hr}=$

Additional Equipment $\$ 413.51 / \# \mathrm{NH}_{3} / \mathrm{Hr}$

$\$ 413.51 \# \mathrm{NH}_{3} / \mathrm{Hr} \times 1751.3 \# \mathrm{NH}_{3} / \mathrm{Hr}=$

Installation of Additional Equipment

$\$ 497.30 / \# \mathrm{NH}_{3} / \mathrm{Hr} \times 1751.3 \# \mathrm{NH}_{3} / \mathrm{Hr}=$

Contingency $15 \%$

Engineering 11.5\%

Subtotal

start-up and Field Supervisioin $10 \%$ subtotal

contractors Fee (12\%)

Subtotal

Inventory

Total

(1) Installed Capital cost

(2) Annualized Capital Expense

(3) Annual O\&M

(4) Energy cost

$(284+2603.3)$ KW $\times 8760$

$\mathrm{Hr} / \mathrm{Yr} \times 0.1 \$ / \mathrm{KW} / \mathrm{Hr}$

(5) Ammonia Cost

$1751.3 \# \mathrm{NH}_{3} / \mathrm{Hr} \times 8760 \mathrm{Hr} / \mathrm{Yr} \mathrm{x}$

Ton $/ 2000 \#-7670$ tons/yr

$240 \$ /$ ton $\times 7670$ tons $/ \mathrm{yr}=$ $1,840,967 \$ / Y r$

(6) Total Annual cost
$\$ 5,862,827$

$\$ 5,471,622$

$\$ \quad 724,180$

$\$ 3,347.7 / \# \mathrm{NH}_{3} / \mathrm{Hr}$

$\$ 497.30 / \# \mathrm{NH}_{3} / \mathrm{Hr}$

$\$ \quad 870,917$

$12,929,570$

$1,939,433$

$1,486,898$

$16,355,881$

$\frac{1,635,588}{17,991,469}$

$\frac{2,158,976}{20,150,445}$

156,000

$20,306,445$

$\$ 20,306,445$

$2,964,741$

842,915

$2,529,275$

$(1,840,967)$

$I V-3$ 
1

-

]

\section{APPENDIX V \\ APPENDIX V}

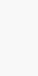

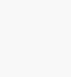




\section{SECTION 13100 \\ REGENERATOR}

PART 1 - GENERAL

\subsection{1 summary:}

This specification is provided as a generic specification for purchasing and cost estimating of two regenerators for the regeneration of the copper oxide absorbent with methane. The regenerators are to be designed as one regenerator for each flue gas train. The design basis for the regenerator is provided in the design basis report, "Establishment of the Design Basis for Application to a 500 MW Power Plant," by A.E. Roberts \& Associates, Inc.

Based upon the design provided in Drawing No. G01, the contractor is to furnish all material, equipment, and incidentals required to install, ready for service, piping, fittings, supports, gauges (temperature and pressure) and appurtenances for the regenerators as specified herein. Based upon the size of the regenerators as discussed in the specification, it is anticipated that the regenerators are to be field erected in multiple stages.

\subsection{Quality Assurance:}

The regenerators shall be manufactured using highest industry standards.

\subsection{Submittal:}

A) The contractor shall submit shop drawings of each regenerator including material of construction, location of inlet and outlet regenerator gas lines, absorbent inlet and outlet lines, interconnection details, weight of each regenerator, dimensions, fittings, wall thickness (shells and head), pressure taps, thermowelds, locations of fittings, location and weights of auxiliary equipment. Included with the submittal shall be a complete set of detail instructions on the installation of the regenerators.

B) Contractor shall submit mounting details for the installation of the regenerators.

c) Contractor shall provide necessary structural details for the regenerators.

$$
\mathrm{V}-1
$$


D) For this specification, the contractor shall provide a layout drawing of both absorbers and regenerators if bidding together. It should be assumed that the absorbers and regenerators are to be mounted out side by side in series. For the design of the absorber and regenerator are to be provided as an " $A$ " and "B" train.

\subsection{Guarantees:}

Contractor's guaranteed for items furnished covers and includes:
A) Matieral and equipment, guaranteed for a period of 12 months after final acceptance.
B) Defective workmanship and materials.
c) Ieakage, breakage, or other failure.

\subsection{Measurement and Payment:}

Regenerators, equipment and installation will not be measured separately for payment.

\section{PART 2 - GENERAL}

A) All parts shall be designed and proportioned as to have liberal strength and stiffness, and to be especially adapted for the work to be done. Ample room and facilities shall be provided for access.

B) Each regenerator shall have the manufacturer's name, address, type or style model or catalog number, and a serial number on a plate secured to the item of equipment.

c) Each regenerator shall be furnished in major assemblies with all accessories such that field work will involve final regenerator assembly and installation and connections for external equipment.

D) The contractor shall be responsible for the design and structural integrity of the regenerators.

E) The contractor shall be familiar with all details of the work, verify all dimensions in the field, and shall advise owner of any discrepancy before performing any work.

$$
\mathrm{V}-2
$$


F) The inlet and outlet absorber piping shall be smooth pipe where possible.

G) Gaskets for internal and external piping connections are to be 1/2" compressed asbestos composition durabla or equivalent.

H) The vessel shall have a designed pressure of 10 psig and a design temperature of $1000^{\circ} \mathrm{F}$.

I) Minimum plate thickness for design should not be less than $1 / 4$ inches.

\section{REGENERATOR}

As shown in Drawing No. G01, the characteristic of the regenerator, excluding controls, should be:

A) Quantity 2

B) Inlet Absorbent Pipe (inches) $\quad 38.5$

C) Outlet Absorbent Pipe (inches) 64.4

D) Regenerator Diameter (feet) 20

E) Regenerator Gas Inlet (inches) 15

F) Regenerator Gas outlet (inches) 37

G) Straight Wall Length (feet) 28.1

H) Straight Wall Above Inlet Gas Iine (feet) 30.1

I) Straight Wall Height Below Inlet Gas Iine and Above Bottom Tangential Line 6

J) Distribution Annual Height Above Inlet Gas Line (feet)

K) Inlet Absorbent Distribution Pipe

Total Length (feet)

Length Below Top Tangential (feet) $1.2^{\prime}$

Length in top Hemisphere (feet) 8.7'

Length from Top Flange to Top of Hemisphere $3.5^{\prime}$

Length from Top Flange to Top Plate 5.2'

Length from Top Plate to Pipe End 4.8' 
I) Regenerator Inlet Gas Annual Internal Diameter 16'

M) Annual Width (inches) 14.3

N) Regeneration Gas Inlet Velocity (ft/sec) 30

o) Regeneration Gas Outlet Velocity (ft/sec) 40

P) Top Plate Diameter (feet) 9.5'

Q) Absorbent Shaft Diameter (feet) 7'I"

R) Absorbent Shaft Iength (feet) 37'2"

S) Total Regenerator Length (feet) 92'g"

PART 3 - EXECUTION

3.01 Inspection:

The contractor is to verify that the piping, ductwork, and materials of construction are compatible with the regeneration gas and absorbent.

3.02 Installation:

A) Equipment installation according to manufacturer's instructions.

B) Provide all valving, dampers, piping and fittings, and structural details required to install the absorbers.

\subsection{Adjust:}

A) Operational Test: Prior to acceptance, an operational test of both absorbers and control systems shall be performed to determine if the installed equipment meets the purpose and intent of the specifications. Tests shall demonstrate that the equipment is not electrically, mechanically, structurally, or otherwise defective; is in safe and satisfactory operating condition; and conforms with the specified operating characteristics. Tests shall include checks for excessive vibration, leaks in all piping and seals, correct operation of control systems and equipment, proper alignment, excessive noise levels, and power consumption. 
B) Retesting: If any deficiencies are revealed during any test, such deficiencies shall be corrected and the tests shall be reconducted at the contractor expense.

C) Manufacturer or supplier's Installation Check: Representative shall be experienced, competent, and authorized to inspect work. 
Two Stage Solids Heater Sizing

Given:

Gas into stage 1: $1200^{\circ} \mathrm{F}$

Gas into stage 2: $1200^{\circ} \mathrm{F}$ from Combustor

Gas into stage 2: $900^{\circ} \mathrm{F}$ from stage 1

(Reference Material Balance)

Number of Solid Heaters:

2

(Numbers are for each unit)

stage 1

Volumetric Flowrate

$501 \mathrm{Ft}^{3} / \mathrm{sec}$

Inlet Pipe Velocity

Inlet Pipe Area

Inlet Pipe Diameter

$40.0 \mathrm{Ft} / \mathrm{sec}$

$12.5 \mathrm{Ft}^{2}$

Solids Flow Rate

Vessel Internal Area

Vessel Diameter

Solids Residence Time

Vessel Height in Stage 1

$4.0 \mathrm{Ft}$

376408.52 pounds/hour

$250.3 \mathrm{Ft}^{2}$

$17.8 \mathrm{Ft}$

5.0 minutes in stage 1

$4.8 \mathrm{Ft}$

Stage 2

Vol. Flowrate from stage 1

$654.6 \mathrm{Ft}^{3} / \mathrm{sec} \quad\left(1200^{\circ} \mathrm{F}\right)$

Vol. Flowrate from stage 2

$1535.9 \mathrm{Ft}^{3} / \mathrm{sec}\left(900^{\circ} \mathrm{F}\right)$

Vessel Diameter

Vessel Internal Area

$17.8 \mathrm{Ft}$

$250.3 \mathrm{Ft}^{2}$

Solids Flow Rate

Solids Residence Time

Fluidizing Density

Volume in stage 2

Vessel Height in Stage 2

376408.5 pounds/hour

15.0 minutes in stage 2

$26.0 \# / \mathrm{Ft}_{3}^{3}$

$3619.3 \mathrm{Ft}^{3}$

$14.5 \mathrm{Ft}$

Combined straight Height

Vessel Diameter

$19.3 \mathrm{Ft}$

$17.8 \mathrm{Ft}$

(Assumed Fluidizing Density Similar to Model)

\section{Capital cost for the Solids Heater system}

Number of Solids Heaters

Refractory cost (@ $\$ 55 / \mathrm{Ft}^{2}$ ) (Total)

straight Wall surface Area Per

Vessel (Ft')

Capital cost for Solids Heater (2 Heaters)

structural cost (2 Heaters)

Total Capital cost

Manufacturer
2

$\$ 120,000$

1082

$\$ 580,000$

$\$ 100,000$

$\$ 800,000$

HPS Industries, Inc. 